\title{
Environmental Audit of the
} Grand Junction Projects Office

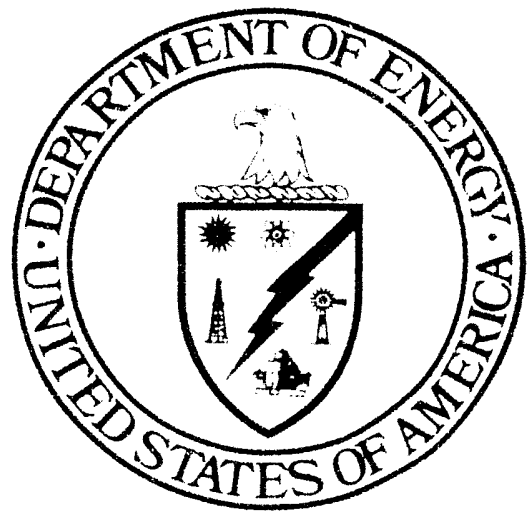

U.S. Department of Energy

Office of Environmental Audit

August 1991 


\section{Environmental Audit of the Grand Junction Projects Office}

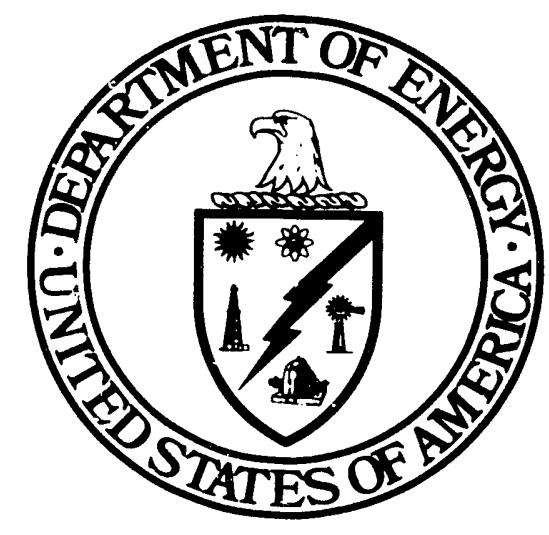

\section{U.S. Department of Energy Office of Environmental Audit Washington, DC 20585}

August 1991 


\section{PREFACE \\ U.S. DEPARTMENT OF ENERGY \\ BASELINE ENVIRONMENTAL AUDIT \\ GRAND JUNCTION PROJECT OFFICE}

On June 27, 1989, the Secretary of Energy announced a 10-point initiative to strengthen environmental protection within the U.S. Department of Energy (DOE). Consistent with this initiative, the Secretary emphasized and strengthened independent internal oversight as a management reform in Secretary of Energy Notice (SEN)-11-89, which would monitor the effectiveness of DOE management in complying with operational, environmental, safety, health, and security standards established by law, relation, and DOE policy.

As part of the internal oversight responsibilities within DOE, the Office of Environment, Safety and Health (ES\&H) has established a program within the Office of Environmental Audit, EH-24, to conduct multidisciplinary environmental audits at DOE's operating facilities. The initial audits in this program are designed to gather baseline information on environmental compliance and management at facilities that have not undergone a DOE Headquarters Environmental Survey or Tiger Team Assessment and are not expected to be scheduled for a Tiger Team Assessment through Fiscal Year 1992.

This document contains findings identified during the Baseline Environmental Audit of the Grand Junction Project Office. This Baseline Environmental Audit was conducted by the DOE's Office of Environmental Audit between May 29 and June 12, 1991.

The objective of the Audit is to provide the Secretary with information on the compliance status of DOE facilities with regard to environmental requirements, root causes for noncompliance, and adequacy of DOE environmental management programs and response actions to address the identified problem areas.

The scope of this Baseline Environmenia? Audit was comprehensive, covering all areas of environmental activities and waste management operations, with the exception of the National Environmental Policy Act (NEPA), which is the responsibility of the DOE Headquarters Office of NEPA Project Assistance. Compliance with applicable Federal, state, and local regulations; applicable DOE Orders; and internal facility requirements was assessed, along with adherence to best management practices.

August 1991

Washington, D.C. 
This page was intentionally left blank. 


\section{Table of Contents}

Section

Page

EXECUTIVE SUMMARY

ES-1

1.0 INTRODUCTION $1-1$

1.1 Purpose 1-1

1.2 Scope 1-2

1.3 Approach 1-2

1.4 Historical Background and Facility Description 1-4

2.0 SUMMARY OF AUDIT RESULTS, KEY ISSUES AND CAUSAL FACTORS 2-1

2.1 Line Management and Environmental Oversight 2-1

2.2 Self-Assessment and Oversight Programs 2-2

2.3 Regulation Agency Concerns 2-7

2.4 Summary of Findings 2-7

2.5 Summary of Findings by Discipline $2-15$

$\begin{array}{lr}2.6 & \text { Causal Factor Summary 2-16 }\end{array}$

2.7 Grand Junction Strengths 2-18

3.0 ENVIRONMENTAL AUDIT FINDINGS

3.1 Air

3.1.1 Overview

3-1

3.1.2 Findings

$3-1$

3-4

3.2 Surface Water

3.2.1 Overview

$3-11$

3.2.2 Findings

3-11

3-14

3.3 Groundwater

3.3.1 Overview

3-18

3.3.2 Findings

$3-18$

3-22

3.4 Soils/Sediment/Biota 3-28

3.4.1 Overview 3-28

3.4.2 Findings 3-31

3.5 Waste Management $3-34$

3.5.1 Overview 3-34

$\begin{array}{ll}3.5 .2 & \text { Findings } 3-37\end{array}$

3.6 Toxic and Chemical Materials $3-44$

$\begin{array}{ll}3.6 .1 & \text { Overview 3-44 }\end{array}$

3.6.2 Firidings $3-47$

3.7 Quality Assurance 3-53

3.7.1 Overview 3-53

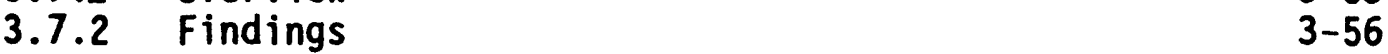

$\begin{array}{ll}3.8 \text { Radiation } & 3-66\end{array}$

$\begin{array}{ll}3.8 .1 & \text { Overview 3-66 }\end{array}$

3.8.2 Findings 3-69

3.9 Inactive Waste Sites 3-81

3.9.1 Overview 3-81

$\begin{array}{ll}3.9 .2 & \text { Findings 3-85 }\end{array}$

3.10 Environmental Management 3-88

$\begin{array}{ll}3.10 .1 & \text { Overview 3-88 }\end{array}$

3.10.2 Findings 3-95 


\section{Table of Contents (continued)}

Section

Page

3.0 ENVIRONMENTAL AUDIT FINDINGS, continued

3.11 Special Issues

3.11 .1 Overview

3-107

3.11 .1 Issue

3-107

3.12 Noteworthy Practices

3-109

3.12.1 Overview

3.12 .2 Issue

3-109

3-109

\section{APPENDICES}

A Biographical Sketches of Audit Team Personnel A-1

B Information Request Letter and Regulator Notification Letters B-1

B Information Request Letter and Regulator Notification Letters C-1

C Environmental Audit Plan $\quad$ D-1

D Daily Activities

E List of Documents Reviewed by the Audit Team Audit Team

$F$ List of Contacts/Interviews Conducted by the Audit Team G-1

$G$ Definition of Causal Factors $\quad H-1$

$H$ List of Acronyms

Figures

Number

Page

1-1 Location Map 1-6

1-2 GJPO Site Facility Map

2-1 Total Findings by Discipline

$1-7$

2-2 Probable Causal Factors at GJPO

2-14

2-17

Tables

Number

Page

2-1 Effectiveness of GJPO's Self-Assessment and Oversight Programs 2-3

in Identifying Audit Findings

Summary of Causal Facotrs Identified by Audit Finding

3-2 List of Applicable Surface Water Regulations/

Requirements/Guidelines

3-3 List of Applicable Groundwater Regulations/

Requirements/Guidelines

3-4 List of Applicable Soils/Sediment/Biota

Regulations/Requirements/Guidelines

3-5 List of Applicable Waste Management Regulations/

3-6 List of Applicable Toxic and Chemical Materials

$3-46$

Regulations/Requirements/Guidelines

Table of Contents (continued) 
3-7 List of Applicable Quality Assurance Regulations/ 3-54

Requirements/Guidel ines
3-8 List of Applicable Radiation Regulations/ 3-67

Requirements/Guidel ines
3-9 List of Applicable Inactive Waste Sites

Regul ations/Requirements/Guidel ines
3-10 List of Appl icable Environmental Management Regulations/Requirements/Guidel ines 
This page was intentionally left blank. 
EXECUTIVE SUMMARY 
This page was intentionally left blank. 


\section{EXECUTIVE SUMMARY}

This report documents the results of the Baseline Environmental Audit conducted at Grand Junction Projects Office (GJPO) located in Grand Junction, Colorado. The Grand Junction Basel ine Environmental Audit was conducted from May 28 to June 12, 1991, by the Office of Environmental Audit (EH-24). This Audit evaluated environmental programs and activities at GJPO, as well as GJPO activities at the State-Owned Temporary Repository. This Audit did not address other GJPO programs such as the Monticello Mill Site, Denver Radium sites, or Grand Junction UMTRA vicinity properties.

The Office of Environmental Audit (EH-24) within Office of the Assistant Secretary for Environment, Safety, and Health, is charged with conducting internal independent oversight of DOE line organizations through a comprehensive environmental auditing program. The Environmental Audit Program is designed to evaluate and improve the environmental compliance status of DOE facilities, and to reflect the responsibility of line management for conducting operations in an environmentally safe and sound manner.

The scope of the Baseline Environmental Audit was comprehensive, addressing all environmental media and applicable Federal, state and local regulations with the exception of the National Environmental Policy Act (NEPA). Also addressed were DOE Orders, formalized facility or program operating procedures, and Best Management Practices (BMP). The technical disciplines addressed by the Audit were: Air; Surface Water; Soils, Sediment and Biota; Groundwater; Waste Management; Toxic and Chemical Materials; Quality Assurance; Radiation; Inactive Waste Sites. In addition, the audit included a review of environmental management programs within the DOE-GJPO and Contractor organizations. The effectiveness of environmental monitoring programs was a major component of the review conducted within applicable technical disciplines. On-site activities included document review; field inspections; interviews with site personnel (both DOE and the primary support contractor), as well as representatives of Federal, state and local regulatory agencies; and reviews of previous audits and self-assessments.

The overall conclusion of the Audit Team is that GJPO is generally conducting its operation in compliance with the substantive provisions of applicable Federal, state and local regulations, and DOE Orders, and that both DOE-GJPO and Geotech management and staff are committed to protection of the environment. Deficiencies observed do not, in the opinion of the Audit Team, reflect situations which pose near term threats to public health and the environment.

Consistent with the Secretary of Energy's objectives to have DOE programs and operations strive for excellence in the performance of their environmental compliance activities, DOE-GJPO and Geotech management have initiated efforts to meet this objective. Management's and staff's technical competence and overall knowledge of Federal, state, and local environmental regulations are excellent. 
Strengths observed in GJPO's environmental programs include the Quality Assurance organization, the Radon Laboratory, the Analytical Chemistry Laboratory, and GJPO's implementation of SEN-23-90 regarding technology transfer. Additionally, a noteworthy practice was observed with respect to the records retention system developed by GJPO for groundwater monitoring well information.

GJPO has fully adopted Secretary Watkins' policy of openness with internal oversight organizations embodied in $\mathrm{SEN}-20-90$, and has set an unprecedented standard within the DOE complex of cooperation and openness. This commendable cooperation and openness was pervasive throughout the management and staff of both DOE-GJPO and Geotech, Inc.

The most significant findings identified by the Audit Team as "Key Findings" involve insufficient DOE oversight of GJPO operations, a lack of cormality of operations, and inadequate environmental monitoring. 


\subsection{INTRODUCTION}


This page was intentionally left blank. 


\section{$1.0 \quad$ INTRODUCTION}

This report documents the results of the Baseline Environmental Audit conducted at Grand Junction Projects Office (GJPO) located in Grand Junction, Colorado. The Grand Junction Basel ine Environmental Audit was conducted from May 28 to June 12, 1991, by the Office of Environmental Audit (EH-24). This Audit evaluated environmental programs and activities at GJPO, as well as GJPO activities at the State-Owned Temporary Repository. This Audit did not address other GJPO programs such as the Monticello Mill Site, Denver Radium sites, or Grand Junction UMTRA vicinity properties.

Secretary of Energy Notice (SEN) 6D-91 assigns the Office of Environment, Safety and Health (EH) the responsibility for conducting independent internal oversight audits to assure compliance with applicable laws related to environmental protection. SEN-20-90 emphasizes the need for and value of audits by authorized oversight organizations such as $E H$, to ensure that DOE activities are undertaken in an "environmentally sound manner". SEN-29-91 establishes the performance indicators and trending program to be in place by DOE operations beginning June 1991. This program sets out to "establish a uniform system of Performance Indicators for trending and analyzing operational data to help assess and support progress in improving performance, as well as strengthen line management control of operations relating to Environment, Safety and Health (ES\&H) activities." The Environmental Audit Program is designed to evaluate and improve the environmental compliance status of DOE facilities, and to reflect the responsibility of line management for conducting operations in an environmentally safe and sound manner.

\section{$1.1 \quad$ Purpose}

The purpose of the Baseline Environmental Audit is to provide the Secretary of Energy, through the Assistant Secretary for Environment, Safety and Health, with concise information pertaining to the following issues:

- Compliance status with applicable environmental regulations (with the exception of NEPA requirements);

- Compliance with DOE Orders which address environmental programs;

- Adherence to best management and accepted industry practices;

- DOE vulnerabilities and liabilities associated with compliance status, environmental conditions, and management practices;

- Root causes of Compliance Findings (CF) and Best Management Practice findings (BMP);

- Adequacy of environmental management programs and organizations; and

- Noteworthy practices.

This information will assist DOE in determining patterns and trends in environmental compliance and BMP deficiencies, as well as causal factors and 
probable root causes contributing to the observed deficiencies. Line management is expected to fully utilize this information to develop corrective actions, and make appropriate modifications to internal self-assessment programs in order to prevent recurrence of deficiencies, and to supplement their formalized lessons learned programs to ensure broad applications to other operations, programs and facilities.

\section{$1.2 \quad$ Scope}

The scope of the Baseline Environmental Audit was comprehensive, addressing all environmental media and applicable Federal, state, and local regulations, with the exception of NEPA. Also addressed were DOE Orders and formalized facility or program operating procedures, as well as BMPs. The technical disciplines addressed were: air; surface water; soils, sediment and biota; groundwater; waste management; toxic and chemical materials; quality assurance; radiation; inactive waste sites; and environmental management. In addition, the audit included a review of the environmental monitoring programs, and the effectiveness of the environmental management programs. Because auditing of NEPA requirements is the responsibility of the DOE Headquarters Office of NEPA Project Assistance, NEPA compliance issues were audited and, therefore, are not addressed in this report.

\section{$1.3 \quad$ Approach}

The Baseline Environmental Audit followed accepted audit techniques and was guided by implementation of procedures and programs cited in the draft $D O E$ Environmental Audit Guidance Manual (June 1990), and the DOE Environmental Audit Program Manual (DOE/EH-0125). The Audit was conducted by a Team of professionals managed by a DOE Headquarters Audit Team Leader and Assistant Team Leader from the Office of Environmental Audit (EH-24), and staffed by contractor technical support personnel. The names, area of responsibility, affiliations, and biographical sketches of the Team members are provided in Appendix A. The Audit included three phases: planning, on-site activities, and reporting.

During the planning phase, a memorandum was sent to GJPO announcing the Basel ine Environmental Audit and requesting information about GJPO and program activities in general. Included in this memorandum was a request that GJPO formally notify appropriate Federal, state, and local regulatory agencies of the Audit and solicit their participation. A copy of the information reques: letter and regulatory agency notifications is included in Appendix B. A preAudit site visit was conducted from April 30 - May 1, 1991. The site's response to the information request memorandum combined with the pre-Audit site visit formed the basis for the Audit Plan (Appendix C), including the onsite agenda. Once on-site, the Audit Team modified the original agenda as more information was obtained, and additional areas of interest were identified. The final daily agenda is contained in Appendix D.

On-site activities were conducted from May 29 through June 12, 1991, and included interviews with site personnel (both DOE and contractor), as well as representatives from Federal, state, and local regulatory agencies; document reviews, including previous audits and self-assessment reports; physical 
inspection of facilities; and observation of on-site activities. The Audit Team corducted daily debriefings that were open to DOE and site personnel, and regulatory officials. Lists of site documents reviewed and interviews performed are provided in Appendices $E$ and $F$, respectively. Using these sources of information, the Audit Team developed findings as discussed in Sections 2 and 3 of this report.

The problems identified are categorized as either "compliance" findings, or "BMP" findings. Compliance Findings (CF) are conditions that, in the judgement of the Audit Team, may not satisfy applicable environmental regulations, DOE Orders, Secretary of Energy Notices (SENs), Consent Agreements with regulatory agencies, environmental permit conditions, and internal DOE or contractor environmental policies and procedures. BMP findings are derived from regulatory agency guidance, accepted industry practice or technical standards, draft DOE Orders, DOE guidance documents, and professional judgement.

Within the "compliance" and "BMP" categories, each finding is prefaced by a Performance Objective(s). The Performance Objectives specify the particular compliance or BMP standards against which the finding is being evaluated. The findings are not arranged in order of relative significance.

Special issues may be identified. These are not findings but are topics or situations requiring further discussion based on the set of circumstances surrounding the issue. A special issue is generally a regulatory requirement, policy direction, or management practice. Because special issues do not meet the criteria of findings, apparent causal probable are not included in the discussion.

Site programs and activities were reviewed for any noteworthy practices, activities, or programs that could have DOE complex-wide application for the purpose of information transfer among DOE facilities. A practice may be noteworthy because its design and/or execution successfully addresses activities that have frequently resulted in compliance problems at other facilities. The presence or absence of noteworthy practices at a facility should not be viewed as a measure of a facility's performance. The purpose of this activity is for information transfer and problem solving across the DOE complex (rather than for the purpose of commendation). It provides the opportunity to identify innovative and cost-efficient solutions, thereby improving the effectiveness of DOE in meeting production goals in a way that is consistent with environmental goals.

It is the intent of this Baseline Environmental Audit to go beyond the findings and to identify the probable causal factors or root causes for certain environmental deficiencies. Causal factors as used by the Audit Team are defined in Appendix G. If one or more of these causal factors can be identified as contributing to a specific finding it will be included in the supporting information of each finding. The causal factors are then used to assist in the determination of corrective actions required to rectify identified findings. 


\subsection{Historical Background and Facility Description}

The Grand Junction Projects office (GJPO) is located in Mesa County, Colorado, immediately south and west of the Grand Junction city limits. GJPO occupies 56.4 acres, and is bounded on the west and south by the Gunnison River, which merges with the Colorado River about 0.5 miles downstream of GJPO. The north and east boundaries of GJPO are county, city, and private property. The area immediately surrounding GJPO is primarily agricultural lands.

The U.S. Atomic Energy Commission (AEC) established the Colorado Raw Materials office at the present-day Grand Junction Projects Office in 1947, to aid in the development of a viable domestic uranium industry. Activities at the site inciuded sampling uranium concentrate; pilot-plant milling research, including testing and processing of uranium ores; and operation of a uranium mill pilot plant from 1954 to 1958 . The last shipment of uranium concentrate was sent from GJPO in January, 1975. Since that time the site has been utilized to support various DOE programs, such as the former National Uranium Resource Evaluation (NURE) Program, the Uranium Mill Tailings Remedial Action Project (UMTRAP), the Surplus Facilities Management Program (SFMP), and the Technical Measurements Center (TMC).

There are approximately 30 structures within GJPO's boundaries, and approximately 650 employees. In addition to DOE, Geotech, Inc., and Oak Ridge National Laboratories, Oak Ridge Associated Universities and the General Services Administration al so have employees at GJPO.

In the past, personnel were primarily involved in uranium procurement, evaluation of domestic uranium resources, development of uranium extractive processes, and advancement of geologic and geophysical exploration techniques. The current scope of activities includes provision of support to the Government's various remedial action programs. GJPO has fully equipped laboratories for analytical chemistry, mineralogy-petrology, radon, and electronics.

A11 known contamination at GJPO is believed to be the result of the past uranium milling, analyses, and storage activities. According to historical records, approximately 29,024 metric tons of ore were processed between 1943 and 1958. The resulting tailings consisted of approximately 105,000 cubic meters of materials that were distributed throughout the site.

Hazards associated with the wastes impounded at GJPO include surface and ground-water contamination and potential radon and gamma-radiation exposure. Tailings-related contamination of surface water within GJPO's boundaries has been documented for many years, and samples from monitoring wells reveal that contamination is present in the alluvial aquifer underlying GJPO. Another potential hazard is the generation of radon, a radioactive decay product of the radium contained in the tailings. Radon is a radioactive gas that can diffuse through the tailings and be released into the atmosphere. The gas and its decay products may be inhaled by humans and thereby increase the risk of cancer. 
Formal site investigations began in 1984 when GJPO was accepted into the DOE SFMP. GJPORAP was later transferred to the Defense Decontamination and Decommissioning Program. Under the guidelines set forth in the Uranium Mill Tailings Radiation Control Act (UMTRCA), site characterization and remedial action studies were initiated to assess the radiological hazards at GJPO. These studies were initially compiled into an Environmental Assessment under the National Environmental Policy Act (NEPA) process which was submitted to DOE Headquarters in January 1987.

Subsequent to the passage of the Superfund Amendments and Reauthorization Act (SARA), a decision was made to re-evaluate the facility under the Comprehensive Environmental Response, Compensation, and Liability Act (CERCLA) process. Although not an NPL site, the earlier studies were incorporated into the Remedial Investigation and Feasibility Study (RI/FS) process. This document was released to the public in April 1989 and was followed by a Record of Decision (ROD) in April 1990. This was the first ROD for a non-NPL site. Remedial actions are currently under way to decontaminate and decommission contaminated buildings, as well as to remove contaminated mill tailings from GJPO to the State-Owned Temporary Repository for storage pending final disposal at the Cheney Reservoir UMTRAP site. 


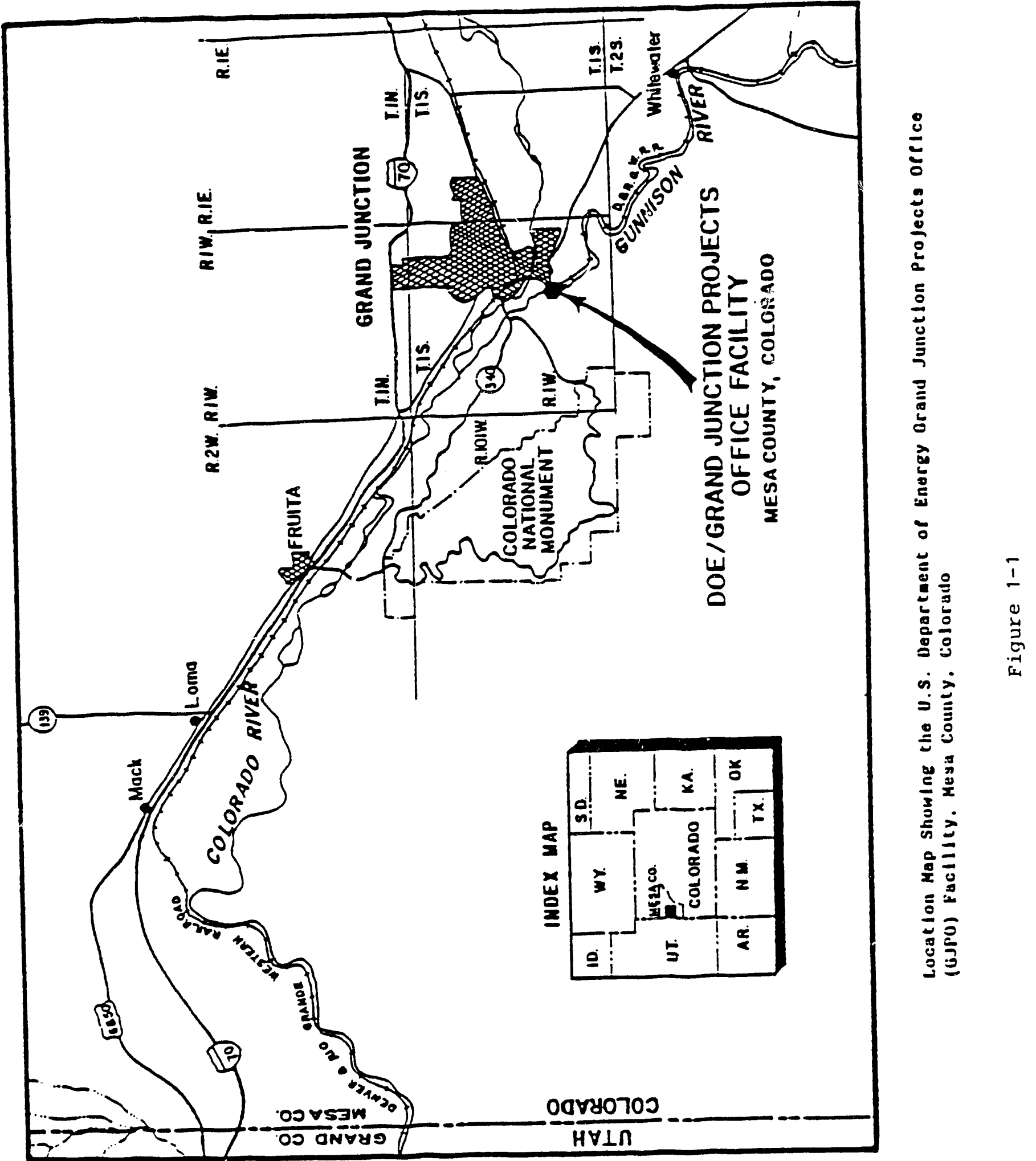




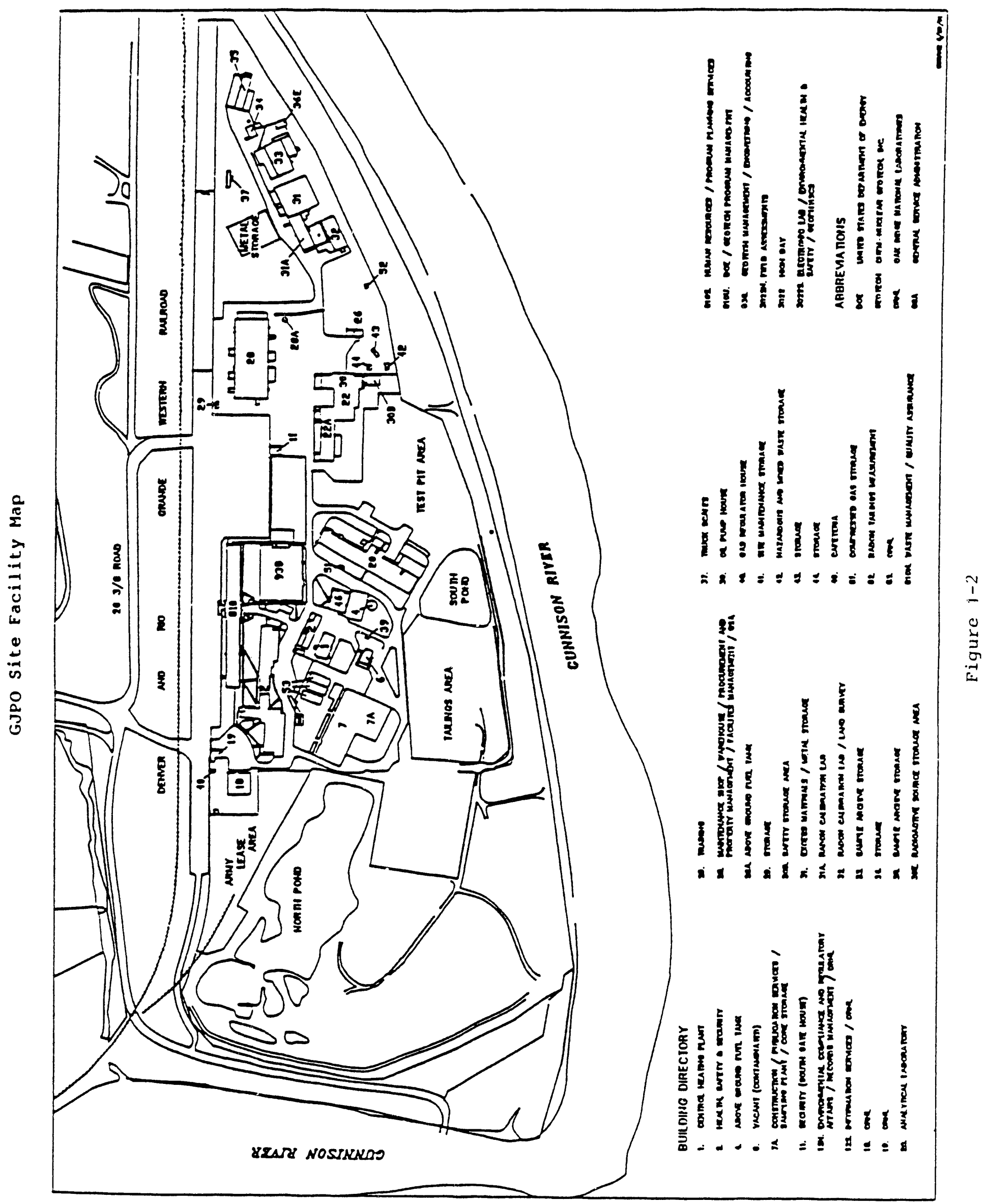


This page was intentionally left blank. 


\subsection{SUMMARY OF AUDIT RESULTS}


This page was intentionally left blank. 
This section summarizes the results and conclusions of the Office of Environmental Audit's (EH-24) May 29 to June 12, 1991 Baseline Environmental Audit of the Grand Junction Project Office located in Grand Junction, Colorado.

The overall conclusion of the Audit Team is that GJPO is generally conducting its operation in compliance with the substantive provisions of applicable Federal, state, and local regulations, and DOE Orders, and that both DOE-GJPO and Geotech management and staff are committed to protection of the environment. Deficiencies observed do not, in the opinion of the Audit Team, reflect situations which pose near term threats to public health and the environment. The findings, in general, represent a trend of "informality of operat;ions" that, al though not endemic in the GJPO operation, is significant and contributed to many of the observed deficiencies.

GJPO has fully adopted Secretary Watkins' policy of openness with internal oversight organizations embodied in SEN-20-90, and has set a unprecedented standard within the DOE complex of cooperation and openness. This commendable cooperation and openness was pervasive throughout the management and staff of both DOE-GJPO and Geotech. Participation in the auditing process by GJPO management and staff was at a high level indicating a desire to constructively utilize the auditing process to enhance the capabilities of both line management and oversight organizations within GJPO.

\section{$2.1 \quad$ Line Management}

Consistent with the Secretary of Energy's objectives to have DOE programs and operations strive for excellence in the performance of their environmental compliance activities, DOE-GJPO and Geotech management have initiated efforts to meet this objective. Management's and staff's technical competence and overall knowledge of Federal, state, and local environmental regulations are excellent.

The DOE-GJPO organization consists of a Director who is supported by the Technical Supervisory Engineer of Technical Programs, whose responsibilities include management and accountability of the UMTRA Program and Remedial Action Construction Projects. The Environmental Engineer is responsible for oversight of environmental compliance, regulatory affairs, health and safety, $Q A$ and Self-Assessments. The Geologist oversees the Grand Junction Projects Office Remedial Action Project (GJPORAP) while the Physical Scientist oversees all laboratory activities, special projects, and strategic planning initiatives.

Line management is under the control of the DOE Supervisory Engineer of Technical Programs at GJPO. The Supervisory Engineer oversees line management at Geotech which consists of Operations and Technical management, including Grand Junction operations, Denver operations, UMTRA Program, Technical Programs, Waste Management Programs, Engineering, Laboratory Services and Field Assessments. Line management is supported by Environmental Compliance 
and Regulatory Affairs, Health, Safety and Security, Quality Assurance, and Self-Assessment organizations. Geotech's line organizations have been effective at implementing programmatic requirements in operations/activities at GJPO.

\subsection{Self-Assessment and Oversight Programs}

GJPO self-assessment responsibilities are split between the DOE-GJPO and Geotech organizations. Despite a late start, Geotech's Self-Assessment Program is currently operational and jroving to be a valuable tool for identifying deficiencies and effeciing resolution. This program, along with a comprehensive program of "Management by Walkdown," will contribute to an increasing improvement in the environmental compliance status of GJPO operations. However, several required elements of the Geotech Self-Assessment program have yet to be implemented. The DOE-GJPO Self-Assessment program has apparently been hampered by delayed guidance from DOE/ID and a lack of available resources, and currently is in initial stages of formalization and implementation.

DOE-GJPO oversight of operations within GJPO consists of quarterly cost plus award fee reviews, newly initiated surveillances, and routine interface with Geotech personnel. A significant concern exists with regard to the intensity of this DOE-GJPO oversight of Geotech due to the high level of program activities and chronic shortage of DOE personnel. This concern is further discussed in Section 3.10 and is embodied in Finding EM/CF-1 and EM/BMPF-4. The DOE/ID ES\&H organization supplements GJPO oversight of Geotech through quarterly inspection; however, the DOE on-site presence is still not sufficient to adequately assess Geotech's environmental performance.

The Geotech organization at Grand Junction is a "matrix" organization which utilizes the skills and resources of the HS\&S and Environmental Compliance and Regulatory Afairs (EC\&RA) organizations to provide technical support to line organizations as well as to conduct internal oversight. A concern regarding the organizational interaction between HS\&S and EC\&RA with line organizations was identified during the audit. These organizations are tasked via matrix management to provide technical support to Geotech line organizations, however, they al so conduct oversight of these same line organizations, thereby potentially compromising their objectivity of their oversigiii in certain instances. This concern is further described in Finding $i M / C F-2$.

The effectiveness of GJPO's (Geotech and DOE-GJPO) Self-Assessment and oversight programs was evaluated with respect to success in internally identifying deficiencies found during this audit. Table 2-1 indicates by finding the success of GJPO's Self-Assessment and oversight programs in identifying these deficiencies. An analysis of this data indicates that formal GJPO Self-Assessments and iniernal audits had previously identified (fully or partially) approximately 35 percent of the findings contained in this report. Additionally, Audit Team investigations indicate that facility personnel were also aware of an additional 25 percent of the findings although this knowledge was not formally documented or included in a corrective action tracking system. The level of previously identified Audit Team findings 


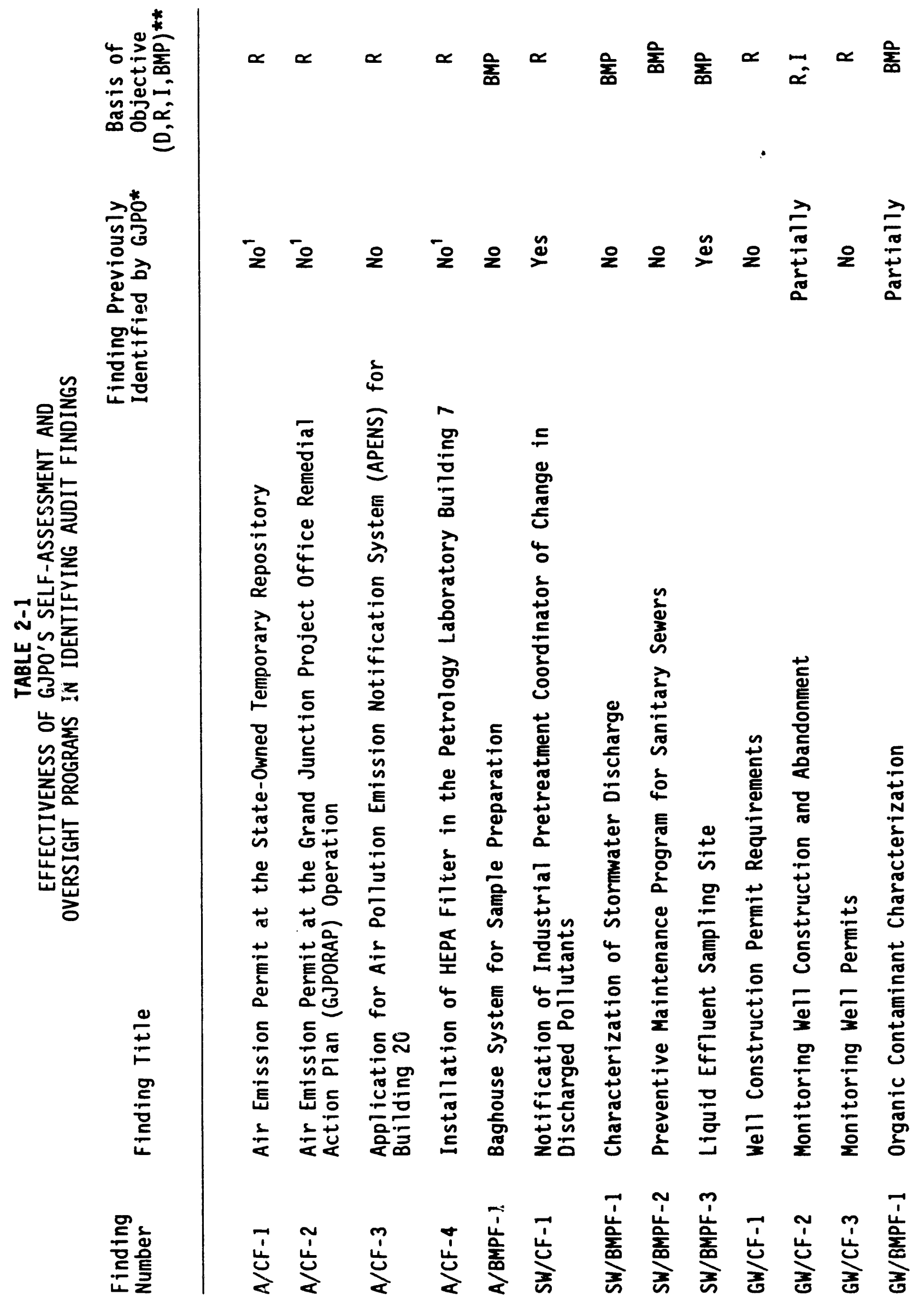




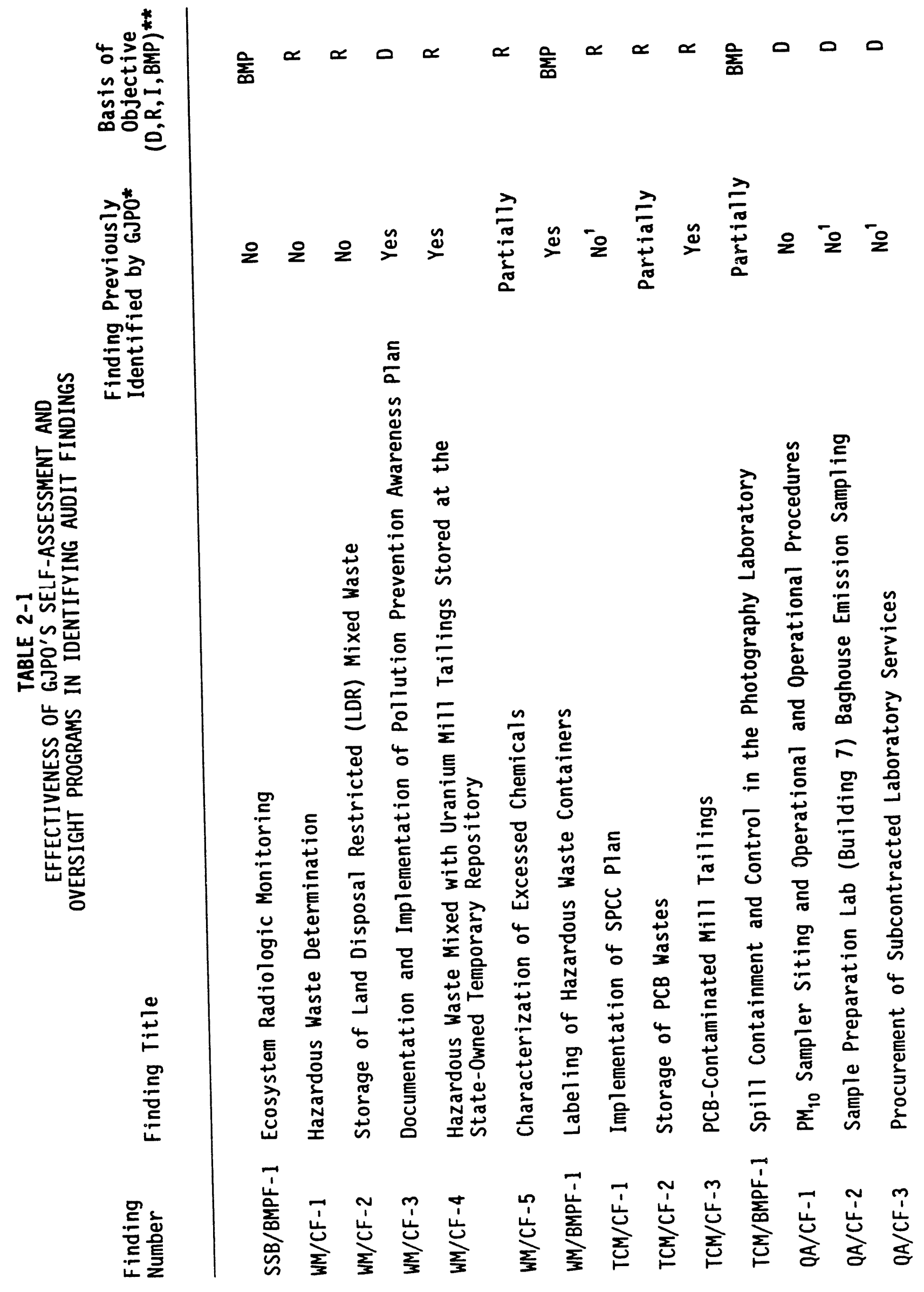




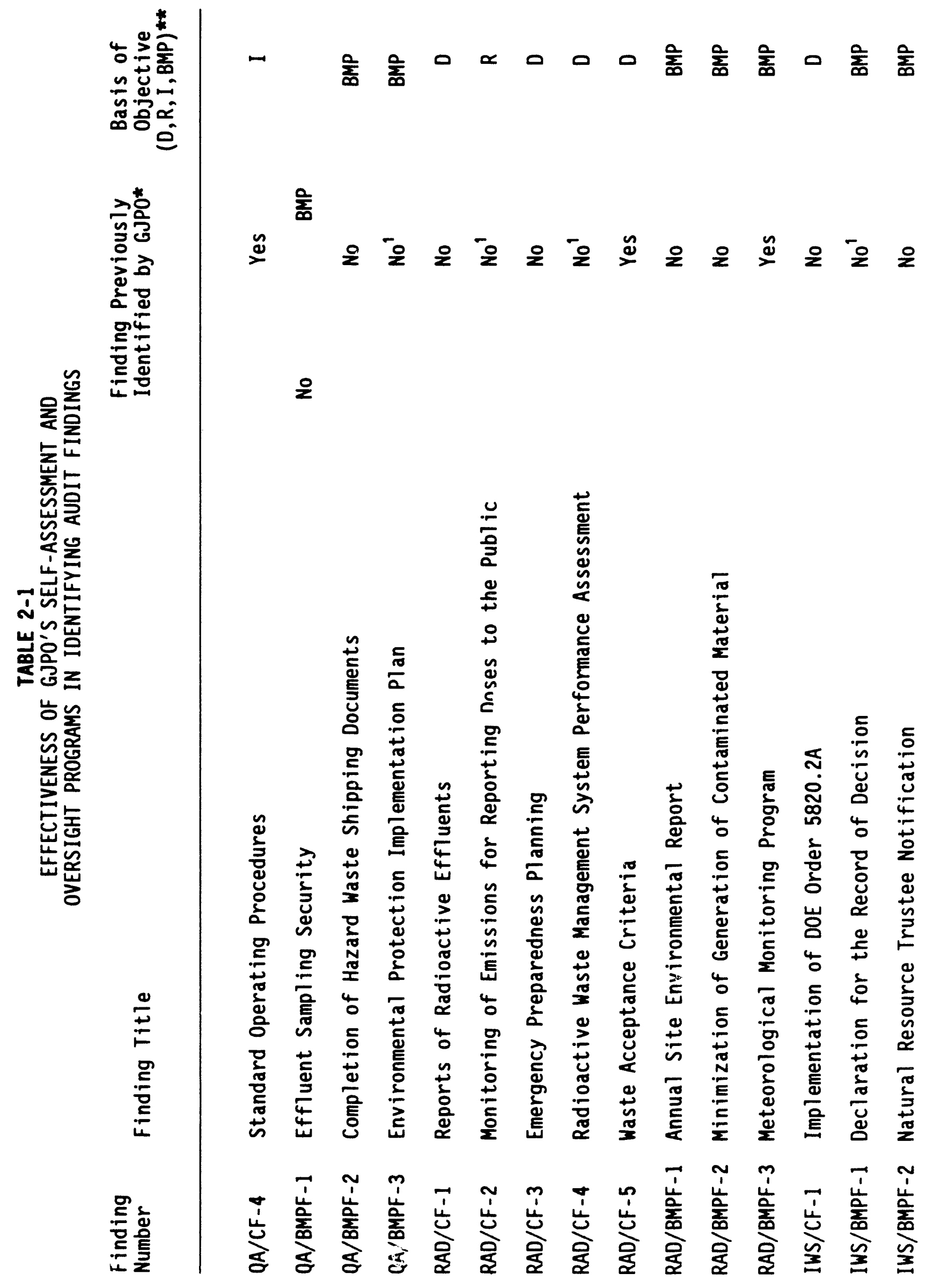




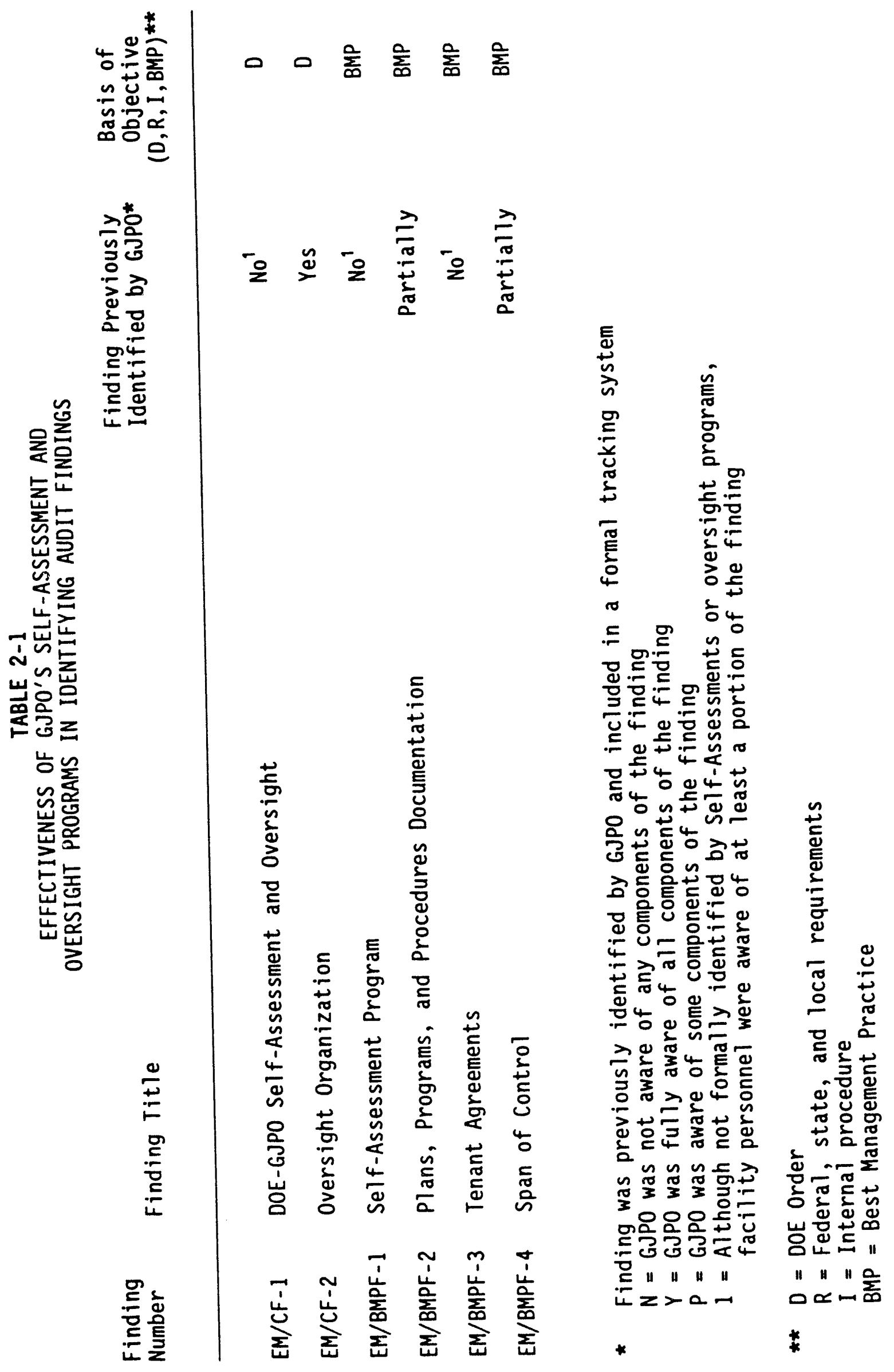


indicates that the Self-Assessment programs are still maturing, and that oversight activities need to expand their areas of inquiry. Neither the newly initiated DOE-GJPO surveillance program nor the facility's Self-Assessment program had identified any of the Audit Team's findings.

\subsection{Regulatory Agency Concerns}

The U.S. Environmental Protection Agency (EPA) Region VIII, the Colorado Department of Health (CDH), the Mesa County Commissioners, and the Grand Junction City Manager were invited to participate in Audit activities. CDH attended the pre-site meetings held on April 30 - May 1, 1991, and expressed the following concerns:

- $\quad$ CDH is in disagreement with DOE-GJPO and Geotech regarding procedures for the use of instrumentation and interpretation of data regarding the characterization of radioactive contamination at UMTRAP vicinity properties.

- $\quad$ CDH believes DOE's approach to verify attainment of UMTRAP standards at vicinity properties is deficient in that independent verifications conducted by Oak Ridge National Laboratory (ORNL) only occur at 10 percent of the vicinity property cleanups and that the contractors conducting cleanups know in advance which properties would be verified by ORNL.

- $\quad$ CDH expressed frustration with GJPO's lack of a resolution of a compliance concern related to the unpermitted storage of commingled hazardous waste and uranium mill tailings from cleanup of UMTRAP vicinity properties at the GJPO operated, State-Owned Temporary Repository.

Investigations into the two $\mathrm{CDH}$ concerns regarding UMTRA vicinity property issues were initiated during this Audit; however, resolution of these issues will be addressed in a subsequent Baseline Audit of UMTRA activities associated with the Rifle, Gunnison, and $\mathrm{Climax} M i l l$ sites. This subsequent Audit commenced on June 10, 1991 and is anticipated to conclude on June 26, 1991. In addition, the Audit Team investigated both the ongoing and historic DOE-GJPO management of the commingled waste issue raised by CDH. The Audit Team observed concerns with respect to DOE-GJPO's handling of the resolution of the commingled waste issue. Because these concerns also involve the management relationships between DOE-GJPO, the DOE/AL UMTRA program, and DOE/EM Headquarters, this issue will be further pursued in the baseline Audit of the Rifle, Gunnison, and Climax Mill UMTRA sites which more directly relates to the UMTRA program. Generally, the Audit Team noted that GJPO and $\mathrm{CDH}$ do not always achieve a high level of openness and cooperation on issues of mutual concern.

Summary of Findings

The number of findings identified during an environmental audit is not directly proportional to the level of environmental compliance nor the degree of environmental protection offered by a facility or program. This is 
exemplified by the situation that a facility with no program in a particular area may have a single key finding on the absence of that program; however, a facility with a sound program in that particular area may have multiple findings on relatively minor components of the program.

The GJPO Baseline Environmental Audit identified 48 findings, one Special Issue, and one Noteworthy Practice. Deficiencies observed do not, in the opinion of the Audit Team, reflect situations which pose near-term threats to public health and the environment. The findings, in general, appear to represent a trend of "informality of operations" that, although not endemic in the GJPO operation, is significant and contributed to many of the observed deficiencies. Twenty-eight findings represent conditions which do not comply with the requirements of Federal, state, or local regulations, DOE Orders, environmental permits, or internal DOE-GJPO or Geotech procedures. Of the 28 "compliance" findings, 11 (40\%) are the result of failure to prepare, receive, or distribute documentation, and an additional 6 findings (12\%) represent instances where significant barriers to achieving full compliance exist and are beyond the direct control of GJPO. Twenty findings represent situations where conditions or practices do not adhere to best management practices (BMPS). Table 2-2, 1ists all findings and indicates the source (regulation, DOE order, internal procedure, or BMP) of the performance objective upon which the finding is based.

Key findings are selected from the GJPO Baseline Environmental Audit findings. These are findings or groups of findings related to the same issue which, in the judgement of the Audit Team, are key to understanding the nature and scope of the environmental problems at GJPO. The key findings the Audit Team identified are:

- DOE Oversight of GJPO Operations - One of the most significant concerns identified by the Audit Team is the apparent lack of historic and ongoing environmental oversight by DOE of Geotech activities. This concern exists not only with regard to general oversight of environmental programs by responsible line management, but also with respect to more "classical" environmental oversight such as appraisals and surveillances by oversight personnel. Human resources afforded to DOE-GJPO are not sufficient to meet the high expectations set by Secretary of Energy with regard to the accountability of DOE line management, nor to ensure the visible and effective presence of DOE environmental oversight needed to measure the success of Geotech environmental programs. This concern is further discussed in Section 3.10 and included in findings EM/CF-2 and EM/BMPF-4. The quality and competence of the existing personnel is not a concern to the Audit Team, but rather is a key factor in the overall strength of GJPO operations. The DOE/ID ES\&H organization supplements GJPO oversight of Geotech through quarterly inspections; however, the DOE on-site presence is still not sufficient to adequately assess Geotech's environmental performance.

- Formality of Operations - A contributing factor to many of the deficiencies observed by the Audit Team was a apparent 1ack of "formality of operations" within GJPO. Areas where a lack of formality 


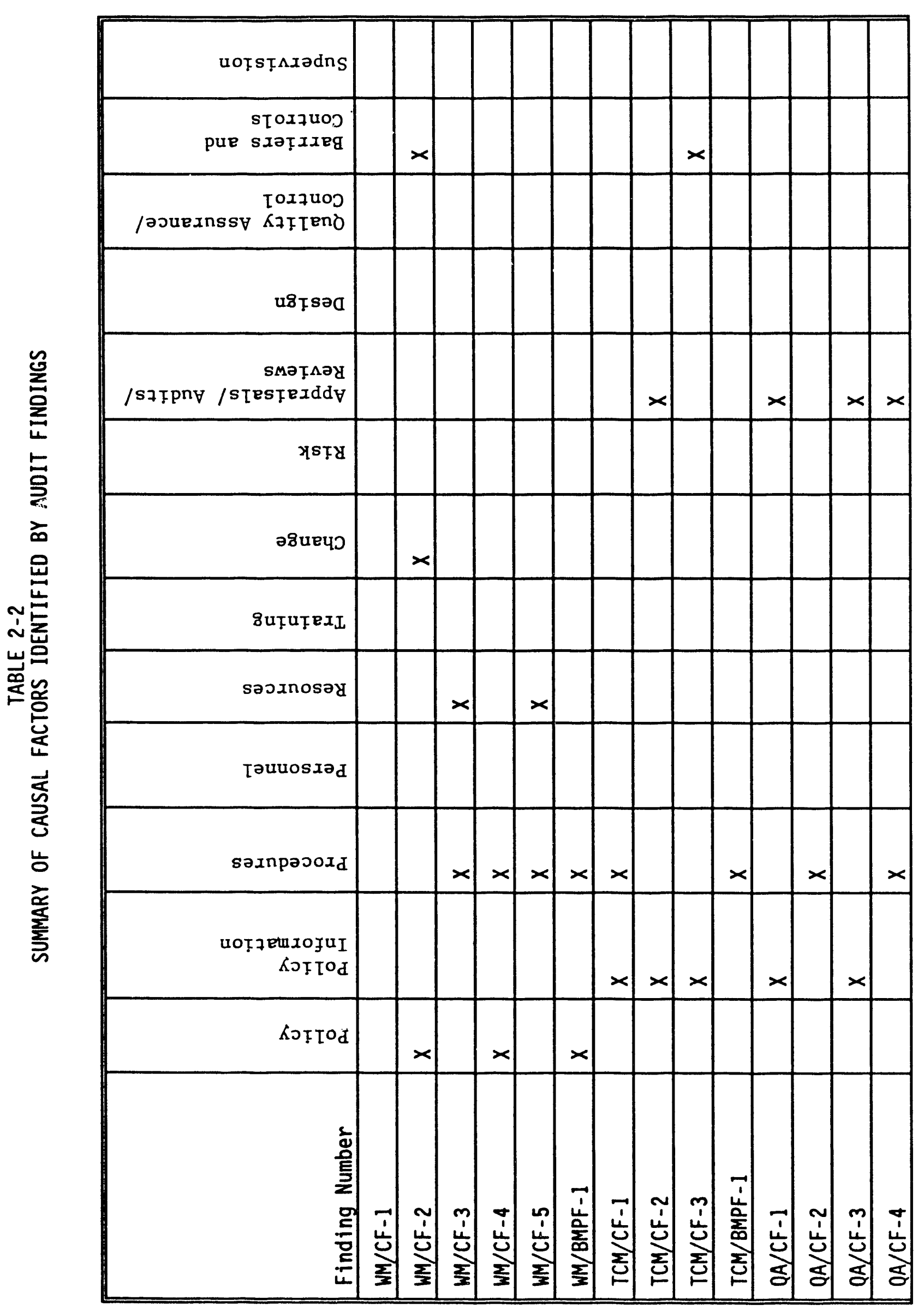




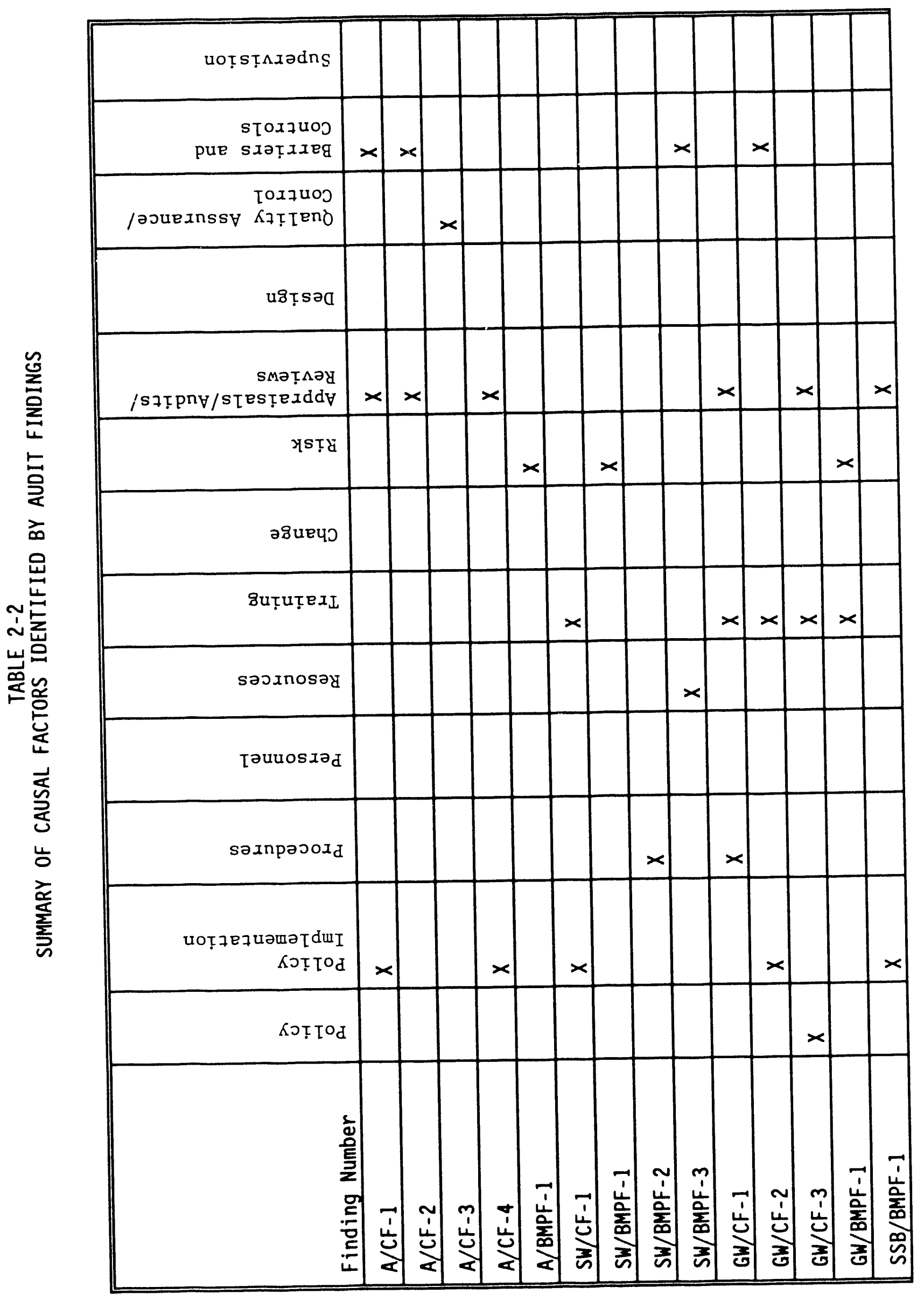




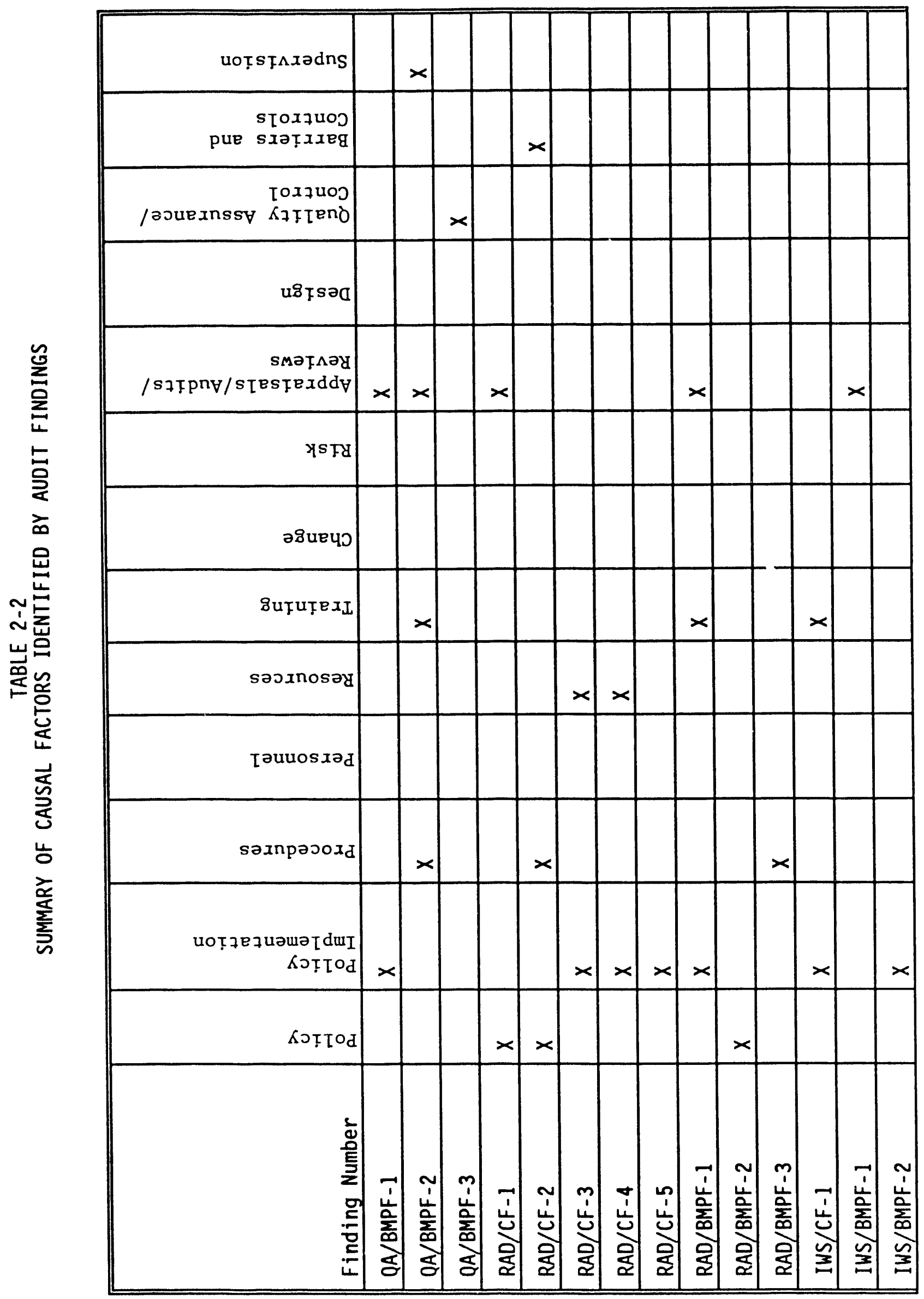




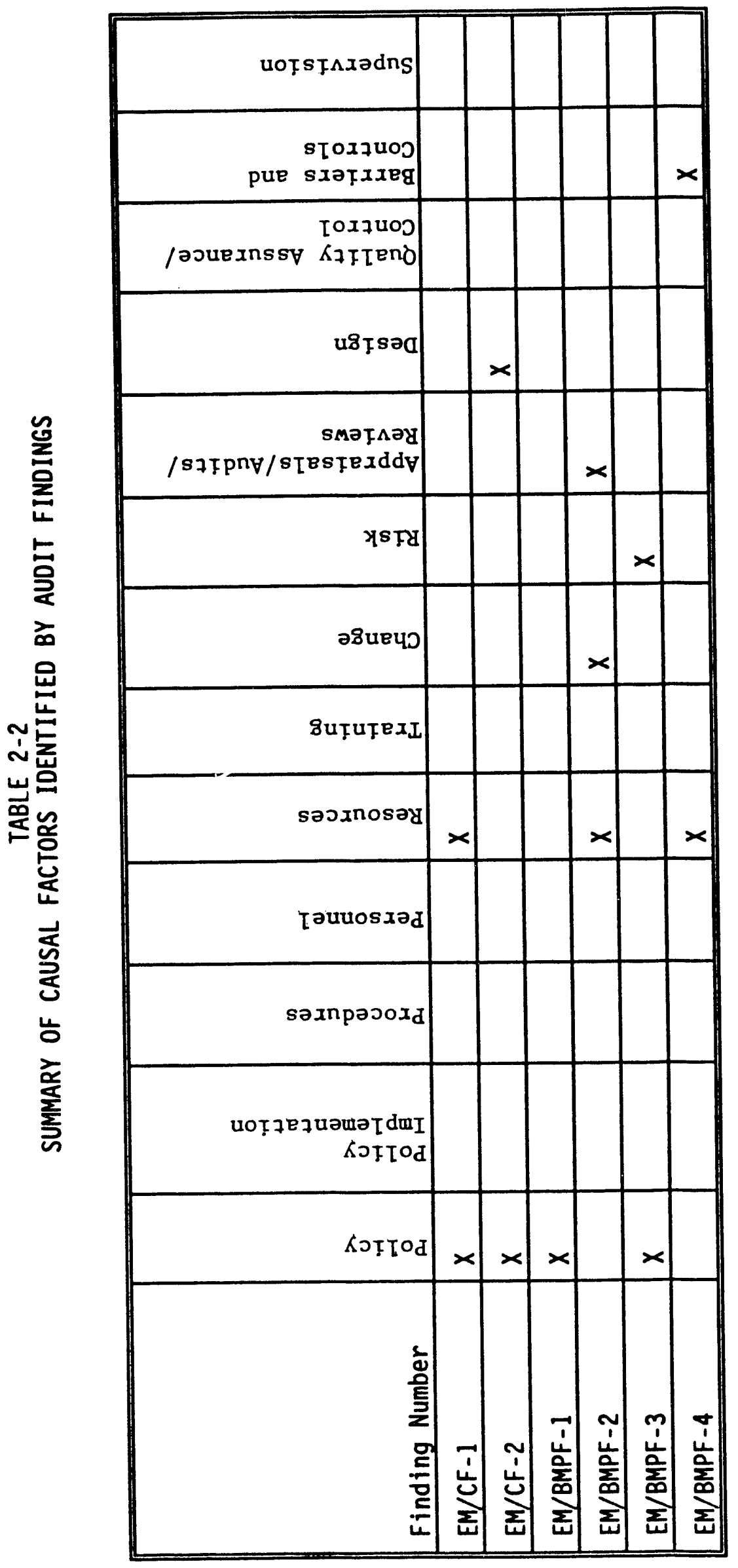


of operations was observed include failure to formally: document decisions; document direction provided by regulatory agencies; document the applicability of regulations and DOE Orders; and failure to prepare required documentation. The observed state of informality, although not endemic in all GJPO operations, was observed in many of the Audit Team's findings. Individually, many of the instances of informality of operations do not pose serious liability to the Department of Energy. However, incrementally, the potential risk to GJPO operations and the Department of Energy escalates. Examples which demonstrate the serious nature of this concern are found in Findings $A / C F-1$ and $A / C F-2$. In these instances, GJPO has failed to obtain a final approval from the State of Colorado for the Air Pollution Emission Notification System (APENS) permits for operations conducted at the State-Owned Temporary Repository and the Grand Junction Remedial Action Project (GJPORAP). At both facilities, the conditional stated on the initial permit requires that a final permit be received within six months of operations or the permit will be revoked. GJPO operations at these facilities have been ongoing for longer than six months without final receipt of the final APENS permit. GJPO has failed to formally document verbal direction from CDH that GJPO still had a valid permit to operate these facilities, and, thus, faces potentially serious liabilities associated with continuing operations. Other examples which further demonstrate the seriousness of this concern include Findings $A / C F-1, A / C F-2, A / C F-3$ $A / C F-4, S W / C F-1$, GW/CF -1 ,

GW/CF-3, RAD/CF-2, RAD/CF-3, RAD/CF-4, and IWS/CF-1.

Deficiencies in Environmental Monitoring - GJPO does not meet the requirements for environmental monitoring as specified in DOE Orders and Federal, state, and local regulations as noted in findings in the areas of air, radiation; groundwater; soils, sediment, and biota, and surface water. The air deficiencies observed include the location of PM-10 samplers, procedures for baghouse sampling and the handling of sampling filters, soil moisture measurements at GJPORAP and the State-Owned Temporary Repository (related to fugitive air emission control), the use of outdated and potentially inaccurate baghouse emissions and other source data to determine doses to the public, and weaknesses in the meteorological monitoring program. The radiological surveillance program does not include soils, river and pond sediments, and terrestrial and aquatic biota. Several groundwater monitoring wells at GJPO are improperly constructed, and organic contamination of the groundwater at the site has not been adequately characterized. The wastewater effluent released to the City POTW contains chemicals not contained in the facility's permit, which and, therefore, are not factored into regulatory compliance monitoring. GJPO's sampling location for its in-house POTW compliance monitoring is inadequate, and the facility has not characterized a potentially contaminated stormwater point source discharge. The specific deficiencies were acluded in Findings $Q A / C F-1, Q A / C F-2, A / C F-1, A / C F-2, R A D-C F-2, R A D / B M P F-1$, RAD/BMPF-3, GW/CF-2, GW/BMPF-1, SSB/BMPF-1, SW/CF-1, SW/BMPF-1, and SW/BMPF -3.

Figure 2-1 presents the total number of findings (compliance and BMP) for each of the disciplines covered by this Audit.

$$
\text { 2-13 }
$$




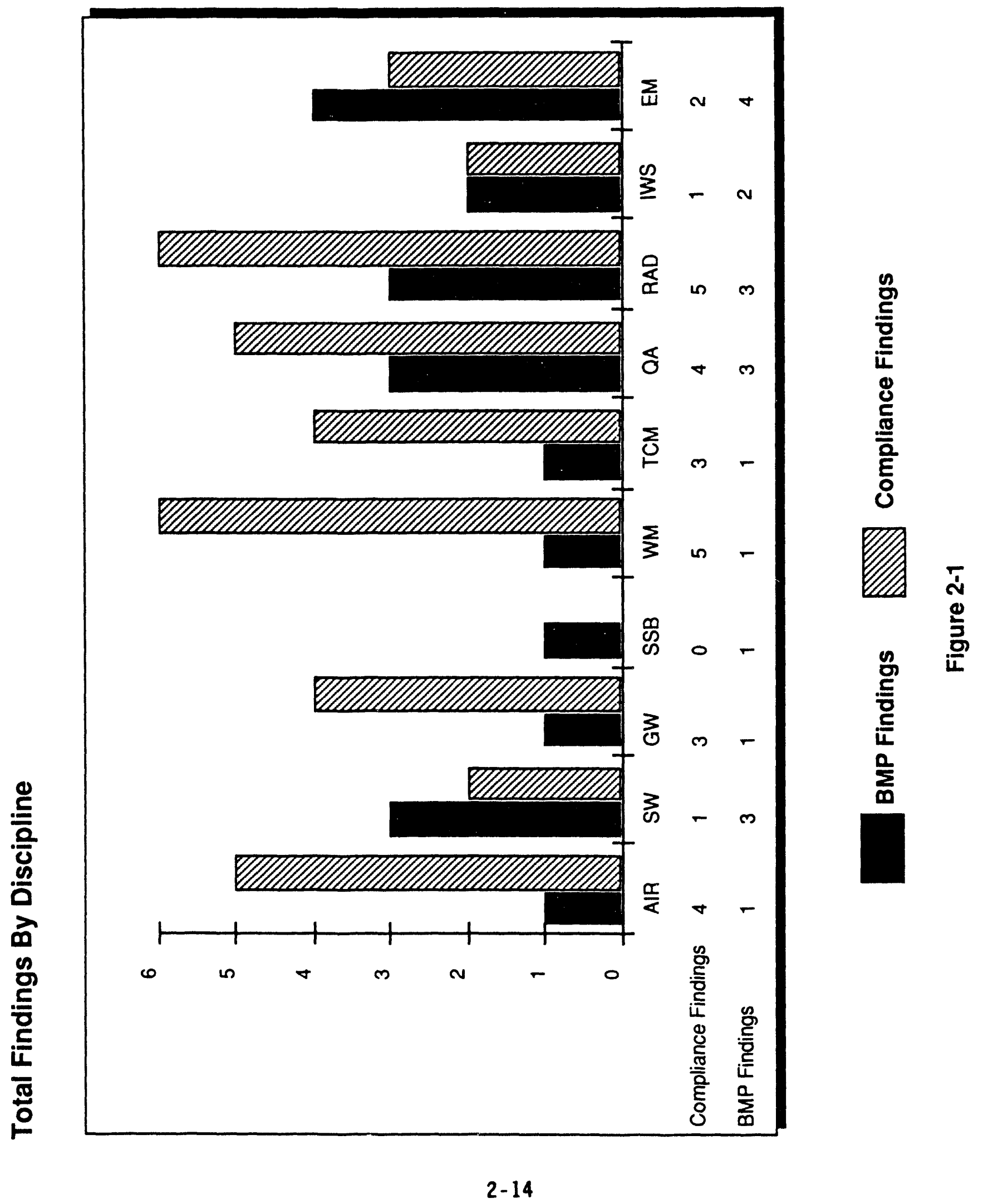


The following naragraphs describe the compliance and BMP findings identified in each of the disciplines included in the GJP( Baseline Environmental Audit:

Air - Four compliance findings and one BMP finding were identified. The compliance findings address the lack of valid air emissions permits to operate at both the State-Owned Temporary Repository and the GJPORAP site due to state administrative delays, an inaccurate statement in the Air Pollution Emission Notice Sy, cem application for the GJPO site, and the need to install a HEPA filter ir. a GJPO laboratory to control potential asbestos emissions. The BMP findiny relates to improvements on the baghouse that collects dust from sample preparation of mill tailings.

Surface Water - There were four surface water findings that included one compliance finding and three BMP findings. The compliance finding deals with changes in chemicals stored on-site, and the composition of the facility's wastewater effluent, neither of which are reflected in the Industrial Pretreatment Permit with the City of Grand Junction. The BMP findings deal with the liquid effluent sampling site for the pretreatment permit, the absence of a preventive maintenance program for the site's wastewater sewer system, and the need to characterize the site's stormwater discharge which may contain pollutants.

Groundwater - There were three compliance findings and one BMP finding. The compliance findings address well construction permit requirement violations, monitoring well abandonment and construction problems, and the lack of appropriate monitoring well permits. The BMP finding identifies inadequate groundwater organic contaminant characterization.

Soils, Sediment, and Biota - There was one BMP finding, which addresses the lack of a comprehensive ecosystem surveillance program as part of the facility's environmental monitoring program.

Waste Management - Five compliance findings and one BMP finding were identified. The compliance findings address the lack of adequate hazardous waste determination due to a recent, atypical increase in waste generated and stored on-site; deficiencies in waste characterization, accounting, and storage procedures; and the absence of a complete, implementable Pollution Prevention Awareness Plan. The BMP finding addresses hazardous waste labeling concerns.

Toxic and Chemical Materials - Three compliance findings and one BMP finding were identified. One compliance finding relates to the fact that the facility has not yet implemented all facets of its SPCC program, including training of personnel in the SPCC plan. The other two compliance findings relate to PCB waste management. One concerns the storage of PCBs in facility buildings in excess of regulatory time limits and the other relates to the PCB contaminated mill tailings at the GJPO site. The BMP finding relates to the storage of chemicals in the Photography Laboratory. 
Quality Assurance - There were four compliance findings and three BMP findings. The compliance findings relate to $Q A$ oversight of environmental monitoring activities, including particulate air pollution sampler locations and operational procedures, baghouse emissions samp? ing, implementation of procedures for procurement of subcontracted laboratory services, and the presence and updating of standard operating procedures. The three BMP findings relate to effluent sampling security, completion of hazardous waste shipping documents and the Environmental Implementation Plan. The Special Issues discussion relates to radon monitoring, precision and controls.

Radiation - Five compliance findings and three BMP findings were noted. The compliance findings include the need for preparation and submission of annual reports of radioactive effluent monitoring of emissions for reporting doses to the public, the need for a formal determination regarding the facility's nuclear/non-nuclear status as it relates to emergency preparedness planning requirements, the lack of complete waste management system performance assessments, and incomplete waste acceptance criteria for on-site storage. The three BMP findings relate to the meteorolo, ical monitoring program, stormwater management practices that adversely impact the facility's efforts to minimize the generation of contaminated material, and information presented in the annual site environmental report.

Inactive Waste Sites - One compliance finding and two BMP findings were identified. The compliance finding identifies the lack of proper implementation of DOE Order 5820.2A, specifically concerning planning related to the decommissioning of radioactively contaminated facilities. The BMP findings concern a lack of notification of potential natural resource damages to the trustees, and a mistake in the Declaration for the ROD.

Environmental Management - There were two compliance and four BMP findings. The compliance findings address the DOE-GJPO evaluation of ES\&H activities and Geotech oversight organizations. The BMP findings concern the Geotech SelfAssessment program, DOE-GJPO and Geotech draft plans, programs, and procedures, DOE-GJPO tenant agreements and DOE-GJPO organizational span of control.

\subsection{Causal Factors Summary}

In an effort to understand why a finding occurred, a systematic approach was implemented to perform a "probable causal factor" analysis. This approach is initiated by a series of "why" questions concerning the apparent cause(s) of a finding. The cause(s) and rationale(s) are identified and placed in the supporting information for each finding. The causal factors are then used to determine the corrective actions required to rectify the identified findings and to prevent recurrence. Definitions of the causal factors used are presented in Appendix $G$.

The Audit Team identified 11 apparent causal factors which contributed to the occurrence of the findings (see Table 2-2 and Figure 2-2). The 7 causal factors which appeared most frequently are: Policy Implementation; Appraisals, Audits, and Reviews; Procedures; Policy; Resources; Training; and Barriers and Controls. 


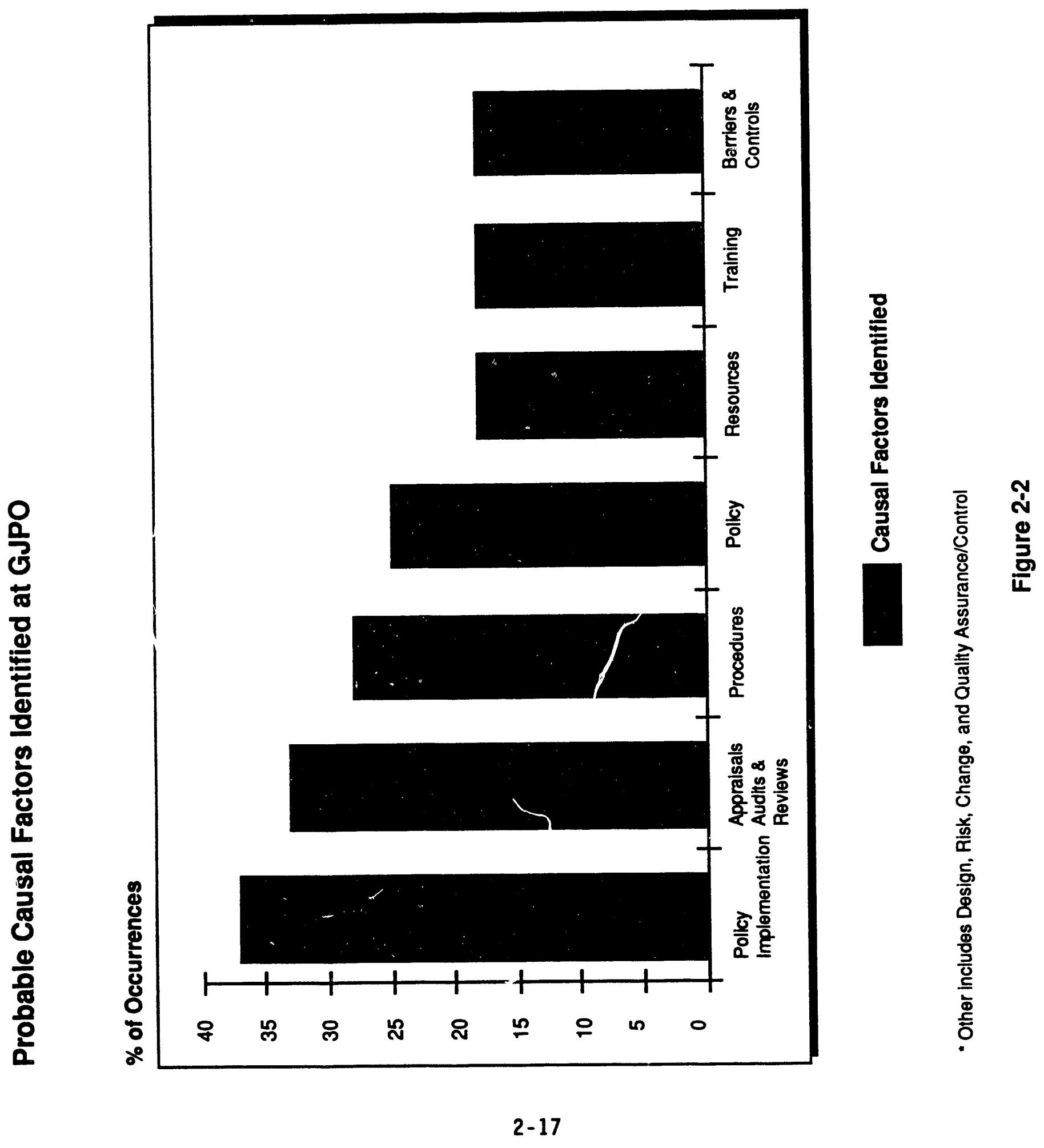


Policy Implementation - appeared most frequently, in approximately 35 percent of the findings, and was evident in findings for most disciplines. In 14 instances, GJPO's failure to implement established Federal and state regulations, DOE Orders, or internal procedures appeared to result from additional causal factors.

Appraisals, Audits, and Reviews - appeared in approximately 31 percent of the findings, and was included in nearly all disciplines. This causal factor indicates that additional internal assessments by DOE-GJPO and Geotech, or a change in the fucus of existing routine assessments, would have resulted in the identification and correction of many of these deficiencies.

Procedures - appeared as a causal factor in approximately 27 percent of the findings. A lack of or inadequate procedures to ensure implementation of Federal and state regulations, DOE Orders, and internal GJPO policies was identified as a causal factor in nearly all Waste Management findings and Toxic and Chemical Materials findings, and many of the Quality Assurance findings.

Policy - appeared as a causal factor in approximately 23 percent of the findinas and was most evident in the Radiation, Waste Management, and Enuironmental Management disciplines. Instances rinere a lack of established policy was identified include unique circumstances such as commingled RCRA and TSCA waste.

Resources - appeared as a causal factor in approximately 17 percent of the findings. Resource concerns were identified as a causal factor in the Waste Management, Radiation, and Environmental Management disciplines. In general, Resource concerns represent the lack of "human" resources to implement and conduct oversight of environmental activities.

Training - appeared as a causal factor in approximately 17 percent of the findings. Most significantly, a lack of Training was identified in all 4 groundwater findings. In general, there was a lack of "historic" training of site personnel involved in construction, monitoring, and permitting of groundwater monitoring wells.

Barriers and Controls - appeared as a causal factor in approximately 17 percent of the findings. Barriers were identified as a causal factor in 8 findings. In these instances, GJPO faced barriers in complying with regulations and DOE Orders, and in implementing best management practices for issues such as: the applicability of the RCRA Land Disposal Restrictions (LDR) which presents a barrier to storage and disposal; barriers to the disposal of commingled TSCA PCB waste; and excessive administrative delays by State regulators.

\section{$2.7 \quad$ GJPO Strengths}

In general, the Audit Team found that the major environmental programs operating at GJPO were sound. The following programs and practices are of notable quality. 
Quality Assurance: The Geotech Quality Assurance (QA) organization reports to the president of the corporation directly. It provides oversight and auditing for the implementation of the GJPO Quality Assurance Program Plan (QAPP) to the Operations, Technical, and Financial/Administrative line management via a matrix management approach. The QA organization is responsible for maintaining the integrity of the GJPORAP operations and data generated as a result of these operations. The organization is well managed and interfaces effectively with all line managers to ensure that the QAPPs are initiated and maintained. The implementation of these plans is necessary to assure compliance with all applicable DOE orders and Federal, state, and 10cal regulations, and is also an advocate of Best Management Practices (BMPs). The Geotech QA organization is an effective and vital asset of the GJPO operations and programs.

As an indication of the QA organization's competence, a number of well managed projects have been instituted. The GJPO Radon Laboratory has proven to be the standard of excellence in its research and development of radon monitoring methodologies. The Radon Laboratory has worked in conjunction with the National Institute of Standards and Testing (NIST) to develop and generate known concentrations of radon, and has been involved with the development of radon monitoring techniques. The high caliber of GJPO's Analytical Chemistry Lab is evident in its ability to obtain excellent results in its participation of EML, EPA, and AMIH audits. The laboratory's diverse abilities to analyze a number of environmental and geophysical parameters is complemented by its precise and accurate measurements. These laboratories have direct interfaces with QA, which further exemplify the depth of competence it has to provide DOE-GJPO with a viable means to remedy its quality problems.

Technology Transfer: In SEN-23-90, the Department of Energy describes a Departmental policy which emphasizes the need for "All of the Department's organizational elements (to) take appropriate steps to use their resources in a way that supports science and mathematics education at both the precollege and university levels." GJPO has responded to the policy in a number of ways. As a participant in the Colorado Alliance for Science Program, GJPO has provided approximately 30 professional volunteers to assist educators in the K-12 range. The volunteers provide classroom lectures and scientific equipment in the areas of math and science to enhance the teachers' ability to interest and develop young scientists and mathematicians. The program targets students in rural areas and minority groups. GJPO personnel al so volunteer their time in the Western Colorado Science Fair to assist students in developing projects and to act as judges during competition.

In 1990, DOE provided start-up funding and expertise to aid in the development of a two-year associate's degree in Environmental Restoration Technology at Mesa State College in Grand Junction. The goal of the program is to develop a work force to augment the available scientists and engineers required for the DOE environmental restoration effort. The curriculum has been fully approved by the State of Colorado. As part of the Environmental Restoration Associate Degree program, DOE has participated in gaining the involvement of industry 
partners. Several colorado based firms as well as the Governor's Office have offered and/or given support by contributions of funds or equipment $(\mathrm{e} . \mathrm{g}$. , AT\&T has donated approximately $\$ 800,000$ in computer equipment to the program).

Monitoring Well Records Retention: The system of groundwater monitoring well records retention developed by Geotech for the GJPO facility has been determined by the Audit Team to be a "Noteworthy Practice". This system is further described in Section 3.12. The records retention system set up for monitoring well records retention is relatively simplistic, yet innovative in that a separate file is maintained for each groundwater monitoring well at the GJPO facility. Each file is updated as new information is generated and includes broad categories of information about the well construction, applicable permits, maintenance, and analytical results. The Audit Team felt that this system of record retention was worthy of emulation because the entire history of each well is contained in one file, thereby providing facility personnel with quick and easy access to important information.

Docket Database: While not fully developed, the GJPO/Geotech docket database has the potential to play a major role in achieving environmental excellence both within GJPO and throughout DOE. The purpose of the database is to identify and cross reference all DOE Orders, Codes, and Standards governing Geotech operations with all applicable Geotech policies and procedures and applicable internal GJPO documents. Once complete, the system will provide an exhaustive reference for compliance management and regulatory development activities throughout DOE. The design of the programmed shell integrating six different databases to provide data input, query, and reporting has been completed, and the majority of the DOE Orders and several Geotech policy manuals have been entered into the system. Although in its infancy, some components of the system are already in use at GJPO. When data entry and the development of a user's guide are completed by the end of September 1991, the system will be accessible for use in all GJPO regulatory compliance activities. 
3.0 ENVIRONMENTAL AUDIT FINDINGS 
This page was intentionally left blank. 
This section contains the findings identifiad by the Environmental Audit Team and presents them in the following subsections by discipline.

\subsection{Air}

\subsubsection{Overview}

The purpose of the air portion of the Grand Junction Projects Office (GJPO) Baseline Environmental Audit was to ascertain the current Site Contractor operating practices with regard to regulations promulgated under the Clean Air Act, the Mesa Couniy Department of Health Regulations, the State of Colorado Rules and Regulations, and other pertinent statutes; DOE Orders; Best Management Practices; and Site Contractor internal procedures. Applicable regulations, guidance documents, internal procedures, and DOE Orders used to evaluate the air related practices are summarized in Table 3-1. Best Management Practices (BMP) are currently accepted standard methods and procedures in both industry and government programs.

The general approach to the air portion of the Audit included an inspection of the facilities and sources, including emission control systems, and effluent monitoring systems; interviews with Geotech, the Site Contractor, DOE-GJPO, Mesa County Department of Health, and Colorado Department of Health (CDH), Air Pollution Control Division (APCD) personnel; on-site inspections of GJPO's ambient air quality monitoring network; and a review of GJPO and Geotech documents and files. Other members of the Audit Team were consulted as appropriate.

Air pollution control and permitting at GJPO is regulated by the CDH-APCD with on-site inspections conducted by the Mesa County Department of Health personne1. GJPO is part of the Eleventh Colorado Air Quality Control Region, which includes Mesa, Garfield, Rio Blanco, and Moffat Counties in northwestern Colorado. This region is in attainment for all air criteria (GRJ0081).

The primary radioactive and nonradioactive point sources are for stacks servicing the following buildings:

- Building 1, the Boiler House;

- Building 7, the Sample Preparation Area with its Baghouse;

- Building 7, the Petrology Laboratory with its Asbestos Preparation Hood; and

- Building 20, the Chemistry Laboratory with its seven stacks.

In addition, there is a potential for emissions from mill tailings at the Grand Junction Projects Office Remedial Action Projects (GJPORAP) site and at the State-Owned Temporary Repository operated by GJPO.

The boiler house has two low pressure boilers that use natural gas as the primary fuel. Both boilers are also capable of burning No. 2 fuel oil as a back-up fuel. The site has an above ground storage tank for 10,000 gallons of 
fuel oil. The primary emissions of concern from these burners are nitrogen oxides.

The discharge from the radiological stack in the Building 7 baghouse is primarily mill tailings particulates containing traces of uranium ore and its associated radon gas. The discharges from the GJPORAP operations and the State-Owned Temporary Repository are also particulates containing traces of uranium and radon gas from the tailings piles.

Four compliance findings and one Best Management Practice (BMP) finding were identified. The compliance findings address the lack of a valid air emissions permit to operate the State-Owned Temporary Repository, the lack of a valid air emissions permit to operate the GJPORAP, an inaccurate statement in the Air Pollution Emission Notice System application for the site, and the need to install a HEPA filter for asbestos removal. The BMP finding relates to needed improvements on the baghouse that collects dust from sample preparation of mill tailings. 
TABLE 3-1

LIST OF APPLICABLE AIR

REGULATIONS/REQUIREMENTS/GUIDELINES

Regulations/

Requirements/

Guidelines

Sections/Title

Authority

40 CFR Part 61

National Emission Standards for

EPA

Hazardous Air Pollutants

40 CFR Part 58

Ambient Air Quality Surveillance

EPA

40 CFR Part 60

Test Methods for Standards of

EPA

Appendix A

EPA-600/4-77-027a

Performance for New Stationary

Sources

Qual ity Assurance Handbook for Air

Pollution Measurement Systems

EPA

Quality Assurance Handbook for Air

EPA

Pollution Measurement Systems, Volume

Vol ume IV-Meteorological

Measurements

DOE Order 5400.1

General Environmental Protection

DOE

DOE Order 5400.5

Radiation Protection of the Public

DOE and the Environment

GJPO Permits

Colorado Department of Health Emission

Permits 89ME080-IF, 89ME080-2F, 89ME316F

GJPO APENS

Colorado Department of Health

Submitted September 20, 1990

DOE/EH-0173T

Radiological Effluent Monitoring and

DOE 
Performance Objective: GJPO operations at the State-Owned Temporary Repository require an air permit from the Colorado Department of Health (CDH). $\mathrm{COH}$ issued an initial Air Emission Permit No. 89ME316F on November 20, 1989. Conditions of this permit include a requirement that final permit approval be obtained within six months of the commencement of operation. In addition, the following fugitive emission controls are required:

- Watering of tailing piles and excavation areas to maintain a surface moisture content of 10 percent or greater;

- Water sprays to control emissions during loading and dumping of materials to achieve a surface moisture of at least 5 percent;

- Watering of unpaved haul roads to achieve a surface moisture content of at least 10 percent; and

- Cessation of operations when wind speed exceeds $40 \mathrm{~m} . \mathrm{p} . \mathrm{h}$.

Although not a condition of the Air Pollution Emission Notification System, calibration of the meteorological station wind speed meters should be conducted pursuant to "Environmental Regulatory Guide for Radiological Effluent Monitoring and Environmental Surveillance" of January 1991, Section 4.6 in order to ensure proper operation and reflect quality assurance standards in ANSI/ASME NQA-1, as required by DOE Order 5700.6B.

Finding: GJPO has been unable to obtain written final approval within six months from the start of operations at the State-Owned Temporary Repository for Colorado Air Emission Permit No. 89ME316F, and has thus operated for nearly one year, at the verbal direction of CDH that operations may continue without a valid permit. In addition, the Operations fail to meet current permit conditions regarding dust control, and the meteorological station wind speed has not been calibraled.

Discussion: GJPO does not have a valid air emissions permit to conduct operations at the State-Owned Temporary Repository since it has not obtained final approval in writing for Permit No. 89ME316F. The permit was initially approved on November 20, 1989; however, initial approval is conditional. Conditions as stated on this permit require that final approval must be obtained within six months of commencement of operations or the permit will automatically be revoked.

State air pollution officials continue to inspect the site and have indicated verbally that all repository operations are in compliance (I-A-10). CDH indicated verbally that it disregards the technical invalidation of the permit resulting from $\mathrm{CDH}^{\prime} s$ failure to issue a final written permit approval for the State-Owned Temporary Repository operations (I-A-9). Despite the tacit approval assumed by $\mathrm{CDH}$ regulators, operations at the site have proceeded for more than six months since commencement of operation without receipt of a final written permit approval, and, as specified by the conditions stated on 
the permit, the air permit has been revoked. As a result, GJPO has been operating the State-Owned Temporary Repository for nearly one year without a valid permit. GJPO officials have made verbal attempts to secure the required written final approval $(I-A-10)$.

An inspection of the State-Owned Temporary Repository revealed the following violations of the permit requirements for dust control:

- M-K Ferguson, the UMTRA contractor charged with the removal of GJPO mill tailings to the final disposal site at the Cheney Reservoir, had removed a portion of the GJPO tailings, thereby exposing the interior of the pile. The area was not watered to ensure a surface moisture of 10 percent, and swirls of fugitive dust were visible.

- A truck operator was observed uncovering and dumping his load of tailings on the pile. A water truck was not present to ensure a surface moisture content of 5 percent during the operation. Unaccompanied dumping of loads is not permitted in the procedure manual (GRJ0161).

- GJPO has not measured and documented the moisture content either in tailing disposal areas, in materials being loaded or dumped, or on the unpaved repository roads.

- There is no documentation or other evidence that the GJPO meteorological station used to measure air speed at the State-Owned Temporary Repository has been calibrated since it was installed in 1989. The equipment must be calibrated to ensure proper operation and reflect the quality assurance standards in ANSI/ASME NQA-1, as required by DOE Order 5700.6B. This calibration is needed to ensure compliance with the permit requirements for cessation of operations at wind speeds above 40 m.p.h.

GJPO made attempts to meet all fugitive emission control conditions of the permit, through regular watering of the site and covering of inactive areas with surfactants. Operations are halted when continuous wind speeds are believed to be in excess of $40 \mathrm{~m} . \mathrm{p} . \mathrm{h}$.

Site's Prior Knowledge: GJPO identified the need for measuring surface moisture in an internal audit (GRJ0146) and identified the lack of final permit approval (GJPO SEN-7A-90). However, GJPO did not recognize the technical revocation of the emissions permit which results from the lack of formal approval nor did it identify the failure to calibrate the wind speed meter.

Probable Causal Factors: The apparent causal factors contributing to this finding are inadequate audits/appraisals/reviews by Geotech in that this finding was only partially identified by GJPO, barriers and controls in that CDH failed to provide final approval of the emissions permit due to administrative barriers, and lack of policy implementation in that the meteorological station was not calibrated. 
Performance Objectivi: GJPORAP operations require an air permit from the Colorado Department of Health (CDH). CDH issued an initial Air Emission Permit No. 89ME080-1F on October 23, 1989. Conditions of this permit include a requirement that final permit approval be obtained within six months of the commencement of operation. In addition, the following fugitive emission controls are required:

- Watering of tailing piles and excavation areas to maintain a surface moisture content of 10 percent or greater;

- Water sprays to control emissions during loading and dumping of materials to achieve a surface moisture of at least 5 percent;

- Watering of unpaved haul roads to achieve a surface moisture content of at least 10 percent; and

- Cessation of operations when wind speed exceeds 40 m.p.h.

Calibration of any required meteorological station wind speed measuring equipment should be conducted pursuant to "Environmental Regulatory Guide for Radiological Effluent Monitoring and Environmental Surveillance" of January 1991 , Section 4.6 in order to ensure proper operation and reflect quality assurance standards in ANSI/ASME NQA-1, as required by DOE Order 5700.6B.

Finding: GJPO has been unable to obtain written final approval within six months from the start of operation at GJPORAP for Colorado Air Emission Permit No. 89ME080-1F, and has thus operated the GJPORAP for two months without a valid permit. In addition, the operations fail to meet current permit conditions.

Discussion: GJPO does not have a valid air emissions permit to conduct operations at the GJPORAP since it has not obtained final approval in writing for Permit No. 89ME080-1F. The permit was initially approved on October 23, 1989; however, initial approval is conditional. Conditions as stated on this permit require that final approval must be obtained within six months of commencement of operations or the permit will automatically be revoked.

State air pollution officials continue to inspect the site, and have indicated verbally that all repository operations are in compliance $(I-A-10)$. CDH indicated verbally on June 3,1991, that it disregards the technical invalidation of the permit resulting from $C D H^{\prime} s$ failcire to issue a final written permit approval for the State-Owned Temporary Repository operations (I-A-9). Despite the tacit approval assumed by CDH regulators, operations at the site have proceeded for more than six months since commencement of operations without a final written permit approval, and, as specified by the conditions on the permit, the air permit has been revoked. GJPO officials have made verbal attempts to secure the required written final approval (I-A10). 
An inspection of the GJPORAP revealed the following violations of the permit requirements for dust control:

- GJPO has not measured and documented the moisture content either in tailing deposition areas, in materials being loaded or dumped, or on the unpaved haul roads.

- There is no documentation or other evidence that the GJPO meteorological station used to measure air speed at the State-Owned Temporary Repository (used for cessation of operation at GJPORAP) has been calibrated since it was installed in 1989. This equipment must be calibrated to ensure proper operation and reflect quality assurance standards in ANSI/ASME NQA-1, as required by DOE Order 5700.6B. This calibration is needed to ensure compliance with the permit requirements for cessation of operations at wind speeds above 40 m.p.h.

The GJPORAP operation uses the data from the repository meteorological station to determine when the wind speed exceeds $40 \mathrm{~m} . \mathrm{p} . \mathrm{h}$. However, topographic conditions may impact wind characteristics such that exceedances of $40 \mathrm{~m} . \mathrm{p} . \mathrm{h}$. may not be detected at GJPORAP.

GJPO has attempted to meet all fugitive emission control conditions of the permit, including regular watering of the site and the covering of inactive areas with surfactants. Operations are halted when continuous wind speeds are believed to be $40 \mathrm{~m} . \mathrm{p} . \mathrm{h}$. or greater.

Site's Prior Knowledge: GJPO identified the need for measuring surface moisture in an internal audit (GRJ0146). However, GJPO did not recognize the technical revocation of the emissions permit which results from the lack of formal approval nor did it identify the failure to calibrate the wind speed meter.

Probable Causal Factors: The apparent causal factors contributing to this finding are inadequate audits/appraisals/reviews by Geotech in that this finding was only partially identified by GJPO, and barriers and controls in that CDH failed to provide final approval of the emissions permit due to administrative barriers. 
Performance Objective: APENS applications submitted to comply with Colorado Regulations, Title 5, Chapter 1001, Article 3 must contain accurate information. Colorado Regulations require that all sources and controls must be listed in the APENS application.

Finding: The APENS application Revision 3, dated September 20, 1990 , submitted by GJPO incorrectly states that a HEPA filter controls emissions from Building 20, Room 31, Hood 50. There is no HEPA filter at this location.

Discussion: During the Baseline Environmental Audit of GJPO, it was determined that there is no HEPA filter installed at Building 20, Room 31, Hood 50. This contradicts the information provided in the APENS application, Revision 3, of September 20, 1990 (GRJ0007). Providing incorrect information on the existence of an air pollution device is in violation of the Colorado Regulations, Title 5, Chapter 1001, Article 3. The GJPO APENS application was prepared by a subcontractor who included this anticipated change as a completed item in the APENS application.

Site's Prior Knowledge: This issue was not addressed in any Self-Assessments conducted at GJPO.

Probable Causal Factors: The causal factors contributing to this finding are inadequate appraisals/audits/reviews which should have previously identified this deficiency, and quality assurance/quality control in that the subcontractor APENS application was not adequately reviewed by Geotech and DOE prior to submittal to $\mathrm{CDH}$. 
Performance Objective: Colorado Regulations, Title 5, Chapter 1001, Article 8 (II)(C)(1)(a) requires that air emissions from operations that invoive asbestos must be controlled by a HEPA filter.

Finding: The emissions from the hood in the petrology laboratory (Building 7) are not controlled by a HEPA filter as required by Colorado Regulations.

Discussion: The GJPO APEN application (Revision 3, dated September 20, 1990) indicates that the facility believed that asbestos emissions from the uncontrolled hood in the petrology laboratory (Building 7) were insignificant and thus did not warrant a permit. A telephone conference record of a GJPO conversation with the Colurado Department of Health, Air Pollution Control Division (CDH-APCD) states that the facility must install a HEPA filter at this location (GRJO159). The facility subsequently made a decision to comply with the $\mathrm{CDH}$ request and now is actively seeking procurement of an acceptable HEPA filter.

Site's Prior Knowledge: This issue was not addressed in any Self-Assessments conducted at GJPO.

Probable Causal Factors: The apparent causal factors contributing to this finding are inadequate policy implementation in that established state regulatory requirements were not implemented, and a lack of audits/appraisals/reviews in that this deficiency was not previously identified. 
A/BMPF-1 Baghouse System for Sample Preparation

Performance Objective: Best Management Practice suggests that appropriate controls be instituted in order to control radiological emissions from operations and equipment.

Finding: GJPO currentiy uses a temporary enclosure, rather than a permanent enclosure below the Building 7 Sample Preparation Area baghouse to contain fugitive radiological dust resulting from baghouse cleanout.

Discussion: GJPO presently installs a temporary enclosure of polypropylene sheeting below the baghouse when it cleans and empties the contents of the baghouse. It then removes the enclosure when the operation is complete. After the enclosure is removed, any residual dust (e.g., on the underside of baghouse) is free to enter the environment. A better practice is to permanently enclose the area below the baghouse to eliminate this potential source of release of fugitive radiological emissions.

Site's Prior Knowledge: This issue was not addressed in any Self-Assessments conducted at GJPO.

Probable Causal Factors: The apparent causal factor contributing to this finding is risk in that the facility did not consider potential environmental risks posed by potential fugitive radiological emissions from the baghouse clean out operations. 


\subsection{Surface Nater}

3.2.1 Overview

The purpose of the surface water portion of this Audit was to evaluate compliance with Federal, state, and local water pollution control requirements established in conformance with the Clean Water Act (CWA), and with drinking water rules promulgated as part of the Safe Drinking Water Act (SDWA) requirements. In addition, the Audit evaluated compliance with DOE Orders and water pollution control practices with respect to industry-accerted Best Management Practices (BMP). It al so included a review of Industrial Pretreatment Permit No. 0023, administered by the City of Grand Junction. Applicable regulations are summarized in Table 3-2. (The Spill Prevention Control and Countermeasures (SPCC) Plan is addressed in the Toxic and Chemical Materials section.)

The general approach to the surface water portion of the Baseline Environmental Audit included inspection of wastewater sources and conveyance systems such as ditches and sewers; inspection of surface water sampling locidions and observation of the sampling procedures; inspection and observation of liquid waste and wastewater handling practices in areas such as tile analytical and photography laboratories, and the State-Owned Temporary Repository; interviews with GJPO personnel, and state and local regulators; review of the water and wastewater monitoring program; and review of pertinent documentation.

As part of the surface water assessment, reviews and inspections were coordinated with other members of the Audit Team as necessary to evaluate the surface water monitoring program and the potential surface water contamination from contaminated areas.

Overall, GJPO's liquid waste and wastewater handling practices appear to be well managed. GJPO receives drinking water from the City of Grand Junction, and liquid effluent (with the exception of stormwater runoff) is discharged into the sanitary sewer and subsequently to the Publicly Owned Treatment Works (POTW) under Industrial Pretreatment Permit No. 0023. Although this permit requires only semi-annual monitoring of sewer effluent, GJPO al so conducts monthly monitoring, including analyses of the analytes required by the pretreatment permit in addition to other analyses to aid in the development of a pollution control data base, to be used internally to monitor changes in the effluent discharges. Review of the liquid effluent monitoring data for January, February, March, and Apri1, 1991, indicates that anaiys is of the analytes required by the Industrial Pretreatment Permit are well within the limits stated in the permit.

Surface water monitoring is performed quarterly from the North Pond, South Pond, Dike Ditch, and the Gunnison River. The North and South Ponds and Dike Ditch are located on GJPO property. The Gunnison River is immediately adjacent, flowing along its west boundary.

Presently, the northern two-thirds of GJPO has a stormwater collection system. The southern one-third has surface runoff which evaporates or infiltrates into 
the soil. Stormwater collected in the storm drains is discharged into the North Pond, whose water is supplied primarily from the shallow gravel aquifer underlying GJPO. Characterization of this stormwater is necessary in order to determine whether or not it contains toxic pollutants.

One compliance finding and three Best Management Practice (BMP) findings were identified. The compliance finding deals with the Industrial Pretreatment Permit. The BMP findings deal with the liquid effluent sampling site, the preventive maintenance program, and characterization of stormwater discharge. 
TABLE 3-2

LIST OF APPLICABLE SURFACE WATER

Regulations/

Requirements/

Guidelines

Sections/Title

Authority

Clean Water Act, 40 CFR Parts

122 and 123

40 CFR Part 125

Safe Drinking Water

Act, 40 CFR Parts

141 and 142

Safe Drinking

Water Act

40 CFR Part 143

Code of Colorado

Regulations,

Title 5, Chapter

1003, Article 5

Code of Colorado

Regulations,

Title 5, Chapter

1002, Article 8

National Pollutant Discharge

EPA

Elimination System (NPDES)

Criteria and Standards for the

NPDES

National Primary Drinking Water EPA

Regulations

National Secondary Drinking Water EPA

Regulations

Colorado Primary Drinking Water Colorado

Regulations

Board of

Health

Colorado Water Quality Standards

CRS 1973

25-8-101

et seq.

Code of Colorado

Regulations,

Title 5, Chapter

1002, Article 2

Regulations

CWQCA

Colorado Revised

Statutes, Title 25,

Colorado Water Quality Control Act

$\mathrm{CDH}$

Article 8

DOE Order 5400.1

General Environmental Protection Program DOE

DOE Order 6430.1A

General Design Criteria

DOE

City of Grand Junction/Mesa County

Industrial Pretreatment Program 
Performance Objective: The Grand Junction Projects Office (GJPO) Industrial Pretreatment Permit No. 0023, issued under the City of Grand Junction/Mesa County Industrial Pretreatment Code of Ordinance, Section 25-62(5)(m), states that the permit is granted in accordance with the permit application filed on September 28, 1987, and that the specifications and other data submitted in support of the application are considered part of the permit. In addition, the permit requires GJPO to notify the City of Grand Junction Industrial Pretreatment Coordinator of new introductions, existing contributions, or substantial changes in pollutants being discharged.

Finding: GJPO has not notified the City of Grand Junction Industrial Pretreatment Coordinator of new introductions or existing contributions in pollutants being discharged that are present or suspected to be present in GJPO activities since the permit application was filed.

Discussion: Following the issuance of the GJPO Industrial Pretreatment Permit by the City of Grand Junction on March 2, 1989, 1aboratory activities at GJPO were expanded to include analyses which result in the use of chemicals not reflected in the permit application, and the generation and release of wastewater containing additional toxic pollutants listed in Section $307(a)$ of the Clean Water Act. GJPO personnel have not notified the Industrial Pretreatment Coordinator of the use of new chemicals or the introduction of new pollutants.

Analys is of laboratory effluents from the sewer trench in Building 20 (Chemistry Laboratory) in Apri1, 1990 revealed the presence of methylene chloride, chloroform, and "unknown organic materials, " all of which are 1 isted as "known to be absent from activities" in the existing Industrial Pretreatment Permit application. In addition, the chemical inventory for Building 20 lists chemicals such as benzene and bromoform which are designated as "known to be absent" on the permit application.

Upon identification of this finding by the Audit Team, GJPO representatives met with the Grand Junction Industrial Pretreatment Coordinator on June 5 , 1991 , and agreed to provide the information necessary to properly characterize GJPO's current effluent stream (I-SW-21, I-SW-22, I-SW-23). In addition, the City has recently clarified its interpretation of the permit language and has agreed to assist GJPO in reconciling the stated concern (GRJ0178).

Site's Prior Knowledge: This finding was identified in the Environmental Monitoring Self-Assessment (GRJ0106) conducted at GJPO.

Probable Causal Factors: The apparent causal factors contributing to this finding are inadequate policy implementation to ensure compliance with applicable laws, regulations, and codes, and inadequate training of GJPO staff in the applicable regulatory requirements and permit conditions. 
Performance Objective: Best Management Practice suggests characterizing the chemical nature of stormwater discharges to surface water bodies in an area of former radioactive waste disposal.

Finding: The Grand Junction Projects Office (GJPO) has not characterized the stormwater discharged to the North Pond to verify that regulatory limits are not exceeded.

Discussion: GJPO has a stormwater collection system which collects runoff from the northern two-thirds of the facility. Stormwater collected in this systiem is discharged into the North Pond. The North Pond water is in direct hydraulic communication with the contaminated surficial aquifer (GRJ0031) and thus fluctuates in direct response to groundwater elevations. Stormwater discharged into the North Pond either evaporates or infiltrates back into the underlying aquifer. The stormwater discharged into the North Pond has not been characterized to verify that it does not contain pollutants in excess of allowable limits as defined by the applicable Colorado regulations ( 5 CCR Part 1002-8). If characterization indicates that discharge waters are in excess of regulatory limits, then a discharge permit may be required.

Site's Prior Knowledge: This issue was not addressed in any Self-Assessments conducted at GJPO.

Probable Causal Factors: The apparent causal factor contributing to this finding is a lack of assessment of the environmental and regulatory risk involved in not characterizing stormwater discharges to the North Pond. 
Performance Objective: In order to minimize the potential of sewer 1 ine infiltration and exfiltration, it is considered Best Management Practice to conduct periodic inspections and preventive maintenance of sanitary sewers in buildings that generate chemical/industrial process wastes, to ensure that they are still performing as designed.

Finding: GJPO does not have a preventive maintenance program for periodic inspection of sanitary sewer lines.

Discussion: The present sanitary sewer lines have been in place since 1981 . Although the lift stations are inspected, there is no established inspection program to ensure the integrity of the sewer lines. Non-domestic waste can accelerate degradation of sewer lines. The potential impact to the environment would be minimized by this preventive maintenance. Inspections would detect weaknesses in the lines themselves (as possibly caused by chemical degradation), infiltration, exfiltration, sediment, grease, and ingrowing roots. Preventive maintenance would help minimize the potential for environmental contamination.

Site's Prior Knowledge: This issue was not addressed in any Self-Assessments conducted at GJPO.

Probable Causal Factors: The apparent causal factor for this finding is that the GJPO has no procedures in place to conduct periodic evaluations of the sanitary sewer lines. 
Performance Objective: In order to accurately characterize the site's wastewater effluent, Best Management Practice suggests that the location selected for monitoring liquid effluents include of all inputs into the effluent discharge lines.

Finding: The GJPO liquid effluent sampling location does not include all discharges to the POTW.

Discussion: Since February 1989, GJPO has performed monthly analyses on sewer effluent to aid in the development of a pollution control database which will be used internally to monitor changes in the effluent discharges (GRJ0014). Sampling is currently performed from Manhole 12. This sampling point does not include any effluent discharges from Buildings 19, 18, and portions of Buildings 12 and 810 . A sampling point which includes sewer effluent discharges from the entire facility would give a more accurate baseline of data.

Site's Prior Knowledge: This issue was identified in GJPO's Environmental Monitoring Self-Assessment (GRJ0106).

Probable Causal Factors: The apparent causal factors contributing to this finding are barriers and controls in that the City will not permit GJPO to conduct routine sampling at a City lift station nearby that would provide an inclusive GJPO sample; and inadequate resources to construct an inclusive sampling location on-site. 
This page was intentionally left blank. 


\subsection{Groundwater}

\subsubsection{Overview}

The purpose of the groundwater portion of the Baseline Environmental Audit was to evaluate the programmatic and technical status of groundwater monitoring associated with DOE activities at the Grand Junction Projects Office (GJPO) as it relates to applicable regulations, industry and regulatory guidance, and Best Management Practices (BMP). Applicable regulations include DOE Orders, State of Colorado Water Well Construction and Pump Installation Rules, 40 CFR Part 192, and 40 CFR Part 300. Industry and regulatory agency guidance includes publications developed as part of RCRA and CERCLA by EPA, and DOE guidance documents. Applicable regulations and guidance documents are summarized in Table 3-3. BMPs are currently accepted standard methods and procedures in both industry and government programs.

The general approach to the groundwater portion of the audit included interviews with DOE, GJPO, and Geotech personnel; interviews with regulatory authorities, including EPA and the Colorado Water Quality Control Division; review of site documents, reports, field logs, and maps; and interaction with other members of the Audit Team, including the Radiation, Inactive Waste Sites, Waste Management, Quality Assurance, and Surface Water technical specialists. On-site inspections were conducted to examine groundwater monitoring wells, and potential source areas of groundwater contamination, and to verify other information gathered during the audit. Groundwater sample collection, decontamination, and recordkeeping procedures were observed during a routine sampling event the field procedures observed were assessed according to Geotech Standard Operating Procedures.

GJPO is located immediately south of the City of Grand Junction within an accretionary bend of the Gunnison River. GJPO is bound on the west and south by the river and on the north and east by county, city, and private property.

The point bar accretionary sediments underlying the facility compose the upper aquifer, which averages approximately 25 feet in thickness. Well boring logs indicate that the lower portion of the aquifer consists of gravel with a sand/silt matrix, overlain by silt/sand flood plain sediments. Bedrock underlying the upper aquifer consists of the Brushy Basin Member of the Jurassic Morrison Formation. The Morrison Formation consists largely of bentonitic shale (mudstone) (GRJ0132) with thin irregular sandstone interbeds. The Brushy Basin Member is generally regarded as an aquitard, capable of impeding downward migration of groundwater below GJPO.

The site hydrology and groundwater geochemistry was characterized by investigations conducted in support of the Remedial Investigation/Feasibility Study (RI/FS) process. The groundwater underlying most of the site has been affected by the disposal of uranium mill tailings from former milling operations. Contamination of the groundwater has been documented in numerous reports (GRJ0031, GRJ0084, GRJ0089, etc.), with contaminants of concern including radionuclides (uranium and radium), metals (molybdenum, arsenic, vanadium, selenium), and organics (trichloroethane, nitrobenzene) (GRJ0031, GRJ0084, GRJ0125, GRJ0129, GRJ0130). 
Aquifer physical parameters were al so characterized as part of these studies through in-situ measurements (potentiometric surface measurements, slug tests, pump tests) and two-dimensional groundwater flow modeling. These studies indicate that groundwater flow underlying GJPO follows a complex pattern in response to surface water elevations in the Gunnison River. Recharge of the surficial aquifer from river water occurs during periods of high flow, typically in response to spring meltwater and increased precipitation. Limited discharge of contaminated groundwater under GJPO to the river occurs during these periods. Alternatively, maximum groundwater discharge to the river occurs during low-flow periods in the summer and early fall.

Groundwater quality at GJPO is regulated through a combination of state and federal standards, including the Colorado Water Quality Control Act (CRS 25-8 Sections 101 to 612), "The Basic Standards for Groundwater". The interim groundwater sampling plan outlined in the Draft Environmental Monitoring Plan (GRJ0089) states that quarterly groundwater sampling is conducted from 16 wells, including two upgradient wells for background groundwater quality characterization.

The GJPO Remedial Action Project Plan (GRJ0134) describes the remedial alternatives selected for the GJPO site, according to the GJPO Record of Decision (GRJ0135). Active groundwater remediation was addressed as an alternative in the Feasibility Study (GRJ0031). The decision was made, based on computer modelling results, to rely upon passive remediation of the groundwater to achieve the clean-up goals specified in the GJPO Record of Decision.

The groundwater portion of the Baseline Environmental Audit identified three compliance findings and one Best Management Practice finding. The compliance findings include well construction permit requirement violations, monitoring well abandonment and construction problems, and 1ack of appropriate monitoring well permits. One BMP finding was identified regarding inadequate groundwater organic contaminant characterization. 
TABLE 3-3

LIST OF APPLICABLE GROUNDWATER

REGULATIONS/REQUIREMENTS/GUIDELINES

Regulations/

Requirements/

Guidel ines

Sections/Title

Authority

40 CFR Part 300

40 CFR Parts 264

and 265

National 0 il and Hazardous Substances

EPA

Pollution Contingency Plan

Standards and Interim Status Standards

EPA

for Owners and Operators of Hazardous

Waste Treatment, Storage, and Disposal

Facilities

OSWER Directive

RCRA Groundwater Monitoring Technical

9950.1

Enforcement Guidance Document

OSWER Directive

9283.1-2

Guidance on Remedial Actions for

Contaminated Groundwater at Superfund

Sites

OSWER Directive

9502.00-60

RCRA Facility Investigation (RFI)

EPA

DOE Order 5400.1

General Environmental Protection

Program

DOE Order 5400.4

Comprehensive Environmental Response, Compensation, and Liability Act

Requirements

EPA

EPA

Environmental Protection, Safety, and

EPA

DOE Order 5484.1

Health Protection Information

Reporting Requirements

Manual 116

Environmental Procedures Catalog

Geotech

* This order compels DOE to take all necessary steps to comply with the requirements of CERCLA. 
TABLE 3-3 (page 2)

LIST OF APPLICABLE GROUNDWATER

REGULATIONS/REQUIREMENTS/GUIDELINES

Regulations/

Requirements/

Guidelines

Sections/Title

Authority

OSWER Directive

9950.3

EPA $600 / 52-85 / 105$

Operation and Maintenance Inspection

EPA

Guide (RCRA) Groundwater Monitoring

Systems

U.S. EPA Decontamination Techniques

EPA for Mobile Equipment Used at Hazardous Waste Sites

EPA Memo, Nov., 1984

EPA Standard Operating Safety Guides

EPA

EPA/NIOSH/OSHA

U.S. EPA Occupational Safety and

EPA

Manual, October, 1985

Health Manual for Hazardous Site

Activities

CRS Section

Water Well Construction and Pump

CRS

37-91-102

Pump Installation Rules

CCR. Title 5

Colorado Groundwater Standards "The

WCQCC 
Performance Objectives: Colorado regulations for monitoring wel1 construction, as defined in the Water Well Construction and Pump Installation Rules, require a permit for all monitoring wells, regardless of their age. Well permit requirements for monitoring wells constructed in 1987 state that "the applicant must submit an as built drawing showing the exact location, construction details, including the total depth of the well, the casing program with zones of perforations, and a description of the grouting type and interval." Conditions for approval for 1984 monitoring well construction permits require that "a detailed log of the materials penetrated by the bore hole shall be submitted to the CDH Division of Water Resources upon completion of the we11" and that "water level measurements and water quality analyses shall be submitted to the Division of Water Resources annually."

Finding: Drawings for monitoring wells constructed and permitted in 1987 were not submitted to the state; monitoring well logs, elevation data, and analytical results for monitoring wells permitted and constructed in 1984 have not been submitted to the state.

Discussion: Monitoring wells were constructed on and around the GJ:0 property in 1982, 1984, and 1987. Wells constructed in 1984 and 1987 were permitted according to state regulations (I-GW-8). The "conditions of approval" for wells constructed in 1987 require that drawings of the wells, including construction details, be provided to the State Engineer. GJPO has not provided these documents to the State Engineer (I-GW-10) for any wel:s constructed in 1987. In addition, the 1984 monitoring well "conditions of approval" require that constructicn details, water level information, and analytical data be provided to the State Engineer on an annual basis. (I-GW10). This information was not supplied for any monitoring wells constructed in 1984 .

Site's Prior Knowledge: This issue was not addressed in any Self.Assessments conducted at GJPO.

Probable Causal Factors: The apparent causal factors contributing to this finding are DOE GJPO and Geotech procedures in that no procedures were in place to ensure that the permit stipulations were adhered to, and DOE GJPO and Geotech audits/reviews/appraisals in that the former Self-Assessments and appraisals did not recognize this issue, and a lack of training in Colorado regulations at the 'ime of well installation. 
Performance Objectives: EPA Guidance Docum: rits, Geotech Standard Operating Procedures, and Colorado Water Well Construction Standards require that monitoring wells be constructed in a manner that "prevents contaminants from entering the well bore and seals off water bearing zones known or suspected to contain contaminants." Further, it is required under these same regulations and guidance documents that monitoring wells be properly abandoned to ensure that the subsurface is not exposed to contaminant migration through the open borehole, casing, screen, or annular space.

Finding: Most monitoring wells constructed on and around Grand Junction Projects office (GJPO) property prior to 1987 were not constructed with an annular space grout, and at least two monitoring wells were not properly abandoned, which is not consistent with state, federal, and GJPO standards.

Discussion: In 1982, 30 monitoring wells were constructed on the GJPO property (GRJO124). These wells were constructed with a sand pack surrounding the well screen and a bentonite seal situated above the sand pack consistent with standard practices. However, in most cases, in-situ sand/gravel material was used to fill the annular space to the ground surface, which is not consistent with current standards. In 1984, 12 additional monitoring wells were constructed both on and outside the GJPO facility. These wells were constructed with "well sand or pea gravel" surrounding the screened interval and a bentonite seal above the sand pack. In most cases, the 1984 wells were completed with pea gravel or open space between the bentonite seal and the surface. For well GJ84-10, 23 feet of open space is present between the bentonite seal and the surface. In many cases, however, this open space was entirely confined within the protective steel casing. In two instances (GJ84-1, GJ84-2), slump material (presumably sand/grave1) was placed in the annular space between the bentonite seal and the surface, over distances of up to 7 feet. These wells are constructed in a manner that is inconsistent with current applicable guidance documents and regulations.

Wells constructed after 1987 included proper annular seals (I-GW-8). Efforts in the recent past to upgrade some existing wells have included reconstruction of the surface finish and filling of the annular space with grout.

The GJPO Well Construction SOP, guidance documents, and state construction standards, referenced above, require that monitoring wells be constructed with an impervious grout (cement/bentonite mix) annular seal, situated from the upper boundary of the bentonite seal to the surface, to ensure that the well bore does not act as a conduit for potential contaminant migration.

Acceptable grout ma erials are described in Table 1 of the Colorado Water Well Construction and Pump Installation Rules.

Two wells are suspected to have not been properly abandoned, as defined in the documents described above (I-GW-8). Well GJ84-7 has no abandonment record. Wel1 9-11N was lost during surface excavation activities. GJPO has made every reasonable effort to identify the location of these wells to properly complete the abandonment process; however, they have been unsuccessful. 
Site's Prior Knowiledge: The abandonment issue was addressed in a 1988 GJP0 Surveillance Report and the Self-Assessment conducted at GJPO dated May 28, 1991 (GRJ0146).

Probable Causal Factors: The apparent causal factors contributing to this finding are inadequate Site Contractor and DOE GJPO training in well construction and abandonment procedures and rigulations in that responsible field and oversight personnel were not aware of proper well construction techniques as defined in the applicable regulations at the time of the well construction, and policy implementation in that applicable policies were not implemented at the time of well abandonment. In addition, there is currently a barrier towards proper well abandonment because remedial activities have disrupted the previous well sites and the wells can no longer be located. 
Performance Objective: Section 12.2.2 of the Colorado Rules and Regulations for Water Well Construction and Pump Installation states that a (monitoring) well owner or his agent shall be responsible for obtaining permits (for all monitoring wells). Section 12.2.3 of the same Rules and Regulations states that all monitoring and observation holes (wells) shall be plugged and abandoned within one year after their construction, unless a permit has been obtained from the State Engineer.

Finding: Monitoring wells constructed prior to 1984 on GJPO and surrounding properties do not have the requisite state monitoring well permits.

Discussion: Thirty groundwater monitoring wells were constructed on the GJP property in 1982. These wells do not have groundwater monitoring well permits, as required by the Rules and Regulations cited above. Further, without a permit, these wells should have been "plugged and abandoned" one year after their construction. According to Geotech (I-GW-10), GuPO is exempt from the state requirement to have permits for on-site wells based upon verbal $\mathrm{CDH}$ guidance in 1984. The Colorado Department of Health, Division of Water Resources stated that the Guju idility is not exempt from the well permit requirements, and that all monitoring wells in excess of one year old should either have a state permit or be properly abandoned in accordance with appropriate state guidance (I-GW-9).

Permits are in place for monitoring wells constructed during 1984 and 1987. No additional monitoring wells were constructed on GJPO after 1987.

Site's Prior Knowledge: This issue was not addressed in any Self-Assessments conducted at GJPO.

Probable Causal Factors: The apparent causal factors contributing to this finding are inadequate Site Contractor and DOE GJPO training in well permit requirements in that the specific regulatory requirements related to this finding were not understood; inadequate DOE GJPO and Site Contractor audits/appraisals/reviews which did not previourly identify this problem; and lack of Geotech policy requiring formal documentation of direction provided by regulatory agencies. 
Performance Objective: It is considered Best Management Practice (BMP) to characterize the nature and extent of all potential contaminants in groundwater underlying and surrounding areas of former waste disposal. The characterization should be of sufficient detail to identify specific organic and inorganic contaminants. Further, the characterization should be of a periodic nature to provide a basis for understanding and predicting the fate and transport of contaminants.

Finding: Groundwater underlying GJPO has not been adequately characterized for the presence of organic chemical contaminants.

Discussion: Hydrogeologic investigations of GJPO have been ongoing since the early 1980s, when it was recognized that former uranium milling and related operations had resulted in inorganic and radionuclide contamination of the soil and groundwater (GRJ0031). Monitoring wells were installed on GJPO and surrounding tracts in 1982, 1984, and 1987 to provide broad coverage, both upgradient and dowgradient, of known or suspected contaminant source areas. Since that time, groundwater monitoring for metals and radionuclides has been conducted at set periodic intervals (GRJ0089). Annual environmental reports report the results of these sampling efforts.

From 1984 to 1986, efforts were made to characterize, on a 1 imited basis, the presence of organic contaminants in groundwater. Total organic carbon and total organic halogen concentrations were routinely found to be 1 to 3 orders of magnitude greater than background concentrations (GRJ0129, GRJ0130) during the same sampling events in 1984 and 1985. Reported concentrations of total organic halogens in well 17-13N (located on the northwest edge of the property) during November, 1984 were as high as 17,000 micrograms per 1iter (ug/1).

Groundwater analyses for specific organic compounds were conducted for 11 samples in 1986 (GRJ0143). These analyses indicated the presence of numerous volatile and semivolatile organic contaminants, including trichloroethane, chloroform, 1,1,1-trichloroethane, 1,2-dichlorobenzene, isophorone, nitrobenzene, and pyrene. Trichloroethane was detected in sample R2-3 at a concentration of $9 \mathrm{ug} / 1$, in excess of the Primary Drinking. Water Standard (MCL) and Colorado Groundwater Standard of $5 \mathrm{ug} / 1$. Nitrobenzene was detected at a concentration of $53 \mathrm{ug} / 7$ in sample R2-8, in excess of the Colorado Groundwater Standard of $3.5 \mathrm{ug} / 1$.

The limited sampling results from these former investigations indicate organic contamination of groundwater beneath GJPO. The Remedial

Investigation/Feasibility Study (RI/FS), which was conducted to characterize contaminants and ovaluate alternatives, dic not include a detailed evaluation of potential organic contamination in aroundwater.

The process of selecting passive groundwater remediation (GRJ0135) from the alternatives outlined in the Feasibility Study did not have the benefit of an adequate characterization of potential organic contamination in groundwater 
underlying GJPO, nor did the Health Risk Assessment (GRJ0031) fully consider the potential risks of organic contaminants.

Site's Prior Knowledge: This issue was addressed as part of Geotech's SelfAssessment dated May 3, 1991. (GRJ0146)

Probable Causal Factors: The apparent causal factor contributing to this finding is assessment of risk in that responsible DOE GJPO and site Contractor personnel were not fully appraised of the environmental and compliance risks of not fully considering the issue of organic contamination in groundwater during previous characterization activities, and training in that GJPO staff did not recognize the need for organic sampling. 


\subsubsection{Overview}

The purpose of the soils, sediment, and biota portion of the Baseline Environmental Audit was to evaluate the programmatic and technical status of soil, sediment and biota monitoring associated with DOE activities at the Grand Junction Projects office (GJPO), as it relates to applicable regulations, industry and regulatory guidance, and best management practices. Applicable requirements include DOE Orders and CERCLA requirements ( $40 \mathrm{CFR}$ Part 300). Industry and regulatory guidance includes DOE guidance documents, and guidance documents developed as part of CERCLA and RCRA. Applicable regulations and guidance documents are summarized in Table 3-4. Best Management Practices (BMP) are those currently accepted methods and procedures in both industry and government programs.

The general approach to the soils, sediment, and biota portion of the audit included interviews with the Site Contractor (Geotech) and DOE-GJPO; review of site documents, reports, field logs, and maps, and interaction with other members of the Audit Team, including the Inactive Waste Site, Radiation, and Surface. Water technical specialists. On-site inspections were conducted to view potential source areas of soils, sediment, and biota contamination and verify information gathered during this Baseline Environmental Audit. The data and information gathered from these activities were reviewed and evaluated with respect to Federal, state, and DOE regulations and guidelines, and current industry standards.

The GJPO facility is situated on an alluvial point bar deposit, adjacent to the Gunnison River. In-situ surficial soils consist of sandy gravel with a silt matrix, derived from alluvial and colluvial processes. Fill material consisting of sandy gravel uranium mill tailings covers much of the site. Radiologic contamination of soil and tailings was documented in studies conducted in 1985 and 1989 (GRJ0040). Radiologically contaminated tailings are currently being removed from the site for temporary disposal at the StateOwned Temporary Repository under the Grand Junction Projects Office Remedial Action Program (GJPORAP).

Sediments are associated with surface water bodies on-site in the North Pond and the South Pond. The North Pond has historically been used for routing of surface water runoff; the South Pond has received effluent discharges from former operations, including chemical and radioactive wastes. Both of these ponds are in direct hydraulic communication with the groundwater underlying the site. Sediments are also associated with the Gunnison River, located adjacent to the west and north sides of GJPO. A flood dike surrounds GJPO along the banks of the Gunnison River, which minimizes surface runoff to the river. Chemical and radiologic contamination of sediments was documented in former site investigations (GRJ0031, GRJ0128). No periodic sampling of Gunnison River sediments is conducted as part of the GJPO Environmental Surveillance Program.

The biological inventory provided in the Remedial Investigation/Feasibility Study (RI/FS) (GRJ0031) listed the species that are likely to be present in 
the GJPO area. The principal habitats include a riparian environment that hosts birds, mammals, aquatic and terrestrial plants and aquatic species. Further, there are "wetland" habitats associated with heavily vegetated areas surrounding North and South Ponds. Because of the lack of focus on potential site-derived contamination of on-site and off-site biota, the nature and distribution patterns of biouptake are poorly understood, including the potential for contamination of dairy cows located adjacent to the facility. Further, the exact biogeochemical transport processes to biotic receptors are poorly understood.

The Soils, Sediment, and Biota portion of the Baseline Environmental Audit identified one Best Management Practice finding. This finding addresses the lack of a comprehensive ecosystem surveillance program as part of the facility's environmental monitoring program. 
TABLE 3-4

LIST OF APPLICABLE SOILS/SEDIMENTS/BIOTA

REGULATIONS/REQUIREMENTS/GUIDELINES

Regulations/

Requirements/

Guidelines

Sections/Title

Authority

40 CFR Part 300

National 0 il and Hazardous Substances

EPA

Pollution Contingency Plan

DOE Order 5400.1

General Environmental Protection

DOE

DOE Order 5400.4

Program

Comprehensive Environmental Response,

DOE

Compensation, and Liability Act

Requirements

DOE Order 5484.1

Environmental Protection, Safety, and

EPA

Health Protection Information

Reporting Requirements

DOE Order 5400.5

Radiation Protection of the Public and

DOE the Environment

DOE/EH-Oi73T

DOE Environmental Regulatory Guide for

DOE Radiological Effluent Monitoring and Environmental Surveillance 
Performance Objective: It is considered a Best Management Practice to follow the intent of DOE guidelines for conducting ecosystem radiologic monitoring.

The DOE Environmental Regulatory Guide for Radiological Effluent Monitoring and Environmental Surveillance states that an assessment of the potential dose to native aquatic organisms should be conducted and included as part of the Environmental Monitoring Plan. This DOE Guidance further states that because of the diversity of organisms and diversity of pathways and radionuclides that must be considered, it is not possible to develop a single generalized model that can be assumed to cover all possible conditions. Instead, a sitespecific assessment... should be conducted. This Guidance also states that aquatic organisms, sediments, and other predictive environmental media should be sampled and analyzed at least annually to provide compliance with the interim aquatic biota limit of $1 \mathrm{rad} /$ day.

The DOE Environmental Regulatory Guide for Radiological Effluent Monitoring and Environmental Surveillance also states that "if dairy herds or family cows (or goats) are present in the vicinity of the site (within $16 \mathrm{~km}$ ), representative milk samples should be taken and analyzed for radionuclides potentially present from site operations".

Finding: The radiological surveillance program at GJPO does not adequately address potential impacts from site-derived contamination to biota and agricultural products.

Discussion: Contamination of both the surface and subsurface environments at GJPO, from radiologic and nonradiologic sources, has been documented in numerous studies (GRJ0031, GRJ0040, GRJ0084, etc.). GJPO has developed a surveillance program (GRJ0089) for radiologic and nonradiologic contaminants that addresses environmental media, such as surface water, air, and groundwater. The radiation surveillance program, as currently designed, does not include the following media: soils, river and pond sediments, and terrestrial and aquatic biota. Comprehensive radiologic soil surveys (GRJ0040) conducted on the GJPO site in 1985 and 1989 have reduced the need for periodic comprehensive soil monitoring. Similarly, former sampling of pond sediments (GRJ0031) has generally defined the conditions present in the sediments of on-site water bodies.

Section 1.1 of the Environmental Monitoring Plan for the GJPO facility (GRJ0089) states that terrestrial and aquatic "foodstuffs" will not be sampled as part of the surveillance program, because they are not produced in areas surrounding GJPO where contaminated tailings may affect them. Further, sediments in the Gunnison River will not be sampled, because limited sampling in 1979 and 1980 indicated that contaminant levels (radium-226) were below UMTRA standards.

The Remedial Investigation (GRJ0031) conducted by GJPO provides a brief description of potential habitats in the GJPO area based on data from the Bureau of Land Management and the U.S. Department of the Interior. Based on 
the tabulation of potential species present, a limited risk assessment to human populations from consumption of $f i s h$ was conducted using predicted concentrations of uranium and base metals in the Gunnison River. The results of the risk assessment suggested that this environmental pathway did not present a human health risk.

Based on the DOE regulatory citations described above, a review of available reports and documentation, and the site conditions as observed at the time of the Audit, a more comprehensive site-wide biological surveillance program is needed to describe baseline environmental conditions for the following purposes:

- To facilitate compliance with applicable regulations;

- To ensure that all site-attributed impacts to biota, foodstuffs, human health, and the environment are systematically reviewed and monitored, as appropriate; and

- To clarify and assess existing contamination levels and patterns in onsite and off-site biota and foodstuffs.

For example, a diverse riparian habitat is present adjacent to the GJPO site along the banks of the Gunnison River. Groundwater studies (GRJ0031) indicate that significant contamination of groundwater is present in this area and that during the drier portions of the year (late summer to fall), contaminated groundwater underlying the facility is discharged entirely to the river and river bottom sediments. The potential impacts of contaminated groundwater to aquatic and non-aquatic plants, benthic organisms, including burrowing species, and higher orders of the riparian food chain, have not been assessed.

Additionally, although feed is provided, dairy cows are allowed to graze on sparse vegetation within 200 feet of a "controlled area" along the northern boundary of the facility. Air-dose radiological computer modeling has been conducted to estimate potential doses to the public through the ingestion of cow's milk; however, no baseline characterization of potential milk and beef contamination has been conducted specifically for the cows at this location. $\mathrm{CDH}$ does monitor milk quality from this site, however, these samples are of milk composited from numerous dairy farms in this region.

The DOE Regulatory Guide for Radiological Effluent Monitoring and Environmental Surveillance describes the basis for sampling sediments as follows: "The sampling of sedimentary material from streams or ponds can provide an indication of the accumulation of undissolved radionuclides in the aquatic environment. Because of the accumulation of contaminants, sediment sampling is a more sensitive indicator of waterborne radionuclides than water sampling or, for some aquatic species, aquatic biota sampling." Sediment sampling in the Gunnison River was conducted on a limited basis in 1980 and again in 1987 (GRJ0128). These samples indicate uranium concentrations as high as 12 milligrams per kilogram $(\mathrm{mg} / \mathrm{kg})$, compared to an upstream concentration of $3 \mathrm{mg} / \mathrm{kg}$, although this does not represent a statistically significant sampling of the river. 
The general lack of baseline biological data underscores the need for an expanded surveillance program to include potential impacts to nonhuman receptors, both in aquatic and nonaquatic habitats.

Site's Prior Knowledge: This issue was not addressed in any Self-Assessments conducted at GJPO.

Probable Causal Factors: The apparent causal factors contributing to this finding include a lack of policy implementation by DOE GJPO and Geotech, in that established DOE guidelines have not been implemented, and incomplete reviews/audits/appraisals in that these issues were not raised as part of the former DOE GJPO and Geotech Self-Assessments. 


\subsubsection{Overview}

The purpose of the waste management portion of the Baseline Environmental Audit was to evaluate the following: current status of waste (hazardous, nonhazardous, and mixed) management at the site; waste management practices with respect to compliance with applicable Federal, state, and local regulations, DOE Orders, Secretary of Energy Notices, and GJPO policies; and waste management practices with respect to Best Management Practices (BMP). In addition, Underground Storage Tank (UST) practices were assessed in accordance with applicable regulations. Applicable Regulations, Orders, and guidance documents are summarized in Table 3-5. BMPs are currently accepted standard methods and procedures in both industry and government programs.

The approach taken for this portion of the audit included a review of site documents concerning waste management practices, facility programs, permitting, and records. Interviews with cognizant site and regulatory personnel, including DOE, GJPO, Geotech, CDH, and EPA personnel, were conducted. Other members of the Audit Team were consulted as appropriate. On-site inspections were conducted to examine waste storage and accumulation areas and practices, to investigate potential source areas for waste generation, and to verify other information gathered during the audit. All information gathered from the conduct of the above activities was reviewed and evaluated against compliance standards and BMPs.

Wastes generated at GJPO include hazardous and mixed wastes, as well as solid non-hazardous wastes. Liquid and solid hazardous wastes result from a variety of operations including: cleaning and degreasing operations in Facilities Management; cleaning and maintenance of counting instrumentation in the Radon Laboratory; data processing; sample preparation in the Petrology Laboratory; degreasing activities in the Boiler Plant; maintenance and repair activities in the Electronics Laboratory; and chemical operations and instrument calibration in the Analytical Laboratory. The hazardous wastes generated include solvents, alcohol, and miscellaneous unused/unusable chemical and sample residues.

Non-hazardous solid wastes such as construction debris, packaging materials, containers, and paper are disposed of at the Mesa County Landfill. All nonhazardous solid waste suspected of radioactive contamination is surveyed. If radioactivity is indicated, it is considered a low-level waste and managed accordingly. Computer and white paper are recycled and the Site Hazardous Waste Minimization Committee is coordinating site-wide efforts to recycle aluminum, paper products, and plastics.

Low-level and mixed wastes primarily result from analytical chemistry operations and facility decontamination and decommissioning activities. In addition, there is the potential for mixed wastes to be generated as a result of the contamination of residual uranium mill tailings with hazardous wastes. Low-level, mixed waste, and hazardous wastes are initially stored at or near their point of generation. Based on accumulated amounts, low-level wastes are transferred from the point of generation to the Radioactive Source Storage 
Area in Building 36; liquid mixed and hazardous wastes are transferred to the Temporary Hazardous and Mixed Waste Storage Area in Building 42.

Historically, the quantities of hazardous waste generated at GJPO have been less than $100 \mathrm{~kg} /$ month and have been accumulated in total quantities of less than $1000 \mathrm{~kg}$ at any time. Waste generation in these small quantities has allowed GJPO to operate under the RCRA status of a "conditionally exempt small quantity generator". As a Conditionally Exempt Small Quantity Generator (CESQG), a RCRA permit for storage, treatment, or disposal of hazardous wastes is not required, nor is the site subject to full implementation of RCRA requirements. Recently, however, site activities have resulted in the increase of wastes generated to surpass limits established for CESQG, thereby resulting in the classification of the facility as a "small quantity generator" (SQG), subject to additional RCRA compliance requirements. A majority of these additional requirements have been addressed at GJPO in anticipation of the potential change of generator status.

Four USTs were identified and removed from GJPO in 1988. This removal is documented in "Underground Storage Tanks Notification and Removal" (GRJO015). There are no USTS currently at the site.

Several good management practices were observed during this Audit related to waste management at GJPO. Satellite Accumulation Areas (SAA) were very well maintained and controlled. Although, as a CESQG the specific guidelines for the maintenance, inspection, and control of these SAAs were not a compliance requirement, it was apparent that concerted efforts had been expended to minimize the potential for adverse effects to the environment by storage of accumulated hazardous wastes. In addition, an effective Waste Minimization Program has been established which provides for employee awareness and incentive in efforts to achieve waste minimization. The Waste Minimization Committee provides the action mechanism for the overall Waste Minimization Program, as well as for suggestions generated under the site-wide Productivity Quality Improvement (PQI) Program. The PQI Program elicits employee suggestions for the identification of changes in site practices to allow for improved product quality, cost savings, waste minimization, and overall improvements in environmental quality.

The waste management findings relate to the five compliance issues and one BMP. The compliance findings address lack of adequate hazardous waste determination, characterization, accounting, and storage, as well as the absence of a complete, implementable Pollution Prevention Awareness Plan. The BMP finding addresses hazardous waste labeling concerns. 
TABLE 3-5

LIST OF APPLICABLE WASTE MANAGEMENT REGULATIONS/REQUIREMENTS/GUIDELINES

Regulations/

Requirements/

Guidelines

DOE Order 5400.1

DOE Order 5400.3

DOE Order 5820.2A

40 CFR Parts

260 and 270

6 CCR Parts 1007-3, 260-268

40 CFR Part 280
Sections/Title

Gene'al Environmental Regulations

Hazardous and Radioactive Mixed Waste Program

Radioactive Waste Management

Hazardous Waste Regulations

Code of Colorado Hazardous Waste

Underground Storage Tank Regulations
Authority

DOE

DOE

DOE

EPA

State of Colorado

EPA

$3-36$ 
Performance 0bjective: As specified in 6 CCR Part 1007-3, 262.11, a generator of a solid waste must determine if waste is a hazardous waste. If the result of this determination indicates that the solid waste is a hazardous waste, then that waste must be labeled in accordance with 6 CCR Part 1007-3, 262.34, and must be included in quantity determinations required for conditionaliy exempt small quantity generators (6 CCR Part 1007-3, 261.5).

Finding: Three drums of uranium mill tailings commingled with hazardous waste (chloroform), located in Building 42 (Hazardous Waste Temporary Storage), were not marked as hazardous waste and were not included in the quantity determination required for generator status identification as required by federal regulations.

Discussion: During Phase I activities of Grand Junction Projects Office Remedial Action Program (GJPORAP), the contents of a liquid and sludge sump in Building 31 were emptied. These materials were determined by analysis io be commingled wastes heavily contaminated with chloroform. These wastes were placed in two 55-galion drums and one 30-gallon drum and were moved to Building 42. Upon inspection by the audit team, it was found that although the drums were labeled "Commingled Waste", they were not labeled as hazardous waste nor were they included in the total inventory of hazardous waste at GilP0 used to determine generator status.

Due to the characterization of these wistes as mixed wastes, and their inclusion in the hazardous waste inventory, the total waste accumulated onsite has increased from approximately $600 \mathrm{~kg}$ to $1100 \mathrm{~kg}$, thereby exceeding the $1000 \mathrm{~kg}$ threshold for conditionally exempt small quantity generator making all accumulated hazardous waste subject to the regulations applicable to generators of between $100 \mathrm{~kg}$ and $1000 \mathrm{~kg}$ of hazardous waste in a month. As specified in 6 CCR Part 1007-3, 262.34, subsequent to the inspection conducted during this audit, Geotech adequately labeled the three drums of mixed chloroform waste and included this waste in the total hazardous waste inventory.

Site's Prior Kncwledge: This issue was not addressed in any Self-Assessments conducted at GJ '0.

Probable Causal Factors: The apparent causal factor for this finding is inadequate policy to assure compliance with the regulations for commingled waste. 
Performance Objective: 40 CFR Part 268.50 prohibits the storage of restricted hazardous and mixed wastes for any purpose other than to accumulate such quantities necessary to facilitate proper recovery, treatment, or disposal. Generators who must store hazardous or mixed waste for longer than 90 days because of the regulations under 40 CFR Part 268 become an owner/operator of a storage facility and must obtain a RCRA permit for storage.

Finding: The Grand Junction Projects office (GJPO) is currently storing small quantities of restricted mixed waste for purposes other than accumulating such quantities to facilitate proper recovery, treatment, or disposal. GJPO does not have a RCRA permit for the storage of restricted mixed waste.

Discussion: Building 42, the temporary hazardous waste storage facility located at the Grand Junction Projects office, is currently used to store a variety hazardous, mixed, and radioactive wastes. Currently in storage in Building 42 are 1,226 small vials containing approximately 24.5 liters of radioactive xylene solvent (F003) which is currently restricted under the RCRA Land Disposal Restrictions. This waste is not being stored for the purpose of accumulating sufficient quantities necessary to facilitate proper recovery, treatment, or disposal. Because of an extreme capacity shortage nationwide of facilities (DOE or commercial) permitted to accept the mixed waste xylene solvent in Building 42 for treatment or disposal, continued storage at GJPO is anticipated.

Because the mixed waste has been stored for longer than 90 days, DOEGJPO/Geotech is an owner/operator of a hazardous waste storage facility and must obtain a RCRA storage permit (refer to Secretary of Energy Notice No. 22 (SEN-22-90) for the DOE policy on signature of RCRA permit applications).

The applicability of the RCRA Land Disposal Restrictions to waste generation and storage of hazardous and mixed waste at the Grand Junction Projects office Site is a result of a change in their status from a conditionally exempt small quantity generator to a small quantity generator (see WM/CF-1).

To address the issue of generation and storage of restricted mixed waste on a national leve1, in December, 1989, DOE Headquarters requested EPA to enter into Federal Facility Compliance Agreements (FFCAs) with all DOE facilities that faced existing or future LDR compliance uncertainty. At several DOE facilities, DOE and EPA Regional offices are negotiating site-specific compliance agreements to resolve the issue of mixed waste storage. At the same time, DOE and EPA Headquarters are continuing to address this issue at a national level.

Site's Prior Knowledge: This issue was not addressed in any Self-Assessments conducted at GJPO. 
Probable Causal Factors: The apparent causal factors contributing to this finding are that the recent change in GJPO's generator status invoked the applicability of additional RCRA requirements, and the lack of available facilities permitted to treat and dispose of restricted mixed waste which pose a barrier towards complying with LDR regulations. 
Performance Objective: In accordance with DOE Order 5400.1 (III.4.c), a Pollution Prevention Awareness Plan (PPAP) should have been specifically identified, documented and implemented by November 9, 1989.

Finding: A PPAP has not been fully documented and implemented at the Grand Junction Projects Office (GJPO) in accordance with DOE Order 5400.1.

Ciscussion: As part of the Waste Minimization Plan prepared by GJPO (GRJ0015), reference is made to the PPAP and a brief description of the plan is provided. This description includes references to the components of the PPAP including: an Employee Awareness Program, an Employee Training Program, and an Employee Incentive and Awards Program. Each of these components requires further development in order to provide for a fully documented and implementable program plan as required in DOE Order 5400.1 .

As part of the Waste Minimization Program implemented by Geotech, employee awareness, incentive, and awards efforts are being addressed. However, pollution prevention training has not yet been addressed.

Geotech received specific guidance from DOE for the preparation of a Waste Minimization and Pollution Prevention Awareness Plan, dated February 1, 1991. Based on this guidance, a revised Waste Minimization and Pollution Prevention Awareness $\mathrm{Plan}$ is being prepared with a planned completion date of July 31 , 1991. Subsequent implementation of the Plan is targeted for initiation prior to the end of FY 91 .

Site's Prior Knowledge: This finding was identified in the Site Surveillance Report dated April 10, 1991 (GRJ0059).

Probable Causal Factors: The apparent causal factors which contribute to this finding are the lack of procedures for ensuring that a PPAP is documented and implemented and inadequate resources to fully implement the :equirements of DOE Order 5400.1. 
Performance Objective: Hazardous and mixed wastes are to be managed in accordance with 6 CCR Part 1007-3. Regulations contained in 6 CCR Part 10073,100 require that permits be obtained for the storage of hazardous and mixed waste. 6 CCR Part 1007-3, 264.251 sets minimum design and operating standards for waste piles.

Finding: As a result of UMTRA activities at vicinity properties in 1988 and 1989, uranium mill tailings commingled with hazardous waste are in storage at the Grand Junction UMTRA State-Owned Temporary Repository. The State-Owned Temporary Repository is not permitted as a RCRA storage facility and does not meet the minimum design and operating standards for RCRA waste piles.

Discussion: In 1988 and 1989, approximately 100 tons of UMTRA mill tailings from vicinity properties, which were later found to be commingled with materials containing hazardous levels of lead and arsenic, were transported and deposited at the Grand Junction UMTRA State-Owned Temporary Repository. The 100 tons of mixed waste stored by Grand Junction Projects Office (GJPO) at the State-Owned Temporary Repository is stored in waste piles without a RCRA storage permit. The waste piles do not meet design and operating requirements specified ir. 6 CCR Part 1007-3, 264.251. Upon characterization of this material as hazardous waste, these compliance deficiencies were recognized by GJPO and the Color ado Department of Health (CDH).

Meetings between Geotech, Department of Energy (DOE) representatives from Grand Junction, Idaho and Headquarters, and the $\mathrm{CDH}$ resulted in a decision to pursue a Consent Agreement in lieu of a RCRA Part B permit in order to address these areas of non-compliance. However, there has apparently been some disagreement between $\mathrm{DOE}$ and $\mathrm{CDH}$ regarding specific language in the Consent Agreement which has delayed the formalizing of the Agreement. In an effort to finalize this agreement, a meeting was held between DOE, Geotech, and CDH on June 3,1991 to discuss suggested language changes. A subsequent meeting was scheduled for the end of June, 1991.

Site's Prior Knowledge: This issue was addressed in the GJPO SEN-7A-90 Environmental Report for October 1 - December 31, 1990, and the SEN-7A-90 Environmental Report for January 1 - March 31, 1991.

Probable Causal Factors: The probable causal factor contributing to this finding is the absence of adequate procedures to ensure proper characterization of mill tailings prior to placement on the GJPO-operated State-Owned Temporary Repository, and lack of policy to address commingled waste policy issues. 
Performance 0bjective: A generator of a solid waste as defined in 6 CCR Part 1007-3, 261.2, must determine if that waste is a hazardous waste in accordance with 6 CCR Part 1007-3, 262.11.

Finding: Excessed (waste) analytical laboratory chemicals are stored in 82 boxes in Building 42. A complete characterization to determine the hazardous waste status of the chemicals has not been completed as required by 6 CCR Part $1007-3,262.11$.

Discussion: In March 1991, 82 boxes containing 876 individual items of excessed solid inorganic analytical laboratory chemicals were entered into storage in Building 42, the Temporary Hazardous Waste Storage Building. Nine items have been determined to be hazardous waste based on their status as "listed" wastes. The remaining 867 chemicals have not been characterized with respect to the hazardous waste characteristics described in Subpart C, 6 CCR Part 1007-3, 261 .

Site's Prior Knowledge: This finding was partially identified in the Site Surveillance Report dated April 10, 1991 (GRJ0059). However, the Site Surveillance Report did not address the waste characterization requirement.

Probable Causal Factors: The apparent causal factors contributing to this finding are the lack of procedures to characterize excess laboratory chemicals and inadequate staffing resources to characterize large quantities of chemicals. 
WM/BMPF-1 Labeling of Hazardous Waste Containers

Performance 0bjective: Federal and state waste management regulations allow generators of hazardous waste to store up to 55 gallons of hazardous waste in containers at or near any point of generation where wastes originally accumulate without a permit. Best Management Practice suggests that these containers of hazardous waste be clearly marked to ensure proper identification and management.

Finding: Containers of hazardous waste at sr near the point of generation in Building 20 Analytical Chemistry Laboratories were not labeled as hazardous waste, creating the potential for ambiguity and confusion with respect to their contents.

Discussion: In an inspection of hazardous waste management practices in Building 20 (Analytical Chemistry Laboratories), hazardous waste containers stored at points of waste generation were observed to be inadequately labeled. These containers were generally marked with respect to the chemical composition of the contents but it was not apparent that tice containers held hazardous waste. In addition, as a containment measure, containers of these wastes were held in high-sided plastic pans which often concealed any container marking. In order to identify the contents of these containers, it was necessary to $1 \mathrm{ift}$ them out of the containment pans.

In order to prevent inadvertent misuse of these containers and to minimize the potential for spills or personnel exposure to these hazardous wastes, Best Management Practice suggests labeling these materials as "hazardous wastes" to make them more readily recognized as such.

Site's Prior Knowledge: This finding was identified in the Site Surveillance Report dated Apri1 10, 1991 (GRJ0059).

Probable Causal Factors: The apparent causal factors which contributed to this finding are the lack of policies and procedures to ensure for the adequate labeling of hazardous waste containers. 


\subsection{Toxic and Chemical Materials}

\subsubsection{Overview}

The purpose of the toxic and chemical materials portion of the audit was to evaluate the compliance of the Department of Energy and its contractor, Geotech, Inc., with the Toxic Substances Control Act (TSCA); Federal Insecticide, Fungicide and Rodenticide Act (FIFRA); portions of the Clean Water Act applicable to the storage of petroleum products; DOE Orders; State of Culorado regulations; Geotech, Inc., policies and procedures, and Best Management Practices (BMP) related to DOE activities at the Grand Junction Projects office (GJPO). Table 3-6 lists the regulations which apply to toxic and chemical materials management at GJPO.

The toxic and chemical portion of the audit was accomplished through discussions with Geotech, Inc., personnel; a review of internal written policies, procedures and programs, including the Spill Prevention Control and Countermeasures (SPCC) Plan; review of internal documents related to PCB and asbestos management; and inspections of chemical storage areas.

Electrical transformers and other equipment at the facility contain less than 50 parts per million (ppm) PCBs. This was accomplished either by retrofilling equipment and re-testing to ensure that the levels were below $50 \mathrm{ppm}$, or by replacing the equipment. This program was completed in 1988. The facility tests soil and mill tailings samples it receives for the presence of PCBs, and uses PCB standards for this purpose. Waste materials from this activity are collected and stored in the analytical lab and are eventually moved to the hazardous waste storage area (Building 42). Index of Refraction 0ils that contain up to $150 \mathrm{ppm}$ PCBs are currently being stored in Building 42.

GJPO has conducted a survey to identify the location and type of asbestos throughout the site. The facility's policy is to abate the asbestos, rather than to encapsulate it. This is accomplished through the use of a subcontractor, although there are Geotech employees at GJPO who are trained asbestos supervisors. Two of these Geotech employees are also certified by the State of Colorado, and they occasionally conduct small asbestos removal projects. There was one asbestos abatement project (in Building 20) being conducted during the Audit.

The facility has two bulk storage tanks for diesel fuel. One is a 15,000gallon capacity painted steel storage tank which is used to store back-up fuel for the boiler. This tank is located in a concrete basin with a 17,280-gallon containment capacity. The other tank is a 300-gallon capacity steel storage tank which is used to store diesel fuel for small utility vehicles. This tank is located in a steel basin with a 495-gallon containment capacity. Neither secondary containment area has drains. Water accumulated in the containment areas is allowed to evaporate or is pumped to the storm drain system after a visual check of its quality. An SPCC PIan for the diesel tanks has been developed. 
Other chemicals are stored at the facility in lab quantities. Purchase requisitions for chemicals must be reviewed and signed by a member of the Environmental Compliance and Regulatory Affairs Department. Material Safety Data Sheets (MSDS) are requested as part of each chemical purchase, and the receiving department will not release a chemical that does not have an MSDS. A site inventory of chemicals is conducted on an annual basis.

Pesticides are applied at the facility by a subcontractor certified in pesticide application. The subcontractor brings the pesticides on-site for each application and does not store pesticides at GJPO.

Three compliance findings and one BMP finding were identified. One compliance finding relates to the fact that the facility has not yet implemented all facets of its SPCC program, including training of personnel in the SPCC plan. The other two compliance findings relate to PCB waste management. One concerns the storage of PCBs in Building 42 for more than one year and in Building 20 for more than 30 days in a room that does not meet the design criteria for one-year storage, and the other relates to the PCB contaminated mill tailings at the GJPO site. The BMP finding relates tis the storage of chemicals in the Photography Laboratory. 


\section{TABLE 3-6}

LIST OF APPLICABLE TOXIC AND CHEMICAL MATERIALS REGULATIONS/REQUIREMENTS/GUIDELINES

Regulations/

Requirements/

Guidelines

\section{Sections/Title}

Authority

40 CFR Part 761

Polychlorinated Biphenyls (PCBs)

EPA

Manufacturing, Processing,

Distribution in Commerce, and Use

Prohibitions

40 CFR Part 112

Oil Pollution Prevention

EPA

Colorado Air Quality

Asbestos Control

EPA

Control Commission

Regulation 8, Part B

DOE Order 5400.1

General Environmental Protection

DOE 
Performance Objective: 40 CFR Part 112 requires that facilities storing in excess of 1,320 gallons of $0 i 1$ aboveground prepare a Spill Prevention Control and Countermeasures (SPCC) Plan. 40 CFR Part 112.7 requires that such facilities store and manage their oil in conformance with certain requirements, including: 1) fail-safe engineering of tank installations, such as high direct vision gauges or liquid level alarms [40 CFR Part 112.7(e)(2)]; and 2) training of personnel in the SPCC PIan [40 CFR Part 112.7(e)(10)].

Finding: GJPO has not fully implemented its SPCC Plan.

Discussion: On March 28, 1991, the facility finalized an SPCC Plan covering the 15,000-gallon and 300-gallon diesel fuel storage tanks (GRJ0112). The SPCC PIan, however, has not been fully implemented. The Audit Team noted the following:

- Training in the SPCC PIan has not yet occurred (I-TCM-23). It is scheduled to be completed by the end of June, 1991 .

- Emergency response training by outside experts, as required by the SPCC Plan, has not yet occurred. It is scheduled to be completed by the end of July, 1991.

- The 15,000-gallon above-ground fuel oil tank does not have a high liquid level alarm, liquid level indicator, or other fail-safe device. The facility plans to install a liquid level indicator, but one had not been ordered at the time of the Audit.

Site's Prior Knowledge: The Technical Department's Self-Assessment of the Site Environmental Monitoring Program identified the lack of a device to reduce the risk of over-filling the tank, and the lack of training.

Probable Causal Factors: The apparent causal factor contributing to this finding is the lack of an SPCC PI an that included formal written procedures, and policy implementation in that these deficiencies have not yet been corrected, thereby preventing the full implementation of the SPCC PIan. 
Performance Objective: 40 CFR Part 761.1(b) prohibits the dilution of PCBs to avoid regulatory requirements. Both EPA Headquarters and Region VIII personnel interpret the prohibition on dilution to mean that any laboratory generating PCB waste as a result of its analytical work must consider all such waste to be at the concentration of the original undiluted lab standard.

40 CFR Part $761.65(\mathrm{c})$ states that PCB containers containing liquid PCBs at a conzentration between 50 and $500 \mathrm{ppm}$ may be stored for up to 30 days from the date of their removal from service in a temporary storage area, provided that an SPCC PIan has been prepared for the temporary storage area. 40 CFR Part 761.65 (b) requires that PCBs at concentrations of $50 \mathrm{ppm}$ or greater which are being stored for disposal be stored in facilities that meet certain design criteria. 40 CFR Part 761.65 (a) requires that PCB articles or PCB containers must be removed from storage and disposed of within one year from the date when they were first placed into storage.

40 CFR Part 761.205 requires that generators storing PCB waste subject to the storage requirements of 40 CFR Part 761.65(b) notify EPA of the ir PCB waste activities. For generators storing PCB waste on or prior to February 5, 1990, this notification was required to be filed by April 4, 1990.

Finding: The Grand Junction Projects Office (GJPO) has been storing waste PCB wastes in excess of the regulatory time limits. Additionally, GJPO has not notified EPA of its PCB waste activities.

Discussion: GJPO uses PCB 1 ab standards as part of its analytical work. As a result of this analytical work, small amounts of waste are generated that have come in contact with PCBs at concentrations of 200 to $1,000 \mathrm{ppm}$ PCBs. This waste is considered by EPA to be PCB waste at the same concentration (e.g., 200 to $1,000 \mathrm{ppm}$ ) as the original lab standards, and must be managed as PCB waste $(I-T C M-26)$.

At the time of the Audit, waste resulting from PCB analytical work was being stored in Room 30 of Building 20 in excess of 30 days, which is the regulatory time limit for the temporary storage of PCB waste. Additionally, this room is not currently designed as a one-year storage area. The facility is currently researching options to modify the design of Room 30 so that it complies with the design requirements for PCB storage areas.

Three hundred fifty-four quarter ounce vials ( 7.5 pounds) of refraction oils that had been used for mineral identification in the Petrology Laboratory have been stored in mixed waste storage in Building 42 since July 27, 1989, which is in excess of one year. These wastes have not been analyzed; however, based on facility personnel's knowledge regarding the initial PCB concentration of the refraction oils, it is likely that they contain PCBs at a concentration of approximately $150 \mathrm{ppm}$ PCBs (I-TCM-21).

Although a radiological survey has indicated that alpha contamination is present on some of the refraction oil vials, GJPO has not attempted to 
decontaminate the exterior of these vials to determine if the oils themselves are actually radioactive. Treatment and disposal of PCB radiologically contaminated waste is limited because of an extreme shortage of DOE and commercial treatment and disposal capacity.

Because GJPO has stored PCB wastes since July, 1989, a Notification of PCB Waste Activity was required to be filed with EPA as of April 4, 1990. This notification has not yet been filed.

Site's Prior Knowledge: The issues of PCB waste storage in Building 42 and the requirement to notify EPA were identified in Geotech's March 11-15, 1991, Environmental, Health and Safety Assessments Results. However, the storage of PCB waste in the Building 20 analytical laboratory was not addressed in any Self-Assessments conducted at GJPO.

Probable Causal Factors: The apparent causal factors contributing to this finding are inadequate policy implementation of established regulatory requirements, and inadequate appraisals/audits/reviews in that some of the deficiencies noted were not identified by GJPO. 
Performance Objective: 40 CFR Part 761.1(b) prohibits the dilutior of PCBs to avoid regulatory requirements. Both EPA Headquarters and Region VIII personnel interpret the prohibition on dilution to mean that the entire area contaminated by a spill of PCBs must be treated as if it contains PCBs in the concentrations of the original spilled material.

40 CFR Part 761.60 (d) requires that spills and other uncontrolled discharges of PCBs resulting from the cleanup and removal of spills, leaks or other uncontrolled discharges must be stored and disposed of in accordance with 40 CFR Part 761.60 (a). 40 CFR Part 761.60 (a) and 40 CFR Part 761.65 require that PCBs at concentrations of $50 \mathrm{ppm}$ or greater be stored in a facility that meets certain design criteria, and that it be removed from storage and disposed of within one year from the date when it was first placed into storage.

Finding: $P C B$ spill material removed to the on-site mill tailings stockpile at GJPO has been stored in excess of one year and has not been stored in a facility meeting the regulatory design criteria.

Discussion: In September, 1990, during a review of analytical data pertaining to the content of the on-site GJPORAP stockpile of mill tailings, the Environmental Compliance and Regulatory Affairs Section of Geotech, Inc., discovered two samples with analyzed PCB concentrations of $110 \mathrm{ppm}$ and $920 \mathrm{ppm}$ PCBs that had previously been taken to identify contaminants from an observed spill. The spill material from which these samples were taken had inadvertently been relocated to the Grand Junction Projects Office Remedial Action Program (GJPORAP) stockpile in late 1989. These PCB spill materials have since been stored on the GJPORAP mill tailings pile.

Upon discovering that PCB-contaminated spill materials had been moved to the on-site mill tailings stockpile, Geotech began a sampling program to determine the extent of detectable levels of PCBs. Characterization of the stockpile indicates that the area of PCB contamination is an oval-shaped disk containing approximately 40 cubic yards of tailings, which is outlined by a PCB concentration of $0.08 \mathrm{ppm}$, the detection limit for EPA Method 8080 . Although the actual concentration of PCBs in the stockpile is below the PCB cleanup action levels, because the original source of the contamination was material with PCB concentrations of 110 and $920 \mathrm{ppm}$ PCBs respectively, the entire PCB contaminated area must meet the requirements for the disposal of non-liquid PCBs at concentrations of $50 \mathrm{ppm}$ or greater. EPA has stated that to comply with the regulations, the entire contaminated area must be removed and disposed of in a landfill permitted for TSCA type waste material (GRJO149).

The 40 cubic yards of PCB-contaminated tailings remains on the top portion of the GJPORAP mill tailings pile. This area is roped-off and a six-inch buffer of soil has been placed over the contaminated tailings; however, it is not covered or stored in accordance with 40 CFR Part 761.60 (i.e., in a facility with a roof and walls to prevent rain water from reaching the stored PCBs, a six-inch curb, adequate containment volume, etc.). 
The excavation and disposal of this material is complicated by the fact that the matrix of contaminated material is uranium mill tailings. Geotech had intended to dispose of the material at the U.S. Ecology site (a licensed PCB disposal site) in Beatty, Nevada; however, U.S. Ecology has recently stated that the mill tailings are considered by-product material and, therefore, under Nevada law, they are unable to accept it (GRJ0147). Because the material is considered a TSCA waste, the State of Colorado will not accept it at the State-Owned Temporary Repository, the selected disposal site for the GJPORAP mill tailings.

Geotech has been working with both the State of Colorado and EPA Region VIII to resolve this issue and has proposed several alternatives to EPA. Because of the lack of capacity to dispose of PCB-contaminated mill tailings, however, this issue is not likely to be resolved in the near future.

Site's Prior Knowledge: This issue has been identified in various documents and memoranda between Geotech and the Department of Energy, EPA Region VIII, and the Colorado Department of Health, and is being tracked closely by personnel in the Envircnmental Compliance and Regulatory Affairs Section.

Probable Causal Factors: The apparent causal factors for this finding are policy implementation in that Geotech procedures were not implemented with regard to preventing the release of contaminated material to the GJPORAP pile until approved by Geotech's Environmental Controls and Regulatory Affairs Section. The fact that the material is still on-site is because of barriers and controls preventing proper disposal of this material. 
TCM/BMPF-1 Spill Containment and Control in the Photography Laboratory

Performance Objective: In order to minimize the potential for the release of toxic and chemical materials to the environment, Best Management Practice suggests storing such materials in a manner that minimizes their potential to spill, and providing secondary containment for such materials.

Best Management Practice also suggests to cleaning and removing residue from the spill of toxic and chemical materials, and assessing whether the spilled materials may have migrated beyond the immediate spill area.

Finding: Some chemicals stored in the Building 7 Photography Laboratory are not provided with secondary containment. Additionally, there has been no evaluation of potential contamination to the flooring and foundation materials in the Building 7 Photography Laboratory from periodic past spills.

Discussion: Some hazardous photographic chemicals were being stored in the sink in the Photography Laboratory. Other hazardous chemicals were being stored above the sink with their flow valves positioned over the sink. The sink drains to the sanitary sewer system (I-TCM-5). Several containers of fixers and developers were being stored on a shelf with their flow yalves pointed toward the floor, and were not provided with secondary containment. A spill or leak of these chemicals would go to the floor. More appropriate storage cabinets for photographic chemicals have been ordered.

The paper processor in the Photography Laboratory has had a history of spills (I-TCM-5). The most recent spill occurred in November, 1990 (GRJ0163). Although this equipment has been shut down since December, 1990, the floor tiles in the area are stained and deteriorated. No assessment of the integrity of the floor or potential contamination of the tile or material beneath has been made.

Site's Prior Knowledge: The issue of improperly stored hazardous chemicals was identified in the Publication Services Copy Center/Photo Lab Self-

Assessment of May, 1991. The potential contamination to the flooring and foundation materials has not been identified in a formal Self-Assessment.

Probable Causal Factors: The apparent causal factor for this finding is the lack of formal spill control and containment procedures for the Photography Laboratory. 
This page was intentionally left blank. 


\subsection{Quality Assurance}

\subsubsection{Overview}

The purpose of the quality assurance (QA) portion of the Baseline Environmental Audit was to evaluate the Site Contractor QA Program and its application to the generation of sound, defensible, and traceable chemical and radiological data. Table 3-7 lists specific regulations and guidelines used to evaluate the Site Contractor during the assignment.

The scope of this review included discussions and interviews with Site Contractor staff; a review of QA policies and procedures, sampling and analytical methods, laboratory records; and an evaluation of QA practices against data quality objectives at the Analytical Chemistry Laboratory, the Radon Laboratory, and the Petrology Laboratory. In addition, the QA portion of the audit included a review of personnel training and qualification records, and environmental monitoring plans and programs. The GJPO training and qualifications tracking system was very well managed.

As part of the QA assessment, reviews were coordinated with other members of the Audit Team to ensure that all potential environmental quality assurance issues were evaluated with regard to quality assurance aspects of their emission/effluent monitoring investigations.

The majority of the environmental analytical chemistry and radiochemistry work for the Site Contractor is done by the Site Contractor Analytical Chemistry Laboratories in Buildings 7 and 20. In addition, contract laboratories are used for some compliance analysis when the on-site laboratories do not perform the required analysis or the number of samples exceeds the laboratory's capacity.

The Site Contractor Analytical Laboratory participates, or has participated, in a number of interlaboratory assessment programs (EML, EPA, AMIH, and PAT). The Geotech 1aboratories are well-managed, expertly staffed, and have excellent instrumentation. The laboratory has established an internal quality Assurance/Quality Control (QA/QC) program based on EPA and NQA-1 requirements. The QC program includes the use of internal and external standards, blanks, duplicates, matrix spikes and matrix spike duplicates, and control charts. The sample tracking system is computer-based with a detailed hard-copy sample log-in/log-out system. Most written procedures are up-to-date and in place for sampling, chain-of-custody, sampla tracking and storage.

There are four compliance findings in the QA section related to QA oversight of environmental monitoring activities, three Best Management Practice (BMP) findings, and one Special Issue. 
TABLE 3-7

LIST OF APPLICABLE QUALITY ASSURANCE

REGULATIONS/REQUIREMENTS/GUIDELINES

Regulations/

Requirements/

Guidelines

Sections/Title

Authority

DOE Order 5400.1

DOE Order 5700.6B

NQA-1-1989

SW-846

QAM $005 / 80$

40 CFR Part 136

40 CFR Part 58

Appendix E

40 CFR Part 50

Appendix $\mathrm{J}$

40 CFR Part 61

General Environmental Protection

DOE

Program Requirements

Quality Assurance

DOE

Quality Assurance Program Requirement

DOE

for Nuclear Facilities

Test Methods for Evaluating Solid

EPA

Waste, Physical/Chemical Methods

Sw846, Third Edition

Interim Guidelines and Specifications

EPA

for Preparing Quality Assurance

Project Plans

Guidelines Establishing Test

EPA

Procedures for the Analysis of

Pollutants

Probe Siting Criteria

for Ambient Air Quality Monitoring

EPA

Reference Method for the

EPA

Particulate Matter as FM10 in the

Atmosphere

Subpart H - National Emission

EPA

Standards for Emissions of Radionuclides other than Radon

from Department of Energy Facilities 
TABLE 3-7 (page 2)

LIST OF APPLICABLE QUALITY ASSURANCE

REGULATIONS/REQUIREMENTS/GUIDELINES

Regulations/

Requirements/

Guidelines

Sections/Title

Authority

DOE/EH-0173T

Environmental Regulatory Guide

DOE

for Radiological Effluent Monitoring and Environmental Surveillance

QAMS - 004/80

Guidelines and Specifications for

EPA

Preparing Quality Assurance Program

Plans 
Performance Objective: DOE Order $5700.6 \mathrm{~B}(\mathrm{a})(\mathrm{f})$ states that ANSI/ASME NQA-1 is the preferred standard for quality assurance. NQA-1, Supplement $10 S-1$ states that where a sample is used to verify the acceptability of a group of items, the sampling procedure shall be based on recognized standard practices.

DOE Order 5400.1, Chapter IV(5)(a) states that effluent monitoring shall be conducted at all DOE sites to verify compliance with applicable Federal, state, and local effluent regulations and DOE Orders; and to provide representative measurements of the quantities and concentrations of pollutants in airborne discharges.

40 CFR Part 58, Appendix D, requires that GJPO, as a middle scale facility, requires sampling activities to measure for the highest concentrations expected to occur in the area, and the impact on ambient pollution levels of significant sources.

40 CFR Part 50, Appendix $J$ requires careful handling to avoid the loss of collected particles from the filters. Recognized standard practice for part sampling filter handling practices is further described in ASTM Method D409682 , which emphasizes the need to avoid the loss of any fiber material or collected particulate matter.

Finding: GJPO's siting of samplers and the handling of the particulate filters is not adequate to ensure representative $\mathrm{PM}_{10}$ sampling.

Discussion: The air sampler (AIR-G-1) at the GJPO facility is not sited properly. Building 35 is an obstacle that protrudes approximately six meters above the $\mathrm{PM}_{10}$ sampler's inlet, while the samipler is at most five meters away from the building. Because of its location, AIR-G-1 does not adequately fulfill the monitoring objectives associated with the sampler's middle scale classification, as defined in 40 CFR Part 58, Appendix D. These objectives include the measurement of: a) the highest concentrations expected to occur in the area, and b) the impact on ambient pollution levels of significant sources (i.e., the tailings piles and excavation activities). Building 35 is located directly between the tailings piles and the dike, thereby sheltering the sampler.

PM $_{10}$ samplers AIR-G-2, AIR-G-3 and AIR-G-7 are situated near unpaved roads and/or over unpaved areas which can potentially bias sample loadings and give higher concentrations than actual ambient levels. In addition, the samplers would be more representative of the facility's airborne effluent impact on the surrounding areas if placed along or outside the site's perimeter. Currently, samplers AIR-G-2 and AIR-G-7 are more centrally located at the GJPO facility.

Geotech's operational procedure impacts all $\mathrm{PM}_{10}$ samplers. Sampler operation and maintenance were conducted according to the recommended method. However, the handling of unexposed and exposed filters did not meet the requirements as specified in 40 CFR Part 50, Appendix J, or ASTM Method D4096-82 which emphasizes the need to avoid the loss of any fiber material or collected particulate matter. The Geotech procedure, Standard Test Method for the 
Detern ination of $\mathrm{PM}_{10}$ Airborne Particulates Using a High Volume Sampler (GRJ0182), references 40 CFR Part 50, Appendix J. However, the actual practice observed by the Audit Team is to place filters in plastic, zip-lock bags which results in fibers from the filters sticking to the inside of the bags. This situation has the potential to lower the exposed filter's final weight, thereby yielding lower than actual airborne particulate concentrations.

It should be noted that not only do the aforementioned concerns affect $\mathrm{PM}_{10}$ reported concentrations, but they also affect the airborne concentrations of natural uranium, $\mathrm{Th}^{230}$ and $\mathrm{Ra}^{226}$. They could also impact the dose assessment model, should the facility include these measurements in its calculations of dose assessment (see Finding RAD/CF-2).

Site's Prior Knowledge: This issue was not addressed in any Self-Assessments conducted at GJPO.

Probable Causal Factors: The apparent causal factors contributing to this finding are inconplete audits/appraisals/review of current standard practices for $\mathrm{PM}_{10}$ sampler siting criteria and sampling procedures by GJPO and policy implementation in that established requirements were not implemented. 
Performance Objective: DOE Order $5700.6 \mathrm{~B}(9)(\mathrm{F})$ states that ANSI/ASME NQA-1 is the preferred standard for quality assurance. NQA-1-1989, Supplement 10S-1, states, "Where a sample is used to verify the acceptability of a group of items, the sampling procedure shall be based on recognized standard practices." DOE Order 5400.1, Chapter IV.5.a.(1) and Chapter IV.5a.(2) state that effluent monitoring shali be conducted at all DOE sites to satisfy the following program objectives: To verify compliance with applicable Federal, state, and local effluent regulations and DOE Orders; to comply with applicable regulations; and to provide representative measurements of the quantities and concentrations of pollutants in liquid and airborne discharges, and solid wastes, respectively.

40 CFR Part 60, Appendix A, Method 1, Section 2 requires that sampling or velocity measurement be performed at a site located at least eight stack or duct diameters downstream and two diameters upstream from any fiow disturbance such as a bend, expansion, or contraction in the stack, or visible flame. If necessary, an alternative location may be selected at a position at least two stack or duct diameters downstream and a half diameter upstream from any flow disturbance. Furthermore, Section 2.5 requires verification of the absence of cyclonic flow in those cases where cyclonic flow may exist.

40 CFR Part 60, Appendix A, Method 5, Section 6.12 (Acceptable Results) states that "if 90 percent $\leq$ I (Isokinetic Variation) $\leq 110$ percent, the (emission sampling) results are acceptable. If the particulate results are low in comparison to the standard, and I is over 110 percent or less than 90 percent, the Administrator may accept the results."

40 CFR Part 61.93(b)(4)(i) states that, "Radionuclide emission measurements in conformance with the requirements of paragraph (b) of this section shall be made at all release points which have a potential to discharge radionuclides into the air in quantities which could cause an effective dose equivalent in excess of $1 \%$ of the standard."

Finding: Dames and Moore's sampling of the GJPO Sample Preparation Laboratory baghouse was not performed in accordance with required standard methods.

Discussion: Air emission sampling of the Sample Preparation Laboratory Baghouse performed October 24-28, 1989 by Dames and Moore's subcontractor, Industrial Hygiene Resources Ltd (IHR), did not meet the criteria specified in the USEPA methods; ANSI N13.1, Section 4.2.1.2 (Guide to Sampling Airborne Radioactive Materials), as referenced in the March 9, 1990 GJPO internal memorandum; or the alternative EPA method described in IHR's April 3, 1990 letter to Dames and Moore. The emission results are not representative for the following reasons: (1) sample ports were installed less than two diameters downstream from the $90^{\circ}$ bend coming from the baghouse and were less than onehalf the stack diameter from a second $90^{\circ}$ bend going into the induction fan, rather than sampling from the straight section of stack upstream of the fan, which is not a standard practice; (2) the sampling procedure did not address 
the cyclonic flow at the sampling location in the stack; and (3) the isokinetic variation for two of these sample runs was less than the $90 \%$ minimum variation required for a valid run per EPA's Method 5. Standard practice would be to accept the sampling results if the isokinetic variation was marginally outside the required criteria, provided there were no other deviations from the method. However, since the sampling location was in question and no cyclonic flows were measured, sampling would not be considered valid.

In addition, the sampling site was upstream from the fan, which had a pre-test stack static pressure equal to -5.5 in $\mathrm{H}_{2} \mathrm{O}$. There is the potential for sample bias at this location as a result of the negative pressure of the stack, and without proper identification of the cyclonic flow, the sample can not be considered representative. Also, the alternative sampling procedure, described in IHR's letter to Dames and Moore (April 3, 1990), did not meet IHR's own criteria.

Finally, the noncompliant baghouse sampling also invalidates GJPO's determination that their baghouse emissions are less than $1 \%$ of the standard and, therefore, their determination that they do not have to measure radionuclide emissions.

Site's Prior Knowledge: GJPO was aware of the need for proper baghouse sampling as described in Geotech's August 23, 1989 letter (GRJ0181), and the Dames and Moore sampling situation through the March 9, 1990 memorandum (GRJ0007). Geotech has received the specified funding from DOE-ID to implement the Sample Plant baghouse upgrade and to perform the required isokinetic emission sampling. This issue was not addressed in any SelfAs sessments conducted at GJPO.

Probable Causal Factors: The causal factor contributing to this finding is an absence of procedures which incorporate both standard stack sampling methods and appropriate health and safety concerns to the sampling crew. 
Performance Objective: DOE Order $5700.6 B(9)(f)$ states that ANSI/ASME NQA-1 is the preferred standard for quality assurance. NQA-1 Basic Requirement 4 states that applicable design bases and other requirements necessary to assure adequate quality shall be included or referenced in documents for procurement of items and services. To the extent necessary, procurement documents shall require suppliers to have a quality assurance program consistent with the applicable requirements of this standard. NQA-1 Basic Requirement 7 states that the procurement of items and services shall be controlled to assure conformance with specified requirements. Such control shall provide for the following as appropriate: source evaluation and selection; evaluation of objective evidence of quality furnished by the supplier; and source inspection, audit, and examination of items or services upon delivery or completion. The Geotech, Inc., Procurement Manual, Secticn 112.1.0 Quality Assurance Policy, requires that procurement shall fully incorporate Quality Assurance (QA) requirements for equipment, materials, supplies, and services as identified by the requisition and its attachments, in all contricts.

Finding: Geotech, Inc., did not obtain copies of the written procedures and/or the required quality assurance program plan or the State of Colorado Laboratory Certification from Grand Junction Laboratories, an outside contractor, and did not perform the required on-site appraisal of this laboratory. Geotech has not received Tech/Ops Landauer, Inc.'s written procedures.

Discussion: Geotech, Inc., procured the services of Grand Junction Laboratories to analyze biological oxygen demand (BOD), chemical oxygen demand (COD), and total organic halogenated compounds (TOX), but did not have copies of Grand Junction Laboratories' written procedures or quality assurance plans available for inspection on-site. BOD analysis is required for Manhole \#12 effluent sampling pursuant to the City of Grand Junction/Mesa County Class II Industrial Pretreatment Permit No. 0023 issued to Geotech. COD and TOX are monitored, but are not required by Permit No. 0023. Geotech has not conducted on-site inspection as required by NQA-1.

Geotech also has contracted the Tech/Ops Landauer, Inc., laboratory services for the analysis of track-etch radon monitors without obtaining standard operating procedures, but has received a MIL-STD-45208A QA/QC manual as required in Geotech's Statement of Work (GRJ0185). Geotech has not conducted regular, on-site inspections as required. Geotech does have a three-tiered quality control program in place that includes double blind "controls" and two types of blind "controls."

GJPO could not provide any evidence that the required contractor QA procedures were evaluated for Grand Junction Laboratories prior to the procurement of their services.

Site's Prior Knowledge: GJPO had not identified the Grand Junction Laboratory finding as part of a previous self-assessment or audit. GJPO did not recognize the need to obtain Tech/Ops Landauer, Inc.'s procedures. 
Probable Causal Factors: The apparent causal factors contributing to this finding are policy implementation in that the requirements specified in $D O E$ Order 5700.6b were not implemented, and inadequate appraisals/audits/review that failed to identify these problems at a later date. 
Performance Objective: Analytical Chemistry Laboratory's Administrative Plan and Quality Control Methods states in QP-1, Section 1.9 (Quality Assurance) that "The laboratory will operate within the framework of the Geotech Quality Assurance Manual, as directed by the Analytical Lab Manager." Criterion 6, Document Control, in the Quality Assurance Manual has a "Standard" QA requirement that states, "A system must be established and implemented for the control of documents. The system shall assure that current and correct documents are available to personnel where the work is performed . . ."

Finding: Method C-3, Determination of Gross-alpha and Gross-beta Activity of Water Samples (Revision 02, July 10, 1987), as described in Geotech's Handbook of Analytical and Sample-Preparation Methods, was not updated to include Americium-241 ( $\left.{ }^{24} \mathrm{Am}\right)$ as an alternate standard for Uranium-236 ( $\left.{ }^{236} \mathrm{U}\right)$; and no documented procedures existed for a laboratory information management system database.

Discussion: Geotech Analytical Chemistry Laboratory performs the radiochemical analysis for gross-alpha and gross-beta by Method C-3, which specifies ${ }^{236} \mathrm{U},{ }^{90} \mathrm{Sr}$, and ${ }^{90} \mathrm{Y}$ as the standards to be used in the calibration procedure. For some gross-alpha and gross-beta water sample analyses, ${ }^{241} \mathrm{Am}$ was used as an alternate standard for ${ }^{236} \mathrm{U}$. This procedural change was not documented in the current facility version of Method C-3, Determination of Gross-alpha and Gross-beta Activity of Water Samples (Revision 02, July 10, 1987). However, laboratory staff were aware of this change in the procedure, performed analysis accordingly without an updated version, and made appropriate entries on the laboratory bench/work sheets indicating the calibration standards used in the analyses when applicable. In addition, laboratory personnel document procedure deviations on worksheets which are verified by a senior scientist and included as part of the data report.

In addition, there were no procedures for the operation of the laboratory database computer program. The database system is used to store sample results and generate data package reports. A new laboratory information management system (LIMS) is scheduled to be in use by year-end 1991, and the facility does not anticipate documenting procedures for the current system (QA-009).

Site's Prior Knowledge: Geotech was aware that Method C-3 required an update by Apri1 21, 1991 (QA-028).

Probable Causal Factors: The apparent causal factors are inadequate policy implementation and inadequate appraisals/audits/reviews that would have identified the problems. 
QA/BMPF-1 Effluent Sampling Security

Performance Objective: DOE Order 5700.6B(9)(f) states that ANSI/ASME NQA-1 is the preferred standard for quality assurance. NQA-1, Supplement 8S-1 states that specific requirements be employed in the program identification and traceability of items (i.e., samples). Geotech's Environmental Procedures Catalog (GR.j0046), Procedure GN-9(P), Standard Practice for Chain-of-SampleCustody Control defines custody as follows: "to have within sight, immediate possession, or locked under your personal control."

Finding: Tthe 24-hour Manhole \#12 effluent sampling container was not secured with a lock to preverit possible tampering.

Discussion: No provisions have been made to secure, with a lock, the 24-hour sample collected at Manhole \#12 as per the City of Grand Junction/Mesa County Industrial Pretreatment Permit No. 0023 (I-QA-27). Immediately after this finding was discussed with GJPO, a padlock was installed on the composite sampler.

Site's Prior Knowledge: This issue was not addressed in any Self-Assessments conducted at GJPO.

Probable Causal Factors: The apparent causal factors contributing to this finding are inadequate policy implementation and inadequate appraisal/audits/reviews of the effluent sampling activities. 


\section{QA/BMPF-2 Completion of Hazard Waste Shipping Documents}

Performance Objective: Geotech GJPORAP Quality Assurance Project Plan (QAPP), Criterion 13, states "When applicable, organizations must establish procedures appropriate to their work for shipping, handling and storing items (test specimens and samples, materials, equipment, components, and designated waste materials) to preclude deterioration or damage to the item or environment." Geotech, Inc. Supply, Property, and Transportation Manual, Procedure XXXHMT003, Preparation of Hazardous Material Shipping Papers, states, "The qualified shipper is responsible for reviewing and certifying that the shipment is properly classified, described, packaged, marked, and labeled and in proper condition for transportation according to the applicable regulations of the Department of Transportation."

Finding: Geotech shipping documents (GRJ0054) have inconsistencies with respect to the specified procedures and with respect to each other.

Discussion: A review of Geotech's Shipping Documents (GRJ0054) for 55-gallon drums of Asbestos steam pipe lagging removed from uranium mill tailing contaminated soils showed deficiencies in their completion. Examples of the deficiencies include cross-outs without proper initials and dates, missing shipping dates, missing survey numbers, missing "Received in Good Condition by Consignee Except as Noted" signatures, no shipping, packaging and transportation authorization signatures, no warehouse signatures, and/or no receipt signature under company name.

Site's Prior Knowledge: This issue was not addressed in any Self-Assessments conducted at GJPO.

Probable Causal Factors: The apparent causal factors contributing to this finding are inadequate supervision for implementation of procedures, inadequate training, and insufficient appraisals/audits/reviews of the shipping documents. 


\section{QA/BMPF-3 Environmental Protection Implementation Plan}

Performance Objective: DOE Order 5400.1 Chapter III.2 states, "Each field organization shall prepare a plan for implementing the requirements of this Order." Best Management Practice suggests that environmental protection documents be technically accurate.

Finding: The Environmental Protection Implementation Plan (EPIP), Section 2, contains technical inaccuracies about effluents from the site.

Discussion: The GJPO EPIP (GRJ0019) does not adequately address effluents from the site. Page 2-1 of the EPIP states, "GJPO facility air emissions and liquid effluent discharges are limited to those that originate from the Sample Preparation Facility and the Radon and Analytical Laboratories, which are operated in support of a variety of remedial action programs. All liquid effluents are directed to the city/county operated Publicly Owned Treatment Works (POTW) under conditions established in an Industrial Pretreatment Permit administered by the City of Grand Junction." The EPIP in Section 2 is incomplete in that it does not address air emissions from the tailings piles, the calibration test pits, the sample storage area, or the Oak Ridge National Laboratory sample preparation facility. These were addressed in Chapter 5 of the EPIP, which is also incomplete in that it also does not address liquid discharges through groundwater.

Site's Prior Knowledge: This finding was not identified in any SelfAssessment conducted at the GJPO, although the facility has identified issues that are is related to review of reports.

Probable Causal Factors: The apparent causal factor contributing to this finding is inadequate quality assurance in that this finding was not previously identified. 
This page was intentionally left blank. 


\subsubsection{Overview}

The purpose of the radiation portion of the Baseline Environmental Audit was to evaluate the Grand Junction Projects Office's (GJPO) compliance with applicable Department of Energy (DOE), Federal and state regulations, and conformance with referenced guidelines commonly accepted industry performance standards, and Best Management Practices (BMP). Radiation issues were evaluated against the applicable guidelines and regulations listed in Table 3-8.

The general approach to the radiation portion of the Basel ine Environmental Audit included a site document review of the environmental monitoring program, dose calculation methodologies, and radiological procedures; interviews with Site Contractor personnel; field observations of current. environmental radiation protection practices; and reviews with other members of the Audit Team to ensure that all potential environmental radiation issues were evaluated in sufficient detail.

Programs and systems to control and monitor radiological releases and to evaluate the environmental impact of radiological contamination have been developed and implemented by GJPO. Of particular interest from an environmental radiological viewpoint are potential airborne radiological emissions. Airborne emissions from the GJPO are mainly fugitive emissions from the tailings piles and emissions from Sample Preparation Facility (Baghouse).

Liquid effluents include stormwater run-off, sanitary sewer discharge, and groundwater. There is extensive groundwater contamination from previous GJPO operations.

GJPO generates small quantities of low-level radioactive and mixed wastes and has an extensive commingled waste management program. Low-level radioactive waste is stored on-site in Building 36, while mixed and commingled wastes are stored on-site in Building 42 .

The radiation portion of the Baseline Environmental Audit identified five compliance issues related to: reports of radioactive effluents; monitoring of emissions for reporting doses to the public; emergency preparedness planning; waste management system performance assessment; and waste acceptance criteria. In addition, three BMP findings were identified related to: meteorological monitoring program; minimization of generation of contaminated material; and Annual Site Environmental Report. 
TABLE 3-8

LIST OF APPLICABLE RADIATION

REGULATIONS/REQUIREMENTS/GUIDELINES
Regulations/

Requirements/

Guidelines

DOE Order 5400.1

DOE Order 5400.3

DOE Order 5400.5

DOE/EH-0173T

DOE Order 5480.4

DOE Order 5480.11

DOE Order 5480.19

DOE Order 5500.3

DOF Order $5820.2 \mathrm{~A}$

DOE Order SEN-7A

10 CFR Part 20

\section{Sections/Title}

General Environmental Protection Program

Hazardous and Radioactive Mixed Waste Program

Radiation Protection of the Public and the Environment

Environmental Regulatory Guide for Radiological Effluent Monitoring and Environmental Surveillance

Environmental Protection, Safety and Health Protection Standards

Radiation Protection for Occupationa? Workers

Conduct of Operations Requirements for DOE Facilities

Reactor and Nonreactor Nuclear Facility Emergency Planning Preparedness and Response Program for DOE Operations

Radioactive Waste Management Policy on Line Management's Responsibility DOE to Achieve Environmental Compliance

Standards for Protection Against Radiation
DOE

Authority

DOE

DOE

DOE

DOE

DOE

DOE

DOE

DOE

NRC 
TABLE 3-8 (Page 2)

LIST OF APPLICABLE RADIATION

REGULATIONS/REQUIREMENTS/GUIDELINES

Regulations/

Requirements/

Guidelines

10 CFR Part 834 (Draft)

40 CFR Part 61 , Subpart H

40 CFR Part 61 , Subpart Q

40 CFR Part 192

ANSI N13.1-1969

ASME NQA-1

Code of Colorado

Regulations, Title 5

Code of Colorado

Regulations, Title 5

Code of Colorado

Regulations, Title 5
Sections/Title

Authority

Radiation Protection of the Public and the Environment

National Emission Standards for

EPA

Emissions of Radionuclides Other than

Radon from DOE Facilities

National Emission Standards for Radon

EPA Emissions from DOE Facilities

Health and Environmental Protection

Standards for Uranium and Thorium Mill

Tailings

Guide to Sampling Airborne Radioactive Materials in Nuclear Facilities

ANSI

Quality Assurance Program Requirements

ASME for Nuclear Facilities

$\mathrm{CDH}$

Colorado Air Pollution

Control Regulations

Colorado Water Quality Control Act

$\mathrm{CDH}$

Colorado Ground Water Standards

$\mathrm{CDH}$ 
Performance Objective: DOE Order 5400.1 Chapter II(5)(a) states, "Radioactive Effluent and On-site Discharge Data Reports covering the previous calendar year shall be submitted to the Waste Information Systems Branch, EG\&G Idaho, Inc., Idaho Fails, Idaho 83415, by April 1; a copy of the cover letter shall be sent to EH-1."

Finding: The Radioactive Effluent and On-site Discharge Data Reports are not submitted as required by DOE Order 5400.1.

Discussion: The Grand Junction Projects office (GJPO) Environmental Protection Implementation Plan (FPIP), on page 2-3, states, "Because of the limited nature and extent of air emissions and liquid effluent discharges from GJPO, there presently are no established procedures for preparing and submitting Radioactive Effluent and On-site Discharge Data Reports to the Waste Information Systems Branch, EG\&G Idaho." Discussions with personne] revealed that Geotech considered that they were exempt from submitting this report by the U.S. Department of Energy Idaho Operations Office EPIP and so do not submit the reports as required by DOE Order 5400.1 (I-RAD-25).

There is also a concern associated with this finding in that the oversight office for Grand Junction, DOE Idaho, the Waste information Systems Branch, and $E H$ all failed to recognize that the required reports were not being submitted.

Site's Prior Knowledge: This issue was not addressed in any Self-Assessments conducted at GJPO.

Probable Causal Factors: The probable causal factors contributing to this finding appear to be inadequate policy implementation in that the requirements of DOE Order 5400.1 were not complied with and inadequate appraisals/audits/reviews by Geotech, DOE-ID and DOE-EH in that this finding was not previously identified. 
Performance Objective: 40 CFR Part 61, Subpart H lists the "National Standards for Emissions of Radionuclides Other than Radon for Department of Energy Facilities." 40 CFR Part 61.94 contains the compliance and reporting requirements for the National Emission Standards for Hazardous Air Pollutants (NESHAPs) and states, "Compliance with this standard shall be determined by calculating the highest effective dose equivalent to any member of the public at any off-site point where there is a residence, school, business or office. The owners or operators of each facility shall submit an annual report to both EPA headquarters and the appropriate regional office by June 30 which includes the results of the monitoring as recorded in DOE's Effluent Information System and the dose calculations required by 40 CFR Part 61.93(a) for the previous calendar year."

40 CFR Part 61.93(a) states, "To determine compliance with the standard, radionuclide emissions shall be determined and effective dose equivalent values to members of the public calculated using EPA approved sampling procedures, computer models CAP-88 or AIRDOS-PC, or other procedures for which EPA has granted prior approval." 40 CFR Part 61.93(b)(4)(i) addresses the sampling requirements in accordance with paragraph 61.93 (b) and requires, "periodic confirmatory measurements shall be made to verify low emissions," for release points which have demonstrated that emissions will cause an effective dose equivalent less than $1 \%$ of the standard $(0.1 \mathrm{mrem})$.

DOE Order 5400.5 Chapter II(1) requires compliance with 40 CFR Part 61. DOE Order 5400.5 Chapter II(6) states, "Compliance with the dose limits of this Order shall be demonstrated by documentation of an appropriate combination of measurements and calculations to evaluate potential doses and the results of the evaluations."

DOE Guidance Document "Environmental Regulatory Guide for Radiological Effluent Monitoring and Environmental Surveillance (DOE/EH-0173T), Chapter 8.1 states, "The information used in dose assessments should be as accurate and realistic as possible." DOE/EH-0173T, Chapter 8.0 states, "The off-site dose estimates require detailed knowledge (or estimates) of the concentrations of radionuclides in the facility effluents and emissions and in various environmental media resulting from site operations."

Finding: Monitoring of emissions for determining doses to the public was not performed in accordance with 40 CFR Part 61, DOE Order 5400.5, and DOE/EH0173T.

Discussion: Monitoring of effluents from the Sample Preparation Facility Baghouse were not performed during 1990 to provide inputs for the dose models used to calculate doses to the public from operations at the facility. Because no effluents estimates were performed, doses to the public were calculated using parameters obtained during 1989 sampling of the Baghouse. Use of these data is not valid for estimating doses to the public from 1990 operations. Also, the 1989 data were deemed during the Audit to be invalid (see Finding $Q A / C F-2$ ) and so in effect both the 1989 and 1990 dose estimates

$$
\text { 3-70 }
$$


are invalid. The site (I-RAD-25) responded that Baghouse sampling was not performed as required by 40 CFR Part $61.93(\mathrm{~b})(4)(i)$ because of delays in DOEID and DOE-HQ approval of the NEPA permits required to perform the sampling.

It also should be noted that the facility does not use available particulate monitoring data in its dose assessment model, although the inclusion of reliable measurements at the site would be appropriate and advisable. Should the facility decide to incurporate site air emission measurements in the model, it must first improve its methods of data collection for both baghouse and perimeter particulate monitoring (see Finding $Q A / C F-1$ ). Use of the present site particulate monitoring would aiso be deemed invalid because of the inadequacy of perimeter particulate monitoring (see Finding QA/CF-1).

Site's Prior Knowledge: GJPO was aware of the finding, but it was not addressed in any Self-Assessments.

Probable Causal Factors: The probable causal factors contributing to this finding are inadequate policy implementation in that established requirements were not implemented, inadequate procedures for air emission sampling, and barriers/controls related to DOE HQ failure to obtain NEPA approval for sampling. 
Performance Objective: DOE Order 5500.3 "establishes the requirements for the development of Department of Energy (DOE) site specific emergency plans and procedures for the radiological emergencies occurring in existing or planned DOE reactors and nonreactor nuclear facilities." One of the purposes of the emergency planning documents is to ensure that procedures are in place to provide for protection of the public and the environment in the event of an emergency at a DOE facility. The purpose of Attachment 1 of the Order "is to establish the minimally acceptable criteria for the development of site specific emergency plans and procedures for radiological emergencies occurring at DOE reactor and nonreactor nuclear sites." Section 2 of Attachment 1 states that the requirements for the plan, "shall be addressed in the written documents of the emergency planning, preparedness and response programs of all DOE organizations and contractors. The degree of implementation of each of these requirements will depend upon the facilities, operations, and the identified potential emergencies. Safety analysis reports, environmental impact statements, and similar documents may be helpful in the identification of such emergencies."

Finding: The GJPO Emergency Preparedness and Response Plan (EPRP) and Emergency Preparedness Program do not address radiological emergencies (and provide for protection of the public and the environment) as required by DOE Order 5500.3.

Discussion: GJPO currently has one-half man-year devoted to the preparation of emergency response documents. Included in this staffing are the requirements for document preparation, drill preparation, and interface with outside agencies. The emergency preparedness specialist (I-RAD-29) was aware of the requirements of the Draft DOE Order 5500.3A and is in the process of incorporating some of the requirements into the GJPO EPRP. Allotted staffing does not appear to be adequate to properly implement the requirements of DOE Order 5500.3.

GJPO questions the applicability of DOE Order 5500.3, in that it may not be a "nuclear facility." This position is supported to some extent by contracting and legal issues (i.e., DOE-ID has determined that the site is not covered by the Price-Anderson Act). However, the site could not produce a written, formal determination, or other documentation sufficient to demonstrate nonnuclear status. GJPO has initiated development of a site Safety Analysis Report (SAR) and plans to use the SAR to force a formal determination of the facility's nuclear/non-nuclear status.

The GJPO EPRP does not address many of the functional areas identified in Attachment 1 to DOE Order 5500.3. Many of the omitted functional areas provide information or actions necessary for protection of the public and the environment in the event of an radiological emergency at GJPO. The following are examples of how GJPO in not in compliance with the DOE Order:

- The GJPO Safety Analysis Report (SAR) is in the process of being written by a contractor. 
- Radiological emergency planning zones are not defined pending completion of the SAR.

- Protective Action Guidelines (PAG) for identification of emergency event classification have not been defined pending completion of the SAR.

- Source terms and potertial roleases have not been identified pending completion of the SAR.

- GJPO has no off-site team designations, but instead relies on site staff during an emergency to provide personnel for monitoring. These personnel do not receive emergency response training as required by the DOE Order.

- GJPO has no emergency response teams, and relies on the Grand Junction Fire Department (GJFD) Haz Mat Team to respond to on-site emergencies. This could have deleterious effects if there is an emergency response required at GJPO while the GJFD Haz Mat Team is responding to another emergency.

- GJPO has no Memoranda of Understanding (MOU) with off-site agencies such as the GJFD or local hospitals to deal with on-site emergencies or treatment of radiologically contaminated, injured personnel, although discussions are well underway between all parties to reach the required agreement.

- GJPO has not performed a radiological emergency response drill in at least three years, al though the facility has performed annual nonradiological emergency response drills.

The above listing represents a sampling of areas which are not part of the current EPRP, but which are required for GJPO 20 be in compliance with DOE Order 5500.3.

Site's Prior Knowledge: The site was aware of this finding, but had not addressed it in any self-assessments.

Probable Causal Factors: The probable causal factors contributing to this finding are inadequate policy implementation in that the requirements of DOE Order 5500.3 have not been implemented, and inadequate resources in that sufficient manpower has not been allocated to meet the requirements of 5500.3. 
Performance Objective: DOE Order 5820.2A Chapter III.3.b.2 states, "Each field organization shall, for each DOE reservation within its cognizance, prepare and maintain an overall waste management system performance assessment supporting the combination of waste management practices used in generation, reduction, segregation, treatment, packaging, storage, and disposal."

Finding: Grand Junction Projects office (GJPO) has not performed an overall Waste Management System Performance Assessment as required by DOE Order $5820.2 A$.

Discussion: No overall Waste Management System Performance assessment has been prepared for GJPO radioactive waste storage facilities. The GJPO generates small quantities of low-level radioactive and mixed wastes. The annual quantities of waste estimated in ThE GJPO Waste Minimization Program Plan (GRJ0015) are 949 pounds of low-level waste and 194 pounds of mixed waste. The low-level waste is stored on-site in Building 36 and the mixed waste is stored on-site in Building 42 .

The GJPO personnel are aware of the requirement for an overall waste manägement performance assessment, but believe that not all requirements are nece!;sary for GJPO. They consider the relatively small quantities of waste stored on-site to pose little threat to the public, and the guidance for the assessinent describes a fairly extensive process (I-RAD2-23, GRJ0176).

Site's Prior Knowledge: GJPO raised this issue in a document entitled, GJPO Waste Management Plan Annual Update (GRJ0015).

Probable Causal Factors: The apparent causal factors contributing to this finding are inadequate policy implementation in that responsible DOE-GJPO and Geotech personnel have not implemented established DOE policy, and resources in that this process requires significant investment of personnel. 
Performance Objective: DOE Order 5820.2A, Chapter III(3)(e)(5) states, "The waste acceptance criteria for storage, treatment, or disposal facilities shall address the following issues: (a) Allowable quantities/concentrations of specific radioisotopes to be handled, processed, stored or disposed of; ... (d) External radiation and internal heat generation;.... [and] (g) Restrictions for chelating and complexing agents having the potential for mobilizing radionuclides..."

Finding: The waste acceptance criteria established for the GJPO low-level and mixed waste storage facilities do not address the issues of allowed quantities and concentrations of radioisotopes, external radiation levels, or restrictions for chelating agents in the waste form, as required by DOE Order 5820.2A.

Discussion: GJPO generates and stores, on-site, low-level and mixed radioactive waste. As a consequence, GJPO is required to develop waste acceptance criteria for these on-site waste storage areas to ensure environmentally safe storage. The Waste Form Requirements chapter of the "U.S. Department of Energy Grand Junction Projects Office Waste Acceptance Criteria for On-Site Radioactive, Hazardous, and Mixed Waste Storage" (GRJ0015) does not address allowed quantities and concentrations of radioisotopes, external radiation levels, or restrictions for chelatioll agents for waste packages accepted into the waste storage facility. Failure io $^{\circ}$ address these criteria may result in waste acceptance into the storage facilities which the storage facilities cannot safely contain.

Site's Prior Knowledge: GJPO was aware of this finding which was identified in a prior Self-Assessment (GRJ0015).

Probable Causal Factors: The apparent causal factor contributing to this finding is inadequate policy implementation in that the requirements of DOE order 5820.2A have not been properly implemented. 
Performance Objective: DOE Order 5400.1 Chapter II(4)(b) states, "[Annual Site Environmenta1] Reports [ASERs] shall be prepared for all sites that conduct significant environmental programs." Attachment II to DOE Order 5400.1 states, "The report should be of the high quality typical of DOE and contractor technical and public reports."

Attachment II.5 to DOE Order 5400.1 states, "The total quantity of radioactivity by radionuclide released as airborne and liquid effluents should be included, along with descriptive information on nonradioactive effluents." Section 8.a of Attachment II to DOE Order 5400.1 states, "Effluent data for radionuclides should be summarized. The nuclides of concern and the total number of curies in airborne and liquid effluents released to the offsite environment should be included in the portion of the report dealing with air and water monitoring, respectively."

Section 8.d of Attachment II to DOE Order 5400.1 details the reporting units to be used in reporting radiological data.

Finding: The Annual Site Environmental Reports (ASER) for 1989 and 1990 contain technical inaccuracies and do not present all data as required in DOE Order 5400.1.

Discussion: The following technical inaccuracies were noted in the 1989 and 1990 ASERs:

- The 1990 ASER Appendix lists the uranium effluent data in $u C i / m 1$, but the numbers reported are in the $1 \times 10^{-3}$ range. These reporting units appears to be in error as the uranium effluent values, in $u C i / m 1$, are in the $1 \times 10^{-12}$ range.

- The ASERs state in the introductions, "No point-source discharges or waste treatment activities occur on the Facility." DOE Guidance Document, "Environmental Regulatory Guide for Radiological Effluent Monitoring and Environmental Surveillance" (DOE/EH-0173T) defines a point source as "the single defined point (origin) of an airborne release such as a stack or a vent." The site has numerous point source discharges including the Sample Preparation Facility, the Radon Laboratory, and the Oak Ridge National Lab Sample Preparation Facility.

- The 1989 ASER referenced DOE Order 5480.1 and made comparisons to the airborne limits 1 isted in that Order. DOE Order 5400.1 references the airborne limits contained in DOE Order 5480.11, which are different than the limits 1isted in DOE Order 5480.1. DOE Order 5400.1 supersedes DOE Order 5480.1 and was in effect at the time this report was issued. Therefore, the limits specified by DOE Order 5400.1 should have been referenced.

The following items are not reported as suggested by DOE Order 5400.1: 
- The 1989 and 1990 ASERs do not include in the summary or in the environmental radiological program information sections the total number of curies by radionuclide released by the site.

- The ASERs do not report air releases for uranium and thorium in $\mathrm{pg} / \mathrm{ml}$.

Site's Prior Knowledge: This issue was not addressed in any Self-Assessments conducted at GJPO.

Probable Causal Factors: The apparent causal factors contributing to this finding are inadequate training of personnel in the requirements of DOE Order 5400.1 regarding ASERs, inadequate appraisals/audits/reviews since this finding was not previously identified, and policy implementation in that the requirements of 5400.1 were not implemented in GJPO ASERs. 
Performance Objective: It is considered Best Management Practice to avoid contacting clean material with contaminated material to avoid the possibility of contaminating the clean material.

Finding: GJPO is contaminating potentially clean (see Finding SW/BMPF-1) stormwater runoff by directing the runoff into the radiologically contaminated North Pond.

Discussion: Stormwater runoff is collected from the northern two-thirds of the facility. This runoff is assumed to be radiologically clean and is carried into the North Pond through a series of drains and an underground collection system. The North Pond is noted in the 1990 Annual Site Environmental Report as being historically radiologically contaminated by uranium "because of recharge from the shallow alluvial aquifer underlying the Facility." Directing the radiologically clean stormwater runoff into the radiologically contaminated North Pond results in the storm water becoming contaminated by mixture with the contaminated North Pond water. This would be analogous to directing clean storm water runoff into a process lagoon at an industrial facility. GJPO is being remediated at the present time and all contaminated pond sediments will be removed by 0ctober, 1992. However, until the remediation is complete, Best Management Practice suggests keeping radiologically clean material segregated from radiologically contaminated material in order to minimize the volume of contaminated material.

Site's Prior Knowledge: This finding was not identified in any SelfAssessment conducted at the GJPO; however, the site was aware of the radiologically clean water contacting the radiologically contaminated water.

Probable Causal Factors: The apparent causal factors contributing to this finding appear to be inadequate policy with regard to the minimization of the volume of radiological materials produced as a result of GJPO activities, and the regulatory and environmental risks involved in such activities. 
Performance Objective: DOE Order 5400.1, Chapter IV(6) states, "Representative meteorological data are required at DOE facilities to support environmental monitoring activities."

DOE Guidance Document "Environmental Regulatory Guide for Radiological Effluent Monitoring and Environmental Surveillance" (DOE/EH-0173T), Chapter 4.0 states, "Each DOE site (facility) should establish a meteorological monitoring program that is appropriate to the activities at the site, the topographical characteristics of the site, ..."

DOE/EH-0173T, Chapter 4.0 states, "Some sites may choose to establish a meteorological program that makes use of meteorological measurement obtained from off-site sources such as the National Weather Service. For data from an offsite source to be acceptable, the data should be representative of conditions at the DOE facility and provide statistically valid, hourly data consistent with on-site monitoring requirements."

DOE/EH-0173T Chapter 4.4.1 states, "Wind measurements should be made at a sufficient number of heights to adequately characterize the wind at potential release heights. At a minimum, wind measurements should be made at a height of $10 \mathrm{~m} . "$

DOE/EH-0173T, Chapter 4.6 states, "Inspection, maintenance, and calibrations should be conducted in accordance with written procedures, and logs of the inspections, maintenance, and calibrations should be kept and maintained as permanent records. All systems should be calibrated semiannually, unless system performance indicates that more frequent calibrations are necessary. The instrument system should provide data recovery of at least $90 \%$ on an annual basis for wind direction, wind speed, atmospheric stability, and other meteorological elements required for dose assessment."

Finding: The current meteorological monitoring program for the GJPO does not meet the requirements of DOE Order 5400.1, Chapter IV, which becomes effective in November 1991, and DOE/EH-0173T.

Discussion: DOE Order 5400.1, Chapter IV(6) requires that representative meteorological data be used to support environmental monitoring activities at DOE facilities. DOE/EH-0173T requires that off-site sources of meteorological measurements must be representative of conditions on-site. Currently, the Grand Junction Projects office (GJPO) is using meteorological data from Walker Field, which is five miles from the GJPO, for off-site dose assessment. However, GJPO is situated within the valley of the Gunnison River. Discussions with personnel revealed that the local topography creates a microclimate around GJPO (I-RAD2-15). This micro-climate will cause a difference in the local wind speed and wind direction between GJPO and Walker Field. Therefore, the meteorological data collected at Walker Field may not be representative of the conditions at GJPO. 
The current on-site meteorological station is not adequate to collect the meteorological data required by DOE Order 5400.1 and DOE/EH-0173T. Wind speed data from the on-site meteorological station included in the "Environmental Monitoring Report on the U.S. Department of Energy's Grand Junction Projects Office Facility, Grand Junction, Colorado, for Calendar Year 1989" (GJR0014). The wind speed and wind direction are monitored at a height of about 10.5 feet above the ground, which is below the release height of some of the site discharge points and less than the 10 meters recommended by DOE/EH-0173T.

There has been no calibration for wind speed and wind direction for the meteorological station as required by DOE/EH-0173T. Meteorological data are recorded on a magnetic tape, which is reported to result in about $75 \%$ data recovery (RAD2-16). This data recovery percentage is 1ess than the $90 \%$ data recovery required by DOE/EH-0173T.

The site has purchased a new meteorological station which is projected to be installed in the summer of 1991 to meet the requirements of DOE/EH-0173T.

Site's Prior Knowledge: GJPO was aware of this finding. The finding was identified in a GJPO Self-Assessment (GRJ0041).

Probable Causal Factors: The apparent causal factor contributing to this finding is inadequate meteorological monitoring procedures. 
This page was intentionally left blank. 


\subsection{Inactive Waste Sites}

\subsubsection{Overview}

The inactive waste sites portion of the Baseline Environmental Audit of evaluated the compliance of the facility relative to the identification and management of past disposal sites and spills or releases of hazardous substances.

The GJPO inactive waste sites were evaluated against applicable laws, regulations, and U.S. Department of Energy (DOE) Orders, including the Comprehensive Environmental Response, Compensation, and Liability Act (CERCLA), as amended by the Superfund Amendments and Reauthorization Act of 1986 (SARA); the National $0 i 1$ and Hazardous Substances Pollution Contingency Plan (NCP); the provisions of the Emergency Planning and Community Right-toKnow Act (EPCRA) of 1987, Title III of SARA; applicable DOE Orders, and GJPO policies and procedures.

The standards and regulations used for evaluating the inact ve waste sites at GJPO are shown in Table 3-9. In particular, the requiremenis of CERCLA and SARA, in 40 CFR Part 300, are implemented to ensure the over 11 protection of the public health and the environment from the risks associated with the GJPO facility. Specific hazards at GJPO include organics, heavy metals, asbestos, and radioactive and commingled waste contamination. These hazards are found in the site's abandoned buildings and are associated with uranium mill tailing contamination of the soil, surface water, sediments and groundwater at the site.

Initial characterization of the inactive waste sites at GJPO began in 1984 with studies of the abandoned mill buildings when the facility was accepted into the DOE Surplus Facilities Management Program (SFMP). In 1988, the facility's remedial programs were transferred into DOE's Decontamination and Decommissioning (D\&D) Program. These programs include surveillance, maintenance, and decommissioning of surplus DOE facilities that are radioactively contaminated.

The hazards associated with the uranium mill tailings were originally investigated following the guidelines set forth in the Uranium Mill Tailings Radiation Control Act of 1978 (UMTRCA). The characterization and remedial action studies under the UMTRCA guidelines were initially compiled into an Environmental Assessment (EA) under the National Environmental Policy Act (NEPA) process which was submitted to DOE headquarters in January, 1987. However, in October, 1986, the Superfund Amendments and Reauthorization Act (SARA) was passed by Congress, and a decision was made to reevaluate the facility under the CERCLA process in early 1987. DOE Order 5400.4, CERCLA Requirements, states that it is DOE policy to respond to releases and potential releases of hazardous substances from any facility under DOE jurisdiction, custody or control in accordance with the provisions of CERCLA as amended, as well as those of the National Contingency Plan. (NCP) and Executive Order 12580, "Federal Compliance With Pollution Control Standards." The response actions covered under the Order shall be "as appropriate" to 
reduce adverse impacts on the public health and the environment whether or not the facility is listed on the National Priorities List (NPL).

Under CERCLA, a Hazard Ranking System score (14.6) was prepared that determined that the site did not warrant inclusion on the NPL (a score of at least 28.5 is required to be placed on the NPL). Correspondence between GJPO and EPA Region VIII and interviews with EPA, DOE, and Geotech have documented that because the site did not rank on the NPL, EPA policy did not require GJPO to enter into a Federal Facilities Agreement with EPA, nor did EPA desire to participate in the Remedial Investigation/Feasibility Study (RI/FS) process. In addition, the building decontamination and demolition studies which had been ongoing were incorporated into the GJPO RI/FS and included the former facility mill Buildings $31,33,34$, and 35. The joint CERCLA/NEPA RI/FS EA was released to the public in April 1989, followed by a Record of Decision (ROD) in Apri1, 1990.

The ROD selected a remedy which called for the co-disposal of the mill tailings from GJPO (approximately 89,000 cubic yards) with those of the Uranium Mill Tailings Remedial Action (UMTRA) project at the State-Owned Temporary Repository in Grand Junction. These radioactive mill tailings would then be transported to the final UMTRA disposal site, the Cheney Reservoir. In addition, the ROD included the decontamination of the surplus mill Buildings $31,33,34$ and 35 through vacuuming and/or chemical washing.

Following the ROD in 1989, contamination was detected in Building 6 . Alternatives were considered and demolition was selected as the viable option. At the suggestion of DOE Office of Environmental Restoration and Management (EM), no formal decision document was prepared to include the Building 6 project. During remedial activities, work on Building 31 was suspended. The building was reassessed when higher and additional levels of contamination than was originally found in the 1985 building survey were discovered. As a result, no decision has been made concerning Building 31 's ultimate fate, i.e., decontamination, restricted or unrestricted release, or demolition.

Some portions of remedial construction occurred under the D\&D program prior to the decision to follow CERCLA and the ROD issuance. These activities included underground storage tank (UST) removal in August, 1988, asbestos removal from Buildings $31,33,34$ and 35 , and disposal and stockpiling of excavated mill tailings beginning in August, 1989. No tailings were removed from GJPO until after the ROD signature.

The remedial activities specified in the ROD are being implemented in a sixphase approach. Phase I activities, which concentrated on the removal of mill tailings from the building surroundings, began in 1989 and continued until March 1990. These tailings were stockpiled on the western portion of the site, and have subsequently been hauled to the State-Owned Temporary Repository. Phase II, the excavation of tailings along the southwest dike area, is presently ongoing. Phase III involves further excavation of the main tailings piles and wetland areas not including the southwest dike area. Work on Phase III began in August, 1990 and was recently suspended as a result of regulatory issues concerning the DOT radiation limits for transportation and because of PCB contaminated tailings. In Phase IV of the remedial action, 
North and South Pond, Treasure Island, and the North Dike, will be remediated. Either the demolition or decontamination of Building 31 and the demolition of Building 6 will occur in Phase $V$ of the remedial action. In Phase VI, the wetlands will be replanted with appropriate wetland species. Overall remedial construction is scheduled to be completed in November 1992.

GJPO was reviewed for SARA Title III compliance and no findings or inadequacies were identified. The facility is in compliance with the existing requirements and GJPO's existing chemical inventories do not contain substances in large enough quantities to exceed the reporting requirements. There have been no releases of hazardous substances or extremely hazardous substances above reportable quantities. GJPO maintains an internal check of purchase orders to ensure that substances remain below their threshold planning quantities.

A total of three findings, including one compliance finding and two Best Management Practice (BMP) findings, were identified during the Baseline Environmental Audit. The compliance finding concerns the lack of proper implementation of DOE Order 5820.2A, specifically concerning the decommissioning of radioactively contaminated facilities. The BMP findings concern a lack of notification of potential natural resource damages to the trustees, and a mistake in the Declaration for the ROD. 
TABLE 3-9

LIST OF APPLICABLE INACTIVE WASTE SITES

REGULATIONS/REQUIREMENTS/GUIDELINES

Regulations/

Requirements/

Guidelines

Sections/Title

Authority

Public Law 96-510

42 U.P.C. Section

9601 et. seq.

Public Law 99-499

42 U.P.C. Section

9601 et. seq

40 CFR Part 300

40 CFR Part 302

40 CFR Part 355

40 CFR Part 370

43 CFR Part 11

Comprehensive Environmental Response, Compensation, and Liability Act,

EPA as amended

Superfund Amendments and Reauthorization

EPA Act of 1986

EPA

National 0 il and Hazardous Substances

Pollution Contingency Plan

EPA

Designation, Reportable Quantities and Notification

Emergency Planning and Notification EPA

Hazardous Chemical Reporting: Community EPA

Right-to-know

Natural Resource Damage Assessments DOI

DOE Order 5400.1

General Environmental Protection Program

DOE

DOE Order 5400.4

Comprehensive Environmental Response,

DOE

Compensation, and Liability Act

Requirements

DOE Order $5820.2 A$

Radioactive Waste Management

DOI 
Performance Objective: In DOE Order 5820.2A, Chapter V, requirements are specified concerning the management, decontamination, and decommissioning of radioactively contaminated facilities under DOE ownership or control. The Order requires that candidate decommissioning alternatives be identified, assessed, and evaluated and that a preferred decommissioning alternative be selected based on the results of the environmental review. Detailed engineering planning shall be conducted during the environmental review process to assure that proper documentation is prepared. Specifically, a Decommissioning Project Plan (DPP) shall be prepared for approval by the appropriate program office. The DPP shall include, among other requirements, a summary evaluation of decommissioning alternatives for the facility, including the preferred alternative; plans for meeting requirements of the environmental review process; projections of occupational exposure; and detailed administrative, cost, schedule and management information.

Finding: The facility has not implemented all the requirements of DOE Order $5820.2 A$, Chapter $V$ concerning the decommissioning of radioactively contaminated facilities.

Discussion: While GJPO has implemented many of the requirements of DOE Order $5820.2 \mathrm{~A}$, the facility does not have thorough documentation justifying the decommissioning alternative selection process on past decommissioning and decontamination plans and activities, and a recent project scope inclusion of Building 6. In addition, subsequent Building 31 investigations have not been evaluated against 5820.2A. Options for remedial alternative selection were prepared for Building 6 (GRJ0145), but the evaluation of relative merits and deficiencies of the various options was not thoroughly documented so that a proper decision can be reached, nor did the documentation list the preferred alternative.

Although the overall project planning was initiated prior to the issuance of $5820.2 A$, no retroactive DPP was prepared for GJPO to comply with the Order. Many elements required in the plan exist as memoranda and/or were bound under separate titles but specific elements such as a comprenensive evaluation of decommissioning alternatives, planning for the environmental review process, and projections of occupational exposure were either not addressed in the available documentation, or were inadequate.

Site's Prior Knowledge: This issue was not addressed in any Self-Assessments conducted at GJPO.

Probable Causal Factors: The apparent causal factors contributing to this finding are inadequate training in that GJPO personnel were not fully aware of the requirements of Chapter $V$ of DOE Order 5820.2A, and policy implementation in that there has been a lack of current and historical efforts to fully comply with the requirements of $5820.2 A$. 
Performance Objective: DOE Order 5400.4, CERCLA Requirements, states that it is DOE policy to respond to releases and potential releases of hazardous substances from any facility under DOE jurisdiction, custody or control in accordance with the provisions of CERCLA as amended by SARA, as well as those of the National Contingency Plan (NCP) and Executive Order 12580. The response actions shall include both removal and/or remedial actions "as appropriate" to reduce adverse impacts on the public health and the environment whether or not the facility is listed on the National Priorities List (NPL).

As part of the appropriate response in implementing this order, DOE utilizes the CERCLA remedial investigation/feasibility study process (RI/FS), which culminates in a Record of Decision (ROD) as the primary instrument guiding remediation of waste sites. Specifically, the NCP regulations, 40 CFR Part 300.430 (e) (5), state "To support the selection of remedial action, all facts, analyses of facts, and site-specific policy determinations considered in tine course of carrying out activities in this section shall be documented, as appropriate, in a record of decision...". Although the use of the NCP process is not a regulatory requirement, all statements and conclusions in the ROD should be valid.

Finding: The statement in the ROD that DOE developed the selection of a remedy for GJPO in conjunction with EPA is incorrect.

Discussion: The declaration for the Record of Decision states that, "In consultation with the U.S. Environmental Protection Agency (EPA)... the DOE Grand Junction developed a remedial action plan...". This statement is inaccurate in that it states that the EPA was involved in this process, when in fact it was not. DOE Grand Junction, in a letter to EPA Region VIII dated August 4, 1989 (GRJ0111), documented that, "It is the policy of EPA Region VIII that under CERCLA, Section 120, EPA does not have any concurrence on the selection on a remedial action at a site not included on the NPL." The letter al so documents the fact that the EPA Region VIII did not wish to review, either formally or informally, a RI/FS for a site which is not included on the NPL, and that the EPA did not even want a copy of the GJPO RI/FS for informational purposes. Since the EPA elected not to concur with the remedy, they did not receive the GJPO RI/FS. Because of these factors, it is not possible for DOE to have consulted with EPA prior to the selection of the remedy for GJPO.

Site's Prior Knowledge: This issue was not addressed in any Self-Assessments conducted at GJPO.

Probable Causal Factors: The apparent causal factor for this inaccuracy is a human factor in that the people who were involved in the oversight process did not adequately proofread the document for errors prior to its issuance. 
Performance 0bjective: DOE Order 5400.4, CERCLA Requirements, states that it is DOE policy to respond to releases and potential releases of hazardous substances from any facility under DOE jurisdiction, custody or control in accordance with the provisions of CERCLA as amended by SARA, as well as those of the National Contingency Plan (NCP) and Executive Order 12580 . The response actions shall be "as appropriate" to reduce adverse impacts on the public health and the environment whether or not the facility is listed on the National Priorities List (NPL).

The NCP regulations, 40 CFR Part 300.430 (b)(7), state that, "If natural resources are or may be injured by the release, ensure that state and Federal trustees of the affected natural resources have been notified in order that the trustees may initiate appropriate actions including those identified in Subpart G, Trustees for Natural Resources."

Finding: GJPO has not narformed official notifications of potential damages to natural resources caused by releases of hazardous substances from the site.

Discussion: The NCP requires that the facility, in this instance DOE/GJPO, when responding to a release of hazardous substances or a threat of a release, notify any natural resource trustee of potential injury to their trust resources, even if DOE itself may be a natural resource trustee for some of the potentially affected resources. Because discharges or releases from GJPO may affect natural resnurces on-site or those off-site which may not be solely under DOE's trust jurisdiction (e.g., groundwater, Gunnison River), personnel responsible for environmental restoration and compliance should also oversee the identification of the applicable natural resources and appropriate Federal and state trustees.

Many of the trustees, such as Department of Defense (DOD), Department of the Interior (DOI), and the State of Colorado have participated in the remedial selection through a NEPA process, but f'urmal trustee notification was never sent by GJPO to these parties. The $\mathrm{DO}_{\mathrm{i}}$ is considered a trustee because of the presence of migratory birds, certain anadromous fish, and endangered species which may be affected by releases from the site. GJPO needs to determine whether other trustees besides DOE, DOD, DOI and the State of Colorado may exist.

Site's Prior Knowledge: The requirement for formal trustee notification was not addressed in any Self-Assessments conducted at GJPO.

Probable Causal Factors: The apparent causal factor contributing to this finding is the lack of proper policy implementation in that the requirements of DOE Order 5400.4 were not implemented. 
This page was intentionally left blank. 


\subsection{Environmental Management}

\subsubsection{Overview}

The purpose of the environmental management and organization assessment of the Baseline Environmental Audit was to evaluate the adequacy and effectiveness of the environmental management systems in administering DOE activities at the Grand Junction Projects Office (GJPO). These environmental management activities must ensure conformance with applicable regulations, industry and regulatory guidance and standards, and Best Management Practices (BMP). Applicable regulations include DOE Orders, Secretary of Energy Notices (SEN), Federal, state, and local statutes, and regulations and DOE guidance documents.

This assessment focused on:

- Top management commitment and support;

- Oversight activities;

- Organization structure and functional reporting; relationships

- Line responsibility and accountability;

- Ongoing environmental, safety and health (ES\&H) awareness and training;

- Quality and quantity of resources; and

- Internal and external communications.

The performance criteria used in the environmental management and organization assessment included, in part, the Tiger Team Guidance Manual - Environment, Safety \& Health and Management and Organization Assessment (February 1990).

The general approach to the environmental management and organization assessment included interviews with DOE-GJPO, Geotech and the Colorado Department of Health personnel; review of site documents, including policies, procedures, and implementation manuals; and interaction with other members of the Audit Team, including Radiation, Quality Assurance, TSCA, Waste

Management, Air, Water, and Inactive Waste Sites technical specialists. Onsite inspections were conducted to examine site management operating practices and to verify other information gathered during the audit.

The mission of GJPO is to apply its project management, engineering, and scientific capabilities to support national programs in environmental restoration, geoscience, and energy. In 1982, GJPO was assigned responsibility for the Uranium Mill Tailings Remedial Action (UMTRA) Project Vicinity Property Program at Grand Junction. The UMTRA Vicinity Property Program represents the most important environmental restoration program to GJPO over the last decade and it will have contributed over $\$ 200$ million to GJPO upon completion. 
Consistent with the Secretary of Energy's objectives to have DOE programs and operations strive for excellence in the performance of their environmental compliance activities, DOE-GJPO management has initiated efforts to meet this objective. Management and staff's technical competence and overall knowledge of Federal, state, and local environmental regulations are excellent, although application of certain regulations was not deemed adequate. The greatest concern in the environmental area of the Audit was the inability of DOE-GJPO to provide effective oversight of Geotech because of a lack of human resources.

The DOE-GJPO organization consists of a Director who is supported by Technical Supervisory Engineer of Technical Programs whose responsibilities include management and accountability of the UMTRA Program and Remedial Action Construction Projects. The Environmental Engineer is responsible for oversight of environmental compliance, regulatory affairs, health and safety, $Q A$ and Self-Assessments. The Geologist oversees GJPORAP while the Physical Scientist oversees a11 laboratory activities and strategic planning initiatives.

DOE-GJPO is the field organization responsible for all programs, operations, and ES\&H activities. DOE-Idaho's Office of Environmental Restoration and Waste Management has overall responsibility and authority for operations at the GJPO site. DOE-GJPO has a small staff of seven managing and overseeing the on-site operations of the Primary Management Contractor (PMC), which totals approximately 650 employees. Virtually all of the approximately 650 contractor employees work for Chem-Nuclear Geotech (Geotech), which is under contract to DOE as the primary support contractor for DOE-GJPO. Geotech provides environmental protection, safety and health, and quality assurance support services in carrying out programmatic operations for DOE. Typically, those activities have included:

- Site maintenance and security;

- Preparation of programs, plans, and procedures to implement DOE-Geotech guidance;

- Development and procurement of subcontracting services;

- Collection and review of data, including sampling results;

- Quality assurance (QA) and quality control;

- Technical guidance to on-site personnel;

- Cost management and schedule control; and

- ES\&H and QA auditing.

The structure and effectiveness of the Geotech organization for ensuring comprehensive, continuous, preventive, and protective ES\&H programs in all operational activities was evaluated. The Geotech President and General Manager is responsible to DOE-GJPO for the effective implementation and 
successful completion of all environmental restoration and construction activities. The Geotech General Manager is supported by a Deputy General Manager, project and program managers, organizations including $Q A$, Environmental Compliance and Regulatory Affairs (EC\&RA), Health, Safety, and Security (HS\&S), engineering, construction, procurement, property management, records management, community relations, and the self-assessment organization.

The environmental management systems of Geotech are very effective in supporting the mission of the GJPO and implementing environmental protection, safety and health, and quality assurance support services in carrying out programmatic operations for DOE. DOE-GJPO's environmental management systems have not been quite as effective in administering DOE and contractor activities. While DOE management is committed to and supports the environmental restoration, geoscience and energy programs at Grand Junction, staffing resources are not adequate to provide appropriate oversight of Geotech activities. Management and functional appraisals of Geotech have not been conducted with adequate frequency to ensure that programmatic operations and ES\&H activities are in conformance with applicable regulations. Because of these concerns, DOE-GJPO is not implementing programs nor is it capable of conducting complete oversight of Geotech.

Each Geotech organizational area's policies and procedures manual specifies each organization's responsibilities. Assignment of EC\&RA and HS\&S staff to the various organizational units is consistent with the requirements of DOE Orders. Communications between the various organizational components to the ES\&H Program was generally considered adequate.

The structure and organization of Geotech's environmental program implementation raises a concern. Technical support and oversight are the responsibility of the EC\&RA, HS\&S, and QA organizations. However, the HS\&S and EC\&RA organizations were observed to be providing both environmental oversight and corrective actions development for line management, as opposed to allowing line management ownership of implementing ES\&H requirements. This is because separate, independent, dedicated oversight groups have only recently been established within the EC\&RA and HS\&S organizations. These organizations are currently in the process of being staffed and will be responsible for ensuring line management implementation of ES\&H responsibilities and developing appropriate methods for compliance.

The environmental management assessment included an evaluation of the extent to which, and how adequately, DOE and Geotech policies, procedures, and standards are written, published, transmitted, updated and implemented. In addition, the evaluation assessed the extent and adequacy of documentation covering environmental activities, including internal communications, procedures, management guidance and policy. Currently, a management system is not in place to ensure a periodic review and update of all applicable internal policies and implementation of procedures relating to environmental programs.

The management review also included an assessment of the extent and adequacy of the evaluation of GJPO ES\&H activities. The ES\&H appraisal program includes management, functional, and internal appraisals, and selfassessments. DOE-GJPO has not met the requirements of DOE Order 5482.1B nor 
the requirements specified in the self-assessment guidance provided in Secretary Watkins' transmittal to Secretarial and Operations Office managers on July 31, 1990. GJPO is aware of this deficiency and has recently initiated efforts to bring itself into compliance. The Geotech ES\&H appraisal program meets many of the requirements of DOE Orders and is consistent with DOE guidance. The Geotech Self-Assessment Program has not yet been completely implemented, although full implementation is expected shortly.

A formal analysis of GJPO's monitoring of operations to ensure compliance with environmental, health, and safety protection requirements was conducted. DOE performs formal surveillances of Geotech line organizations and, in general, operations/activities within the boundaries of GJPO are conducted in conformance with environmental compliance requirements. However, agreements with tenants who occupy and lease space at GJPO that address assignment of responsibilities with respect to environmental liability issues have not been executed. These agreements are currently being negotiated and should be finalized shortly.

DOE's organizational structure was analyzed to evaluate its effectiveness in carrying out the mission of GJPO. Operational effectiveness was measured through the principle of maximum appropriate span of control. Spans of control appear to be adequate with the exception of the Supervisory Engineer, Technical Programs. This position currently also requires functioning in the capacities of Acting Physical Scientist and Acting General Engineer and the nature of each position's responsibilities calls for a much narrower span of control than is currently being applied. It is expected that the position of Physical Scientist will be filled by September 1991.

An analysis of DOE-GJPO's role in the management of commingled waste at the Grand Junction UMTRA State-Owned Repository subsequent to the depositing of Uranium Mill Tailings commingled with materials containing hazardous levels of lead and arsenic has yielded a number of concerns. These concerns relate to proper DOE oversight of Geotech, institutionalization of informal

communication with Geotech, frequency of communication with $\mathrm{CDH}$, and an active pursuit of a resolution to the commingled waste issue specific to the 100 tons of arsenic and lead-contaminated tailings at the State-Owned Temporary Repository. These concerns will be addressed in the subsequent baseline audit of the UMTRAP activities associated with the Rifle, Gunnison and Climax Mill sites.

The environmental management findings address two compliance issues and four Best Management Practice (BMP) findings. The Compliance findings relate to problems with the DOE-GJPO Self-Assessment program and the Geotech oversight organization. The BMP findings relate to the Geotech Self-Assessment Plan, the documentation of plans, programs, and procedures that implement DOE and Geotech guidance, GJPO tenant agreements, and the span of control exercised by the GJPO Supervisory Engineer. 
The management component of the environmental assessment identified two compliance and four Best Management Practice (BMP) findings. The compliance findings addressed the DOE-GJPO evaluation of ES\&H activities and Geotech oversight organizations. The BMP findings concern the Geotech Self-Assessment Program, DOE-GJPO and Geotech draft plans, programs, and procedures, DOE-GJPO Tenant Agreements and DOE-GJPO organizational span of control. 
TABLE 3-10

LIST OF APPLICABLE ENVIRONMENTAL MANAGEMENT

REGULATIONS/REQUIREMENTS/GUIDELINES

Regulations/

Requirements/

Guidelines

Sections/Title

Authority

DOE Order $5000.3 \mathrm{~A}$

Occurrence Reporting and Processing of

DOE

DOE Order 5400.1

General Environmental Protection

DOE

DOE Order $5400.2 \mathrm{~A}$

Programs

Environmental Compliance Issue

Coordination

DOE

DOE Order $5480.1 \mathrm{~B}$

Environment, Safety and Health

Program for DOE Operations

DOE Order 5480.19

Conduct of Operations Requirements for DOE Facilities

DOE Order 5480.4

Environmental Protection, Safety and Health Protection Standards

DOE

DOE Order 5482.1B

Environment, Safety and Health Appraisal Program

DOE Order 5484.1

Environmental Protection, Safety and Health Protection Information Reporting Requirements

DOE Order 5500.2A

Emergency Notification Reporting and Response Levels

DOE

Departmental Organizational and Management Arrangements

DOE

SEN-6B-90

Policy of Line Management's Responsibility to Achieve Environmental Compliance

DOE

SEN-7A-90

Interaction with Internal and External

Oversight Organizations

DOE

DOE

DOE

SEN-20-90 
TABLE 3-10 (page 2)

LIST OF APPLICABLE ENVIRONMENTAL MANAGEMENT REGULATIONS/REQUIREMENTS/GUIDELINES

Regulations/

Requirements/

Guidelines

SEN-29-91

DOE Memorandum, July 31, 1990

\section{Sections/Title}

Performance Indicators and Trending Program for Department of Energy Operations

Guidance on Environment, Safety, and Health (ES\&H) Self-Assessment
Authority

DOE

DOE 
Performance Objective: DOE Order 5482.1B, Section 8(e)(1) requires Heads of Field Organizations to "conduct management appraisals... of ES\&H programs of subordinate field activities at least every three years." DOE Order 5482.1B, Section $8(e)(2)$ requires Heads of Field Organizations to "conduct functional appraisals... of DOE and contractor activities with sufficient scope and frequency to ensure effectiveness of the ES\&H activities."

On January 26, 1990, Secretary Watkins issued a directive to Secretarial and Operations Office managers "that all line organizations implement a comprehensive Self-Assessment program to identify and characterize ES\&H concerns relative to their operations." On July 31, 1990, Secretary Watkins transmitted to Secretarial and office Operations managers detailed guidance to be used by line management organizations in developing and strengthening their Self-Assessment programs. A fundamental element of the Self-Assessment guidance is the requirement that DOE line management conduct functional and management appraisals of contractors.

Finding: The DOE-GJPO Self-Assessment Program (GRJ0181) does not meet the substantive requirements in the ES\&H Self-Assessment Guidance. In addition, al though DOE-GJPO has conducted formal surveillances of GJPO laboratories and Geotech Strategic Planning activities, they have not performed either management or functional appraisals of Geotech, as required by DOE Order 5482.1B.

Discussion: A formal Self-Assessment Program for the DOE-GJPO Environment, Health, Safety and Quality (EHS\&Q) organization has not been developed. DOEGJPO is responsible for monitoring all ES\&H activities at GJPO. DOE-ID Environmental Restoration and Waste Management (ER\&WM) has developed a draft Self-Assessment Program Plan for GJPO dated May 8, 1991 that has not been fully implemented. Additionally, the DOE GJPO Self-Assessment Program does not include the following: formalized operating procedures, including lines of authority, responsibilities, and planning requirements; a formal reporting system to track findings and corrective actions; and formal lessons-learned program to ensure that aggressive dissemination of potential deficiencies has not been implemented.

Functional and management appraisals of contractors by DOE line management are critical to comply with the substantive requirements in the Self-Assessment Guidance and are a requirement of DOE Order 5482.1B. The most recent management appraisal was conducted by DOE-ID Office of ES\&H oversight in December, 1987. The only functional appraisal carried out within the prior three-year time frame was the Health Physics and Emergency Preparedness Appraisal in July 1990. GJPO has performed formal surveillances of Geotech's Strategic Planning activities (GRJ0188) and Geotech 1aboratories (GRJ0087) between December 1990 and January 1991. GJPO also conducts informal appraisals of Geotech and utilizes formal surveillances conducted by the DOEID Office of Environment, Safety and Health Oversight. GJPO conducts two formal and two informal reviews of Geotech's performance each year as part of its Cost Plus Award Fee Evaluation. However, these reviews are conducted only 
to supplement the management appraisal required in 5482.1B. DOE-GJPO has requested two additional Full Time Equivalents (FTE) for fiscal calendar year 1992 to provide additional ESH\&Q oversight. One FTE would be dedicated to overseeing ES\&H activities which would include assisting the EHS\&Q Manager in the performance of Self-Assessments and management and functional appraisals of Geotech.

Site's Prior Knowledge: GJPO is aware of this finding and is currently working to implement the substantive requirements of the ES\&H Self-Assessment guidance. DOE-ID Office of ES\&H Oversight has scheduled a formal management appraisal of Geotech to be conducted in the last quarter of 1991 .

Probable Causal Factors: The apparent causal factors for this findings are a lack of resources allocated to DOE-GJPO in that inadequate staffing has hindered the DOE-GJPO Self-Assessment and Appraisal programs, and a lack of timely policy from DOE/ID regarding issuance of the May 1991, Self-Assessment Program requirements. 
Performance Objective: SEN-20-90 states that "the responsibility for managing Departmental activities in a safe and environmentally sound manner rests with line management - starting with line management at the contractor level and moving up through DOE line management." SEN-20-90 further states, "holding the line responsible for safe operations does not reduce the need for nor diminish the value of appropriate oversight activities. This is particularly true of duly authorized independent bodies charged with oversight responsibilities." Therefore, it is established DOE policy that line management be responsible for ensuring that operations under their jurisdiction comply with DOE Orders, and Federal, state, and local regulations. It is the function of independent oversight organizations to identify deficiencies and concerns throughout the technical, administrative, and operational functions, and to communicate these deficiencies and concerns to line maliagement for resolution. It is line management's responsibility to develop soluitions and implement corrective actions to resolve deficiencies identified by the oversight organizations. The intent of SEN-20-90 is that there be a clear segregation of independent oversight versus line management responsibilities.

The Environmental Compliance and Regulatory Affairs (EC\&RA) Draft Procedures Manual (GRJ0085) and the Health and Safety Manual (GRJ0003) both require that each oversight organization be responsible for providing technical and scientific support to enable line organizations to comply with the ir responsibilities to ensure compliance with health, safety, and environmental protection regulations. It is line management's responsibility to properly implement these requirements in conducting its programmatic operations.

Finding: The Geotech Health, Safety and Security (HS\&S) and Environmental Compliance and Regulatory Affairs (EC\&RA) oversight organizations are actively engaged in both problem identification and solutions development, rather than allowing line management to assume primary responsibility for developing corrective actions.

Discussion: Interviews with both management and staff of HS\&S and EC\&RA indicate that, in practice, line organizations are increasingly relying on the Environmental Compliance and Regulatory Affairs and the HS\&S organizations to identify deficiencies and provide corrective actions (I-EM-22). For example, inspections of 12 Satellite Accumulation Areas (SAA) are conducted monthly by the Waste Management Organization. These SAAs are storage areas for hazardous waste and are managed by the respective line organizations. Inspectors observe the areas and complete a monthly inspection log to identify the areas of noncompliance for line management. The log provides line management with the information needed to determine the appropriate corrective action to bring the area into compliance. However, corrective actions are routinely determined by the EC\&RA waste management inspector and routed to the respective line manager for implementation. 
The current practice of having oversight professionals performing both problem identification and development of corrective actions calls in to question the independence of oversight organizations and impedes their effectiveness in properly monitoring operations. This practice infringes on line management's responsibility to provide assurance to management that it understands the implications of an identified deficiency and can develop viable solutions. Line management must assume ownership of corrective actions by developing them to fulfill their acknowledged responsibility. In effect, there are no distinct oversight groups within the EC\&RA and HS\&S organizations. The Iines of segregation between problem identification and corrective actions development will be clear if oversight organizations establish separate, independent dedicated oversight groups.

Site's Prior Knowledge: Geotech was aware of this finding and is working to establish independent oversight groups within the Environmental Compliance and Regulatory Affairs and the HS\&S organizations. The finding was identified in the Geotech Environment, Health and Safety Assessment conducted March 11-15, 1991 .

Probable Causal Factors: The apparent causal factor is a failure to fully implement SEN-20-90 with regard to line management responsibility, the lack of an oversight policy, and design of the organization in that the current design of the Geotech organization leads to potential organizational conflict. 


\section{EM/BMPF-1 Self-Assessment Program}

Performance Objective: On January 26, 1990, Secretary Watkins transmitted to Secretarial and Operations Office Managers a trends analysis conducted on the results of the first six Tiger Team Assessments. Included in this transmittal was a directive that all line management operations institute a formal SelfAssessment program. Secretary Watkins transmitted to Secretarial and Operations Office Managers detailed "guidance... intended to assist program and field organizations in setting up and/or strengthening their Self-Assessment programs." The guidance indicates that " an ES\&H Self-Assessment program that effectively addresses... deficiencies... should contain the following elements: defined schedules for performing Self-Assessments; a formal system for carrying out and auditing corrective actions; a formal process to identify trends/lessons learned throughout the organization and incorporate them into daily operations and planning; and a formal training program for personnel with assessment responsibilities." Also, Best Management Practice suggests that a central commitment tracking system for identified deficiencies and corrective actions be maintained to ensure that line management is cognizant of and can participate in issue resolution.

Finding: Geotech's Self-Assessment Plan (GRJ0060-B) does not contain all the elements prescribed in Secretary Watkins' guidance of July $31,1990$.

Discussion: In accordance with the DOE Memorandum of Ju1y 31, 1990, Geotech independently initiated development of a formal Self-Assessment program that satisfies many of the requirements specified in the ES\&H Self-Assessment guidance and is currently developing those remaining elements needed to fully satisfy the criteria described in the guidance for Self-Assessment program implementation.

Geotech has conducted eight Self-Assessments to date: four assessments were finalized prior to the start of the Baseline Environmental Audit, and one during the Audit. The remainder are either in draft form or are awaiting line management review (GRJ0060-C), and two of five assessments are within the scope of human resources. A formal three year Self-Assessment schedule has yet to be finalized, but is expected to be implemented by the end of June, 1991. An interim Self-Assessment schedule for Apri1, May, and June has been prepared to guide the Self-Assessment process during these initial months. An additional assessment was done which coincided with the formation of the SelfAssessment Program.

Two concerns arise regarding formal auditing of corrective actions. First, the Self-Assessment Manager indicated the QA organization will be responsible for auditing corrective actions. However, no formal procedures are established in the Self-Assessment Manual for auditing corrective actions nor for designating Quality Assurance as the responsible organization. Second, the lack of a formal audit process indicates that line management organizations are responsible for not only implementing corrective actions, but also their oversight. These dual roles may compromise effective implementation of actions plans. 
The Memorandum on Status of Self-Assessment Items dated May 22, 1991 (GRJ0183) discusses "Lessons Learned" for Self-Assessments, but a formal "Lessons Learned" program has not been formalized and incorporated into the SelfAssessment Manual. Also, the Memorandum indicates an "in-house training course is being developed," which should be available in October 1991. In the interim, the formal Self-Assessment training program has included a briefing on Self-Assessment for all managers and participation in a DOE Facility Surveillance course by approximately one-third of all managers. However, a formal training course for all employees, not only managers, with assessment responsibilities should be implemented to fulfill the requisite training criteria.

Finally, multiple redundant tracking systems are in place. The Commitment Tracking and Management System, if fully utilized, should increase efficient tracking and analysis of corrective actions and eliminate the need for the Site Management Tracking System and the Health and Safety Tracking 1 ist.

Site's Prior Knowledge: The Self-Assessment Manager was aware of these issues and is working to implement these elements into the Self-Assessment Program. However, management issues have not been addressed in any Self-Assessments conducted at GJPO.

Probable Causal Factors: The apparent causal factors contributing to this finding are a lack of timely policy from DOE, and the requirements of a SelfAssessment Program which have not allowed for full implementation. 
Performance Objective: In order to ensure that facility personnel are following current practices and conducting operations in conformance with environmental requirements, it is considered a Best Management Practice to ensure that all required pians, programs, and procedures are in final form and current. Also, it is considered a Best Management Practice to have a desk reference that addresses all training requirements for job qualifications given the significant number of active restoration and construction projects.

Finding: Many programis and plans which implement DOE and Geotech guidance are in draft form. In addition, there is no Geotech comprehensive manual detailing job qualifications and training.

Discussion: Federal and state regulations, DOE Orders, Secretary of Energy Notices (SEN), and other requirements specify a number of plans, programs, and procedures which need to be formalized and documented. Several of these documents, including some with important ES\&H imblications, are still in draft form.

Both DOE-GJPO and Geotech do not have management systems in place to ensure that all guidance documents are in final form and current. For example:

- The DOE-GJPO Projects Office Manual (GRJ0180), which is a management document that specifies procedures for complianci? and implementation of DOE Orders, SENs, and Federal, state and local regulations, is a draft document (dated May 22, 1991). The GJPO Manager indicates that this document will be finalized subsequent to June 17, 1991, when DOE-ID finalizes its Procedures Manual.

- A comprehensive Geotech Training and Employee Development Manual, accessible to all employees, that contains training procedures, training classifications, a course.catalog of training course descriptions, and matrices of mandatory requirements for related job qualifications is currently not in place. At the present time, training procedures are specified in the Management Policies Manual (GRJ0004) and course descriptions and training matrices are listed in each respective organizational area's Policies and Procedures Manual.

- The Geotech Environmental Compliance and Regulatory Affairs organization is operating with a Draft Procedures Manual (GRJ0085), dated May 24, 1991. The Environmental Compliance and Regulatory Affairs organization was created early in fiscal year 1989 and has full responsibility and accountability for guidance and oversight of environmental activities, issues and affairs within Geotech programs and projects, and support of line organizations. The Geotech EC\&RA manager indicates that a final version of the EC\&RA Procedures Manual (GRJ008;) will be issued by the end of fiscal year 1991. (I-EM-07)

- DOE-GJPO Self-Assessment Procedures Manual (GRJ0181) is a draft. document dated May 8, 1991. 
Site's Prior Knowledge: Both GJPO and Geotech were aware of each of these individual examples. With the exception of the Comprehensive Training and Employee Development Manual which was identified in the Geotech Training System Audit (GRJ0186), December 21, 1989, neither organization had identified these examples in any Self-Assessments or surveillances conducted at GJPO.

Probable Causal Factors: The apparent causal factors contributing to this finding are a lack of resources to maintain and manage the significant documentation requirements, inadequate audits/appraisals/reviews in the management area, and change in that chere are frequent weak and modified requirements including Regulations, DOE Orders and policies. 
Performance Objective: It is GJPO's responsibility to ensure that work conducted at its facility is environinentally monitored and performed in compliance with applicable Federal, state, and local environmental, health, and safety laws, regulations and policies. Tenant operations are affected by DOE Orders because of the level of suppoit provided by GJPO as specified by its tenant agreements.

In order to ensure that all operations/activities within the boundaries of the GJPO facility are conducted in conformance with environmental compliance, Best Management Practice suggests that tenant agreements should be executed that address facility operating procedures and assignment of responsibilities with respect to environmental liability issues. Such agreements provide guidance regarding occupancy and use of DOE-owned facilities leased by third parties. Tenant agreements should be monitored, modified, and kept current.

Tenant agreements should establish a mechanism to coordinate efforts to mitigate potential safety and environmental deficiencies between GJPO and its tenants. These agreements should address, but not be limited to:

- Common understandings of site management operating practices;

- Investigation, notification, and reporting of occurrences;

- Control of radioactive and hazardous substances; and

- Assignment of responsibilities related to environmental protection reporting and potential liability issues.

Finding: GJPO's separate tenant agreements with the General Services Administration (GSA) and the U. S. Army Engineer District, Omaha, fail to address liabilities and responsibilities with respect to environmental, safety, and health issues. The Memorandum of Understanding between Geotech and Oak Ridge National Laboratory (ORNL) regarding environmental responsibilities has not been formalized in the Subcontract/Purchase Order.

Discussion: There are three tenants who occupy, use, and lease space at the GJPO: Oak Ridge National Laboratory, GSA, and the U.S. Army. A Subcontract/Purchase Order agreement between Geotech and the Oak Ridge National Laboratory was originally signed on January 30,1984 . Although subsequent modifications have been made to the original Subcontract/Purchase Order, it was recently recognized that the lease agreement did not adequately address necessary controls to ensure that activities within the boundaries of the GJPO are in compliance with applicable DOE Orders and environmental protection requirements. Consequently, on May 23, 1991, a Memorandum of Understanding between Geotech and Oak Ridge National Laboratory that out Tines environmental compliance, safety, and environmental protection requirements and associated responsibilities, was executed by Craig A. Little, Group Leader, ORNL, and John R. Bolliger, President, Geotech. A modification to the Subcontract/Purchase Order reflecting this Memorandum of Understanding has yet 
to be implemented, although it is signed by both parties and satisfactorily provides sufficient scope to ensure compliance and resolve any interim disputes.

A Lease Permit (Lease No. GS-08B-04296), originating on August 24, 1959, and modified on December 1, 1963, exists between DOE and the General Services

Administration. Seventeen amendments have been attached to the permit, but the permit and these amendments provide only for occupancy, area, lease rates, and total rental payments. Similarly, an Interagency Permit Agreement (DE-AI0785ID12579) between DOE and the U.S. Army Engineer District, Omaha, was finalized on April 4, 1985. The permit addresses only standard lease terms and rental rates.

Amendments to existing lease agreements should be executed with all tenants who occupy and lease DOE-owned facilities. GJPO agreements should address at a minimum: environmental protection/implementation, industrial and radiological safety, emergency preparedness, radiological hazards, and site management.

Site's Prior Knowledge: The DOE-GJPO Administrative Officer was aware of the problem and is currently negotiating amendments with the GSA and the U.S. Army Engineer District, Omaha to address environmental compliance regulations. This issue was not addressed in any Self-Assessments conducted at GJPO.

Probable Causal Factors: The apparent causal factors contributing to this finding is a lack of policy in that until recently there was inadequate appreciation of the environmental and legal liability risks created by the absence of such coverage in tenant agreements. 
Performance objective: In order to ensure that an organization maximizes its operational effectiveness while directing its business strategy, it is considered a Best Management Practice to ensure maximum appropriate spans of control at all levels of an organizational structure. Span of control defines a manager's own workload and his supervisory workload. Frequently, management spans of control have evolved rather than having been planned formally.

Without formal design, this evolution could impact the responsiveness of an organization and could contribute to ineffective decision making.

There are essentially four criteria that assist in determining the maximum appropriate span of control at GJPO: complexity, variability, criticality, and activity level. Complex tasks require a high degree of involvement by managers in time consuming assignments and are generally characterized by a narrower span of control. Diversity of operations contributes to variability of tasks which also requires a narrower span of control. When assignments require little analysis and their downstream impact is less critical, the span of control can be wider. Finally, span of control should narrow when there is a greater degree of coordination and activity level demanded by a manager's responsibilities.

Finding: The Supervisory Engineer of Technical Programs for GJPO has also been the the Acting Physical Scientist since August, 1990, and the Acting General Engineer since March, 1990, and, as a result, has an inappropriately broad span of control. The demands and responsibilities of each position call for a much narrower span of control.

Discussion: A review of the DOE-GJPO organization and major assignments reveals that the Supervisory Engineer of Technical Programs is al so Acting Physical Scientist and Acting General Engineer. Additionally, DOE-Idaho has not provided authorization to fill the position of General Engineer since March, 1990, when the General Engineer was elevated to the position of Supervisory Engineer of Technical Programs. As a result, the Supervisory Engineer of Technical Programs has also been Acting General Engineer since March, 1990.

The Supervisory Engineer of Technical Programs is held accountable for the management of major environmental restoration program including the UMTRA Program and Remedial Action Construction Projects. These programs provide in excess of \$50M in annual funding to GJPO. The Acting General Engineer position provides engineering, technical and management support to the Grand Junction Vicinity Properties and EPA Denver Radium Superfund Program and directs the DOE-ID Long-Term Surveillance and Maintenance and GJPO Fossil Energy-related activities.

The resignation of the Physical Scientist in August, 1990, created a void which was also assumed by the Supervisory Engineer of Technical Programs. Acting Physical Scientist, he provides overall management and directs the Surplus Facilities Management Program and the Defense Programs Decommissioning and Decontamination activities, and supports the Idaho National Engineering 
Laboratory. Until April 1991, responsibility for GJPORAP was also included in this position.

When applying complexity, variability, criticality, and activity level criteria to these three separate positions, it is clear that each position is characterized by similar traits. Each position:

- Requires expert technical knowledge and a high degree of planning;

- Entails minimal variability in terms of operations as most of the program work involves environmental restoration, construction and technical support although the number of active projects is significant;

- Drives GJPO's operations and, consequently, has critical downstream effects; and

- Requires significant coordination with other DOE Operations Offices, Federal, state and local agencies, contractor management, and project managers.

Based upon these characterizations, the nature of the responsibilities involved in each position dictates a narrow span of control. With the Supervisory Engineer of Technical Programs functioning in three positions, his maximum appropriate span of control has been exceeded. Although the widening span of control has not impacted the Supervisory Engineer's span of competence, it has resulted in a superficial oversight of these programs.

Site's Prior Knowledge: DOE-GJPO is currently interviewing candidates to fill the position of Physical Scientist. This issue was partially addressed in the DOE-ID RE\&WM ES\&H Self-Assessment, October 1 - December 31, 1989 (GRJ0189)

conducted at GJPO. DOE-ID has not authorized the General Engineer's position to be filled.

Probable Causal Factors: The apparent causal factors contributing to this finding are both barriers and controls because if a lack of hiring authorization from DOE-Idaho, until a few months ago when they provided authorization to fill the Physical scientist position; and a lack of experienced personnel and available human resources within DOE-GJPO to fill the Technical Management Project positions. 
This page was intentionally left blank. 


\subsubsection{Overview}

Special issues are not findings, but are topics or situations requiring further discussion based on the matter or set of circumstances surrounding the issue. A special issue is generally a regulatory requirement, policy direction, or management practice. Such topics or situations tend to be contemporary environmental compliance issues that affect many U.S. Department of Energy (DOE) sites overseen by a variety of Program Offices, or a case where environmental compliance deficiencies recur at many DOE facilities. Because special issues do not meet the criteria of findings, probable causal factors are not included in this discussion.

\subsubsection{Issue}

\section{QA/SI-1 Radon Monitoring Accuracy, Precision, and Data Corrections}

DOE Order $5700.6 B(9)(f)$ states that ANSI/ASME NQA-1 is the preferred standard for quality assurance. NQA-1, Supplement 10S-1 states that where a sample is used to verify the acceptability of a group of items, the sampling procedure shall be based on recognized standard practices. DOE Order 5400.1, Chapter IV.5.a(1) and Chapter IV.5.a(2) state that "Effluent monitoring shall be conducted at all DOE sites to satisfy the following program objectives: (a) Verify compliance with applicable Federal, state, and local effluent regulations and DOE orders" and (b) "...Provide representative measurements of the quantities and concentrations of pollutants in liquid and airborne discharges, and solid wastes."

Geotech monitors radon at 13 off-site locations (two devices per site) to assess radon doses to the area surrounding GJPO (QA-51). Passive radon samplers (Terradex Radtrak) are deployed and collected quarterly and sent to a subcontracted laboratory for analysis along with "control" samples prepared by GJPO's Radon Laboratory. Tech/Ops Landauer, Inc., performs the analysis for Geotech. Three concerns arose regarding the accuracy, precision, and the correction factor applied to the track-etch radon measurements.

The first concern is the sample size used to calculate the mean of the "controls". Tech/Ops reports the results of the samplers and the GJPO Radon Laboratory controls. The ratio of the Tech/Ops dose to the GJPO Radon Laboratory's spiked dose is a measure of accuracy. For the Terradex Radtrak sampling devices controls analyzed from November 11, 1988 through

May 7,1991 , the mean ratio was 0.95 with a standard deviation equal to 0.14 and a $95 \%$ confidence interval of 0.68 to 1.23 ; the range was 0.58 to 1.22 . The concern here is that a small number of "control" samples (i.e., typically two) is being used to determine the "control" mean, which is subsequently used as a "normalizing" factor for each sample in an analysis batch. To date, Tech/0ps has not provided accuracy and precision data to assure GJPO confidence in the contractor's QC method. 
A second concern was revealed when a review of the duplicate sample pairs showed measurement differences up to 100\%. State-of-the-art methodology typically exhibits this type of precision (QA-048). More samplers co-located at the sampling sites could produce a more confident estimate of radon exposure. Again, without the Tech/Ops data quality objectives (i.e., accuracy and precision), the validity of their data can not be determined.

The third concern with respect to outdoor radon monitoring is that quarterly data are normalized by dividing each sample by the control ratio for each analys is batch. This procedure is acceptable, but may cause an overall positive bias of the radon exposure estimates based on the mean and expected 95\% confidence interval of the control samples. More comprehensive quality control procedures could be used to improve the quality of radon dose measurement. These procedures would provide a more defensible assessment of the radon impact on the environment and health risks. 


\subsection{Noteworthy Practice}

3.12.1 Overview

A practice may be noteworthy because its design and/or execution successfully addresses activities that have frequently resulted in compliance priblems at other facilities. The presence or absence of noteworthy practices at a facility should not be viewed as a measure of a facility's performance. The purpose of this activity is for information transfer and problem solving across the DOE complex (rather than for the purpose of commendation). It provides the opportunity to identify innovative and cost-efficient solutions, thereby improving the effectiveness of DOE in meeting production goals in a way that is consistent with environmental goals.

\subsubsection{Issue}

\section{NP-1 Monitoring Well Record Retention System}

As part of its the GJPO Baseline Environmental Audit, the Audit Team had an opportunity to review the GJPO groundwater monitoring well records. The Team felt that the GJPO system developed for groundwater well record organization and retention was a noteworthy practice.

GJPO retains all permanent records from various departments in its records repository. The Environmental Compliance and Regulatory Affairs Section of Geotech maintains its permanent records for all facility monitoring wells in this repository. A separate file is maintained for each monitoring well and is updated regularly as new information is generated. The monitoring well file houses the following information for each well

- Well construction details;

- Well permits;

- Lithologic logs from well borings;

- Monitoring well maintenance checklist forms (completed monthly for all wells);

- Water level elevation measurements; and

- Memoranda concerning maintenance requests and activities. 
Sampling and analytical data for each well will be collected in the well file in the near future. The Audit Team felt that this well record organization system was worthy of emulation, because an entire history of each well is contained in one file, thereby providing facility personnel with quick and easy access to important information. It is all too common that tive various pieces of a monitoring well's history are dispersed in a variety of reports, files, and other documents that may be difficult to locate and collect. The complete history of each well, including well abandonment records, may form the basis of reports and documents produced in response to regulatory requirements and litigation support. 
APPENDIX A

BIOGRAPHICAL SKETCHES OF AUDIT TEAM PERSONNEL 
This page was intentionally left blank. 
Name: $\quad$ Arlene G. Weiner

Area of Resp: Team Leader

Association: U.S. Department of Energy

Experience: 13 Years

- U.S. Department of Energy, Office of Environmental Audit Environmental Engineer

- Principal responsibilities include leading multidisciplinary teams of professionals in performing environmental assessments and audits at DOE facilities.

- State of Maryland, Department of Environment

- Experience includes five years with the state of Maryland Department of the Environment itazardous and Sol id Waste Management Administration as a Program Administrator; Division Chief, Groundwater Investigation Division; Water Resources Engineer and investigator in an auditing program for state and federal facilities.

- Fortune 500 Pharmaceutical Company

- Managed all aspects of their regulatory compliance program on a broad range of environmental issues including NPDES permitting, RCRA, air, and water pollution control. Designed and implemented Respiratory Protection, Worker Right to Know, Hearing Conservation, and Safety Awareness Programs.

- Private Environmental Consultant

- Worked as a Project Manager and Hydrogeologist for Environmental Auditing, and assessments of groundwater issues at numerous industrial and federal facilities, including pesticide processing plants, mines, hazardous waste incinerators, and hazardous waste landfills.

Education: M.E., Mining, Pennsylvania State University

B.S., Geology, Pennsylvania State University 
Name: $\quad$ William A. Eckroade

Area of Resp: Assistant Team Leader

Association: U.S. Department of Energy

Experience: 4 Years

- U.S. Department of Energy, Office of Environmental Audit Environmental Engineer

- Environmental Engineer under the direction of the Audit Team Leader/Environmental Subteam Leader, provides guidance, direction and assistance to a multidisciplined group of professional performing Environmental Audits and Tiger Team Assessments at DOE facilities.

- Served as the Assistant Team Leader for the Maywood, New Jersey FUSRAP Site Environmental Audit, the ETEC Tiger Team Assessment and the Grand Junction Environmenta1 Audit.

- U.S. Department of Energy, Office of Compliance, Environmental Engineer

- Environmental Engineer responsible for conducting independent oversight of Environmental Compliance activities at the Savannah River Site.

- U.S. Environmental Protection Agency, Office of Waste Programs Enforcement

- Environmental Engineer responsible for providing assistance in technical case development to assigned EPA regional offices. Additionally, responsible for conducting oversight of regional activities involving all superfund activities at enforcement lead sites.

Education: M.S., Civil Engineering, University of Maryland B.S., Geophysics, Virginia Polytechnic Institute 
Name: Stow Walker

Area of Resp: Audit Team Coordinator

Association: Arthur D. Little, Inc.

Experience: 9 Years

- Responsible for analyzing waste management and site clean-up regulatory programs and requirements, and determining necessary public and private sector compliance activities.

- Participated in numerous environmental audits for private sector clients.

- Managed several projects for private sector clients seeking to identify companies and technologies capable of addressing specific site clean-up requirements.

Education: M.B.A., Boston University

M.A., Environmental Poircy, Tufts University

B.A., Trinity College 
Name: John Brennan

Area of Resp: Environmental Management Systems Specialist

Association: Arthur D. Little, Inc.

Experience: 8 Years

- Responsible for analyzing management information systems for an independent fabricator of turbine engine assemblies. The review included an assessment of project management and evaluated development of engineering cost standards. Our recommendations were fully implemented by the client.

- Participated in numerous hazardous waste management assessments. Evaluated financial resources and financial performance of hazardous waste management facilities.

- At Price Waterhouse, participated in a number of management audits which included an assessment of management perfor-ance, adequacy of audit/financial controls and evaluation of system resources to ensure their adequacy for organization requirements. Also, worked with clients to identify management system requirements selection and procurement of information systems and implementation.

Education: $\quad$ M.B.A., Finance/Quantitative Analysis, Northeastern University B.A., Economics/English, College of the Holy Cross 
Name: $\quad$ Beverly E. Copeland

Area of Resp: Surface Water

Association: Arthur D. Little, Inc.

Experience: 10 years

- For several major oil spills, assisted in the assessment of the environmental impact of spilled oil on the marine environment by measurement of several chemical parameters including saturated hydrocarbons, substituted and unsubstituted polynuclear aromatic hydrocarbon compounds (PAH) and heterocyclic compounds, and total petroleum hydrocarbon (PHC)compounds, using EPA methods.

- Developed chemical reagents for medical diagnostic use including literature search, feasibility study, writing test protocol, pre-pilot and pilot lot testing, final reagent testing, data analysis and interpretation, and writing/publishing the final reports (published in the Journal of Clinical Chemistry).

- Trained in hazardous materials and wastes health and safety.

Education: B.S., Chemistry, Fisk University 
Name: $\quad$ Martha A. Curran

Area of Resp: Toxic and Chemical Substances

Association: Arthur D. Little, Inc.

Experience: 10 Years

- Arthur D. Little Group Coordinator for DOE Sandia National Laboratory Tiger Team Audit.

- Managed a project to assist a group of U.S. utilities in implementing an independent environmental audit program, including developing protocols tailored to the electric utility industry, designing a format for reporting on the compliance status of the companies, and conducting audits at over 40 facilities, including nuclear powered steam electric generating stations, coal and oil fired generating stations, hydroelectric facilities, and substations.

- Managed all aspects of a large civil caseload, including advising clients on the legal implications of environmental audit programs, as well as on a broad range of environmental issues, including hazardous waste, PCB management, and air and water pollution control.

- Key member of the team that developed and implemented Arthur D. Little's comprehensive audit training program that has been taught to over 1,500 people.

Education: J.D., Boston University School of Law B.A., Economics and Environmental Studies, George Washington University 
Name: $\quad$ Scot A. Foster

Area of Resp: Groundwater

Association: Arthur D. Little, Inc.

Experience: 12 Years

- Served as groundwater technical specialist for the ETEC Tiger Team audit for DOE. Responsibilities included assessment of facility compliance with applicable federal and state regulations and guidelines, DOE Orders, and standard industry practices.

- Served as technical specialist for audits and assessments of ground water issues at numerous industrial facilities, including refineries, petrochemical processing plants, and mines.

- Conducted studies for the EPA Office of Radiation Programs, focussing on performance assessment of proposed DOE geologic repositories for radioactive waste and Yucca Mountain. and WIPP. Ground water modeling of radionuclide release and transport was conducted for multiple release scenarios. Carbon-14 transport in unsaturated tuff at Yucca MT. was investigated and modeled with estimations of population and dose exposures.

Education: M.S., Geology, University of Idaho

B.S., Geology, University of Maine 
Name:

Paul H. Jones, Jr.

Area of Resp: Radiation

Association: Arthur D. Little, Inc.

Experience: 9 Years

- Provided radiological data for nuclear power facility exercises. This program included generation of in-plant, on-site and off-site radiological data and development and analysis of data for re-entry/recovery and ingestion pathway drills. Responsible for developing training programs for emergency response. Served on the Weldon Spring Remedial Audit Project, as the environmental audit radiation specialist.

- Served as the site radiological controls auditor. Conducted comprehensive evaluations, audits and surveillance of laboratory and prototype radiological work activities and provided comprehensive assessments useful to management in assuring a high degree of compliance with radiological controls requirements, improvement in radiological work practices and attainment of high and uniform radiological standards.

- Responsible for preparation and review of radiological work permits, procedures and packages, including comprehensive ALARA review. Responsible for technical evaluation of work practices and implementation of proper radiological controls for site facilities including radioactive waste disposal, critical facilities, fuel processing, chemistry laboratories and materials characterization laboratories.

Education: M.S., Radiological Sciences and Protection Physics, University of Lowell

M.S., Environmental Engineering, University of Lowell

B.S, cum laude, Civil Engineering, University of Lowel1

Engineer in Training in Massachusetts

Passed Part I of the American Board of Health Physics

Certification Exam 
Name: $\quad$ Raymond F. Machacek

Area of Resp: Air Pollution Specialist

Association: Arthur D. Little, Inc.

Experience: 25 Years

- Responsible for engineering evaluation, design and testing, and economic evaluation of pollution control systems for public and private sector clients. These activities include the operation of pilot-test facilities, as well as the management of large, multidisciplinary systems.

- Provided systemization support for the Johnston Atoll Chemical Armament Demilitarization Systems (JACADS) for the U.S. Army. As part of his duties he evaluated the air pollution abatement system, including the packed bed scrubber and venturi scrubber, to cool and to remove particulates and acid gases from the exhaust gases of the liquid incinerator, the deactivation furnace, and the metal parts furnace. He evaluated both RCRA and TSCA permit applications for allowable air pollution emissions.

- Assumed control of the management of the startup of a troubled incinerator/electric power generation plant for a private sector client. He directed the correction of numerous design and equipment defects which resulted in the successful and timely completion of acceptance testing. The plant met all the requirements of its permits for air quality, water quality and solid wastes management.

Education: Ph.D., Chemical Engineering, University of Iowa

M.S., Chemical Engineering, University of Iowa

B.S., Chemical Engineering, University of Iowa 
Name: Janet L. Mahannah

Area of Resp: RCRA

Associaton: Arthur D. Little, Inc.

Experience: 10 Years

- Involved in technology assessment, research, and development in areas associated with environmental compliance in industry and government.

- Program Manager for the U.S. Army Toxic and Hazardous Materials Agency for the conduct of efforts to achieve and maintain environmental compliance at Army industrial facilities.

- Led effort directed by the Assistance Secretary of the Army to identify, evaluate, and recommend available technologies and management practices with the maximum potential to reduce hazardous waste generation at Army industrial facilities in accordance with goals established by the Department of Defense. $\begin{array}{ll}\text { Education: } & \text { B.S., Chemical Engineering, University of Tennessee } \\ \text { B.A., History, University of } 111 \text { inois }\end{array}$ 
Name: $\quad$ Anthony M. Majahad

Area of Resp: Quality Assurance Specialist

Association: Arthur D. Little, Inc.

Experience: 18 years

- Involved in quality assurance and quality control, as it pertains to environmental analysis and sampling for a variety of air, water, and hazardous waste projects: designed and implemented QA plans for a commercial Superfund laboratory; established a $Q A / Q C$ program for an air pollution monitoring study; lectured on the subject of air monitoring quality assurance and quality control practices to the Ministry of Health and the Spanish electrical power industry (UNESA) in Madrid, Spain for Harvard University's Kennedy School of Government.

- QA/QC Officer for the Harvard School of Public Health longitudinal air pollution/respiratory health effects study (Six City Study). Responsibilities included establishing standard operating procedures, development of a field and laboratory quality control chart system, performed field/laboratory systems audits, maintained a database of relevant $Q A / Q C$ information, a computer based $Q A$ documentation and forms inventory system, developed Quality Assurance Program Plan for air monitoring/health studies, and developed computer-aided data evaluation programs.

- Performed audits required for litigation on environmental data packages for USEPA CLP program, USATHAMA, and the private sector. Data auditing included field chain-ofcustody, data validation, document inspection, and final database report verification.

Education: Chemical Engineering/Chemistry Studies, Northeastern University Chemistry Studies, Suffolk University 
Name: $\quad$ Bruce Packard

Area of Resp: Radiation Assistant

Association Arthur D. Little, Inc.

Experience: 1 Year

- Performed a variety of radiation monitoring studies for commercial clients. Projects included analyzing depleted uranium contamination on a parcel of land, preparing a release survey for an NRC licensee, and monitoring for radon in residences above a tunnel construction project.

- Performed computer modeling in a series of studies for the EPA predicting the performance of the WIPP and the proposed Yucca Mountain repository as required in 40 CFR 191. Responsible for predicting radioisotope releases through undisturbed, natural disruption, and human intrusion events by developing original release scenarios. Worked with the EPA to modify the REPRISK computer code to model hydraulic transport events characteristic of Yucca Mountain.

- Conducted radiation audits for a variety of commercial clients. Responsible for internal audits as Arthur D. Little's Assistant Radiation Safety Officer. Completed 40 hour Arthur D. Little Auditing training course.

Education: M.S., (Expected December, 1991) Radiological Sciences and Protection, University of Lowell

B.S., Health Physics, Trenton State College 
Name: $\quad$ Robert A. Shatten

Area of Resp: CERCLA

Association: Arthur D. Little, Inc.

Experience: $\quad 9$ Years

- Managed and performed environmental due diligence assessments at manufacturing facilities in the U.S. and Europe. Assessment involved facility inspections, and a review of environmental management systems and past disposal practices. Where necessary, soil, ground water and waste stream sampling were performed and remedial recommendations developed.

- Managed $\$ 1.6$ million remedial investigation and feasibility study, and their $\$ 2.5$ million design and construction activities at a Superfund site in Massachusetts. Developed work plans, sampling plans, and was responsible for and supervised site health and safety activities, budgeting and financial expenditures. Maintained intergovernmental cooperation and coordination throughout the RI/FS process.

- Developed a \$44 million long-term cleanup plan involving on-site soil incineration, ground water interception and treatment and wetland restoration at a Superfund site in Massachusetts. Conceptual design included health and safety considerations and procedures to minimize adverse effects of construction and incineration.

Education: $\quad$ M.S., Environmental Engineering, Stanford University B.S., Environmental Engineering, Northwestern University 
This page was intentionally left blank. 
ÁPPENDIX B

INFORMATION REQUEST I.ETTER AND REGULATOR NOTIFICATION LETTER

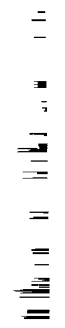


This page was intentionally left blank. 


\title{
memorandum
}

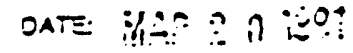 \\ AEXYYTO \\ ATIN OF: EH-24 \\ subiecr: Environmental Audit of the Grand Junction Site
}

To: Michael K. Tucker, Manager

Grand Junction Projects office

This memorandum is to inform you that an Environmental Audit of the Grand Junction Site is scheduled to begin the morning of May 29, 1991. The audit is part of the Department of Energy's (DOE's) intarnal oversight responsibilities. The Office of Environment, Safety and Health (ESait) established a program within the Office of Environmental Audit (OEV) to conduct comprahensive environmental audits at DOE operating facilities and program oificas.

The environmental audit is consistant with the Secratary of Energy 'Wat'ins' 10-point Initiative announced June 27, 1989, to strengthen environmental protection and waste management activities in the DOE. Pursuant to this Initiative, the Secratary addrasses the concapt of independent intarial oversignt as a management reform in Secratary of Energy Notica (SE:Y)-!!-39. This SEN establishes a requirement for monitoring the efiectiveness of DCE management in complying with operational, environmental, sajety, health and security standards established by Iaw, regulation, and DOE policy.

The Audit of Grand Junction will require approximately two and one hai weeks, and will be conducted in acsordance with the DOE Environmental Audit Manual. As stated in SEN-20-90, Departmental elements are expected to cooperate iully and openly, and to be responsibe to all questions, findings, and recommendations.

The scope of the Audit is broad and will include, but not be limited to the following aroas:

- comoliance with applicabie Foderal, state and local regulations, requirements, permits, agreements, orders and consent decraes;

- compliance with DOE Order requirsments;

- adequacy of DOE and site contractor's environmental management programs, including planning, organization, resources, training, and reiationships with regulatory agencies and the puolic;

- conformance with anplicable "best management" or "accaptad industry" practices; and 
o identification of root causes for relevant findings.

To initiate the Environmental Audit, a pre-Audit site visit to the jrand Junction area office is scheduled for April 30 - May. 1, 1991.

The purpose of this pre-Audit site visit is to acquaint the principal Audit Team participants with Grand Junction personnel, to become familiar with the facilities by means of briefings (see suggested topics and schedule on Attachment 1), to review site documents needed by Audit Team members prior to coming on-site as identified in Attachment 2, and to discuss logistics for the Audit. The briefings shou $7^{-}$. emphasize the results of all previous environmental program self-assessments, regulatory inspections, and program appraisals.

Please identify a member of your staff to serve as the Area Office Representative for the Audit. The Area Office Representative will participate in the Audit and be responsible for coordinating the pre-Audit and Audit site visits, including contracting the appropriate personnel and advising them of upcoming meetings, establishing site tours and briefings, obtaining appropriate office space and support. It is also requested that appropiate Fedr:ral, State and Local regulatory agencies be formally notified in order to appraise them of the pending Environmental Audit and request their attendance at both the Pre-Audit and Site Audit. Copies of these notifications should be forwarded to me.

One of the Secretary's initiatives involves strengthening line management ES\&H capabilities, and requiring 1 ine management to conduct self-assessments of its operating facilities. The Environmental Audit of Grand Junction will provide you with an opportunity to train your staff to conduct solf-assessments of your operating facilities ihraıgh directly observing the Audit Team's activities.

To ensure that the Audit Team develops a thorough understanding of the facility during the pre-Audit site visit, we are requesting that copies of the asterisked information identified in Attachment 2, to be EXPRESS MAILED as soon as possible to the appropriate address shown. The information which is not asterisked must be easily accessible for review by the Audit Team at the pre-Audit site visit on April 30 - May 1, 1991 and during the on site Audit. 
We are aware that the information request list is extensive and several information items may very well be in one document or, in some cases, the information may not exist. New environmental reports or documents should not be generated in the process of responding to this information request.

If you have any questions concerning this request or the upcoming pre-Audit or Audit, please contact me, at FTS 896-4419.

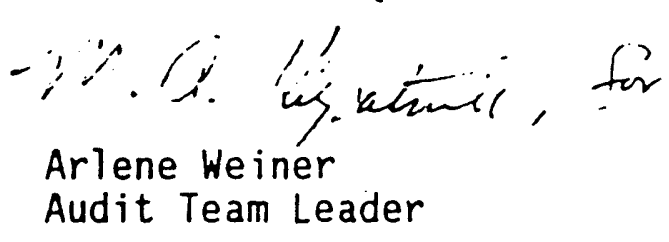

\section{Attachments (2)}

CC: Leo P. Duffy, EM-1

Eric J. Fygi, GC-1

Joseph C. Karpinski, CP-I

Raymond P. Berube, EH-20

Mike Kilpatrick, EH-24

Lawrence $A$. Weiner, $E H-5$

Carol Borgstrom, $\mathrm{EH}-25$

Kathleen Taimi, EH-22

Anthony Kluk, EM-443

Tony Brazley, EM-451

J. E. Solecki, ID

Mark Matthews, AL 


\author{
Attachment 1 \\ Proposed Agenda \\ Pre-Audit Site Visit \\ Grand Junction \\ April 30 - May 1, 1991
}

\title{
Aoril 30
}

$8: 30$ A.M.

8:45 A.M.

9:45 A.M.

$11: 45$ A.M.

$12: 45$ P.M.

May 1

8:30 A.M.

10:30 A.M.

$11: 30$ A.M.
Introduction

Audit Team's Introduction and Briefing on the PreAudit Site Visit and Audit

Overview of Overall Organizational Structure, (Include identification of problems/issues)

- Operations and Processes

- Environmental Program

- Site Management

Lunch

Site and Vicinity Property Tours

Audit Logistics

- Security

- Work Space and Support

$0 \quad$ Audit Logistics Between the Springfield and the Substations

- Public Affairs

Review Information Request

Lunch 
ENVIRONMENTAL AUDIT

\title{
ENVIRONMENTAL AUDIT
}

INFORMATION REQUEST

* Items required by Environmental Audit Team. Asterisked items should be submitted before the Pre-Audit Site Meeting. All other items should be available at Pre-Audit Site Meeting and Audit.

NOTE: ASTERISKED ITEMS SHOULD BE EXPRESS MAILED TO:

\author{
Authur D. Little \\ Attention: Tony Montrone \\ Acorn Park \\ Cambridge, MA 02140-2390
}

I. General Site Information

1. Location maps, small scale.

*2. General description of plant site and facilities.

3. Aerial surveys (especially historical surveys showing disturbed areas, construction areas, old dump sites, etc.).

*4. History of operations, including purpose and scope of activities.

5. Description of operations (flow diagrams, narrative, and sketches).

6. Process description (flow diagrams, including raw material inputs and process outputs including waste streams).

*7. Organization charts and description of responsibilities for overall plant manageinent and environmental and health and safety programs.

*8. Annual Environmental Monitoring reports for the site for the last three years. 
*9. Historic audit/appraisal reports for last three years, including the self-assessment required by the Secretary of Energy memorandum of January 26, 1990 (see Attachment 5).

10. Contractor incident/accident report (i.e. unusual occurrence reports).

*11. List of buildings with building manager names and telephone numbers.

12. Topographic map(s) of the facility.

13. Contracts excessing any property since 1988.

14. Implementation Plan for DOE Order 5400.1.

15. Network diagram of Five Year Plan tasks arid progress.

II. Hydrogeology

»1. Reports on site-wide geology and hydrogeology for the site and/or immediate area.

*2. Site-specific reports performed under DOE Orders for environmental groundwater monitoring and CERCLA assessments.

3. Annual Groundwater Monitoring reports for RCRA units.

4. Groundwater Protection Management Program Plan and Groundwater Monitoring Plan (as required in DOE Order 5400.1), including the sampling plans, quality assurance plans, and reports.

$\star 5$. Current site map of all monitoring wells.

III. Surface Water

1. Complete sewer and storm drain layout plan.

*2. Drawings showing the location of outfalls, sampling locations, treatment/storage facilities (including holding ponds), and sources of wastes being treated/ stored.

*3. Block-flow diagrams of wastewater treatment facilities.

(Note: Wastewater treatment facilities include individual onsite disposal systems) 
4. Description of operation of wastewater treatment facilities.

5. Piping and instrumentation ( $P$ \& I) diagrams of wastewater treatment facilities.

6. Studies of wastewater and sludge disposal, wastewater treatability, waste characterization, or other similar tests, investigations, or studies involving site wastewaters.

7. Description of any recent (within 3 years) significant changes in manufacturing processes or equipment, new sewer connections or construction, major changes in raw materials used or other similar indications of activities that could signal a significant change in quantity or characteristics of raw wastes.

8. Surface water quality data and reports other than Annual Environmental Monitoring Reports.

9. Description of maintenance and calibration procedures for liquid effluent process and monitoring equipment.

10. Progress/status reports provided to regulatory agencies as per FFCA, Consent Decree, etc.

*11. Descriptions of planned/ongoing construction or upgrades of treatment systems and schedules.

12. Permits-to-install and applications for Permits-to-Install.

*13. Past 3 Years of NPDES monitoring reports. Descriptions of actions required as a result of NPDES violations/ schedules.

14. Implementation Plan/Tracking System for BMP/SPCC Plan items or deficiencies:

- Reports to POTWs on monitoring of wastewater discharges.

- Pretreatment applications and permits.

- Analytical data on drinking water.

*15. List of on-site personnel and off-site contractors used for environmental monitoring.

16. Descriptions of environmental sampling training programs and training courses used by on-site personnel and off-site contractors.

*17. Copies of local, State, and Federal regulatory agency reports of compliance inspections within the last 3 years. 
18. List of personnel with certificates to operate a WWTP.

IV. Drinking Water

1. Construction drawings of the water collection, treatment, storage, and distribution system.

2. List of personnel certified to operate a potable water treatment plant and/or $d$ tribution system.

3. Analytical results of organic and inorganic samples taken to comply with the SDWA and/or State regulations, and copies of reports sent to regulatory agencies as required under the SOWA.

4. List of personnel certified to inspect, test, and repair backflow prevention devices.

5. Inspection and maintenance records of backflow prevention devices.

v. Spill Prevention and Control

1. SPCC plan.

*2. List and location for ongoing projects (e.g., decontamination and decommissioning) that could affect 0 il/hazardous substances storage, piping, or spill response.

VI. Air

*1. Description of meteorological monitoring system and data acquisition system, copies of maintenance and calibration procedures, and maintenance and calibration records.

*2. Description of ambient air sampler network, siting criteria, operational procedures, cal ibration and maintenance procedures, and maintenance and calibration records.

3. Complete source and source emissions inventory for the complex (if no formal source inventories exist, please provide the data most related to this information).

4. Description of source emission controls applied at the complex, type of air contaminants controlled, data verifying effectiveness of emissions control, operating and test procedures for control equipment, emissions controls maintenance records.

5. Description of stack monitoring/sampling program, analytical procedures, calibration procedures, and data.

$$
\text { B-8 }
$$


6. Site-specific meteorological data and air quality data.

7. Dose modeling methodology, results with supporting data/calculations.

8. A complete list of operating permits.

9. NESHAPs applications for approval of construction of new sources; NFSHAPs notification of start-up or new sources; and notification or demolition or renovation activities.

VII. Present and Past Solia Waste Management

*1. Location (map) and description of all active and inactive solid waste (includes hazardous, nonhazardous, and radioactive wastes) treatment, storage, and dispesal facilities (TSDFs). Indicate which facilities are RCRA (Interim Status, Part B, or section $3004(u)$ solid waste management units), CERCLA (including those listed or proposed NPL sites), and other facilities in which solid waste is, (or has been in the past) treated, stored, or disposed.

2. Operational history of all active and inactive solid waste TSDFs. Indicate if records were kept, and if so, what they contain and the periods covered.

*3. Include a 1 ist of chemical analyses of past and present waste streams and/or a list of the known or possible waste constituents.

*4. Information regarding past waste TSD practices and locations gathered from interviews with past and present employees.

*5. Records of facility expansion relevant to disposal of building rubble.

*6. Documents pertaining to the identification of on-site and off-site areas that my be contaminated with hazardous or radioactive substances (i.e., Installation Assessment Report, Phase I prepared under DOE Order 5480.14).

*7. Documents (final or draft) pertaining to CERCLA response actions or RCRA corrective actions including preliminary assessments/site investigations or RCRA facility assessments, RI/FS work $\mathrm{plans}$ or corrective action plans, RI/FS or corrective measures study reports, records of decision, remedial action/remedial design documents, studies associated with all of the above, and comments from EPA/States or DOE Area Offices, Operations Offices and Headquarters on all of the above. 
*8. Reports pertaining to past spills or other accidental releases, including those which exceeded reportable quantities and were reported to the National Response Center.

9. Facility procedures for reporting spills to the National Response Center.

*10. DOE .Order 5480.2 Hazardous Waste Management Plan.

11. DOE Order 5820.2 Radioactive Waste Implementation Plan and Radioactive Waste Management Plan.

*12. Description of current nonhazardous solid waste management practices.

13. Facility source terms for at least the last 10 years including annual quantities released per release point (atmospheric, surface water, groundwater, soil, and off-site disposal), release point description, release point location, any effluent prior to release, effluent monitoring at each release point, monitoring equipment used, calibration procedures for monitoring equipment, and the process description creating the radiological release.

14. Description of the environmental monitoring program for on-site nonliazardous solid waste disposal sites.

*15. Names and locations of past and present off-site TSDFs. Include both commercial and noncommercial facilities. Indicate if records were kept regarding date(s) of shipment(s), type and quantity of waste.

16. Historical iniventory of hazardous, radioactive, or mixed waste, including quantities and characteristics of the waste streams.

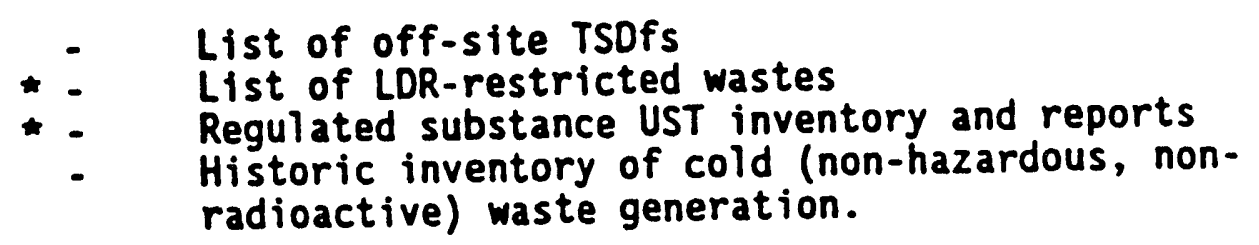

*17. RCRA Part B Permit Application submitted since 1986, and Part B Permit, if received.

*18. Hazardous waste minimization plan.

*19. Hazardous waste analysis plan.

ॠ20. RCRA contingency plan. 
21. TSD facility operation and inspection procedures.

«22. Procedures for hazardous waste generation, accumulation, and onand off-site transport.

23. Hazardous waste training program, hazardous waste personnel position descriptions, and training records.

VIII. Toxic Substances (Toxic Materials, PCBs, Asbestos, and Pesticides)

*1. Current inventory of toxic substances maintained at the facility.

*2. List of toxic substances currently used at the facility.

*3. Plans and/or procedures for purchase, use, and hazard information dissemination for toxic substances.

*4. Description of all treatment, storage, and disposal operations for all toxic materials (to the extent not addressed in item VII).

*5. Identification and location of all PCB-containing equipment, fluids, and contaminated items currently used or stored at the . facility, and the Annual PCB Reports for the past 5 years.

6. All standard operating procedures associated with PCB handling, storage, and use.

7. All internal TSCA-related audits completed in the past 2 years and notices of noncompliance derived from any regulatory agency inspection/audit.

8. Description and/or standard operating procedures for PCB leak and spill .cleanup.

9. All PCB spill cleanup records for the past 2 years.

10. All inspection records for $P C B$ transformers, $P C B$ fluid storage areas, and PCB waste storage areas for the past 2 years.

11. Information on off-site TSD of PCB material (transport manifests, certificates of disposal, etc.).

*12. List of buildings that contain asbestos materials and outside pipelines with asbestos insulation.

13. List of demolition or renovation projects completed in the last 5 years that involve friable asbestos. 
14. List of off-and on-site disposal operations where asbestos has been disposed of within the last ten years (to the extent not addressed in item VII).

*15. Reports pertaining to decommissioning and decontam-inating buildings and process facilities of the site.

*16. List of pesticides/herbicides that are or. have been used on-site, and locations where used, on-site storage facilities, names of approved applicators and 11st of off-and on-site disposal operations for empty containers ito the extent not addressed in tem VII).

IX. Regulatory/Enforcement Related Environmental Information Developed Since 1986

*1. Federal/state/local permit applications and the permits which have been issued, e.g., NPDES, CAA, RCRA Part B. If available, a summary of permit requirements and conditions, e.g., sampling schedules, effluent limitations, emission limitations, pollution control instrumentation calibration and maintenance schedules, maintenance of pollution abatement equipment, etc.

*2. Federal/State/Administrative and civil actions, e.g., Interagency Agreements, Federal Facility Compliance Agreements, orders, complaints, consent decrees, notices of violations, warning letters, notice letters, notices of permit denial, notices of intent to deny permits, and pertinent correspondence with Federal/ State regulatory agencies regarding non-compliance with substantive permit conditions and/or regulations.

*3. Most recent Federal/state/local inspection reports. Names, addresses and. phone numbers of inspectors.

X. Environmental Monitoring Quality Assurance

* Q Quality Assurance Program Manual for the facility.

ॠ2. Analytical Laboratory QA Manuals including a list of laboratory standard operating procedures.

3. Sampling QA procedures and manuals.

*4. Departmental QA Manual and/or implementing guidance for the environmental monitoring program.

*5. Standard operating procedures for: chain of custody; data management reporting; reporting of laboratory $Q A / Q C$ nonconformances; and corrective action protocols. 
*6. List of all environmental monitoring parameters and responsible analytical laboratories (on-site and off-site).

7. QA/QC clauses in all contracts and subcontracts.

$X I$. Above Ground and Underground Storage Tanks

*1. Location map showing above/below ground storage tanks.

*2. A list of the storage tanks capacities, fabrication materials, product or chemical inventory, date of installation and date of the latest leak test and the results.

*3. Tank inventory report to EPA.

4. Plans to comply with new UST regulations.

XII. SARA Title III

1. Notification to SEPC that the facility is subject to Title III.

2. Notification of a facility emergency coordinator.

3. Documentation of Title III spill reporting procedures, follow-up reports, reporting logs.

4. MSDS submittals to SEPC, LEPC, and fire departments as they apply to the requirements of SARA.

*5. Tier I and/or Tier II forms.

*6. EPA Form $R$ and back-up documentation of information for past 3 years.

XIII. Hazardous Materials Transport as applicable to Environmental Statutes and Regulations

1. Shipping records (e.g. manifests, certifications).

2. Package testing results.

3. Notification records and precautions.

*4. Waste acceptance criteria.

5. Design specifications and certifications for package.

6. Record of identification/markups.

7. Labeling/Placarding records information. 
8. Records for exceptions opted.

*9. Plans and procedures for shipments.

$B-14$ 
EH-24: DONNACHAPMAN - TURNER: Rm. 3E-094 : FORSTL : $586-3708$ :

IBM PC DISKETTE "OEV STUFF $8 / 19 / 90$ " FILE "CHUCK-AUDIT"

$$
\text { B-15 }
$$




\section{Department of Energy}

Grand Junction Projects Office

Posi Office Box 2567

Grand Junction, Colorado 81502-2567

Apriา 12, 1.991

Mr. David Shelton

Colorado Department of Health

4210 East 11th Avenue

Denver, CO 80220

SUBJECT: DOE-HQ Comprehensive Environmental Baseline Audit of The Grand Junction Projects Office (GJPO) Facility.

Dear Mr. Shelton:

Beginning May 29, 1991, and continuing through June 14, 1991, a DOEHeadquarters audit team will visit the GJPO Facility to perform a comprehensive environmental baseline audit. In keeping with the philosophy of the Secretary of Energy's policy to involve federal, state, and local regulators, you or a member of your organization are invited to observe and/or participate in the audit.

A pre-audit meeting is scheduled for April 30, and May 1, 1991, at the GJPO Facility. You or a member of your organization are also invited to attend this meeting; a tentative agenda is enciosed for your information.

Please call Larry Ball of my staff at (303) 248-6007 or Robert D. Sanders of Chem-Nuclear Geotech, Inc. (Gectech) at (303) 248-6035 if you have any questions or to confirm your organization's participation in the audit.

$$
\text { sincerely, }
$$

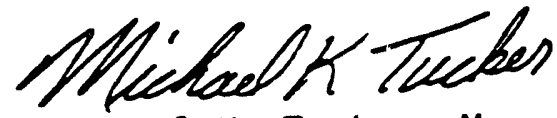

Michael K. Tucker, Manager

Grand Junction Projects Office

Enclosure

CC: A. Weiner, DOE-HQ

J. Solecki, DOE-ID, MS-1115

L. Ball, GJPO

R. Sanders, Geotech 


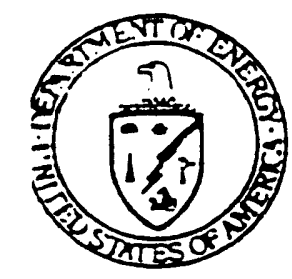

Department of Energy

Grand Junction Projecis Office

Post Office Box 2567

Grand Junction, Colorado 81502-2567

April 12, 1991
RECEIVED BY

R. D. SANCE.SS

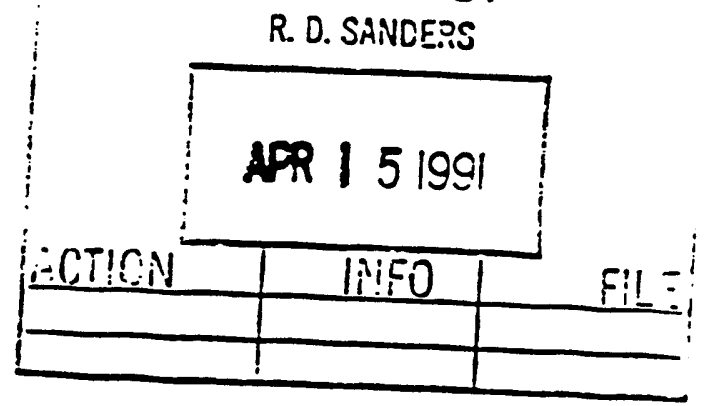

Mr. Robert Duprey, Director

Hazardous Waste Management Division

Environmental Protection Agency

Region VIII

18th Street, Suite 500

Denver, Colorado 80202-2405

SUBJECT: DOE-HQ Comprehensive Environmental Baseline Audit of The Grand Junction Projects Office (GJPO) Facility

Dear Mr. Duprey:

Beginning May 29, 1991, and continuing through June 14, 1991, a DOEHeadquarters audit team will visit the GJPO Facility to perform a comprehensive environmental baseline audit. In keeping with the philosophy of the Secretary of Energy's policy to involve federal, state, and local regulators, you or a member of your organization are invited to observe and/or participate in the audit.

A pre-audit meeting is scheduled for April 30, and May 1, 1991, at the GJPO Facility. You or a member of your organization are also invited to attend this meeting; a tentative agenda is enclosed for your information.

Please call Larry Ball of my staff at (303) 248-6007 or Robert D. Sanders of Chem-Nuclear Geotech, Inc. (Geotech) at (303) 248-6035 if you have any questions or to confirm your organization's participation in the audit.

Sincerely,

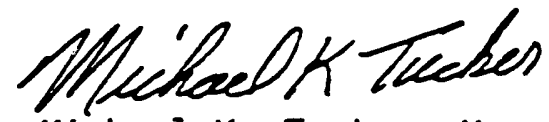

Michael K. Tucker, Manager

Grand Junction Projects Office

Enclosure

CC: A. Weiner, DOE-HQ

J. Solecki, DOE-ID, MS-1115

L. Ball, GJPO

R. Sanders, Geotech 


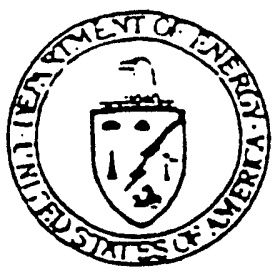

Department of Energy

Grand Junction Projects Oftice

Posi Otíice Box 2567

Grand Junction. Colorado 81502-2567

April 12, 1991

The Honorable Bill McCurry

Mayor of Grand Junction

250 North 5 th Street

Grand Junction, Co 81501

SUBJECT: DOE-HQ Comprehensive Environmental Baseline Audit of The

Grand Junction Projects Office (GJPO) Facility

Dear Mayor McCurry:

Beginning May 29, 1991, and continuing through June 14, 1991, a DOEHeadquarters audit team will visit the GJPO Facility to perform a comprehensive environmental baseline audit. In keeping with the philosophy of the Secretary of Energy's policy to involve federal, state, and local regulators, you or a member of your organization are invited to observe and/or participate in the audit.

A pre-audit meeting is scheduled for April 30, and May 1, 1991, at the GJPO Facility. You or a member of your organization are also invited to attend this meeting; a tentative agenda is enclosed for your information.

Please call Larry Ball of my staff at (303) 248-6007 or Robert D. Sanders of Chem-Nuclear Geotech, Inc. (Geotech) at (303) 248-6035 if you have any questions or to confirm your organization's participation in the audit.

Sincerely,

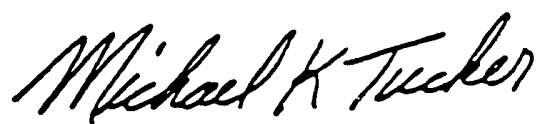

Michael K. Tucker, Manager Grand Junction Projects Office

Enclosure

CC: A. Weiner, DOE-HQ

J. Solecki, DOE-ID, MS-1115

L. Ball, GJPO

R. Sanders, Geotech 


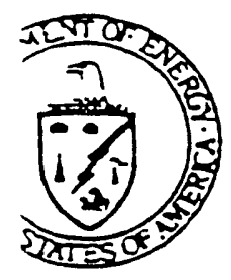

\section{Department of Energy}

Grand Junction Projects Otfice

Post Office Box 2567

Grand Junction. Colorado 81502-2567

April 12, 1991

FE: : : : ED BY

R. A. Juiloress

APR $\mid 5$ ! $99 \mid$

\begin{tabular}{r|r}
$-1 ; 150$ & $5:=$ \\
\hline$-\ldots$ & \\
\hline
\end{tabular}

Mesa County Conmissioners

Mesa Count.y Courthouse

Grand Junction, Colorado 81501

SUBJECT: DOE-HQ Comprehensive Environmental Baseline Audit of The Grand Junction Projects Office (GJPO) Facility

Dear Ms. Genova, Mr. Spehar, and Mr. Leane:

Beginning May 29, 1991, and continuing through June 14, 1991, a DOE-

Headquarters audit team will visit the GJPO Facility to perform a comprehensive environmental baseline audit. In keeping with the philosophy of the Secretary of Energy's policy to involve federal, state, and local regulators, you or a member of your organization are invited to observe and/or participate in the audit.

A pre-audit meeting is scheduled for April 30, and May 1, 1991, at the GJPO Facility. You or a member of your organization are also invited to attend this meeting; a tentative agenda is enclosed for your information.

Please call Larry Ball of my staff at (303) 248-6007 or Robert D. Sanders of Chem-Nuclear Geotech, Inc. (Geotech) at (303) 248-6035 if you have any questions or to confirm your organization's participation in the audit.

\section{Sincerely,}

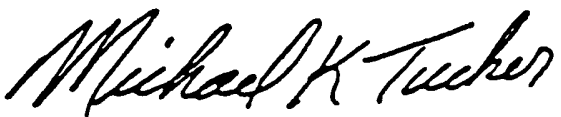

Michael K. Tucker, Manager

Grand Junction Projects Office

Enclosure

CC: A. Weiner, DOE-HQ

J. Solecki, DOE-ID, MS-1115

L. Ball, GJPO

R. Sanders, Geotech; 


\section{Department of Energy}

Grand Junction Projects Office

Post Office Box 2567

Grand Junction, Colorado 81502-250̄7

April 12, 1991

Mr. Mark Achen

City Manager

250 North 5th Street

Grand Junction, Colorado 81501

SUBJECT: DOE-HQ Comprehensive Environmental Basel ine Audit of The

Grand Junction Projects office (GJPO) Facility

Dear Mr. Achen:

Beginning May 29, 1991, and continuing through June 14, 1991, a DOEHeadquarters audit team will visit the GJPO Facility to perform a comprehensive environmental baseline audit. In keeping with the philosophy of the Secretary of Energy's policy to involve federal, state, and local regulators, you or a member of your organization are invited to observe and/or participate in the audit.

A pre-audit meeting is scheduled for April 30, and May 1, 1991, at the GJPO Facility. You or a member of your organization are also invited to attend this meeting; a tentative agenda is enclosed for your information.

Please call Larry Ball of my staff at (303) 248-6007 or Robert D. Sanders of Chem-Nuclear Geotech. Inc. (Geotech) at (303) 248-6035 if you have any questions or to confirm your organization's participation in the audit.

Sincerely,

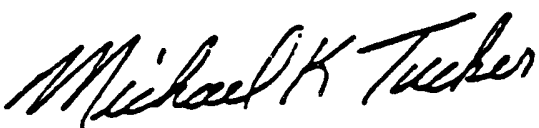

Michael $K$. Tucker, Manager

Grand Junction Projects Office

Enclosure

cC: A. Weiner, DOE-HO

J. Solecki, DOE-1D, MS-1115

L. Ball, GJPO

$R$. Sanders, Geotech 
APPENDIX C

ENVIRONMENTAL AUDIT PLAN 
This page was intentionally left blank. 


\section{AUDIT PLAN \\ for \\ GRAND JUNCTION PROJECTS OFFICE \\ GRAND JUNCTION, COLORADO}

MAY 1991

C-1 


\subsection{Introduction}

On June 27, 1989, Secretary of Energy Watkins announced a 10-point Initiative to strengthen environmental protection and waste management activities in the Department of Energy (DOE). One of the initiatives involves conducting Environmental Assessments at DOE's operating facilities.

The purpose of the Environmental Audit (Audit) of the Grand Junction Projects Office is to provide the Secretary with information on the current environmental regulatory compliance status and associated vulnerabilities of the facility, root causes for noncompliance, adequacy of environmental management programs, and response actions to address the identified problem areas.

The scope of the Grand Junction Projects Office Environmental Audit is comprehensive, covering all environmental media and applicable :ederal, State, and local regulations, requirements, and best management practices. The environmental disciplines to be addressed in this audit include air, soil, surface water, hydrogeology, waste management, toxic and chemical materials, radiation, quality assurance, and inactive waste sites. The Audit also addresses the performance of environmental management functions.

The Grand Junction Projects Office is located on a 56.4 acre site along the Gunnision River. The facility is occupied during normal working hours by approxinately 600 employees of Chem-Nuclear Geotech, the DOE, Oak Ridge National Laboratories, Oak Ridge Associated Universities, and the General Services Administration. Technical, administrative and support personnel are provided to various DOE, U.S. Department of Defense, and U.S. Environmental Protection Agency programs. Analytical laboratory and construction-related services support a variety of public sector site remediation programs.

The Grand Junction Remedial Projects Office Remedial Action Program (GJPORAP) addresses the removal of uranium mill tailings and mill-related contamination from early operations at the site. Uranium milling, analyses, and storage were conducted for a period of approximately 30 years, and ceased in the mid1970 's. Remedial action site investigations formally began for GJPORAP in 1984 when the facility was accepted into the DOE Surplus Facilities Management Program. In 1989, the facility was iransferred to the DOE Office of Environmental Restoration and Waste Management, Division of D\&D.

A Remedial Investigation/Feasibility Study-Environmental Assessment was prepared in 1989 to satisfy both the NEPA and SARA (CERCLA) requirements. Although the site did not score high enough to be included on the NPL, a GJPORAP Record of Decision was finalized and approved by the DOE's Idaho Operations office in April 1990. Remedial design and construction activities are ongoing at the site. Mill tailing material hauled from the site is now taken to an interim storage site in Grand Junction known as the State Repository. This material will ultimately be hauled to the Cheney Reservoir site, located 18 miles southeast of the Grand Junction Projects Office. 
The Audit of the Grand Junction Projects Office will be conducted by a Team managed by a Team Leader and an Assistant Team Leader from the DOE's Office of Environmental Audit (OEV) and technical specialists from Arthur D. Little, Inc. (ADL). The names and responsibilities of the team members are listed below:

$\begin{array}{ll}\text { Arlene Weiner } & \text { DOE } \\ \text { William Eckroade } & \text { Team Leader } \\ \text { Stow Walker } & \text { ADL Team Coordinator } \\ \text { Ray Machacek } & \text { ADL Air } \\ \text { Beverly Copeland } & \text { ADL Surface Water } \\ \text { Scot Foster } & \text { ADL Groundwater, Soils, Sediment and Biota } \\ \text { Janet Mahannah } & \text { ADL Waste Management } \\ \text { Martha Curran } & \text { ADL Toxic and Chemical Materials } \\ \text { Anthony Majahad } & \text { ADL QA } \\ \text { Paul Jones } & \text { ADL Radiation } \\ \text { Bruce Packard } & \text { ADL Radiation } \\ \text { Robert Shatten } & \text { ADL Inactive Waste Sites } \\ \text { John Brennan } & \text { ADL Environmental Management } \\ \text { Heather Haley } & \text { ADL Administrative Support }\end{array}$

\subsection{Pre-Audit Activities}

Pre-Audit activities for the Grand Junction Projects Office Environmental Audit included the issuance of an introduction and information request memorandum, a pre-Audit site visit, and initial review of documentation which was sent to the Environmental Team by Grand Junction Projects Office as a result of the information request memorandum.

A pre-Audit site visit was conducted on April 30 - May 1, 1991 by the Team Leader, Assistant Team Leader, and the ADL Team Coordinator. The purpose of the pre-Audit visit was to become familiar with the site, to review information being supplied and request additional information, and to coordinate plans for the upcoming Audit with Grand Junction Projects Office personnel.

This Environmental Audit Plan is based on the information received by the Environmental Team as of May 20, 1991.

\section{$2.2 \quad$ On-Site Activities and Reports}

The on-site activities for the Environmental Audit will take place from May 28, 1991 through June 14, 1991. On-site activities will include field inspections, file/record reviews, and interviews with site personnel and regulatory personnel. A map of the Grand Junction Projects Office Site (see Figure 1), identifies the mill tailings areas, surface water ponds, and major buildings and features that will be the focus of the environmental audit at this location. The State Repository site, located nearby in Grand Junction, will also be evaluated during the environmental audit. The preliminary daily 
activity schedule for the audit is shown in Appendix $A$. The daily agenda will be updated and expanded once the on-site audit commences on May 28. Any and all modifications to the daily agenda will be coordinated with the principal contacts from the Grand Junction Projects Office on an on-going daily basis.

A daily debriefing with site/facility personnel will be held each afternoon, at which time team specialists will relate their activities for the day, as well as any observations and concerns that they think may develop into findings.

A formal site close-out briefing will be conducted at the conclusion of the on-site audit activities. A draft report containing findings from the Environmental Audit will be presented to the site at this time. The Grand Junction Projects Office will have two weeks from the date of the site closecut to review and comment on the technical accuracy of the findings identified in the draft report prior to the report becoming final. 
The surface water portion of the Environmental Audit at the Grand Junction Projects Office Site will encompass activities that may cause liquid releases to the environment, as well as controls or administrative procedures designed to minimize or eliminate the potential for such releases. The audit will address domestic wastewaters and their dispnsal via local sanitary wastewater collection and treatment systems, septic tanks or other practices; wastewaters from maintenance and service operations; design and maintenance of stormwater collection and control ditches, interceptors, and outfalls. Grand Junction's methods for preventing possible cross-connections between potable and nonpotable water distribution systems will be reviewed as part of the drinking water portion of the Environmental Audit.

Emphasis will be placed on compliance with federal, state, and local water pollution control requirements established in conformance with NPDES permits, the Clean Water Act (CWA), and with drinking water rules promulgated as part of the Safe Drinking Water Act (SDWA) requirements. In addition, the Grand Junction Site will be evaluated tc determine whether requirements expressed in DOE Orders and Secretary of Energy Notices (SEN) are being addressed in an appropriate manner. The audit will evaluate water pollution control practices with respect to industry-accepted best management practices (BMPs).

\subsection{Issue Identification}

Specific areas of interest with respect to surface water/drinking water issues inc?ude, but are not limited to:

- Interviews with site personnel and review of documents in order to evaluate DOE's and its contractor's environmental management of contaminated wastewaters to surface waters, sanitary sewer system, and/or septic tank systems

- Inspection of stormwater ditches and run-off patterns for possible offsite transport of contaminants. Pathways for off-site migration of pollutants include:

1) spills or releases into permeable soil areas

2) releases (accidental or planned) to sanitary sewers and/or storm water drains without retention, chemical and radiological analysis, or treatment

3) contaminated surface run-off into drains or sewers leading to local surface water features or into permeable soil areas

- Observation of liquid waste and wastewater handling practices

- Assessment of the effectiveness of sewage treatment systems and/or septic tank operations 
- Identification of adequacy of Grand Junction's controls for el iminating cross-connections and preventing backflow from non-potable water systems into potable water distribution lines

- Observation of the sampling of surface water and sample preparation

- Examination of any sampling and analysis data generated by Grand Junction for waters and wastewaters

- Review of spill prevention, control and countermeasure plans/procedures

\section{$3.2 \quad$ Records Required}

The following items are examples of the types of documentation to be reviewed during the surface water/drinking water audit:

- POTW permits and applications

- Correspondence with state or county regulatory agencies regarding water or wastewater controls and requirements

- Communications between Grand Junction Projects Office and DOE offices pertaining to water or wastewater issues

- Sampling and analytical plans (SOPs) and data

- Records relating to training staff in environmental controls related to liquid releases

- Meteorological data related to rainfall events

- Notices of unusual occurrences as reported in memos or in operator logbooks, if they have any impact on water or wastewater

- Plans or diagrams showing where building floor drains and roof drains discharge

- An inventory of oil storage tanks complete with volumes typically stored in each tank

- Any other information pertaining to liquids used at the site

- $\quad$ SPCC plan 


\subsection{Groundwater}

\subsection{Issue Identification:}

Groundwater contamination has been recognized under most of the Grand Junction Project Office (GJPO) facility. Groundwater monitoring efforts have identified specific contaminants of concern that routinely exceed applicable state and federal water quality criteria, including uranium, radium-226, molybdenum, vanadium, selenium, and arsenic. The principal sources of groundwater contamination are believed to be the uranium mill tailings, located in several areas on site. The non-radioactive metals present in high concentrations typically occur with uranium in the ore prior to beneficiation. Additional potential sources of groundwater contamination include on-site surface water impoundments, such as North Pond, South Pond, and ponded water along the base of a flood protection dike. Surface water in these locations is in direct contact with shallow alluvial groundwater through much of the year.

The GJPO is situated on a thin (approximately 25 feet thick) alluvial aquifer consisting largely of sand, silt, and gravel comprising a point-bar deposit. he basal unit of the point bar is essentially gravel, with a sand and silt matrix. Overlying the basal gravel is a silty sand unit, derived from flood water deposition. Groundwater is present in this aquifer at shallow depths over most of the site. The alluvial aquifer is underlain by mudstone of the Jurassic Morrison Formation. This unit is widely considered to be an aquitard, capable of forming an impervious barrier to vertical groundwater migration. The nearest potable groundwater resources are thin sandstone units, located several hundred feet below the GJPO.

Previous investigations have determined that groundwater flow directions vary in direct response to water levels in the adjacent Gunnison River. The general flow direction is from south to north, parallel to the flow direction of the river along the west boundary of GJPO. During periods of high flow volume, however, the alluvial aquifer is recharged by river water influx under most of the GJPO facility, resulting in highly variable flow directions. During periods of normal to low flov: conditions, the alluvial aquifer discharges to the river along the west and north boundaries of the property.

The alluvial aquifer has become contaminated with various inorganic species, described above, as groundwater flows below and through the uranium mill tailings, from the southern recharge area to the northern discharge area. Uranium contamination has been observed in most monitoring wells on the site, with concentrations as high as several milligrams per liter (mg/l) near the dike (wells P-10, 7-6S, 11-1S) and near North Pond (well 11-15N). Radium has been detected in a single well $(13-16 N)$ located west of North Pond. The highest on-site surface radiation levels were detected in this same general area during a survey conducted in 1985.

The general approach to this assessment will include the evaluation of existing groundwater monitoring reports, the plans and procedures in place to ensure compliance with State, Federal, and DOE regulations, Orders, and 
guidelines, and the operating procedures in place to ensure proper maintenance of monitoring wells, proper sample collection, and reporting. This approach will involve detailed facility inspections, records inspections, interviews with appropriate technical and management personnel, observation of sampling procedures, and discussions with the appropriate regulatory authorities.

Several issues of particular interest have been identified from a preliminary review of the documents provided by the facility. These include :

- The regulatory justification for reliance on "passive remediation" of groundwater

- Characterization of groundwater contamination at the state-owned temporary tailings disposal facility

- The uncontrolled discharge of contaminated groundwater from the facility to the Gunnison River

- The disposition of contaminated groundwater from monitoring well purging

- The justification for not conducting a full characterization of potential organic compound contamination in groundwater during recent years

- Groundwater sampling and equipment decontamination procedures

- Monitoring well maintenance, security, and construction

- The justification for not examining maximum nonradiologic contaminant loading rate from groundwater to surface water under low-flow conditions in the risk assessment

Additional documents and files will be required for review as part of this assessment. A list of required documents includes, but is not limited to, the following:

- All groundwater monitoring results for the last two years

- Standard Operating Procedures for groundwater sampling, sampling equipment decontamination, monitoring well maintenance, security, and abandonment, and monitoring well construction

- A Health and Safety Plan, including special precautions required when constructing or sampling monitoring wells

- Correspondence with state and federal regulatory agencies (specifically EPA) authorizing reliance upon "passive groundwater remediation"

- Documentation that no significant impact to surface water occurs from contaminated groundwater discharge under very low flow conditions

- Groundwater sampling and analysis plan 


\subsection{Issue Identification}

Uranium milling activities, conducted at the Grand Junction Project Office (GJPO) facility for over 30 years, have resulted in on site disposal of mill tailings. Radiologic contamination of surface soils and tailings has been documented in two comprehensive surveys conducted during 1985 and in 1989. Contaminated soil volume calculations suggest that the total volume of radiologically contaminated material on site, exceeding applicable federal regulatory limits, is approximately 105,000 cubic meters (137,000 cubic yards). In addition to the presence of uranium in surface soils, radium-226 has been detected in both soils and ground water.

The principal areas of radiologic contamination in soil include the tailings area, the flood control dike, situated along the Gunnison River, the northwest section of the facility and the old mill area along the southern end of the property. Surficial contamination, to depths of 1 foot, is widespread. Deeper soil contamination, to more than 8 feet, is confined to the tailings area, the dike, and the northwest portion of the facility. Nonradiologic contamination of soil includes high concentrations of arsenic, molybdenum, barium, vanadium, selenium, and a variety of heavy metals such as lead, chromium, and zinc. No program of on-going soil characterization for either radiologic or non-radiologic contamination is in place at GJPO.

There are several locations on and around the GJPO where sediments may be impacted by ongoing or former operations. Sediments in Gunnison River receive little direct impact from surface water runoff, however, contaminated ground water discharges through these sediments into the river along most of the site. Previous river sediment sampling efforts identified radium-226 concentrations above background in 1979 and 1980 . North Pond and South Pond receive most of the surface runoff from the facility. Historically, these ponds received process and sewage waste waters. Sediments within North Pond, South Pond and the dike ditch have shown elevated concentrations of both radiologic and nonradiologic contaminants. Low concentrations of organic contaminants have been detected in sediments from South Pond. There is no ongoing program to monitor sediment quality in Gunnison River, where potentially sensitive biologic receptors may be exposed to both radiologic and nonradiologic contamination.

Biota within the general vicinity of the GJPO include a variety of plants indiginous to arid to semiarid regions and a wide range of wildlife, however, the wildlife populations are not high. Endangered or threatened species are also present in this area, including a variety of plants, fish, and birds. The vegetation adjacent to the facility along the Gunnison River is characterized by riparian species, including salt cedar and saltgrass. Highland species include the arid pinyon juniper, and related juniper and pinyon species. The various habitats in the GJPO area support populations of deer, elk, bighorn sheep, waterfowl, and numerous nongame birds and mammals. 
Biota in the vicinity of GJPO may be impacted by both radiologic and nonradiologic contaminants through a variet,y of pathways, including, but not limited to, direct exposure to soil/tailings, exposure to or consumption of contaminated surface water, uptake of contaminated ground water, and ingestion of contaminated plants, mammals, fish, and benthic organisms.

The general approach to this assessment will include the evaluation of existing monitoring reports, the plans and procedures in place to ensure compliance with State, Federal, and DOE orders, regulations, and guidelines. Further, the operating procedures to ensure proper sample collection, documentation, and reporting will be evaluated. The approach to this assessment will involve detailed facility inspections, records inspections, interviews with appropriate technical and management personne1, observations of sampling procedures, and discussions with appropriate regulatory authorities.

Several issues of particular interest have been identified from a preliminary review of the documents provided by the facility. These include:

- The general lack of biota sample data for exposure evaluation to both radiologic and nonradiologic (inorganic) contaminants

- The lack of ongoing river sediment sampling to determine the potential accumulation of both radiologic and nonradiologic (inorganic) contaminants from surface runoff and ground water discharge

- The general lack of routine monitoring of soils, sediment, and biota for organic contaminants

- The applicability of EP-Toxicity data for tailings and soil characterization, given the implementation of the more rigorous TCLP method

- Lack of biota monitoring or protection at the temporary state-owned tailings disposal facility

\subsection{Reports Required}

Additional documents and files will be required for review as part of this assessment. A list of required documents includes, but is not limited to, the following:

- All biota sampling results over the last five years

- All river and pond sediment sample data, including analyses for organic contaminants

Standard operating procedures for the collection of sediment and biota samples 
- Correspondence with State and Federal regulatory agencies regarding potential impacts from facility activities to sediment and biota

- Justification for not collecting sediment and biota samples on a routine basis 


\subsection{Air}

The radioactive and nonradioactive air-related compliance assessment activities involve an assessment of the site-wide air emissions, emissions monitoring equipment, and the acquisition and processing of ambient air quality data. Operational and procedural practices assciated with emission control equipment will be evaluated. Compliance with the applicable local air authority's regulations, Colorado Air Pollution Control Regulations air regulations, and National Emission Standards for Hazardous Air Pollutants (NESHAP) requirements will also be assessed. In addition, fugitive sources of particulate and gaseous emissions and any mitigative procedures will be investigated.

The ambient air monitoring system assessment will involve inspection of the ambient samplers and meteorological equipment, and review of procedures applicable to data acquisition, calibration, data validation, and data processing. The primary emphasis will be an assessment of these procedures to characterize the environmental impact of facility operations and the defensibility of the collected data.

\subsection{Issue Identification}

Areas of special interest include:

- Colorado APENs for facility point sources

- gJPORAP Air Permit

- Repository Air Permit

- Location and operation of sampling network

- Compliance issues for Subparts $H$ and $Q$ of Colorado Air Regulations

- Airborne dose assessment

- Personnel training and recordkeeping

Personnel to be interviewed include, but are not limited to:

- Site monitoring personnel regarding ambient monitoring system

- Site radiation personnel regarding dose assessment

- GJPO/GJPORAP Project EH\&S Manager and Assistant Manager

- Chem-Nuclear/Geotech Self Assessment Program Manager

- Colorado Department of Health, Mesa County Air Quality Division Engineer 


\subsection{Records Required}

The following items are examples of the types of documentation to be reviewed during the air pollution control audit:

- Permits and applications/APENs

- Correspondence with state or county regulatory agencies regarding air controls and requirements

- Communications between Grand Junction Projects Office and DOE offices pertaining to air issues

- Sampling and analytical plans (SOPs) and data

- Records relating to training staff in environmental controls related to air releases

Meteorological models and data

- Notices of unusual occurrences as reported in memos or in operator logbooks, if they have any impact on air pollution

- Plans or diagrams showing the exact locations of monitoring equipment and existing and potential air pollution sources

- Any other information pertaining to air emissions and monitoring at the site 


\subsection{Waste Management}

The purpose of the waste management section of this Environmental Audit is to examine the compliance of GJPO programs with applicable Federal and state regulations, DOE Orders, Secretary of Energy Notices, and GJPO policies with respect to the generation and management of solid and hazardous wastes.

\subsection{Issue Identification}

The audit process will include interviews with cognizant site and regulatory personne 1 as necessary. Site tours will be undertaken to review waste generation, accumulation, and management practices. Relevant documents concerning waste management practices, facility programs, permitting, records, and training will be reviewed. Specific issues that will be investigated include, but are not limited to:

- Waste-generating operations, waste characterization, analyses, volume of waste generated

- Status, characterization, and inspection of waste containers

- Waste accumulation and storage practices

- Manifesting and tracking of wastes

- Personnel training plans and records

- Planning documentation relating to waste minimization and emergency response

In adilition, specific issues identified in a pre-audit survey and in a review of i.iformation provided by GJPO will be addressed. These issues include, but are rot limited to, management of wastes generated during laboratory chemical analyses, the disposition of solvent-contaminated rags generated during operations in the electronics shop, verification of conditionally exempt regulatory status, and mixed waste management.

\subsection{Records Required}

This audit will require the review of documents and records which include, but are not limited to:

- Written policies and procedures relating to waste management activities including management plans and guidance documents

- Inspection reports or notices of violation from regulatory authorities regarding waste management activities including corrective actions taken

- Any regulatory permits, permit applications, exclusions, or waivers related to GJPO waste management activities 
- Contingency ard emergency response plans and procedures

- Training plans and documentation including relevant personnel records

- Waste manifests and waste generator reports

C- 15 


\subsection{Toxic and Chemical Materials}

\subsection{Issue Identification}

The toxic and hazardous substances part of the GJPO Environmental Audit will address the management and use of raw materials and chemical products used at GJPO as they may effect the environment. Particular emphasis will be placed on their handling, storage, and disposal, although disposal of hazardous wastes will be addressed by the waste management specialist. of particular concern will be polychlorinated biphenyls (PCBs) and other substances regulated by the Toxic Substances Control Act (TSCA), and substances regulated by the Federal Insecticide, Fungicide, and Rodenticide Act (FIFRA). Large storage tanks used for bulk chemicals and fuels, drum storage and dispensing facilities, and asbestos management will also be included in the assessment.

Management and control of toxic and hazardous substances will be determined through interviews with site personnel, inspections of relevant facilities and observations of site practices, and a review of relevant documents. Federal, state, and local regulatory officials may also be interviewed to help clarify issues. The information obtained will be evaluated to assess whether GJPO's management and control of toxic and hazardous substances are in compliance with federal, state and local regulatory requirements, and with DOE Orders. In addition, those activities that are not specifically regulated will be evaluated against best management practices that would prevent or minimize the release of toxic substances to the environment.

GJPO documents indicate that, during 1990, 40 cubic yards of uranium mill tailings containing $226 \mathrm{ppm}$ PCBs were discovered. This material is located approximately 50 yards north of the South Pond. The circumstances under which this contamination took place will be assessed, as will the management of the problem once it was discovered. This will include an evaluation of notifications to and interactions with regulatory agencies, and any remedial activities.

PCB transformers at the site have been retrofilled. One cubic yard of PCB contaminated soil located adjacent to a transformer has been excavated. Spent solvents at Grand Junction have been found to contain up to $32 \mathrm{ppm}$ PCBs. Calibration standards are also a source of PCBs.

General PCB management practices will be evaluated as part of the audit. This will include an evaluation of the procedures, including testing and analysis, used to identify PCB-containing equipment and other potential sources of PCBs. Any equipment containing PCBs will be inspected to determine its condition, the potential for leakage, and whether spill containment is available. Additionally, disposal practices for PCB fluids and equipment and PCBcontaminated soils will be evaluated to determine the methods of disposal and the locations of disposal sites. The program for retrofilling PCB transformers will be reviewed, as will the procedures used to ensure that retrofilled equipment is now below specified levels. Particular attention will be paid to whether PCB oils in bushings were included in the retrofill 
program. Inspection and reporting requirements for PCB equipment and any past spills will be evaluated to determine any potential problem areas.

Pesticide and herbicide usage at GJPO will be reviewed to determine the risks of environmental contamination. The assessment will focus on application records, disposal practices, and environmental monitoring procedures.

Other toxic and chemical substances are used and stored at GJPO. Diesel fuel is stored in a 7,500-gallon tank, and there are lab quantities of many chemicals, including alcohols, acids, trichloromethane, freon TF, and mercury. The management and handling of these materials will be examined and procedures, including secondary containment and spill control training, will be evaluated to determine whether they are adequate to prevent or minimize releases to the environment. As many of these locations as possible will be inspected during the audit. Asbestos management, the past records or proposed plans to remove, store, and dispose of the material from contaminated buildings, soil, water, and equipment will be evaluated during this portion of the assessment.

\subsection{Records Required}

Files will be reviewed as part of the environmental audit, including documents not yet reviewed or received. Specific documents and files to be reviewed as part of the audit include, but will not be limited to, the following:

- Toxic substances labelling and tracking

- Procedures for handling, control and management of toxic substances

- $\quad$ PCB annual inventories

- Inventory of PCB-containing equipment, or documentation of removal

- Records of inspections of PCB transformers

- $\quad$ PCB handling, storage, and disposal practices

- Correspondence and documents with regulatory agencies related to PCB

- Documents related to the PCB-contaminated mill tailings

- Notifications regarding PCB activities

- Manifests for PCB wastes

- Pesticide and herbicide training, handiing, storage, and disposal records and environmental monitoring records

- SOPs for pesticides

- Pesticide reports to regulatory agencies 
- Spill control and emergency preparedness for chemicals, as well as training pragrams and records

- Asbestos management procedures and inventory/monitoring records for uncontained asbestos

- Audits or inspections pertaining to the toxic substances program

- $\quad$ other records as determined on-site 


\subsection{Quality Assurance}

The Quality Assurance (QA) portion of the environmental audit of the GJPO will focus on both agency support operations as well as GJPORAP site characterization and remediation plans and activities. Specific areas of inquiry will include air, surface water, ground water, CERCLA-related activities, waste management, radiation protection, and toxic substance control. These area $Q A$ investigations will be integrated into a comprehensive review of QA activities at the GJPO.

\subsection{Issue Identification}

The Quality Assurance part of the GJPO Audit will consist of the review and evaluation of activities that result in the generation of valid, scientifically sound and defensible data. The objective of the audit will be to assess the QA procedures as they pertain to the following areas:

- Aspects of the Quality Assurance Program Plan(s) and Quality Assurance Project Plan(s) as they relate to the environmental management of the GJPO site

- Document control

- Procurement control

- Results of previous internal and external QA Audits

- Organizational structure of the facility and the QA management system

- QA manuals, implementation procedures, and training programs and policies for the environmental management tasks and activities

- Environmental sampling (training, sample collection, preservation, handling and documentation/chain-of-custody)

- Sample analysis (training, chain-of-custody, standards/traceability, instrument calibration and maintenance, quality control, laboratory notebooks/forms, data reduction, data reporting, and sample disposal procedures/documentation)

- Quality Control (QC) plans, documentation, and effectiveness

- Data validation (logbooks, lab notebooks, forms, and calculation reviews)

- Archival information storage (sample data, performance audits, QA procedures, etc.) 
The identified issues, including but not limited to those provide above, will be addressed with respect to the effluent monitoring and environmental surveillance activities. These activities encompass the following environmental monitoring requirements:

- Clean Air Act

- Clean Water Act

- Toxic Substances Control Act (TSCA)

- Resource Conservation and Recovery Act of 1976 (RCRA)

- Comprehensive Environmental Response, Compensation, and Liability Act "Superfund" (CERCLA)

- U.S. DOE Quality Assurance Program Requirements

- Colorado Department of Health (CDH) and Mesa County Health Department Regulations and Requirements

\subsection{Records Required}

Part of the assessment will consist of a review of pertinent documents and files. This will include documents not previously reviewed or received, individual files, and documents which have not been identified at this time. Some of the documents and files to be reviewed in this phase of the assessment include, but will not be limited to, the following:

- QA PIans for GJPO characterization and remediation activities and supporting analytical laboratories

- GJPO environmental sampling and analysis procedures

- GJPO Petrology Laboratory methods and procedures

- GJPO Radon Laboratory methods and procedures

- QA manuals for all ongoing activities

- Periodic or annual QA summary reports

- Summaries of QA Sample results from EPA and DOE's Environmental Measurements Laboratory

- Training records for all sampling and laboratory personnel 
- Laboratory notebooks, standard data reporting forms, and sampling/instrument logbooks

- Instrument maintenance, repair, and calibration records for field and laboratory equipment/apparatus

- Internal QC studies 


\subsection{Environmental Management}

The environmental management portion of the Environmental Audit at GJPO will include an assessment of the adequacy and effectiveness of environmental management systems in place to ensure conformance with Federal, state, and local statutes and regulations, DOE order, and Secretary of Energy Notices. More specifically, the assessment will address:

- Top management support and oversight

- Quantity and quality of resources

- Line responsibility and accountability

- Organization structure and functional reporting relationships

- Internal and external communications

- Ongoing Environment, Safety and Health (ES\&H) awareness and training

\subsection{Issue Identification}

The general approach to assessing the environmental management systems at GJPO includes extensive interviewing of DOE and contractor site management personnel, review of selected documents (see below) and a physical inspection of the site. Particular emphasis will be placed on coordinating the management assessment with the activities and findings of the other team members who are focusing on specific environmental issues (RCRA, CERCLA, TSCA, radiation, hydrogeology, etc.). Two mechanisms will be used to ensure adequate intra-team communication:

- Daily one-on-ones - The management specialist will have daily one-on-one discussions with each team member in order to identify relevant management issues in each functional area.

Common issues 1ist - Prior to arrival on-site, a list of management issues will be distributed to each team member (similar to the six bullet points listed above, but more specific). The team members will be asked to evaluate each issue in the context of their interviews, document reviews and inspections. This assures that the management assessment includes structured input from a wide range of organizational levels and disciplines.

\subsection{Records Required}

- Environmental implementation program

- GJPO environmental policies, procedures and other management-provided guidance

- Environmental compliance audits, self assessment/appraisal reports and related internal follow-up documents

Ongoing/institutionalized environmental management reporting 
- Job descriptions (or equivalent documentation) of key management positions (both within and outside of the ES\&H function)

- Contractual or other documentation describing the roles and responsibilities of the various contractor entities 
This page was intentionally left blank. 
APPENDIX D

DAILY ACTIVITIES 
This page was intentionally left blank. 


\begin{tabular}{|c|c|c|c|}
\hline \multirow{6}{*}{ 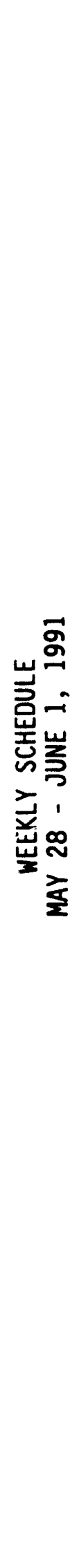 } & 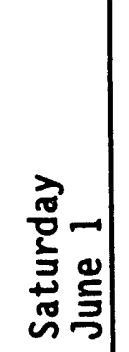 & 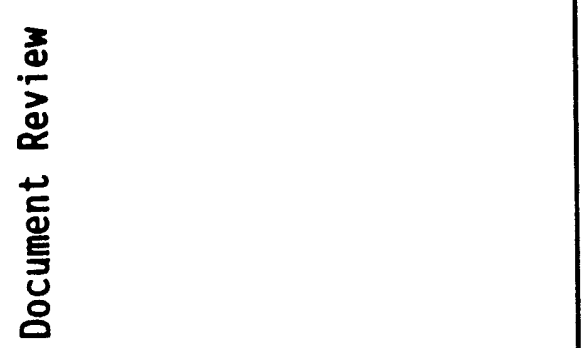 & 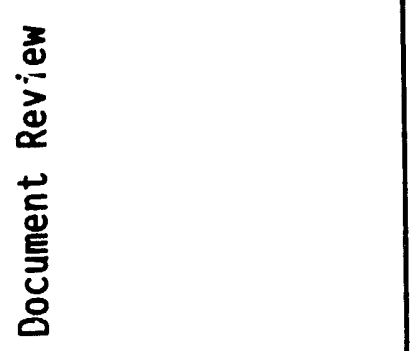 \\
\hline & $\begin{array}{l}\text { तेले } \\
\frac{0}{2} \\
\frac{0}{2}\end{array}$ & 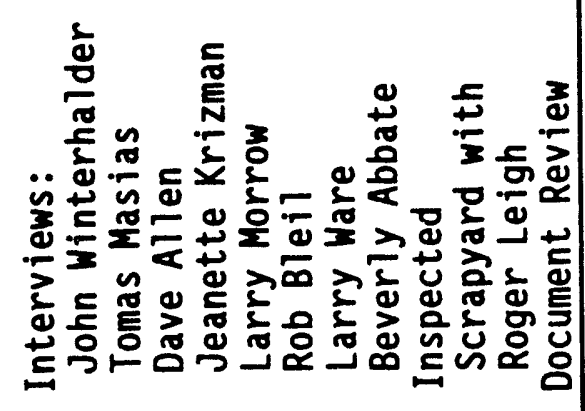 & 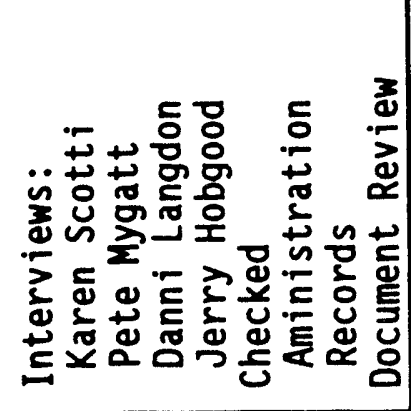 \\
\hline & 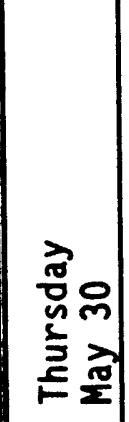 & 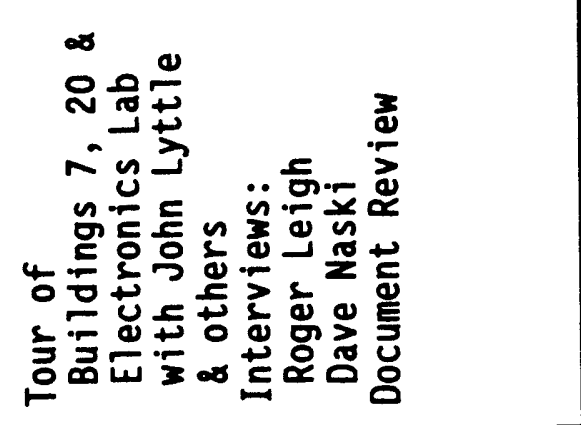 & 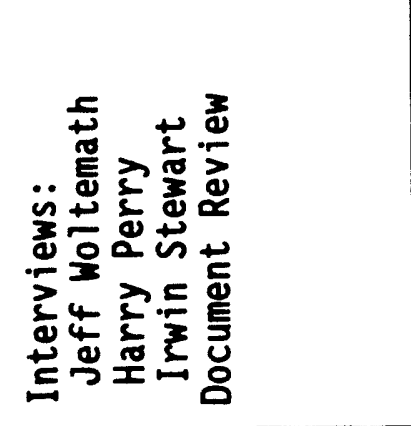 \\
\hline & 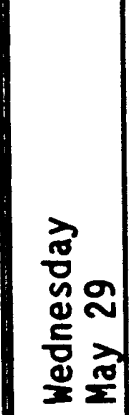 & 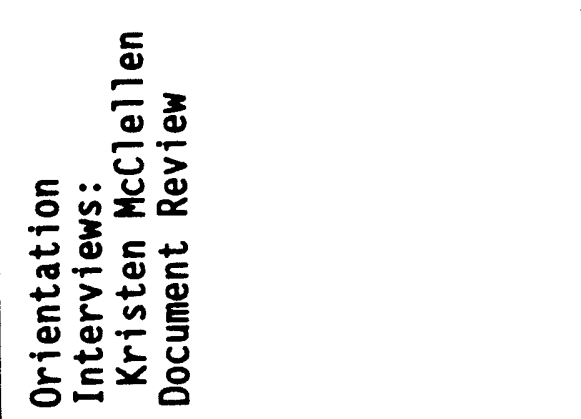 & 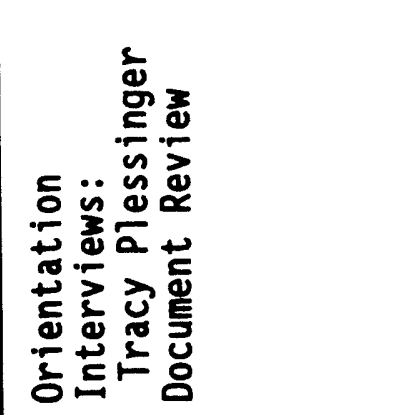 \\
\hline & 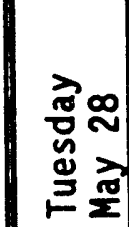 & 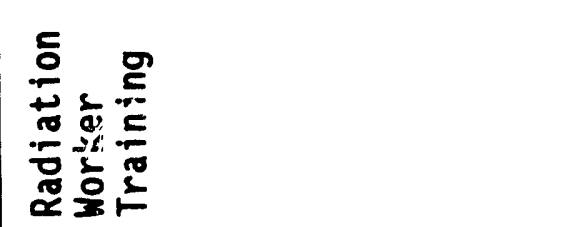 & 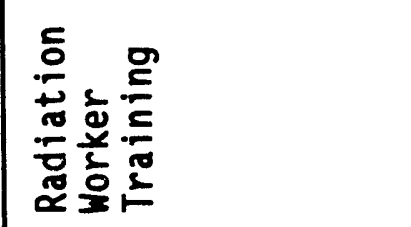 \\
\hline & & 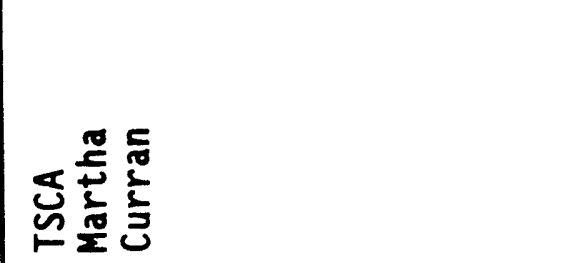 & 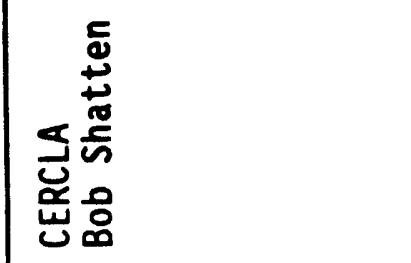 \\
\hline
\end{tabular}




\begin{tabular}{|c|c|c|c|c|}
\hline \multirow{6}{*}{ 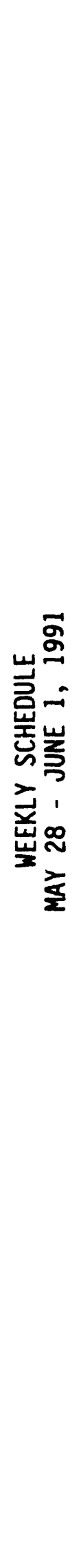 } & 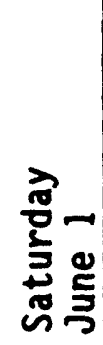 & 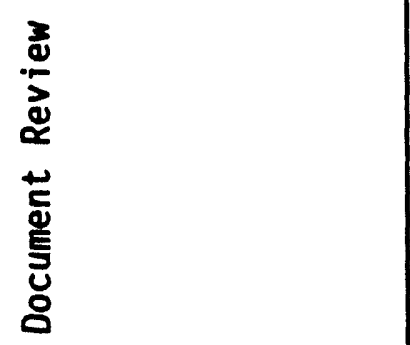 & 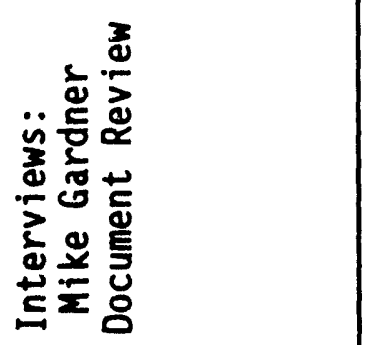 & 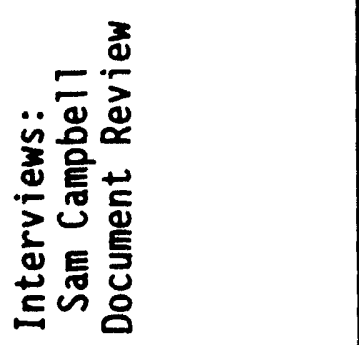 \\
\hline & 突再 & 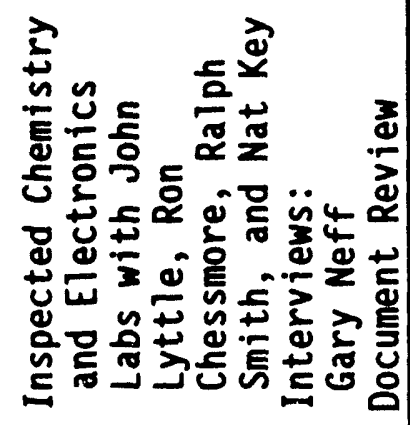 & 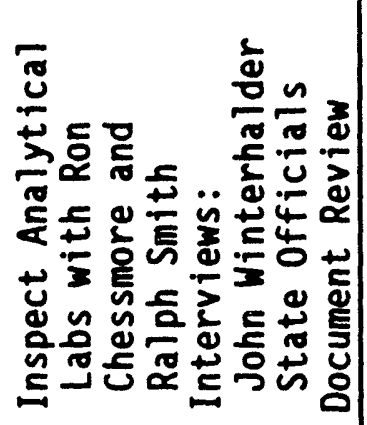 & 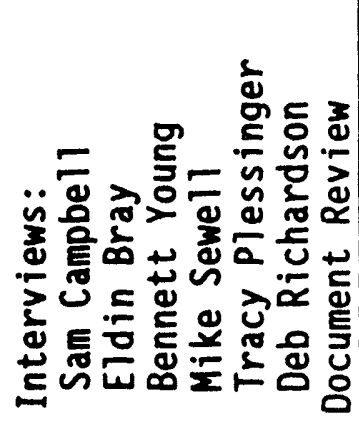 \\
\hline & 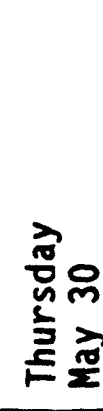 & 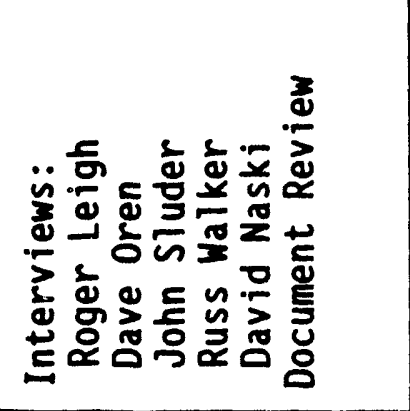 & 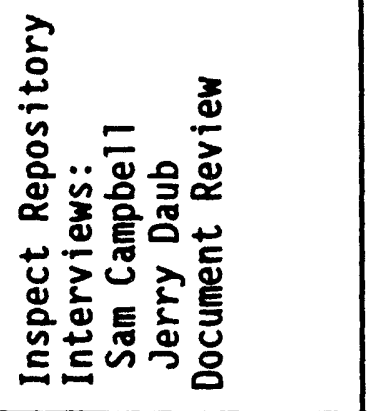 & 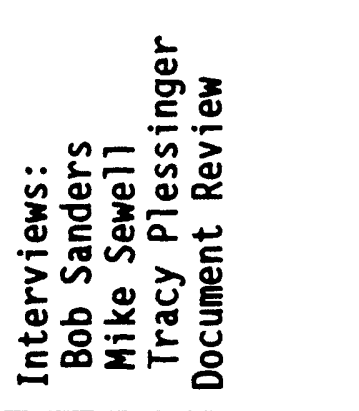 \\
\hline & 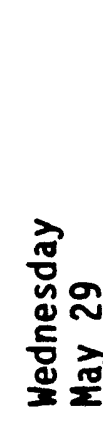 & 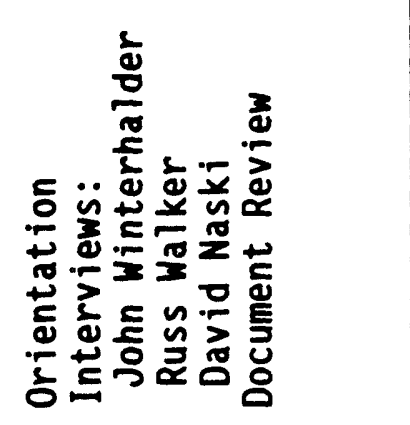 & 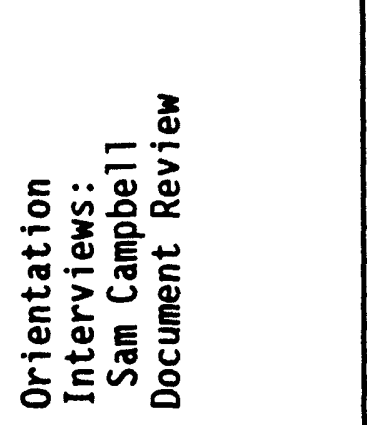 & 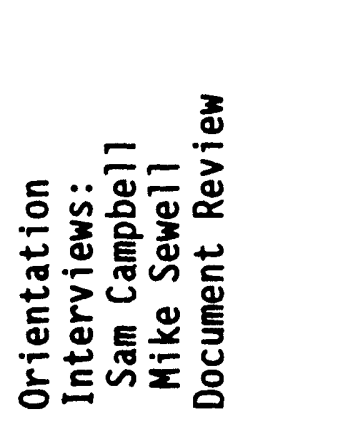 \\
\hline & 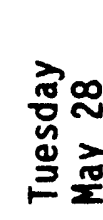 & 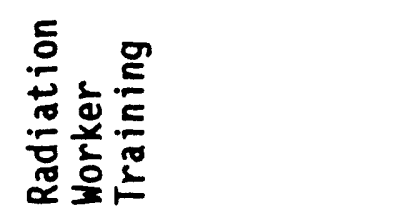 & 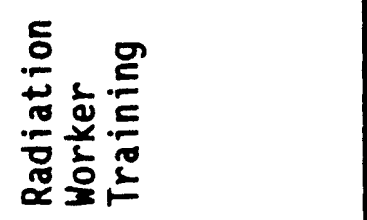 & 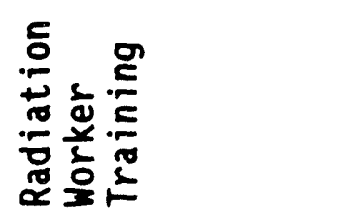 \\
\hline & & 突 & 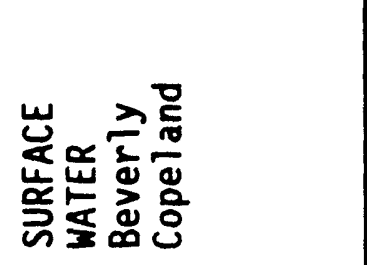 & 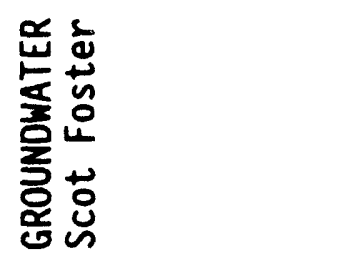 \\
\hline
\end{tabular}




\begin{tabular}{|c|c|c|c|}
\hline \multirow{6}{*}{ 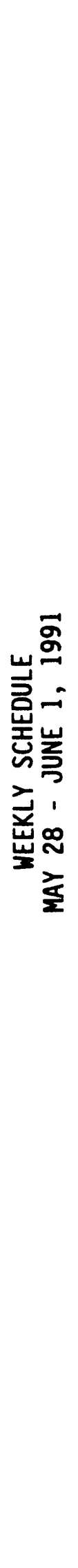 } & 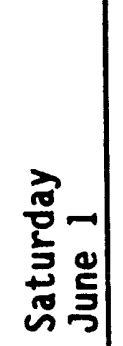 & 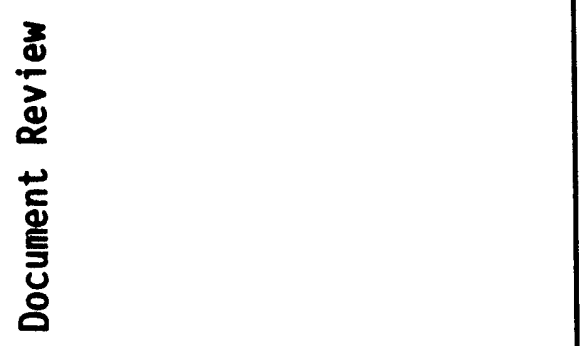 & 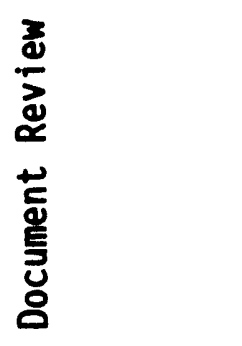 \\
\hline & $\begin{array}{l}\text { 용 } \\
\text { 은 }\end{array}$ & 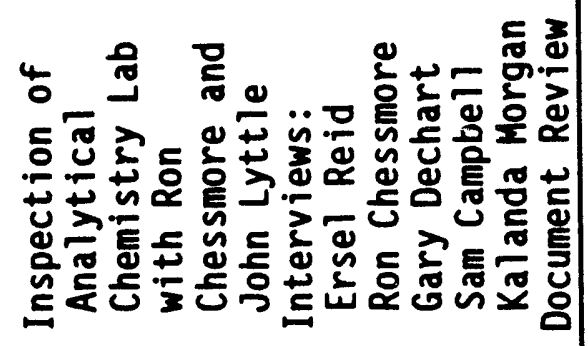 & 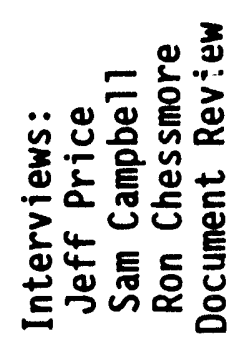 \\
\hline & 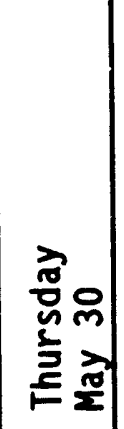 & 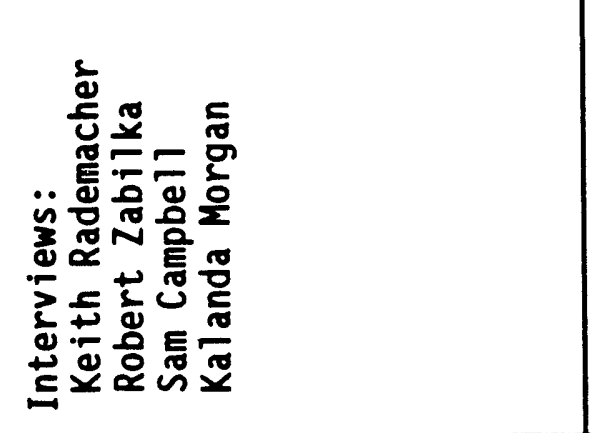 & 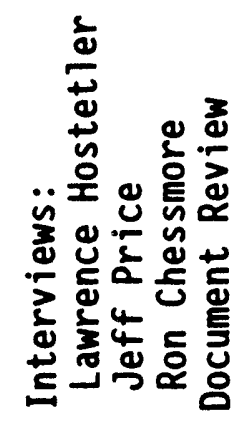 \\
\hline & 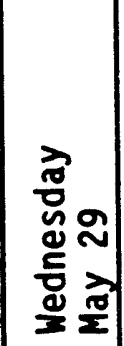 & 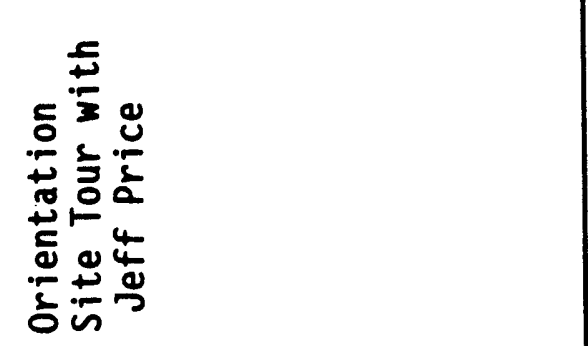 & 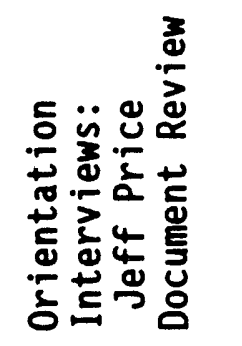 \\
\hline & 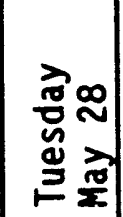 & 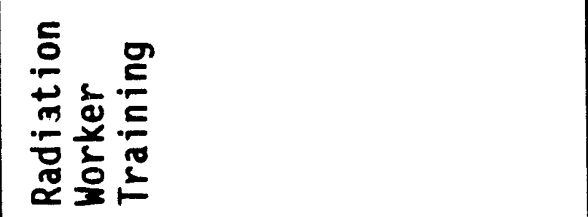 & 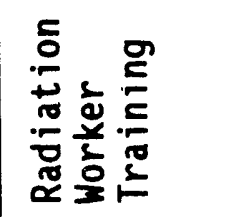 \\
\hline & & 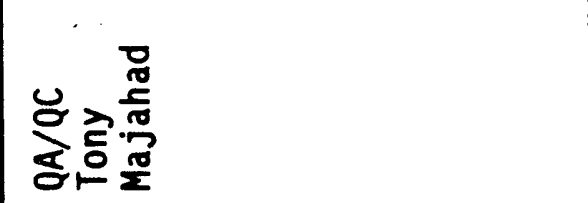 & 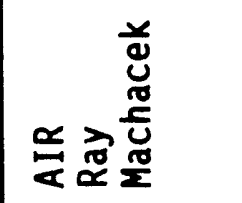 \\
\hline
\end{tabular}




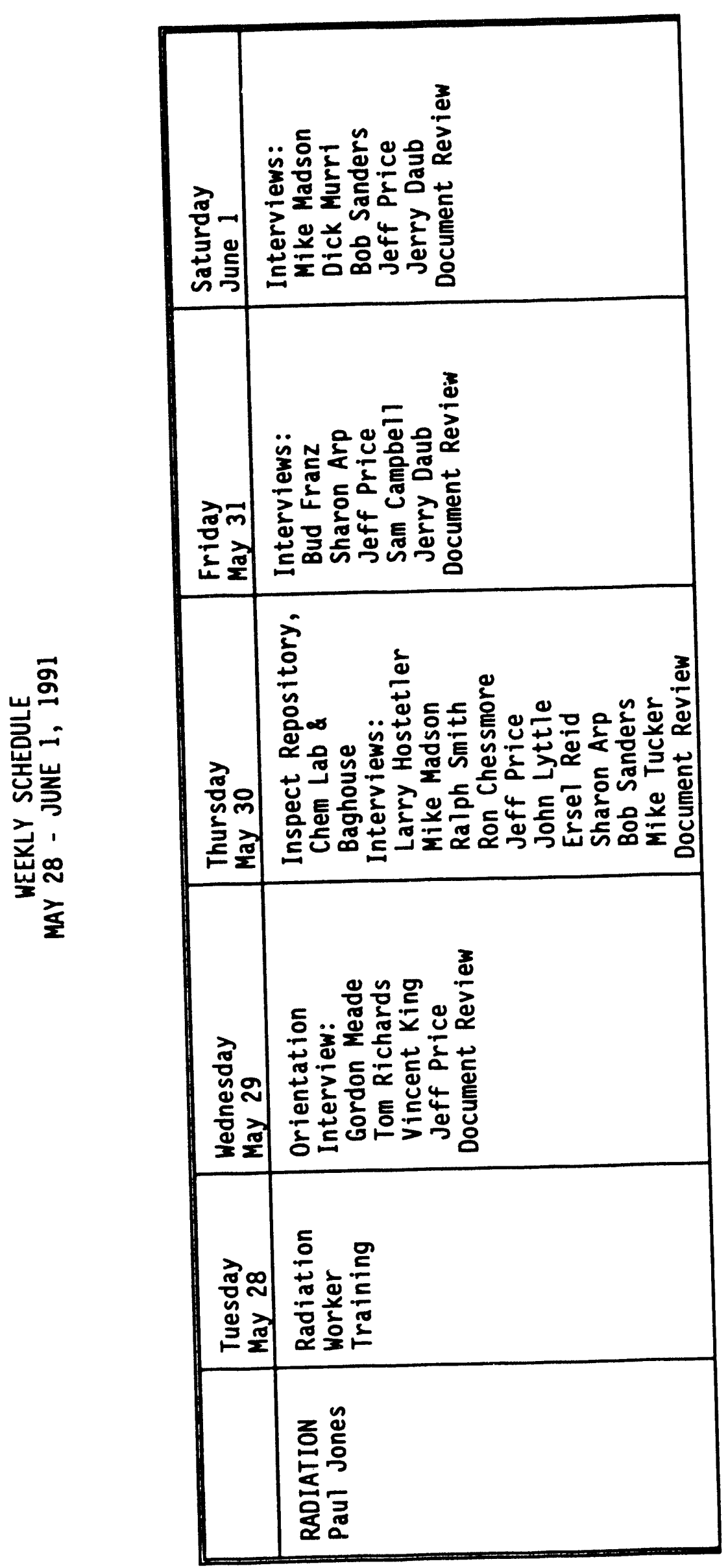




\begin{tabular}{|c|c|c|c|}
\hline \multirow{6}{*}{ 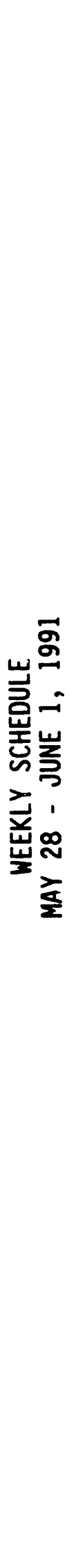 } & 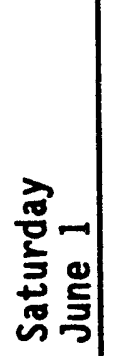 & 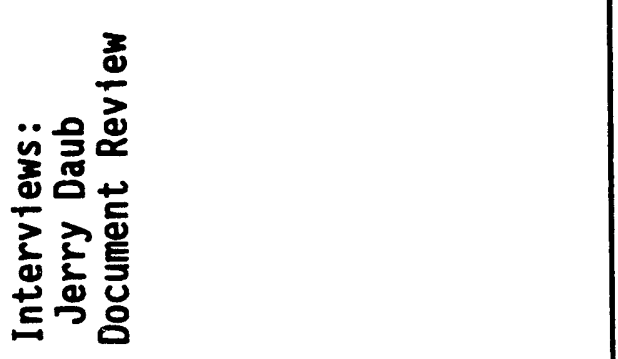 & 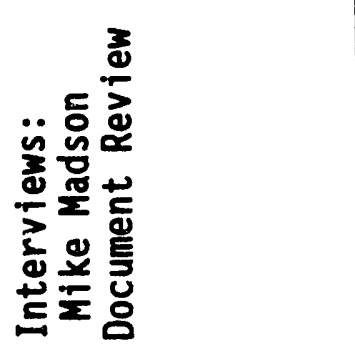 \\
\hline & 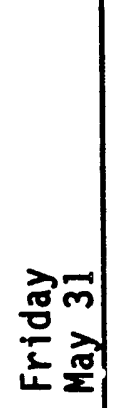 & 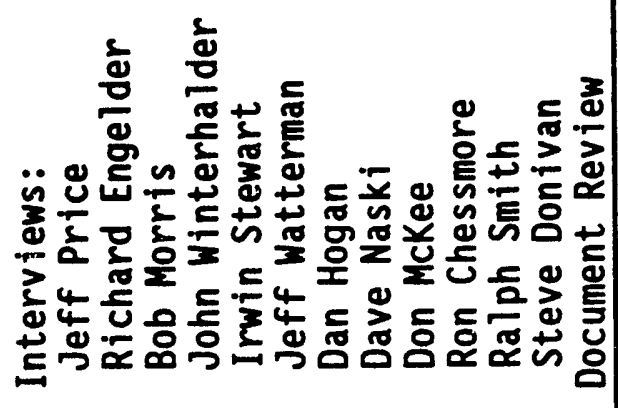 & 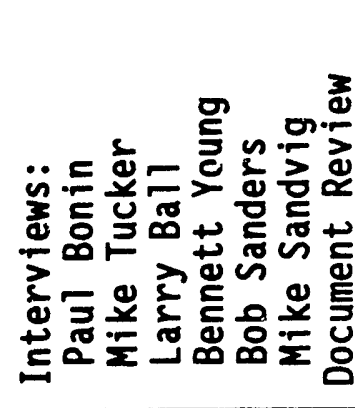 \\
\hline & 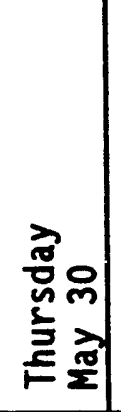 & 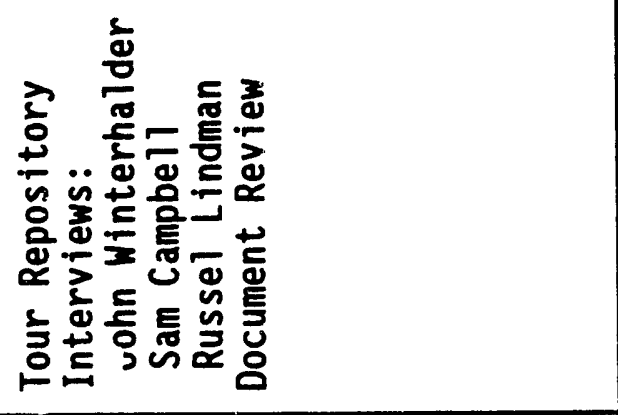 & 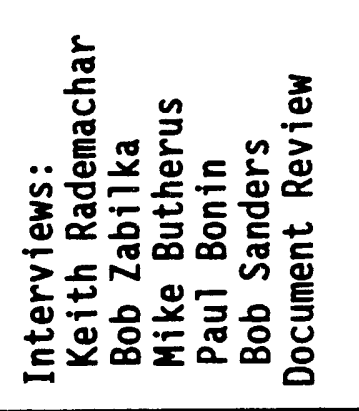 \\
\hline & 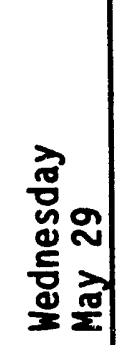 & 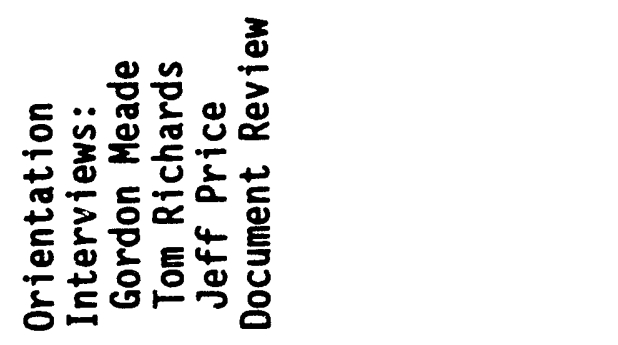 & 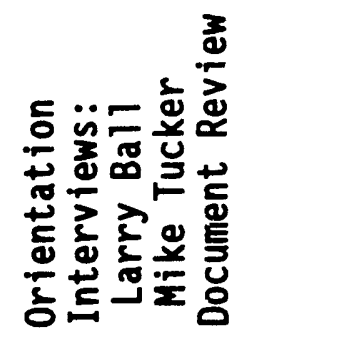 \\
\hline & 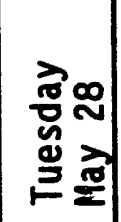 & 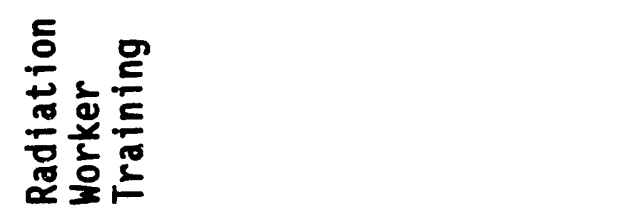 & 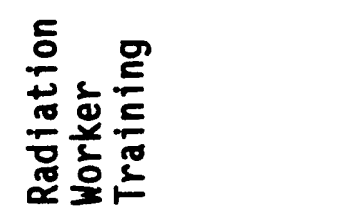 \\
\hline & & 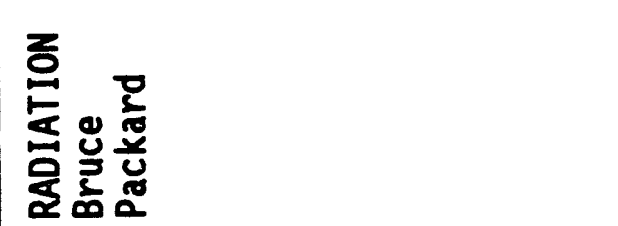 & 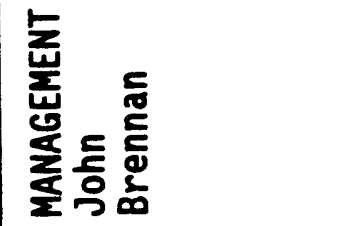 \\
\hline
\end{tabular}




\begin{tabular}{|c|c|c|c|c|}
\hline & 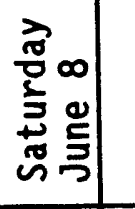 & & & \\
\hline \multirow{6}{*}{ 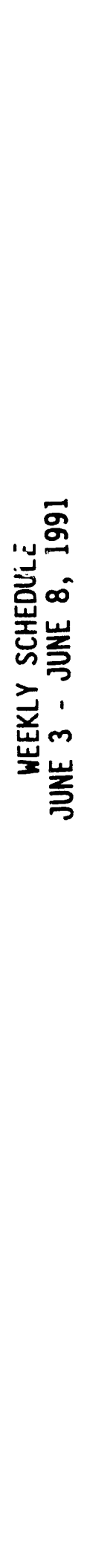 } & 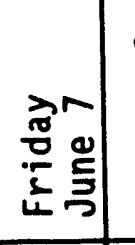 & 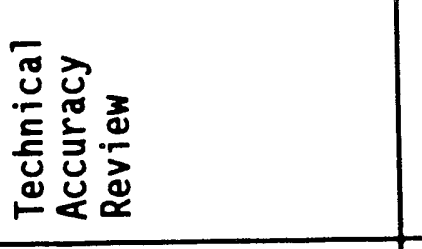 & 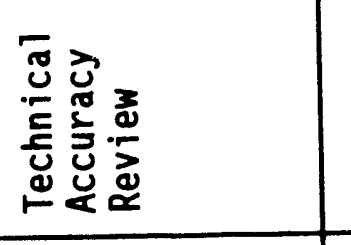 & \\
\hline & 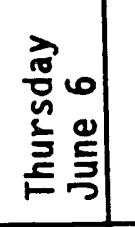 & 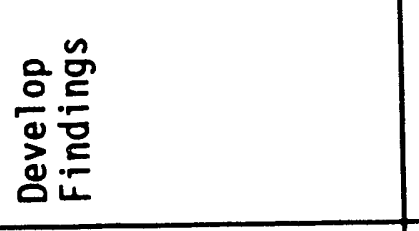 & 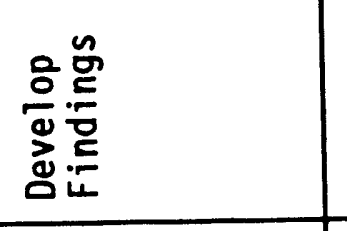 & 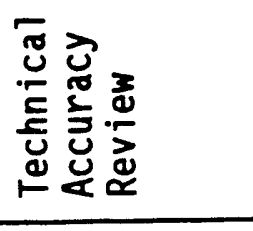 \\
\hline & 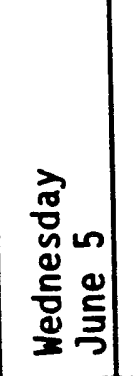 & 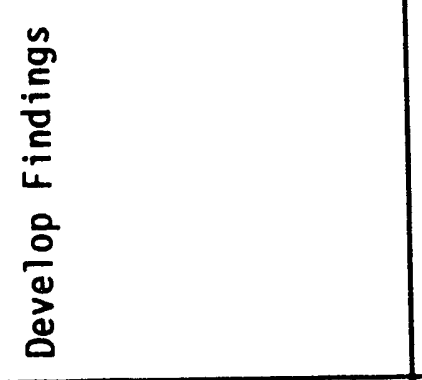 & 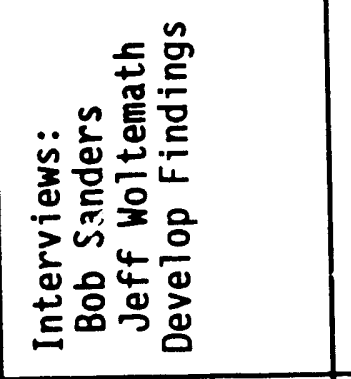 & 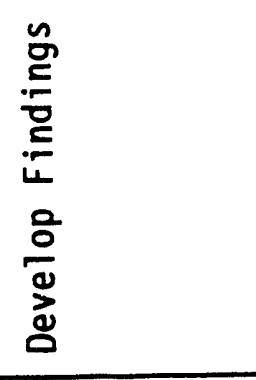 \\
\hline & 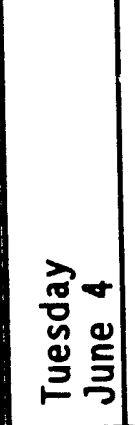 & 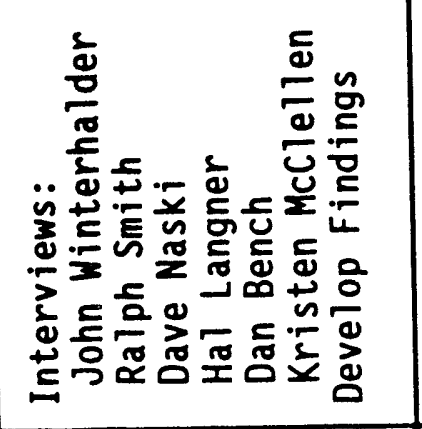 & 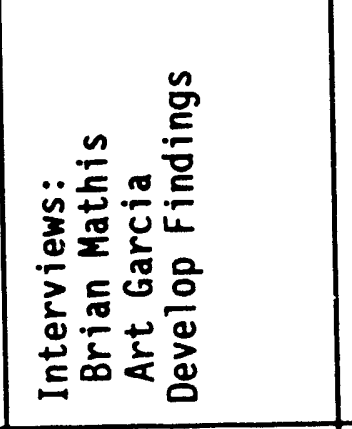 & 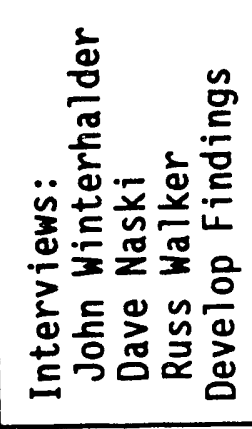 \\
\hline & 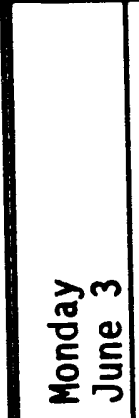 & 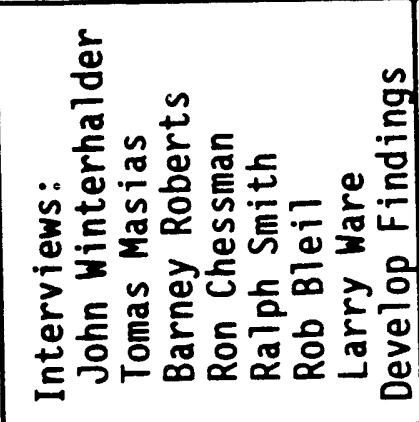 & 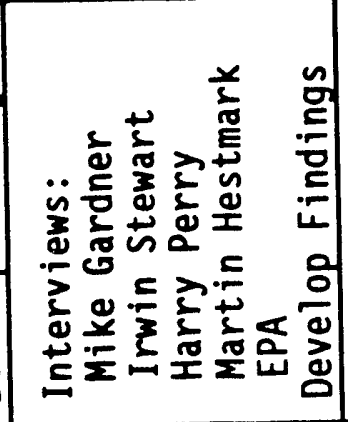 & 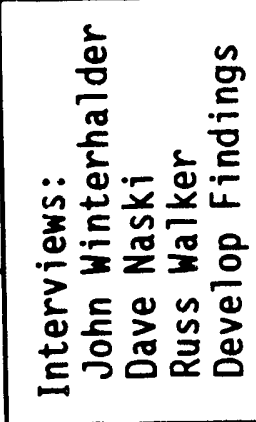 \\
\hline & & 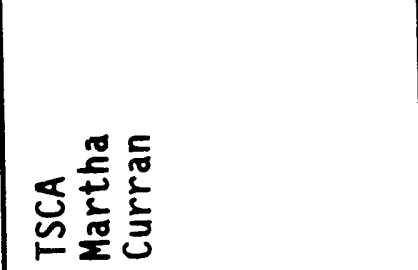 & 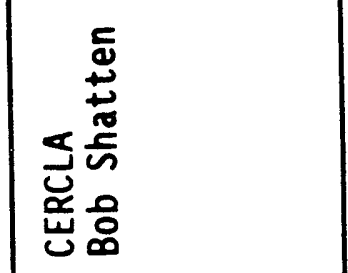 & 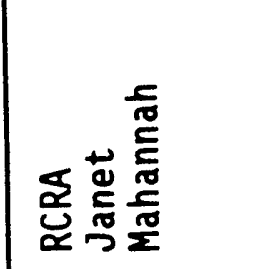 \\
\hline
\end{tabular}




\begin{tabular}{|c|c|c|c|}
\hline & 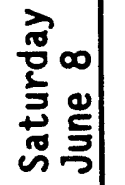 & & \\
\hline \multirow{6}{*}{ 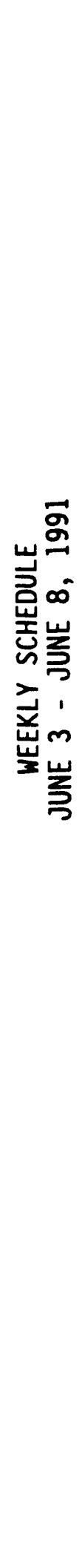 } & 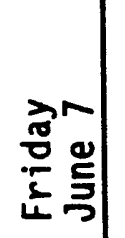 & 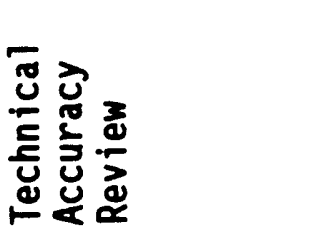 & \\
\hline & 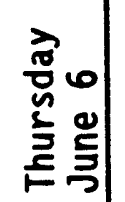 & 응 & 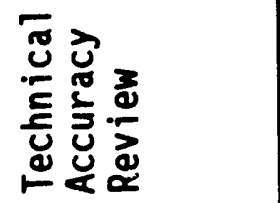 \\
\hline & 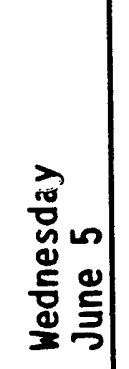 & 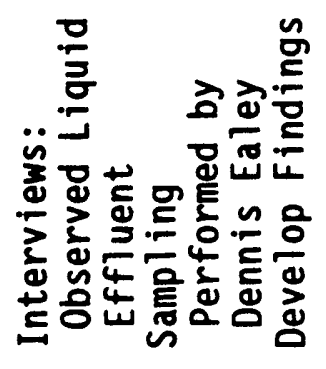 & 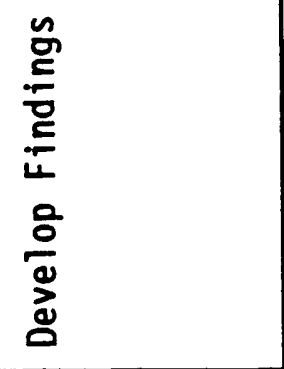 \\
\hline & 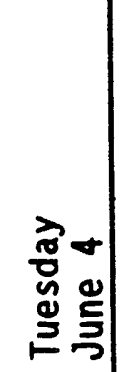 & 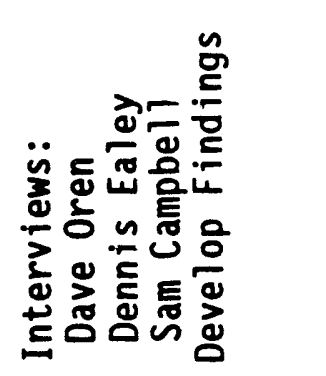 & 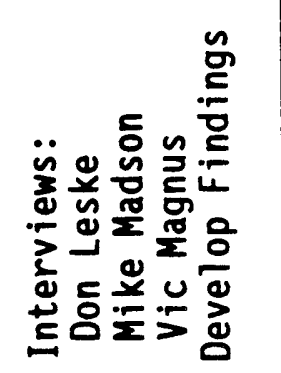 \\
\hline & 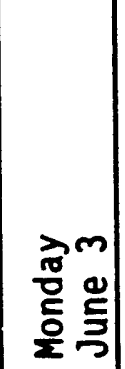 & 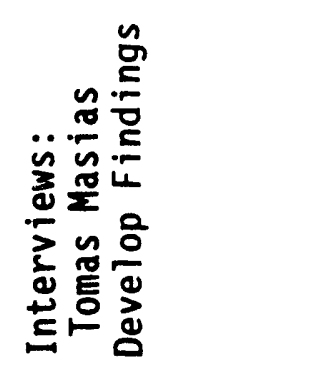 & 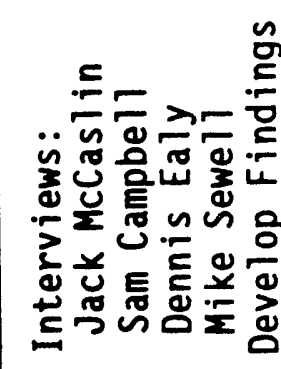 \\
\hline & & 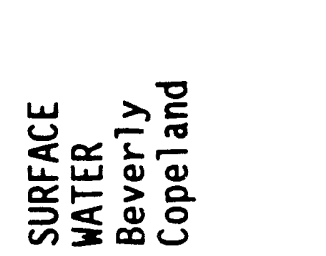 & 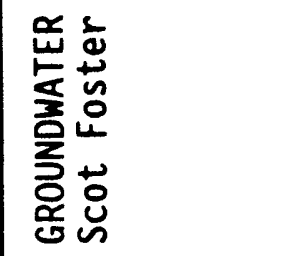 \\
\hline
\end{tabular}




\begin{tabular}{|c|c|c|c|}
\hline & 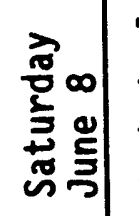 & 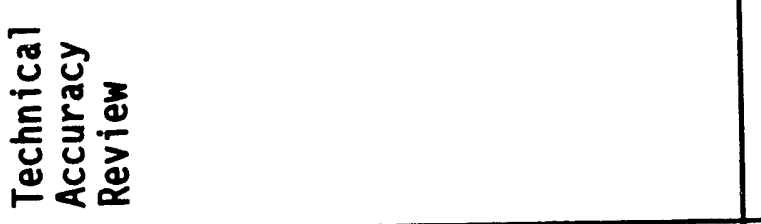 & \\
\hline \multirow{6}{*}{ 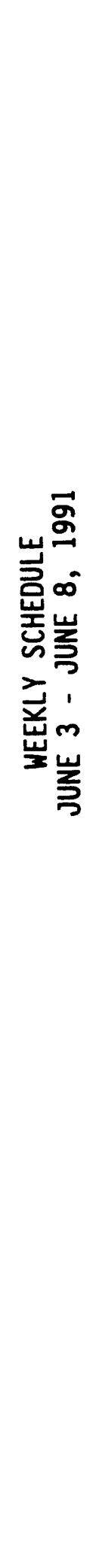 } & $\begin{array}{ll}\overrightarrow{0} & 0 \\
\frac{0}{2} & 0 \\
\frac{1}{5} & 5\end{array}$ & 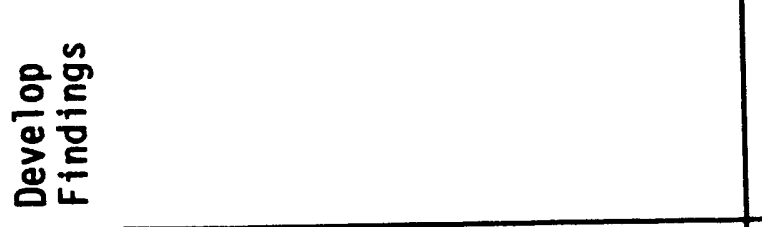 & \\
\hline & 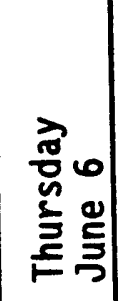 & 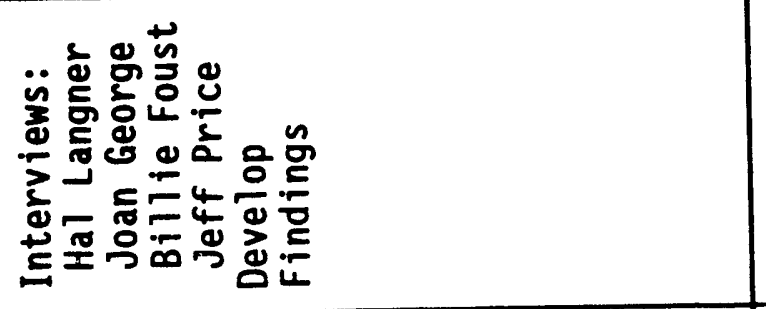 & 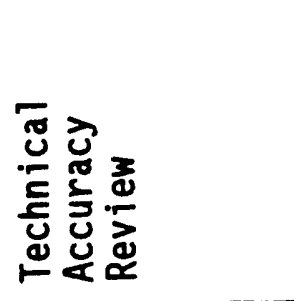 \\
\hline & 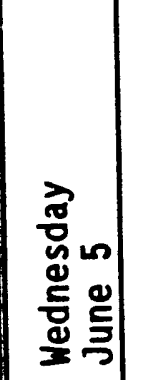 & 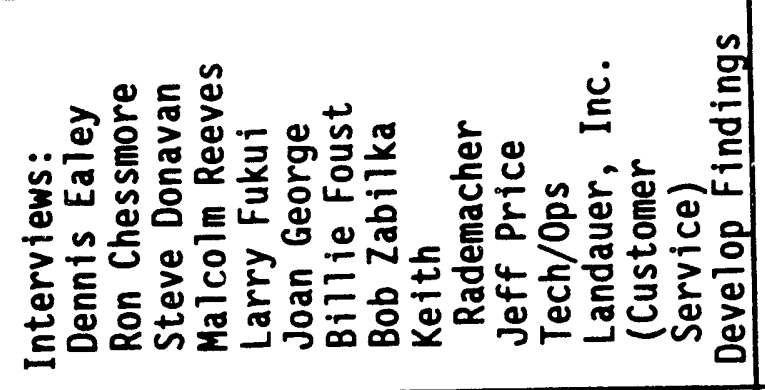 & 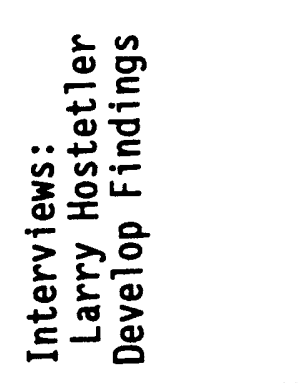 \\
\hline & 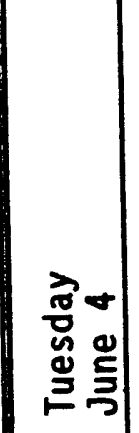 & 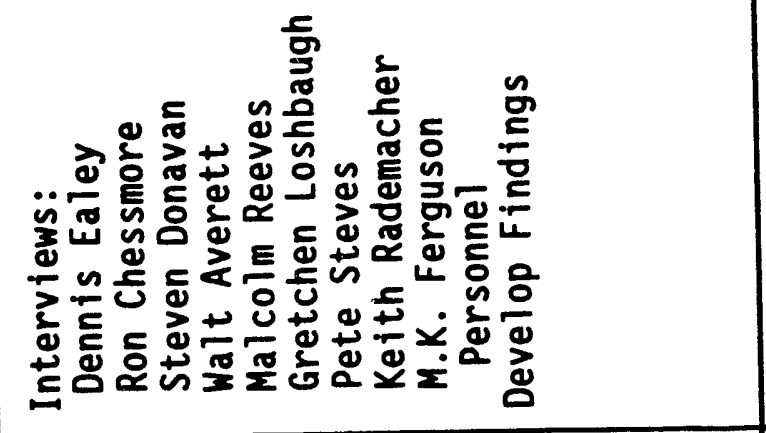 & 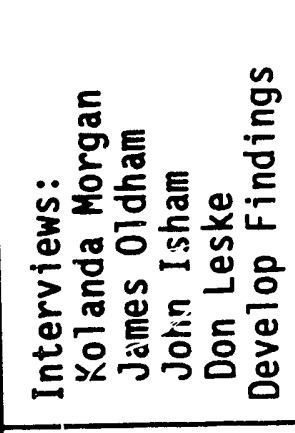 \\
\hline & $\begin{array}{l}\text { 용 } \\
\text { 듣 } \\
\text { 을 }\end{array}$ & 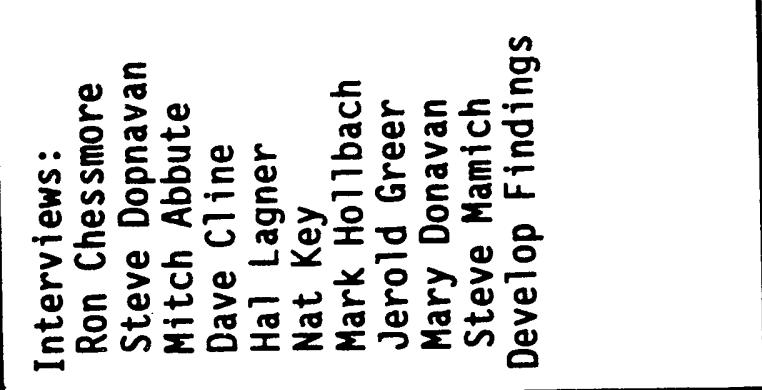 & 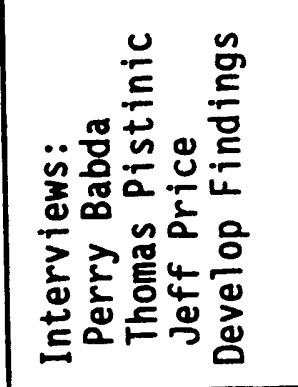 \\
\hline & & 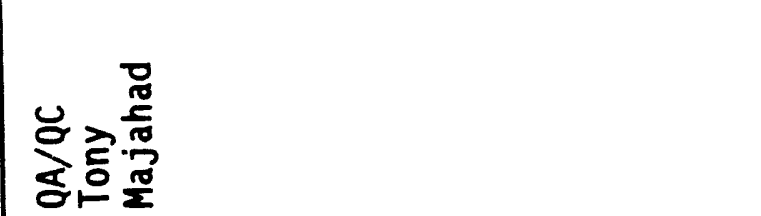 & 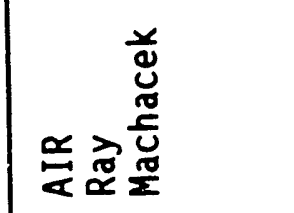 \\
\hline
\end{tabular}




\begin{tabular}{|c|c|c|c|}
\hline & 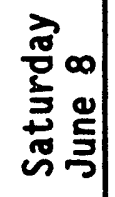 & & \\
\hline \multirow{6}{*}{ 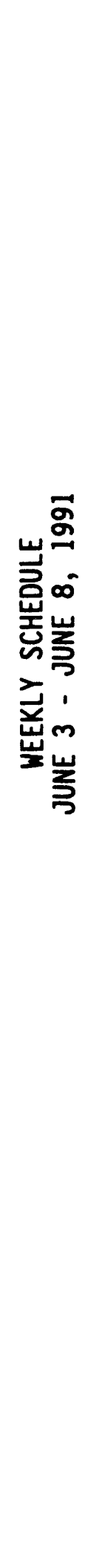 } & $\begin{array}{ll}\lambda_{0} & \\
\frac{8}{2} & 0 \\
\frac{5}{2} & 5\end{array}$ & & 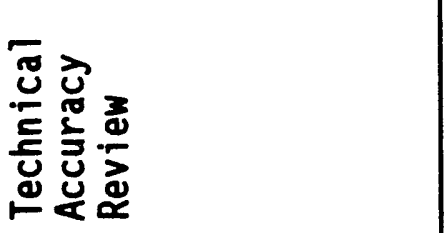 \\
\hline & 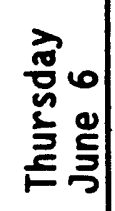 & 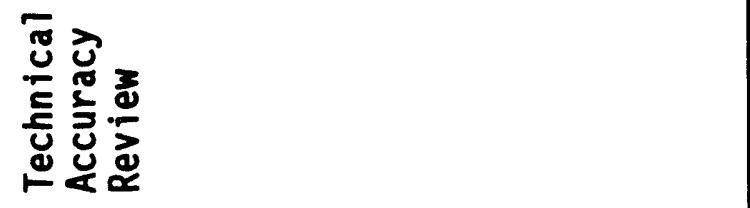 & 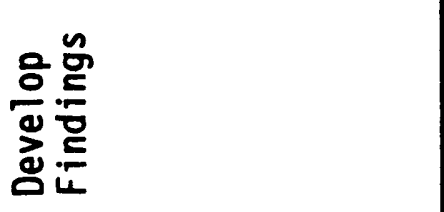 \\
\hline & 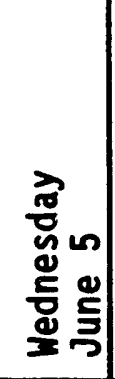 & 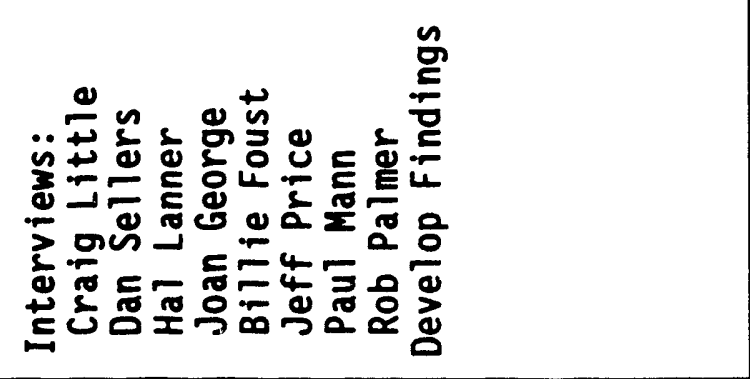 & 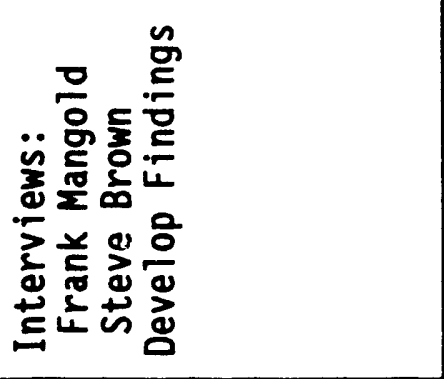 \\
\hline & 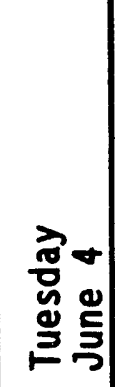 & 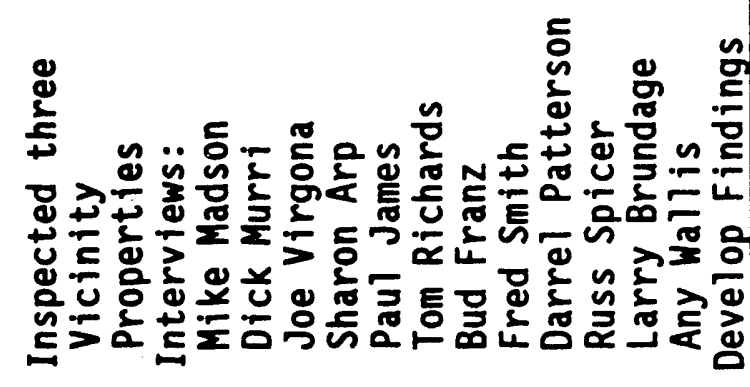 & 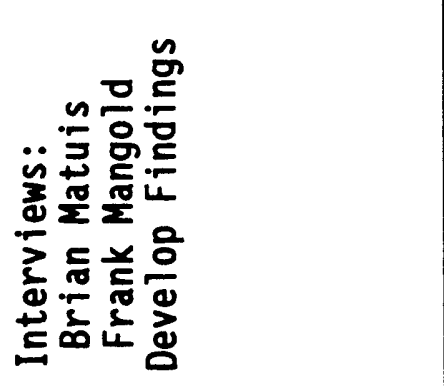 \\
\hline & $\begin{array}{l}\text { तेm } \\
\text { 음 } \\
\text { 을 }\end{array}$ & 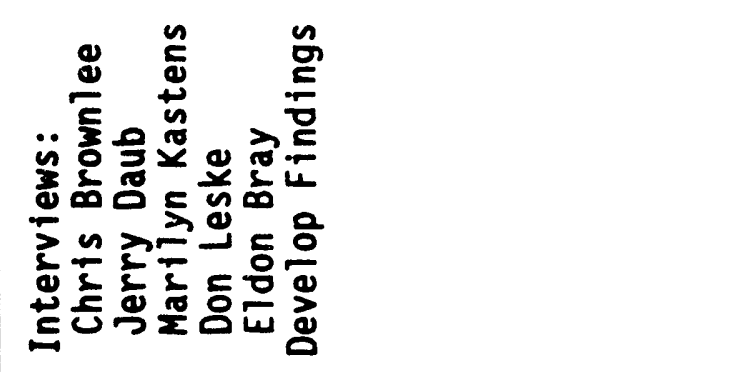 & 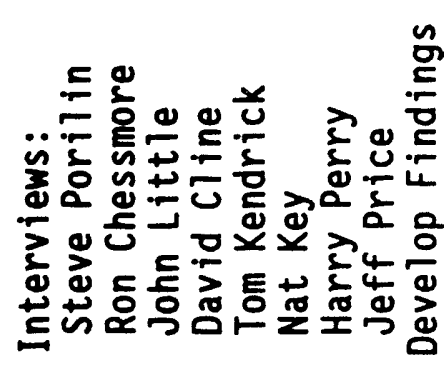 \\
\hline & & 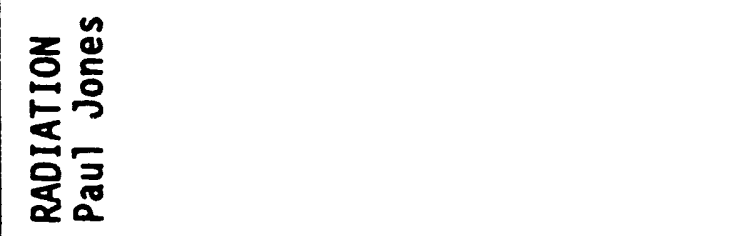 & 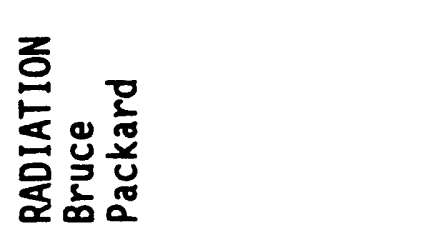 \\
\hline
\end{tabular}




\begin{tabular}{|c|c|c|}
\hline \multirow{7}{*}{ 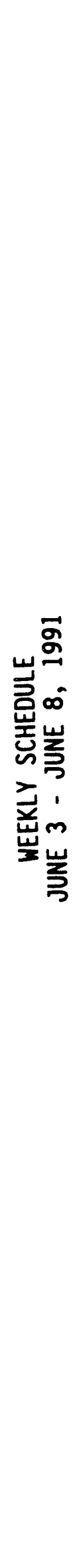 } & 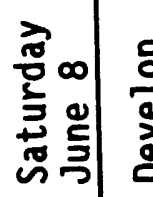 & 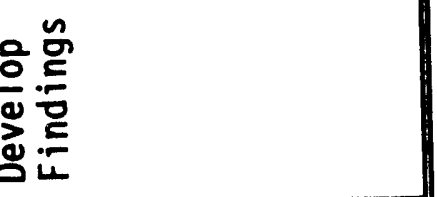 \\
\hline & $\mid$ & 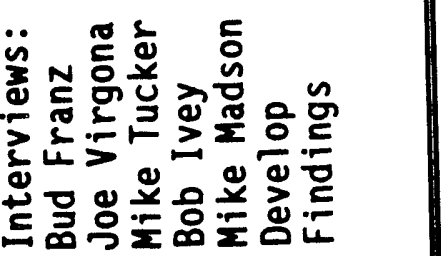 \\
\hline & 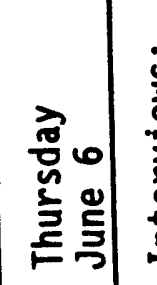 & 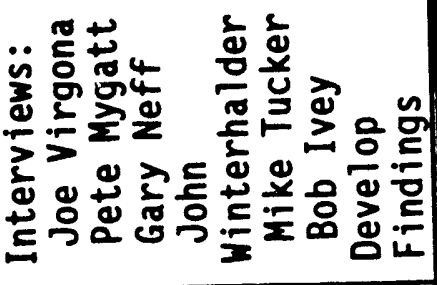 \\
\hline & 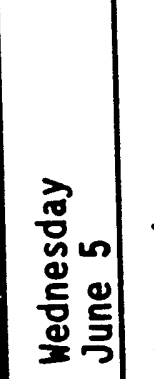 & 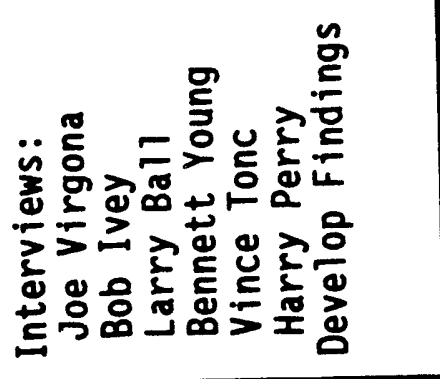 \\
\hline & 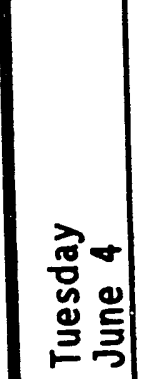 & 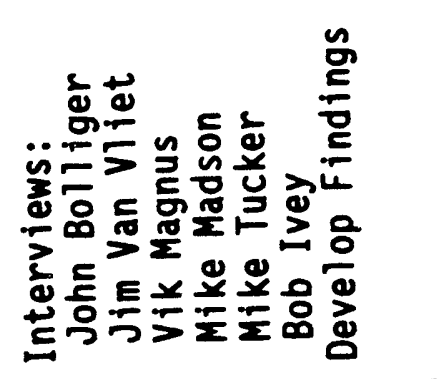 \\
\hline & 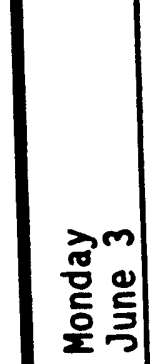 & 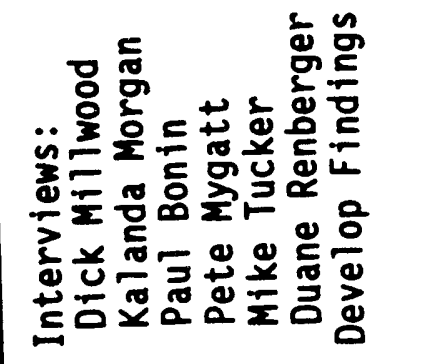 \\
\hline & & 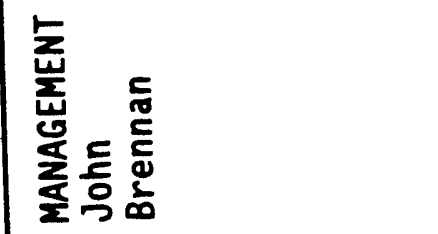 \\
\hline
\end{tabular}




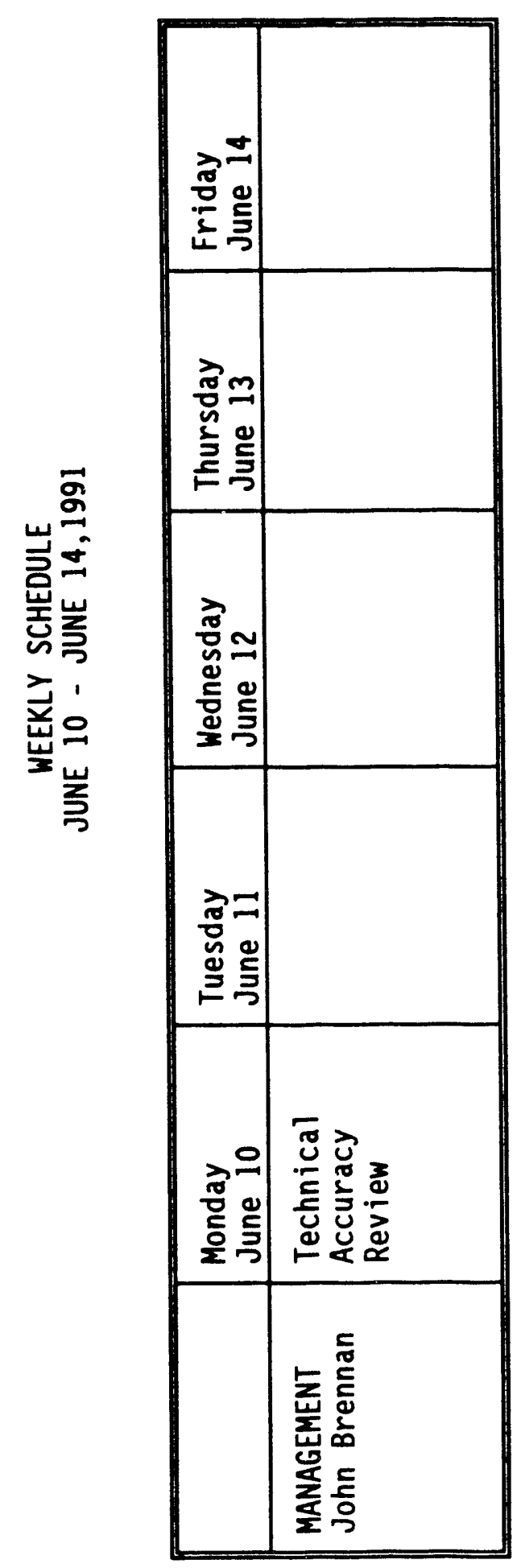

D- 11 
This page was intentionally left blank. 
APPENDIX E

LIST OF DOCUMENTS REVIEWED BY THE AUDIT TEAM 
This page was intentionally left blank. 


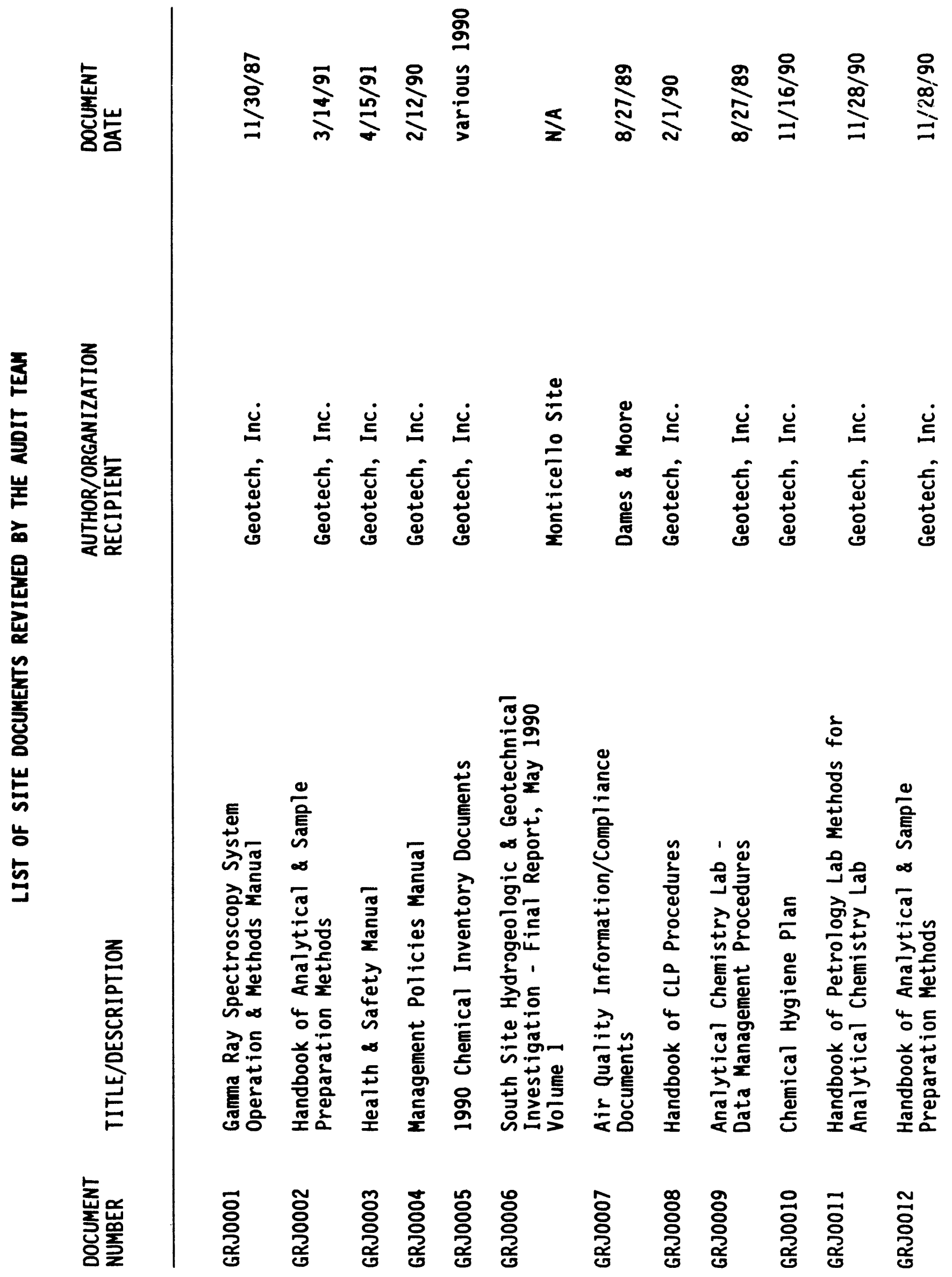




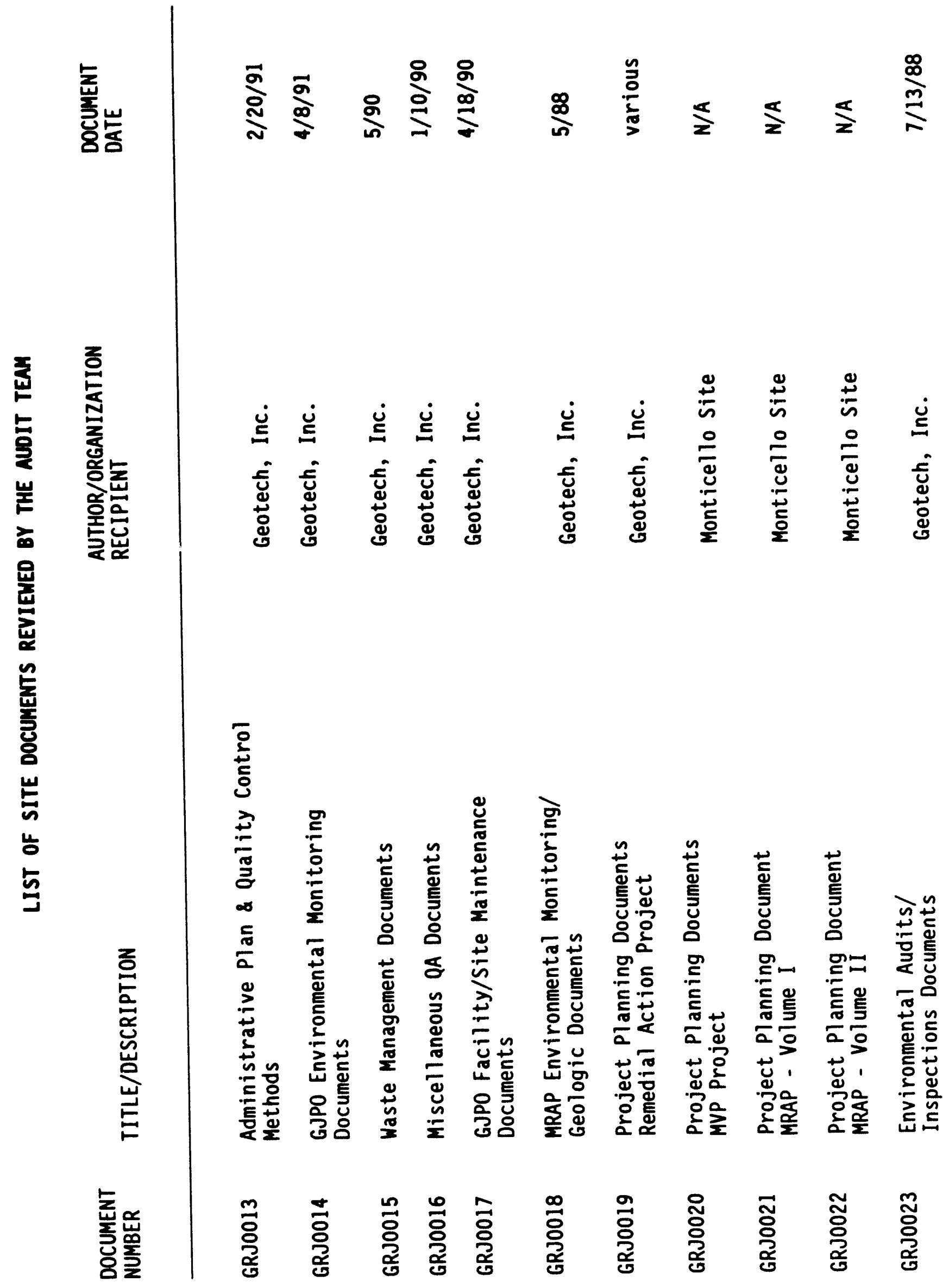




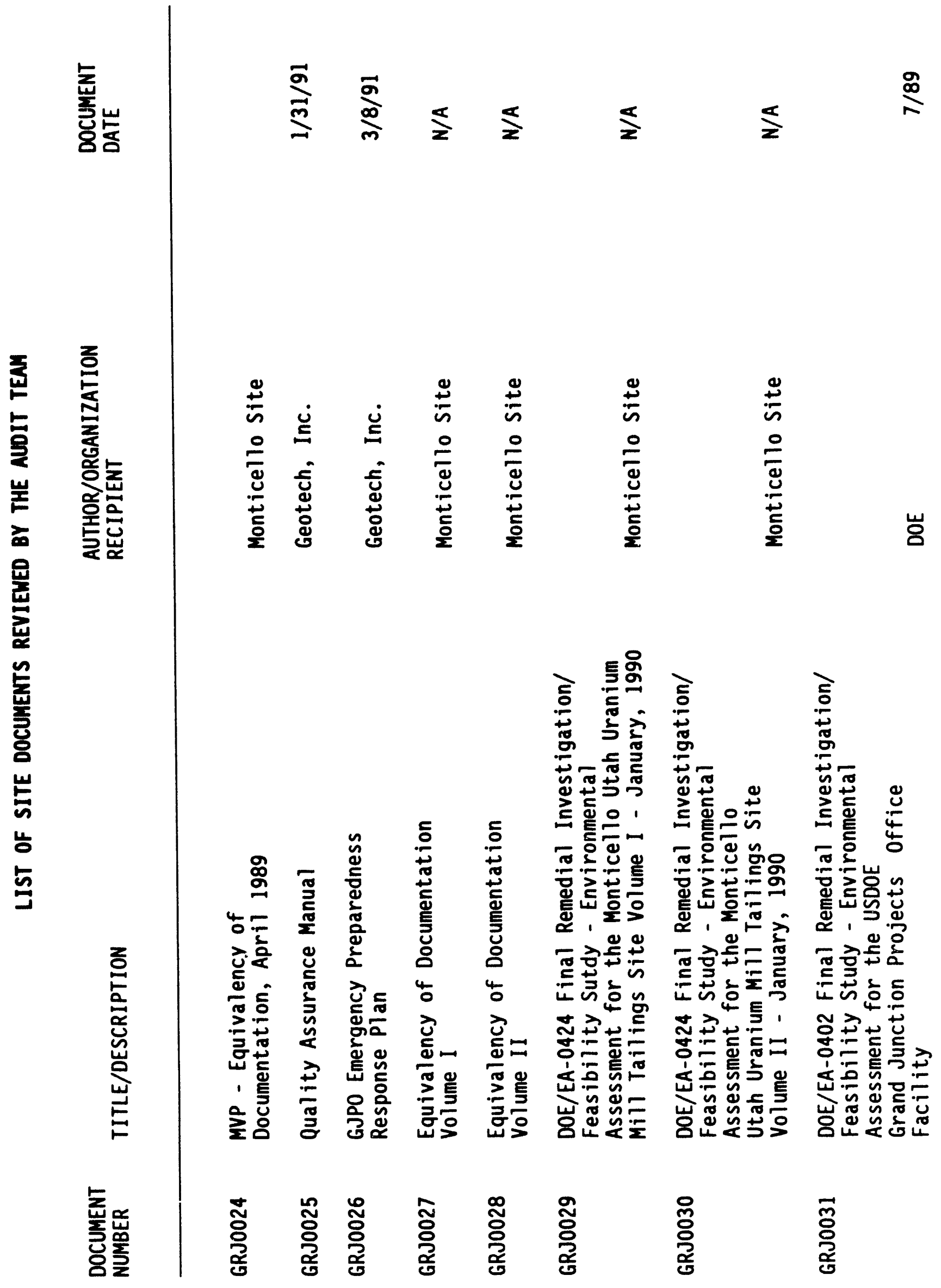




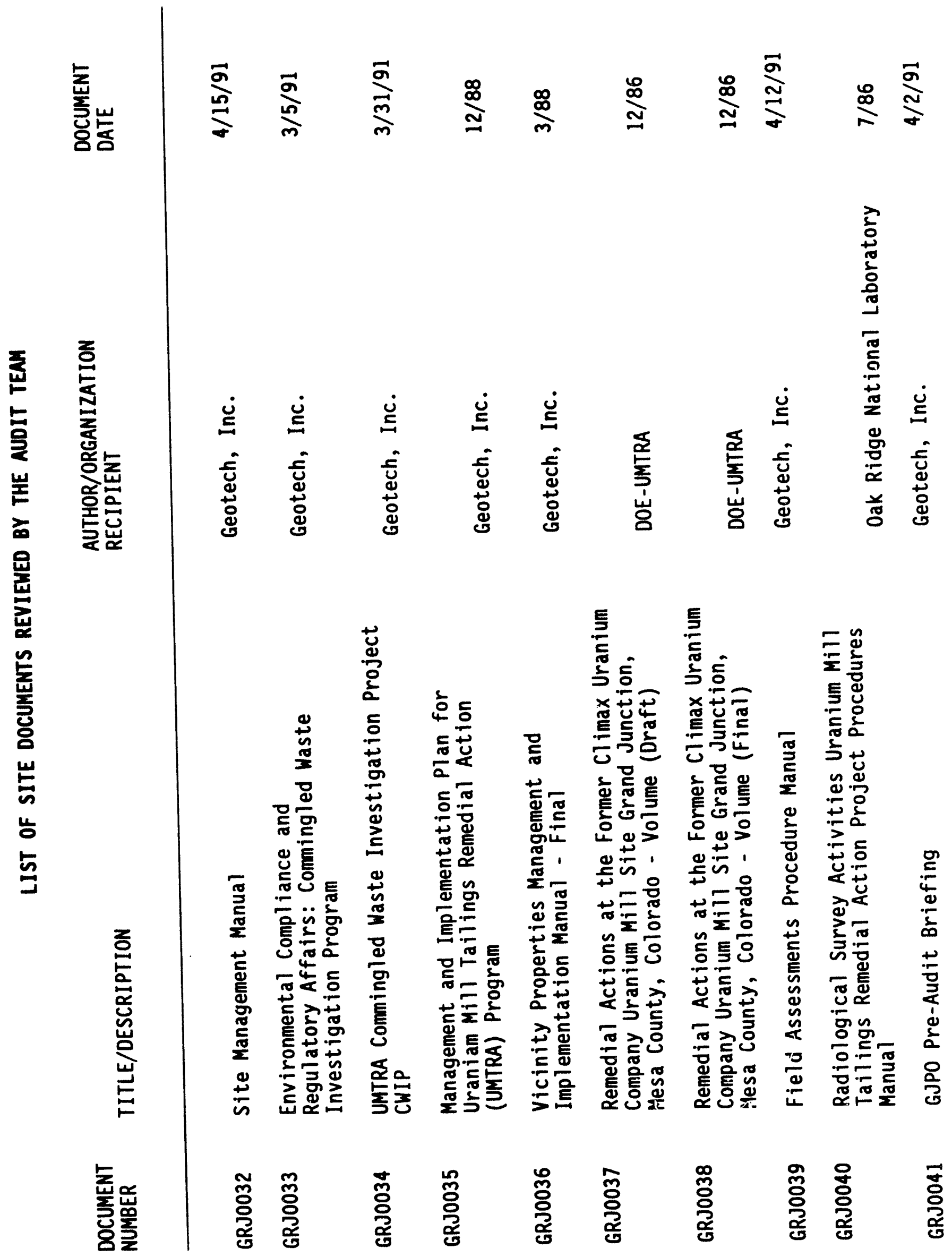




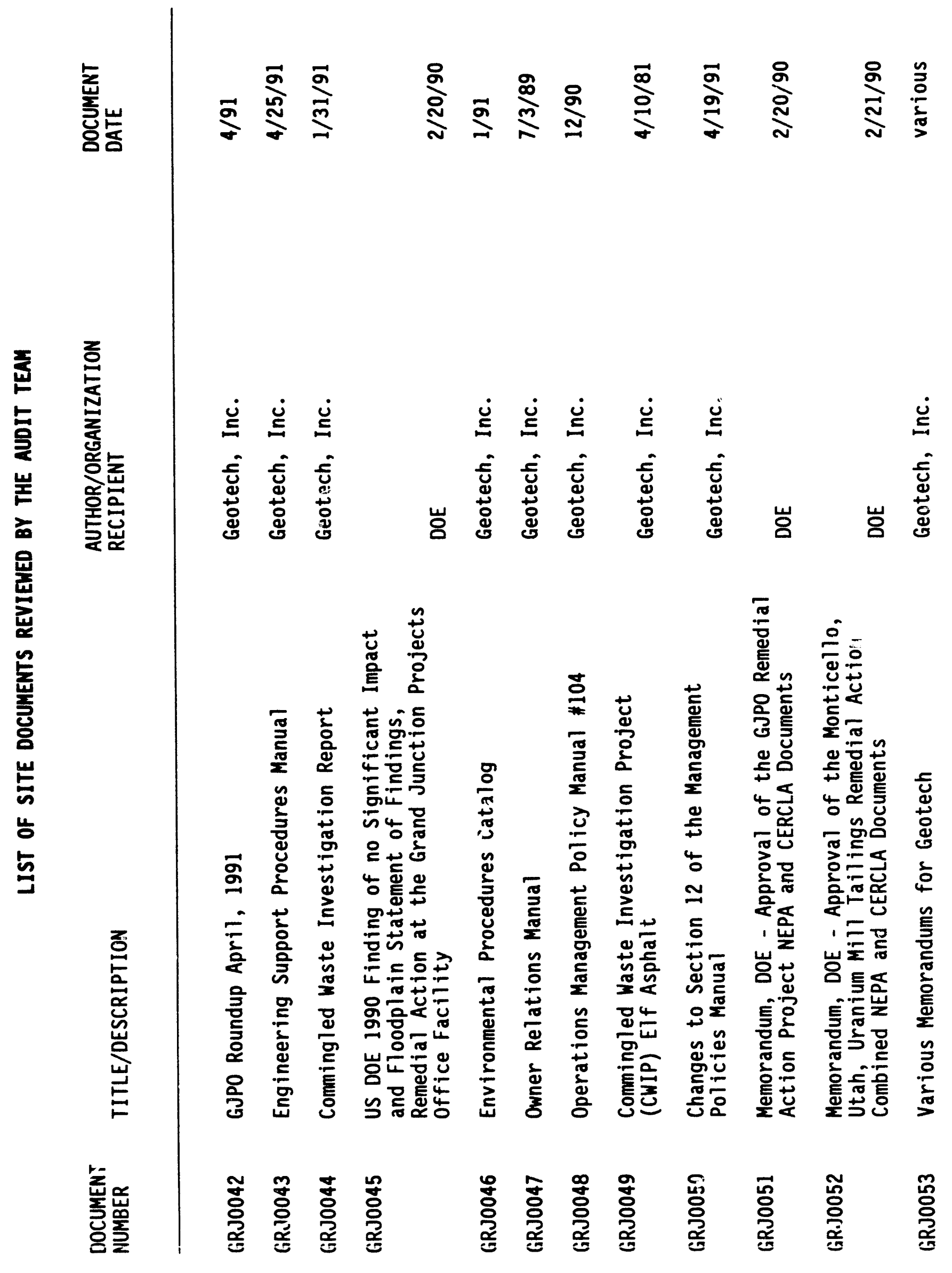




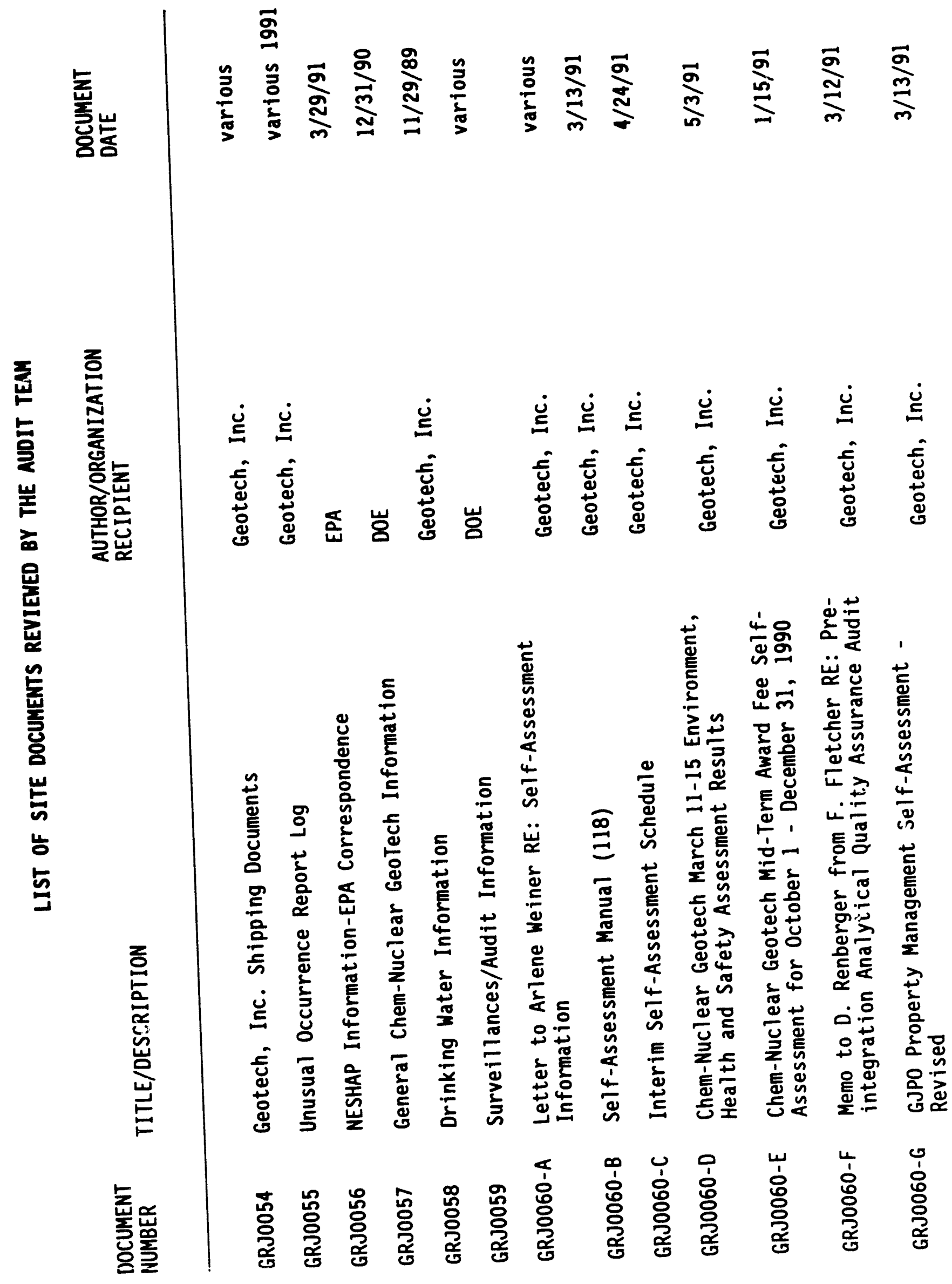




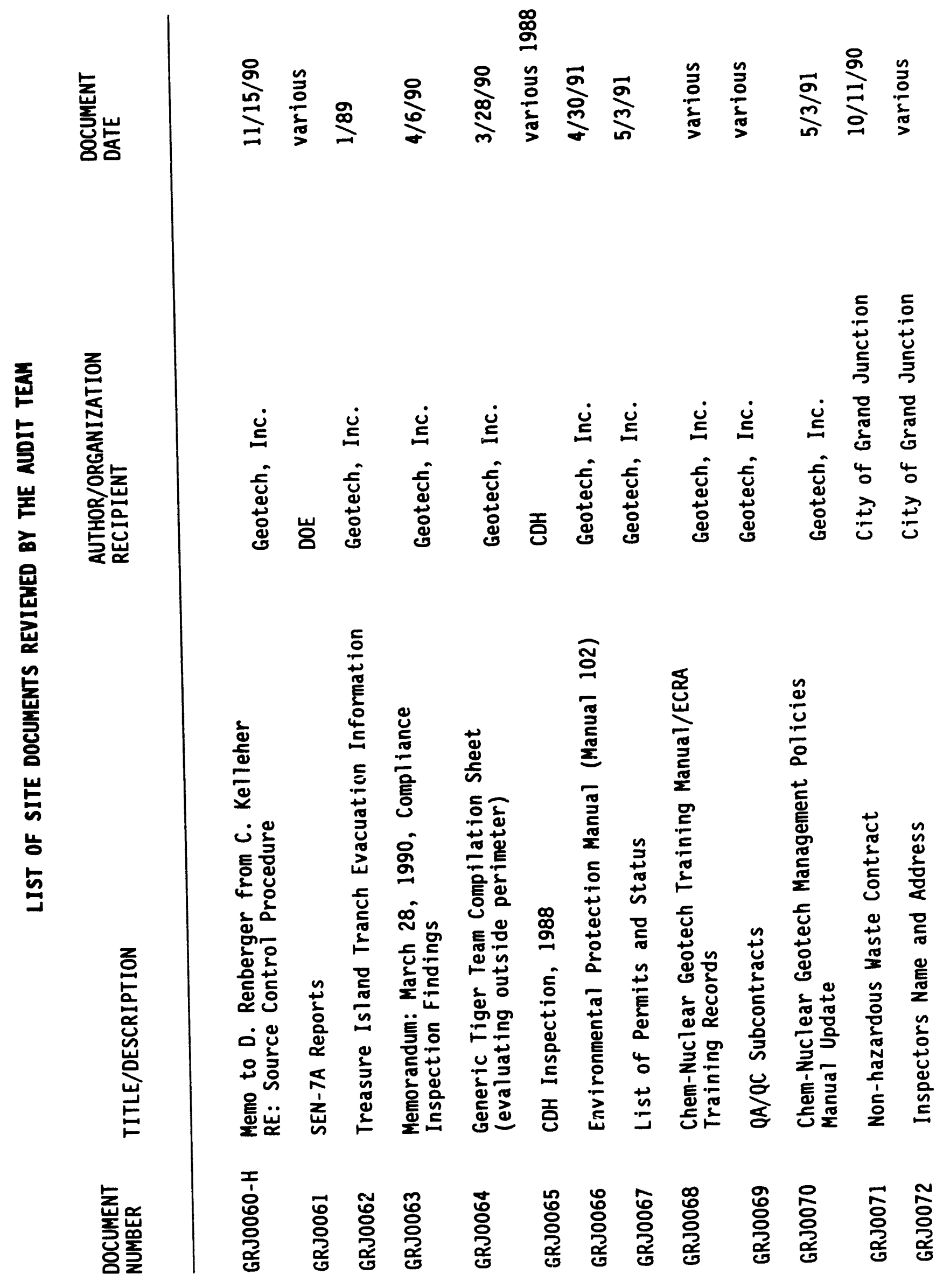




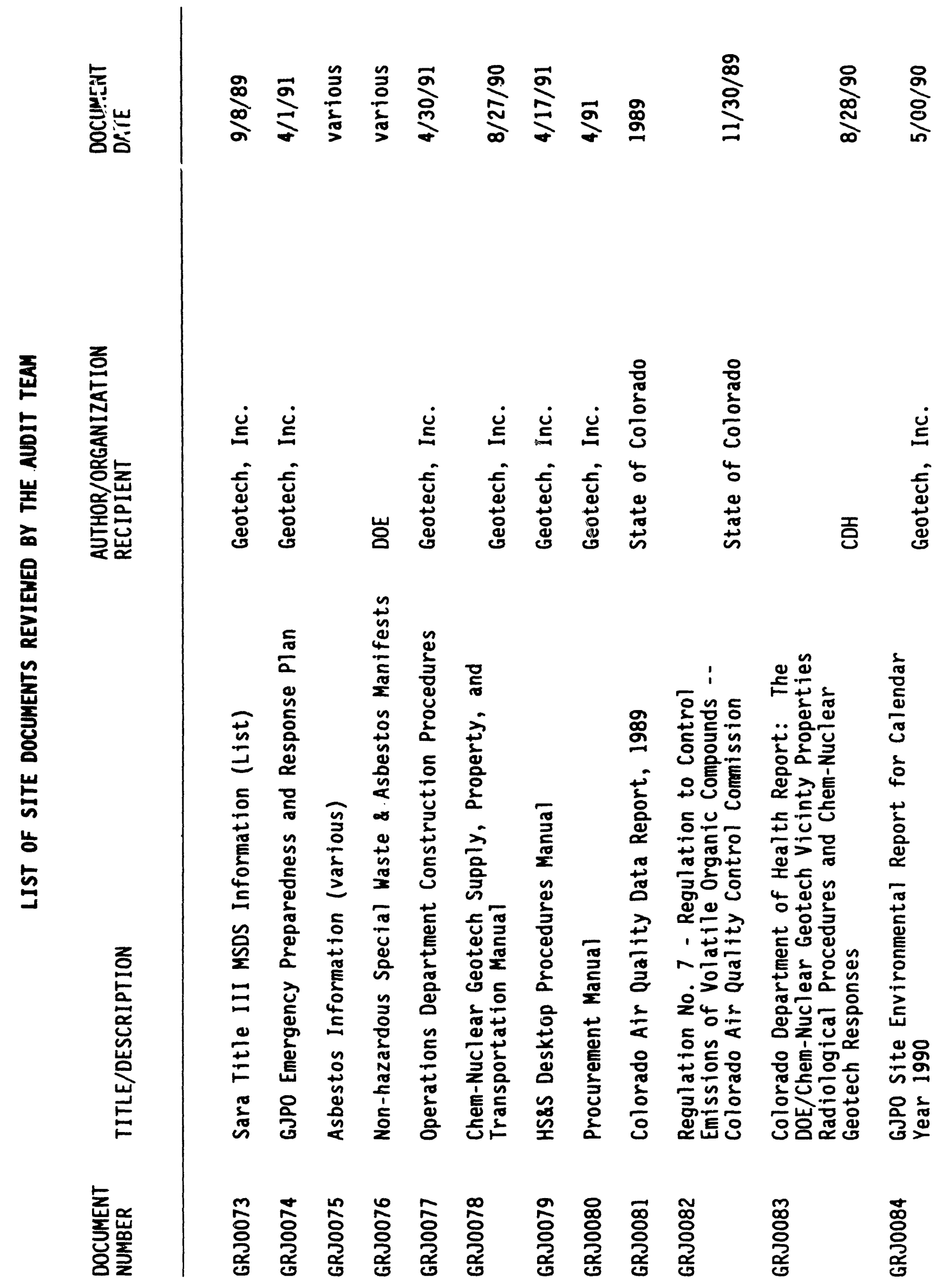




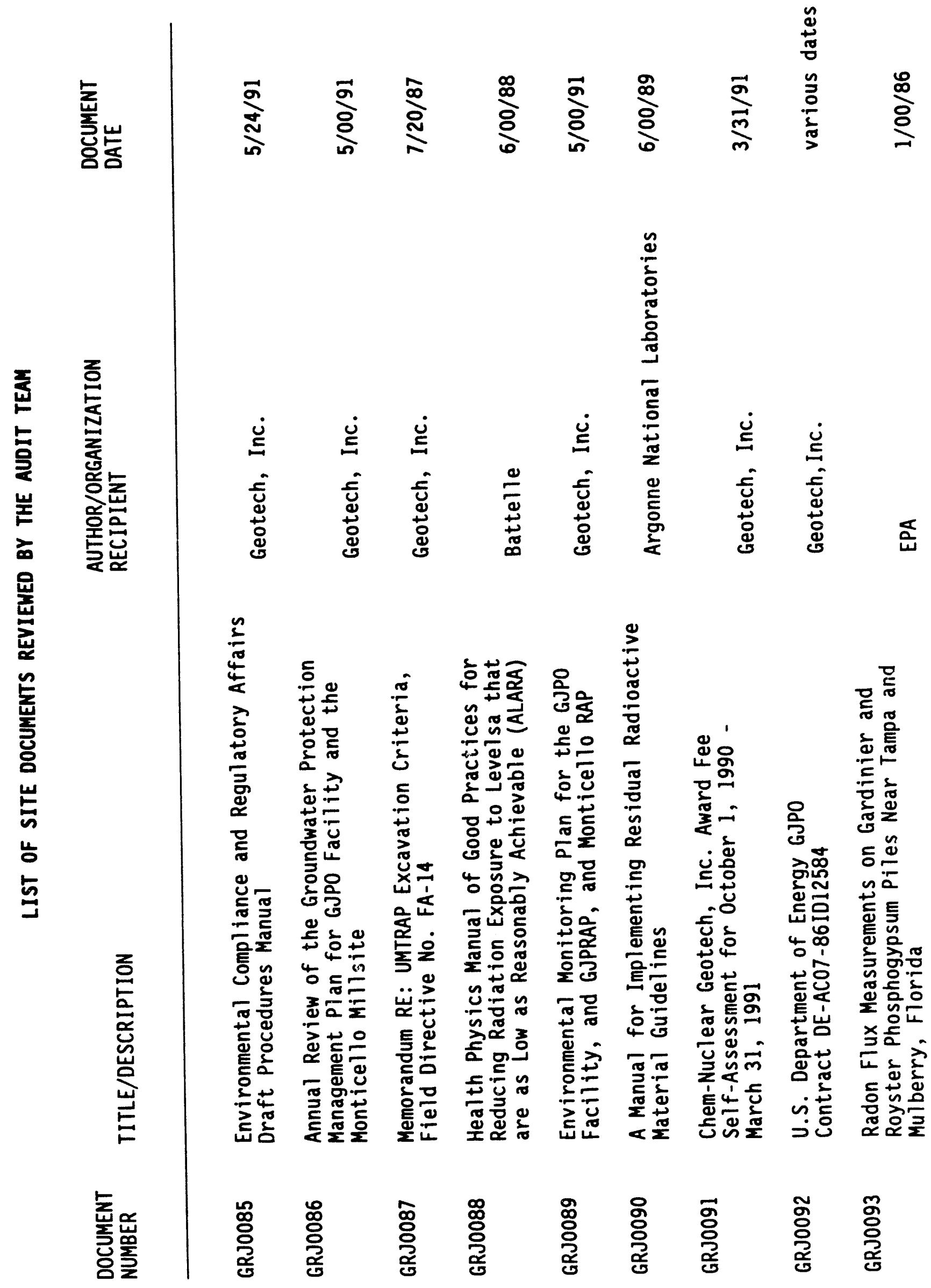




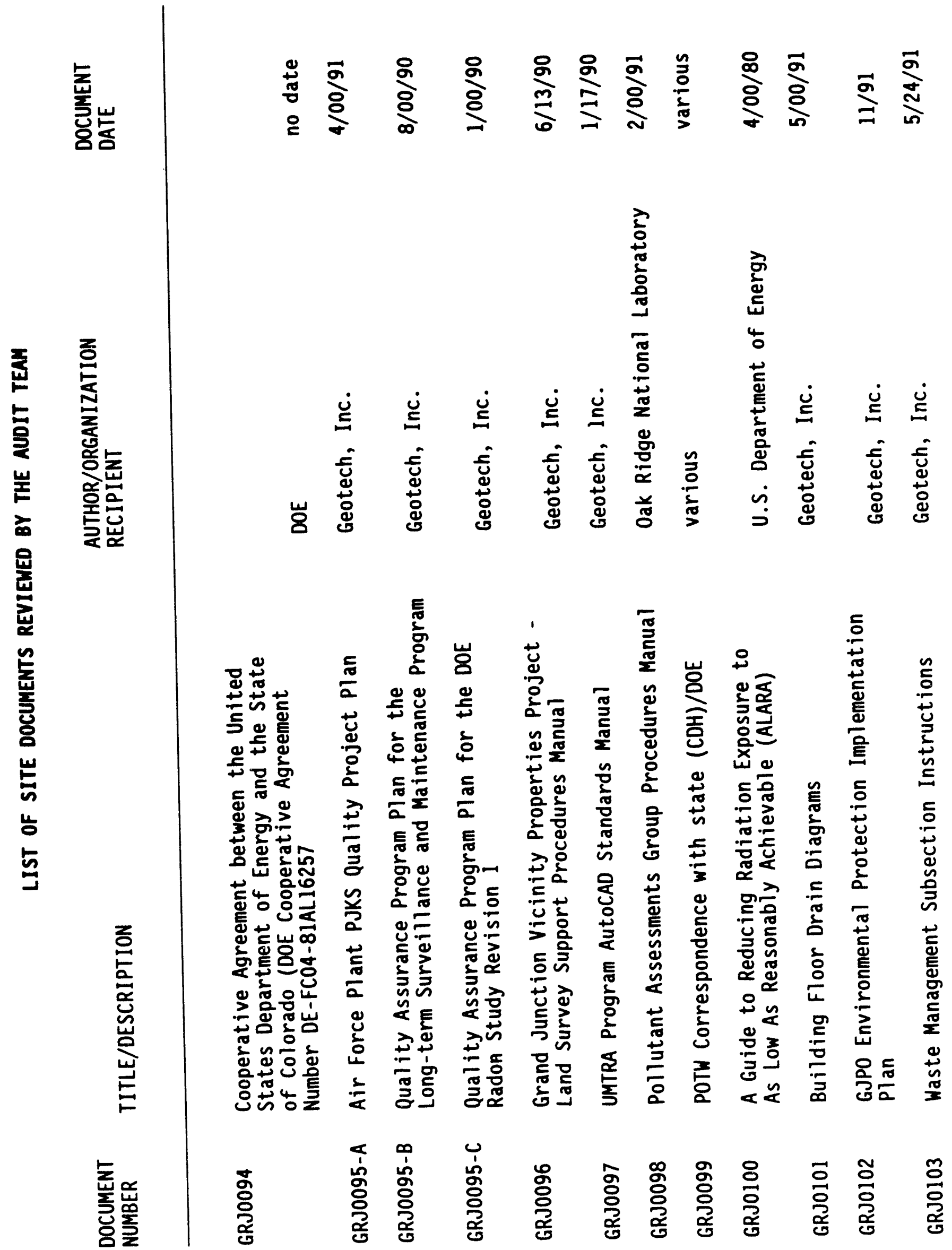




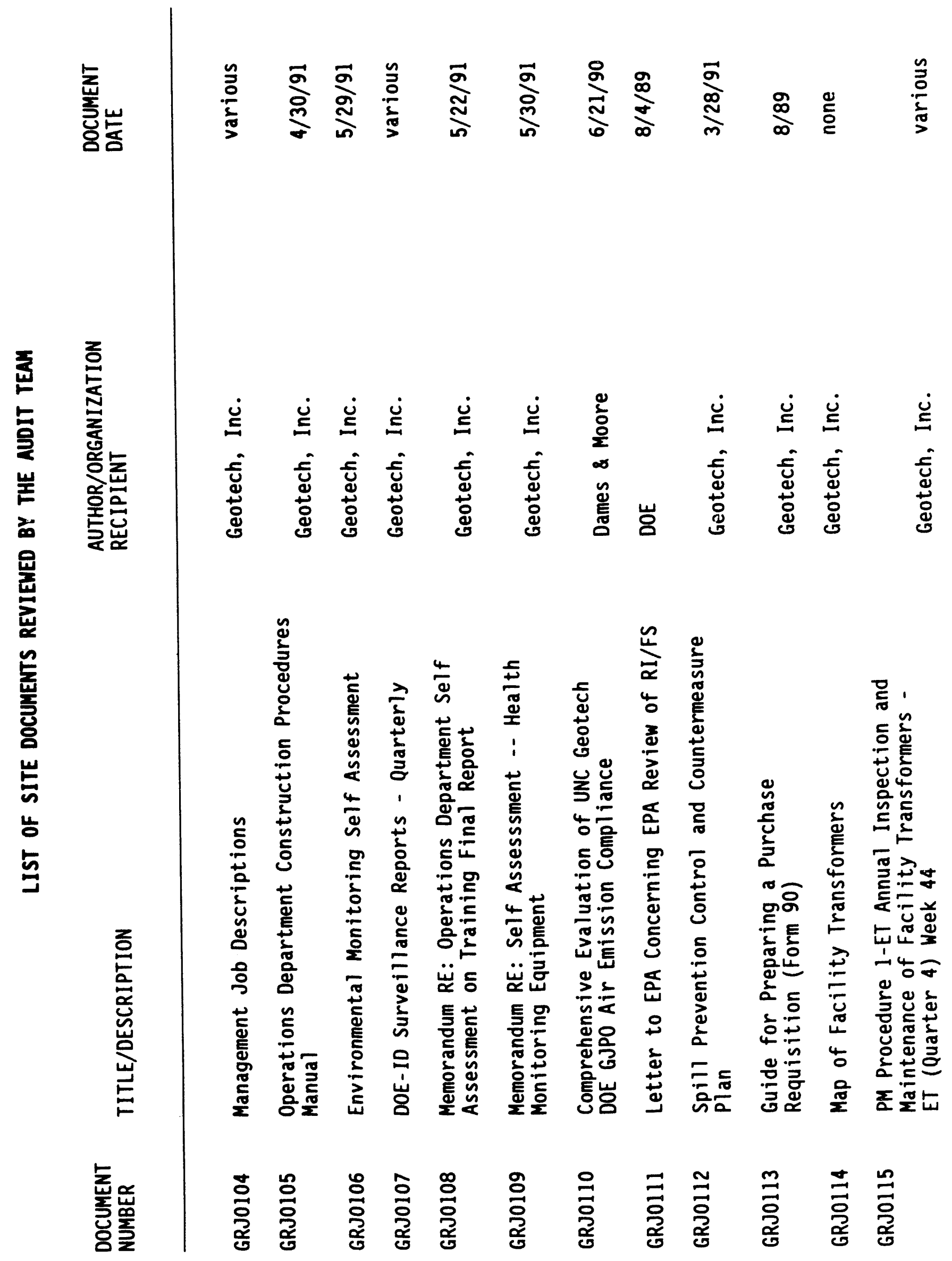




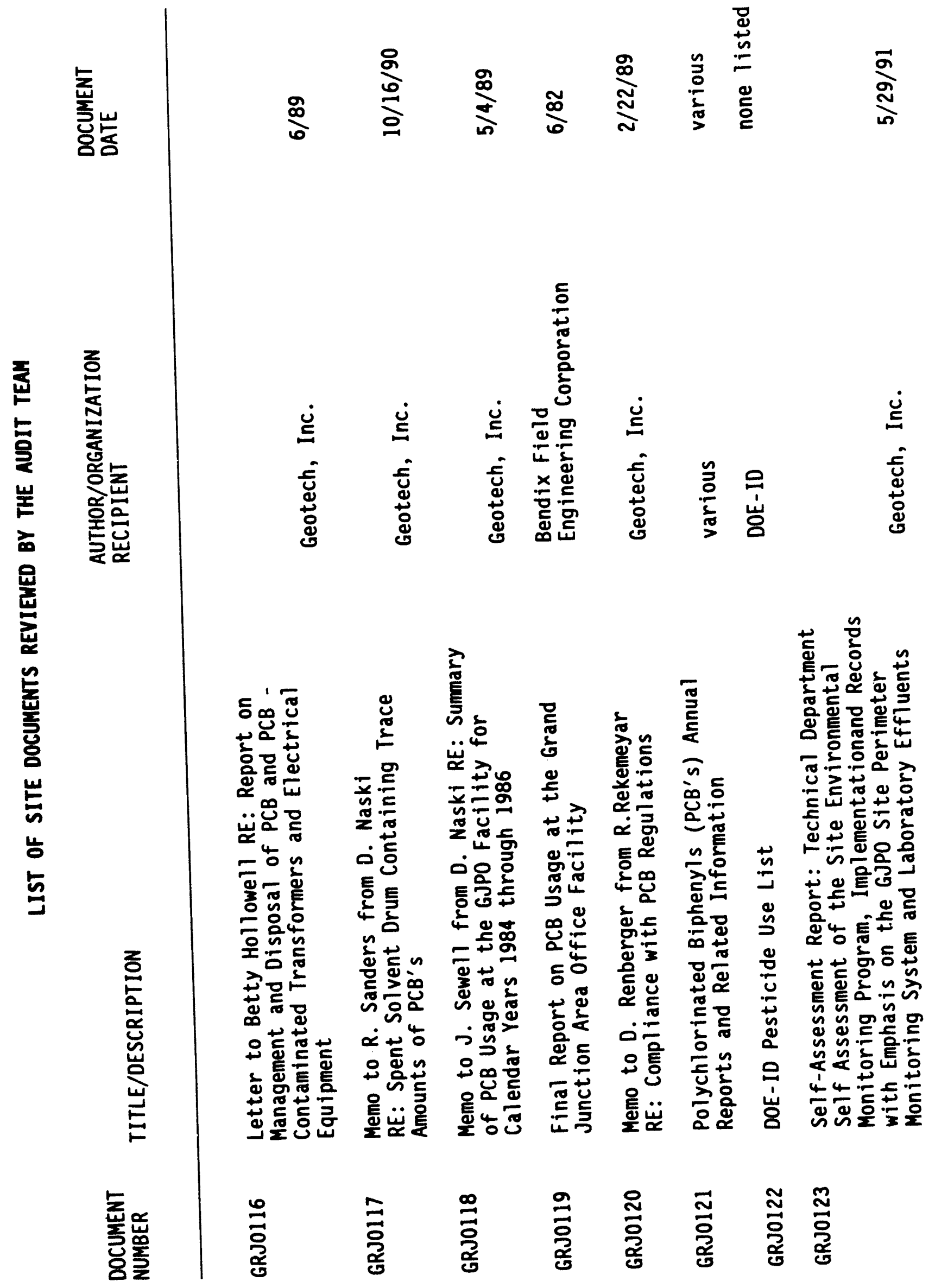




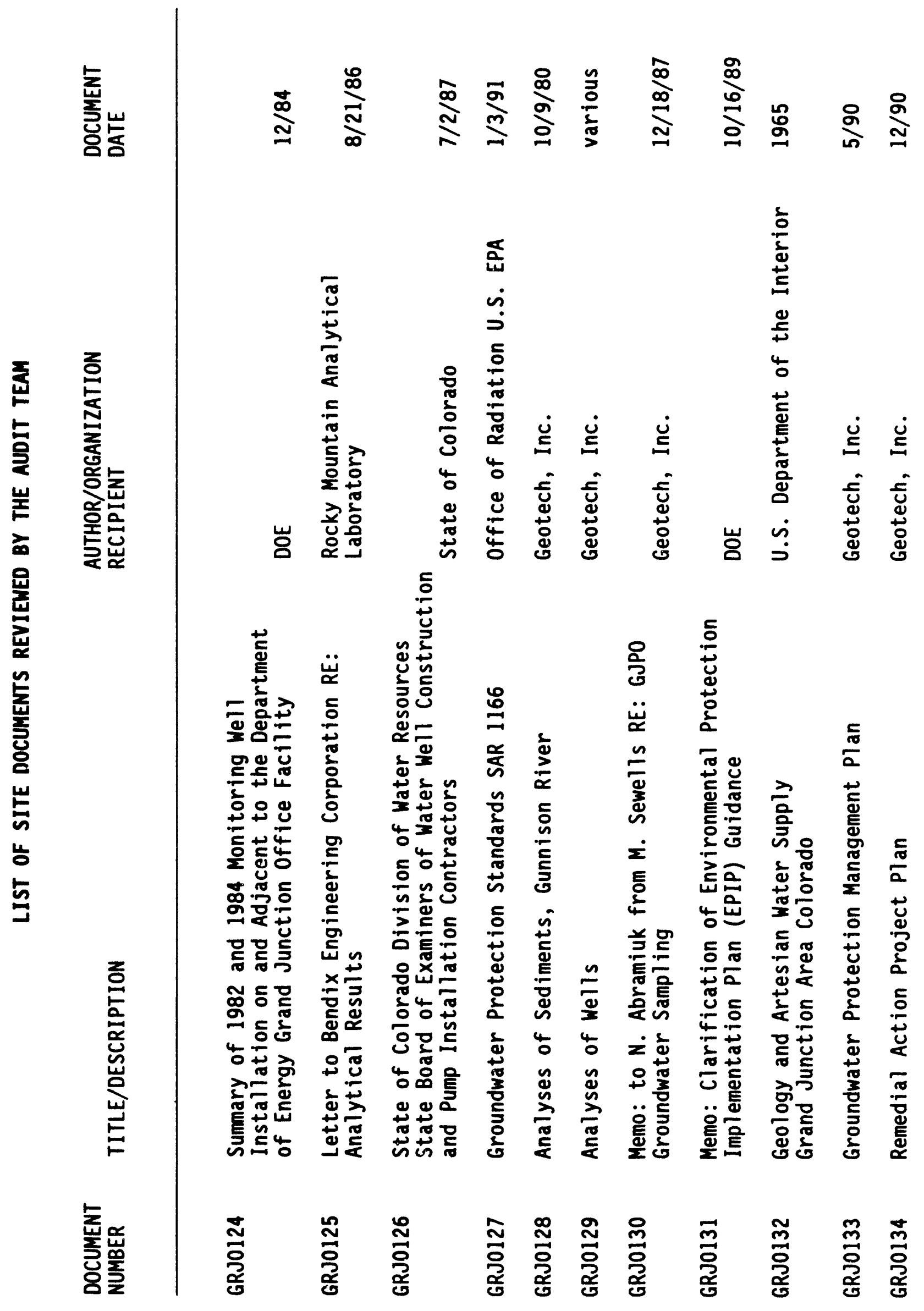




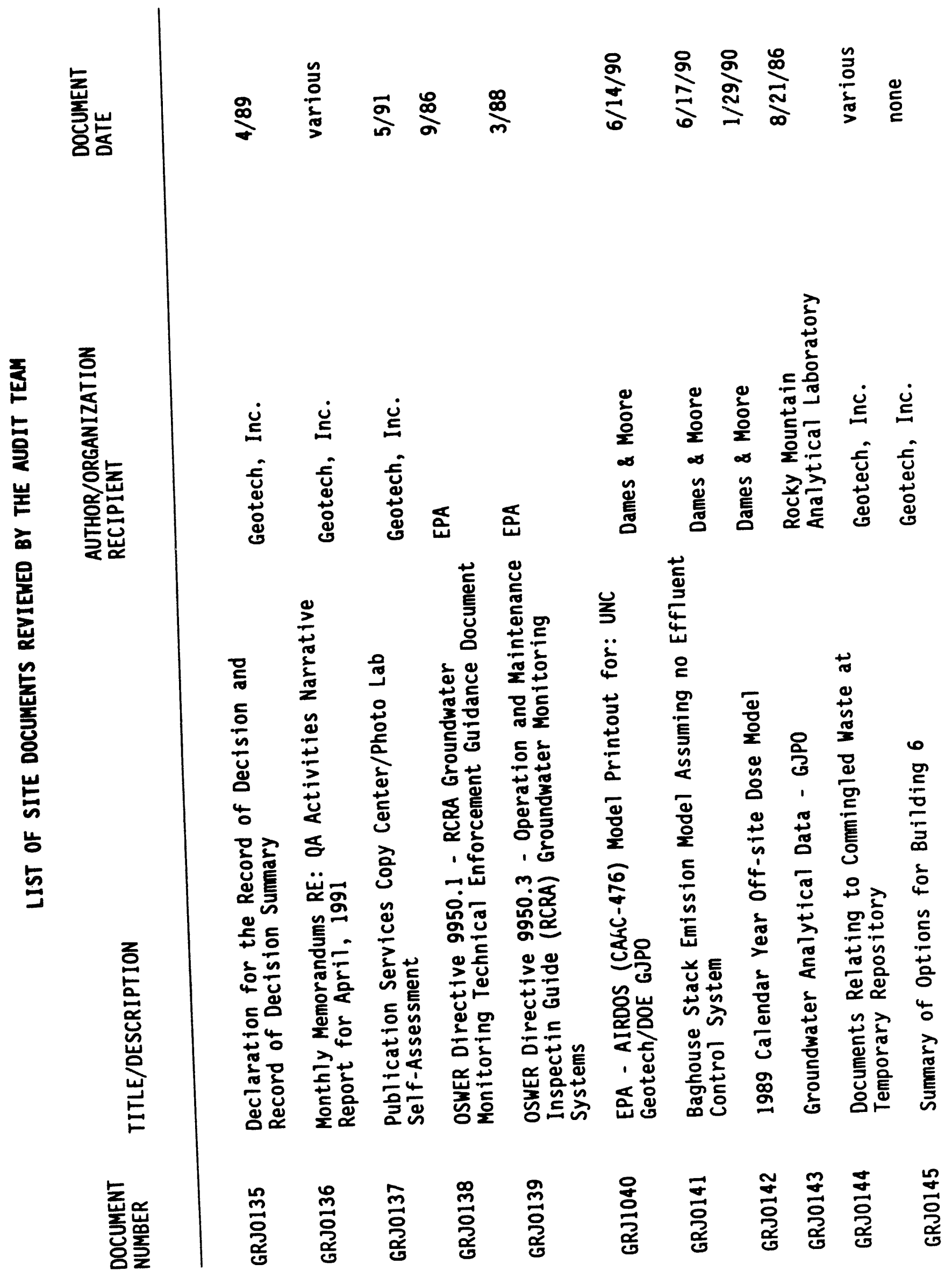




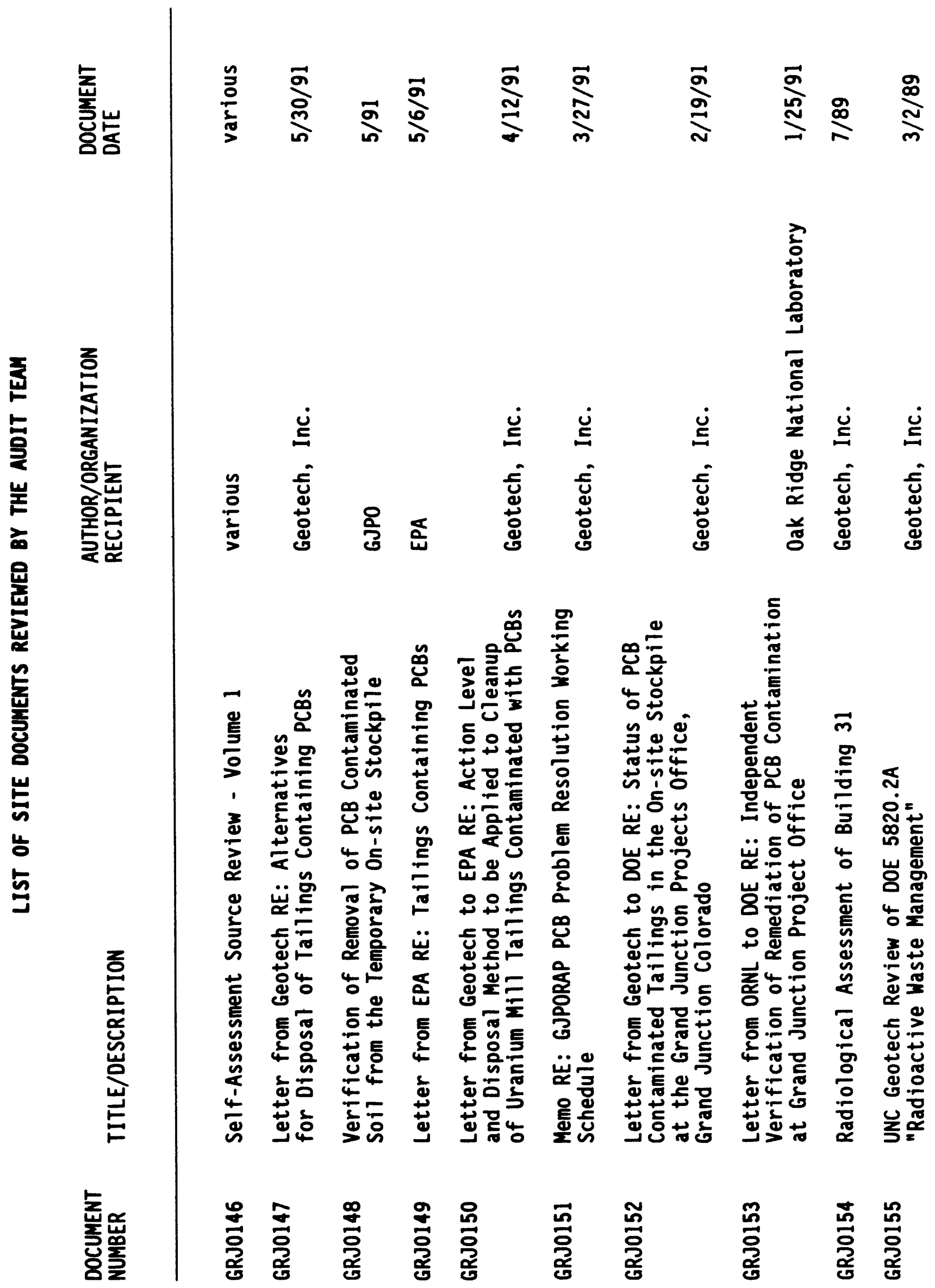




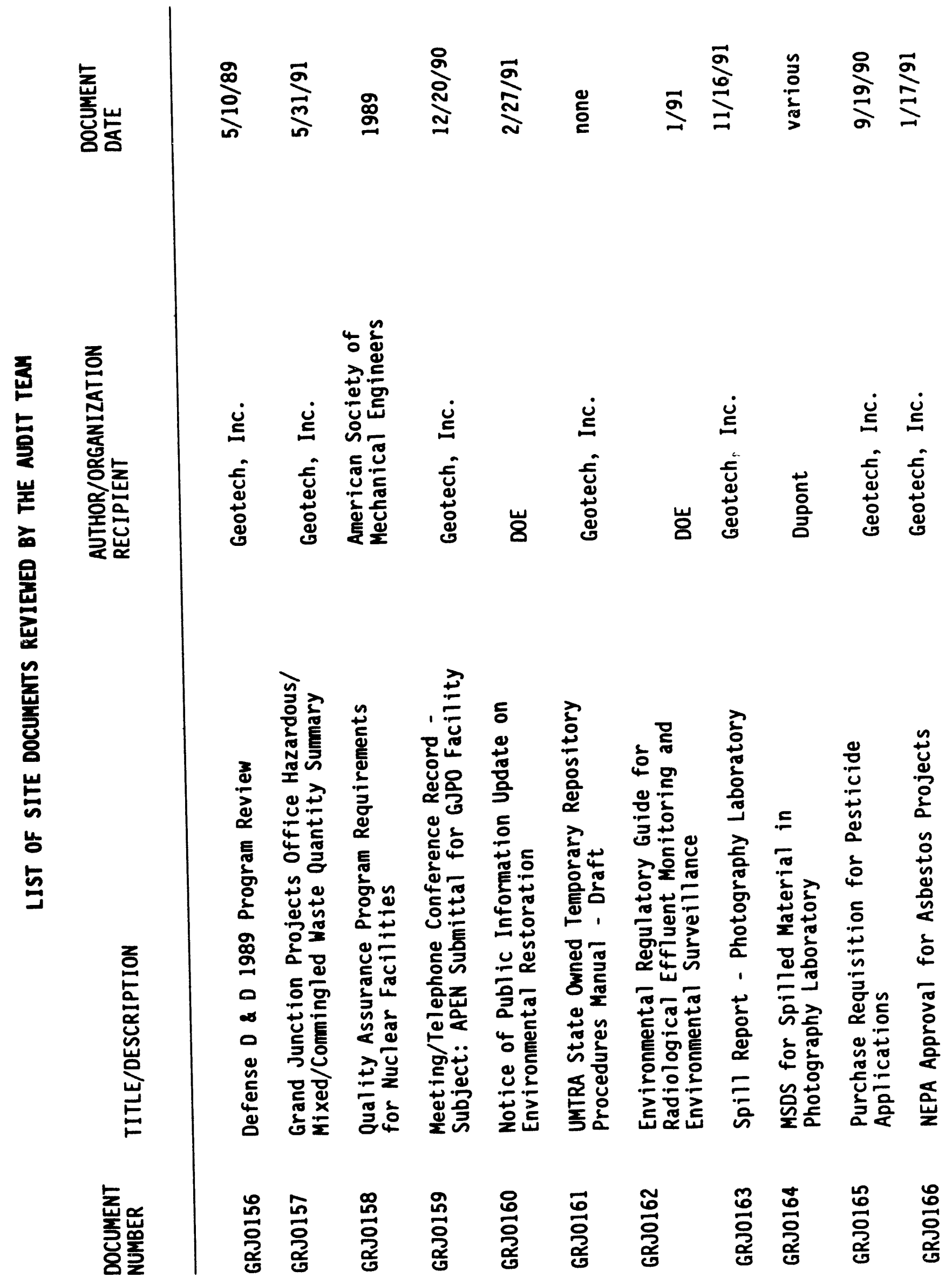




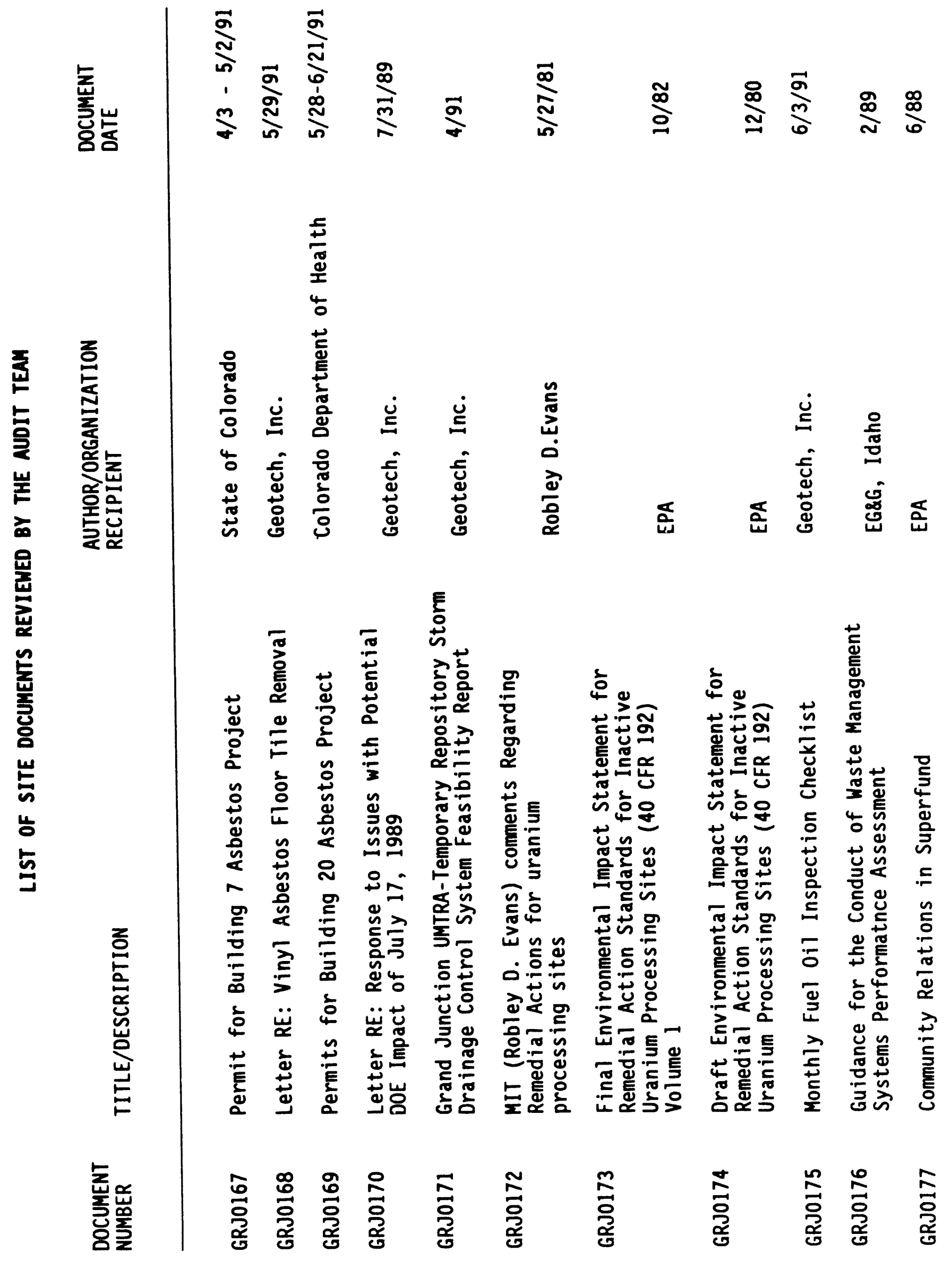




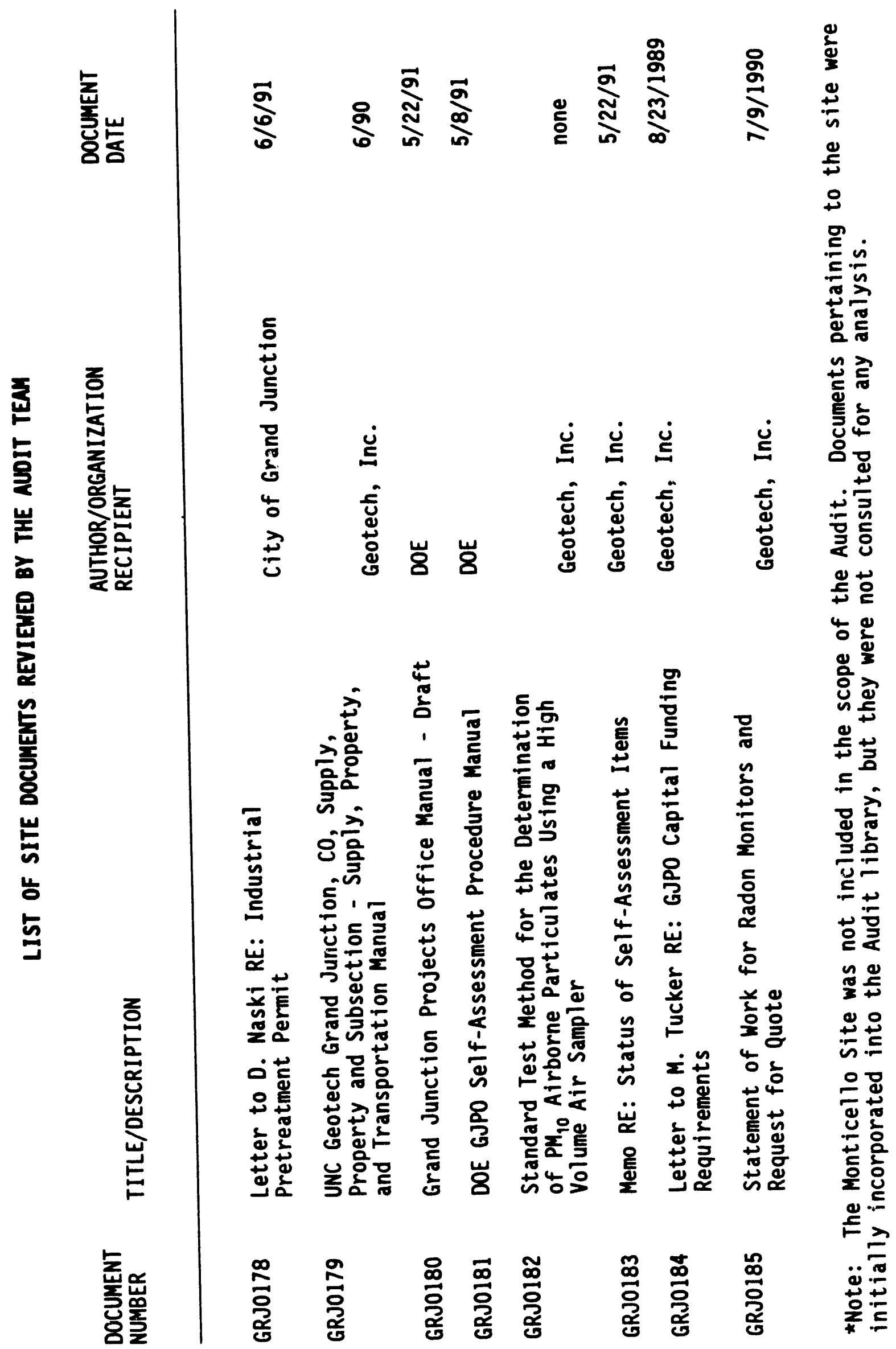


This page was intentionally left blank. 


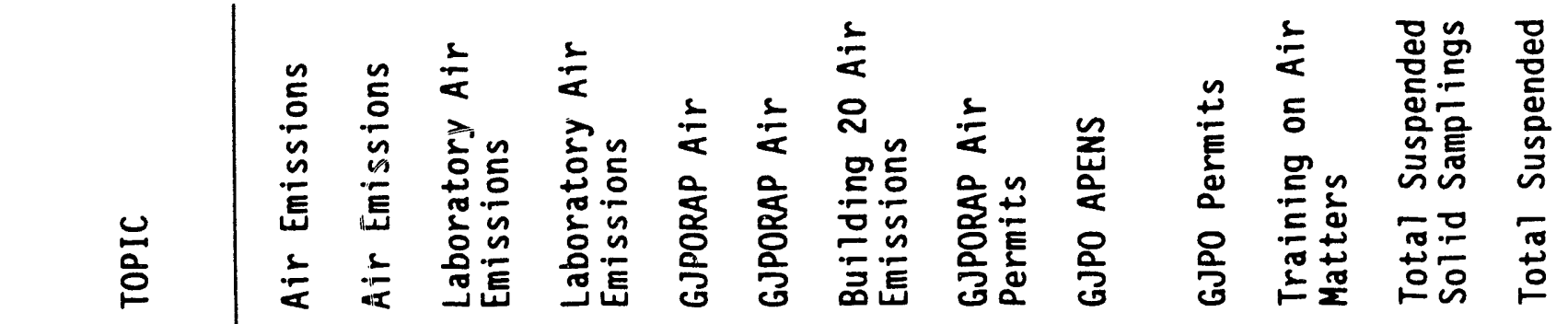

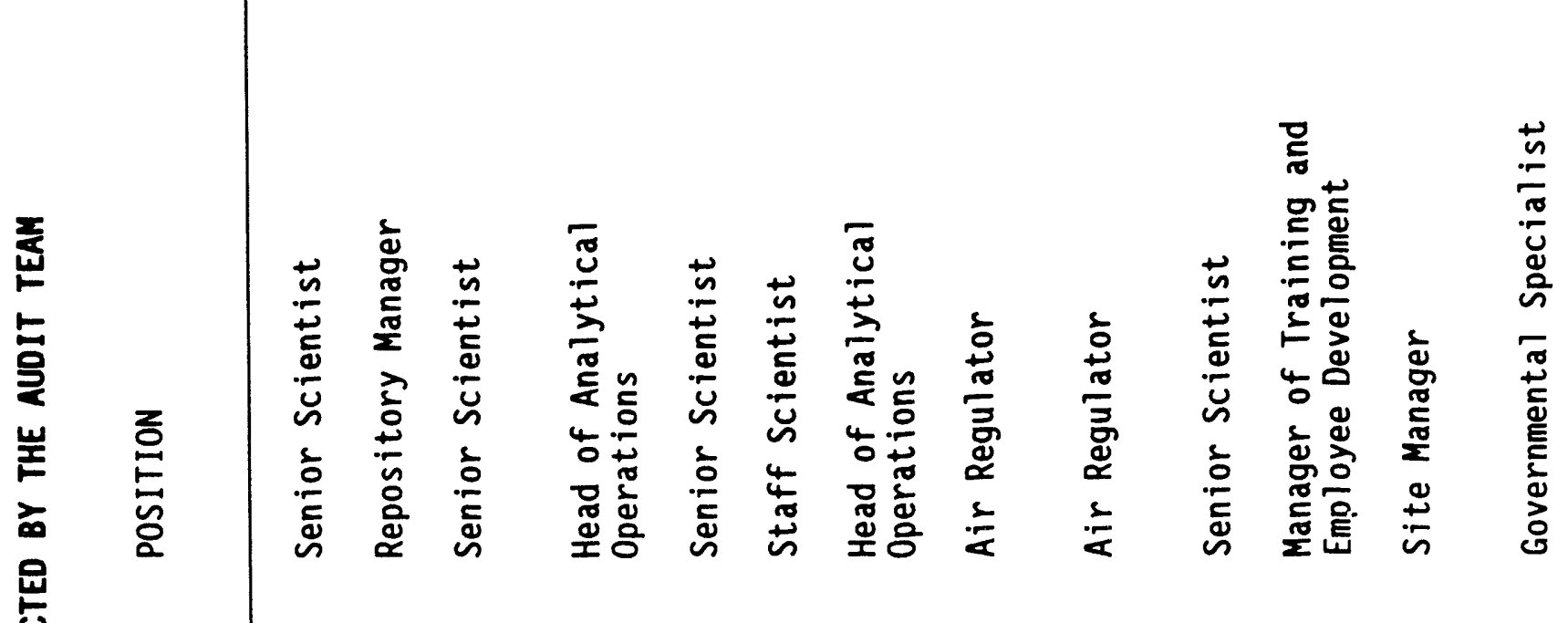

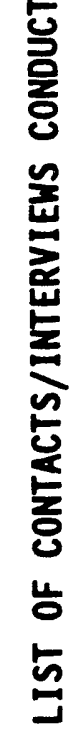

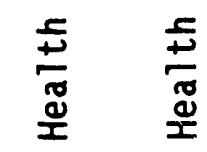

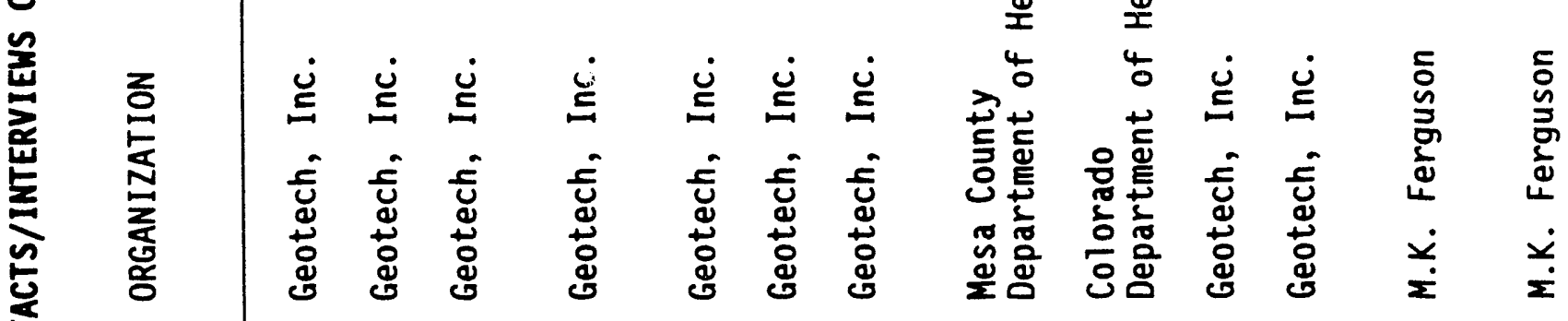

$$
\begin{aligned}
& \text { 范 }
\end{aligned}
$$

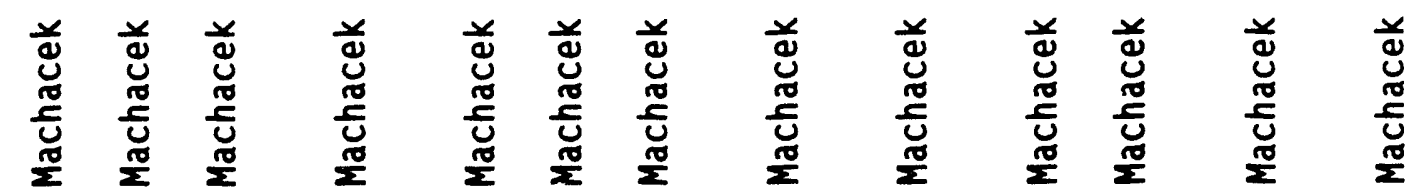

$$
\begin{aligned}
& \dot{\propto} \dot{\propto} \dot{\propto} \quad \dot{\propto} \quad \dot{\propto} \dot{\propto} \dot{\propto} \quad \dot{\propto} \quad \dot{\propto} \quad \dot{\propto} \dot{\propto} \quad \dot{\propto} \quad \dot{\propto}
\end{aligned}
$$

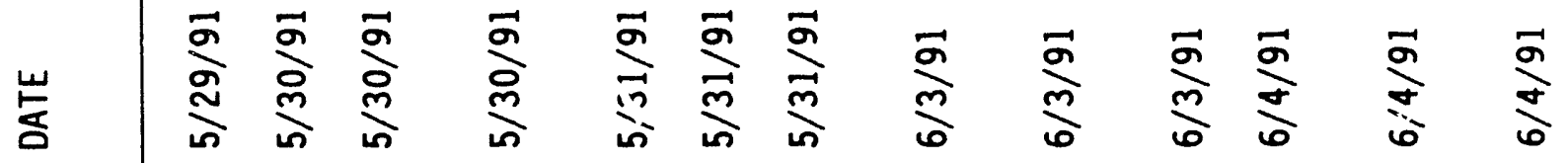

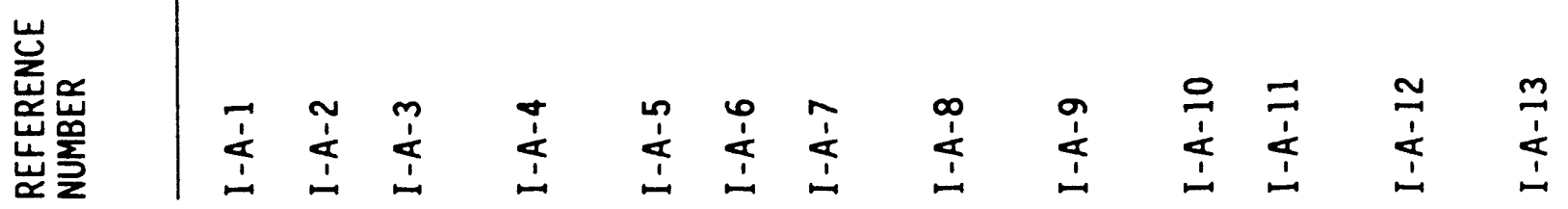




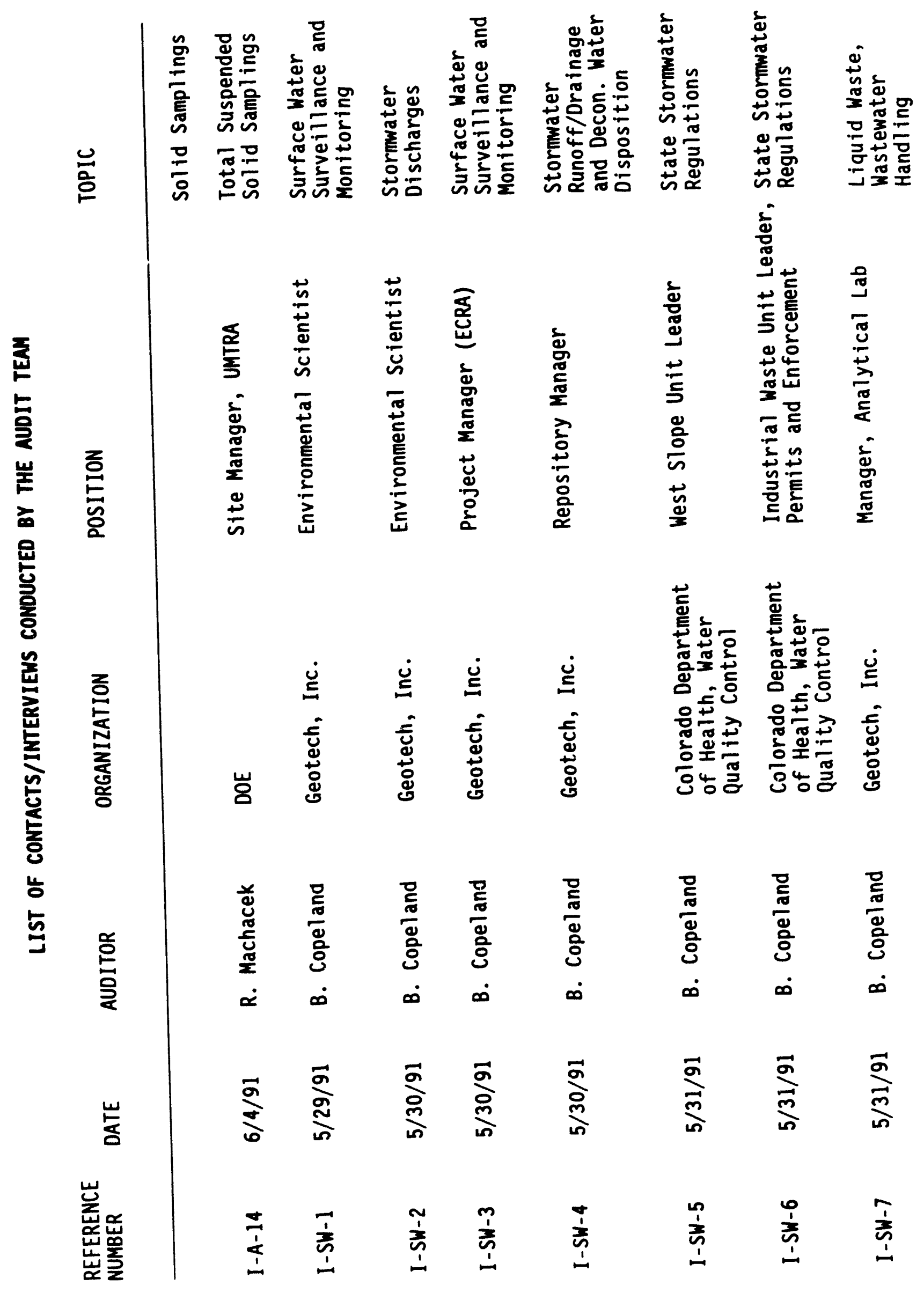




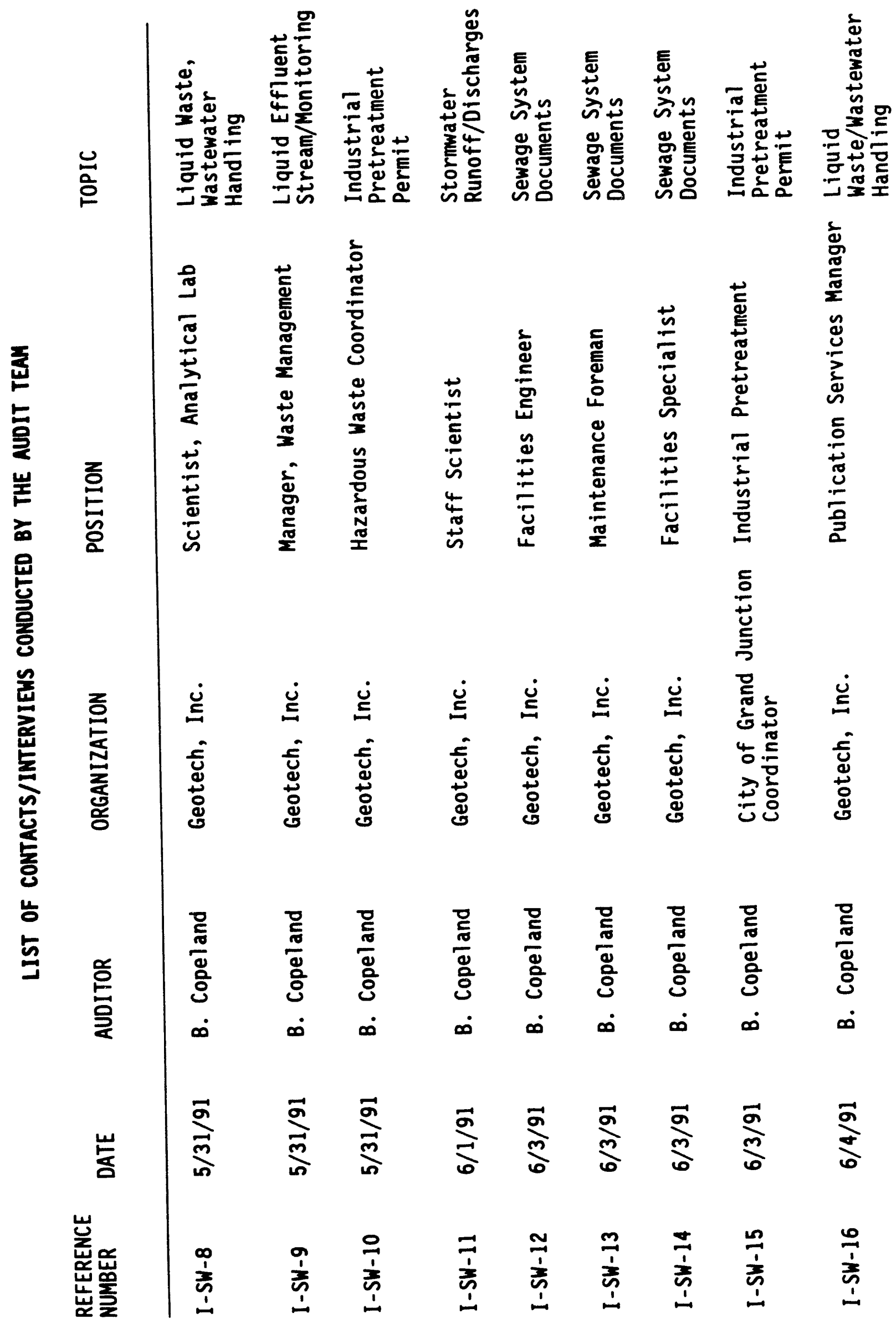




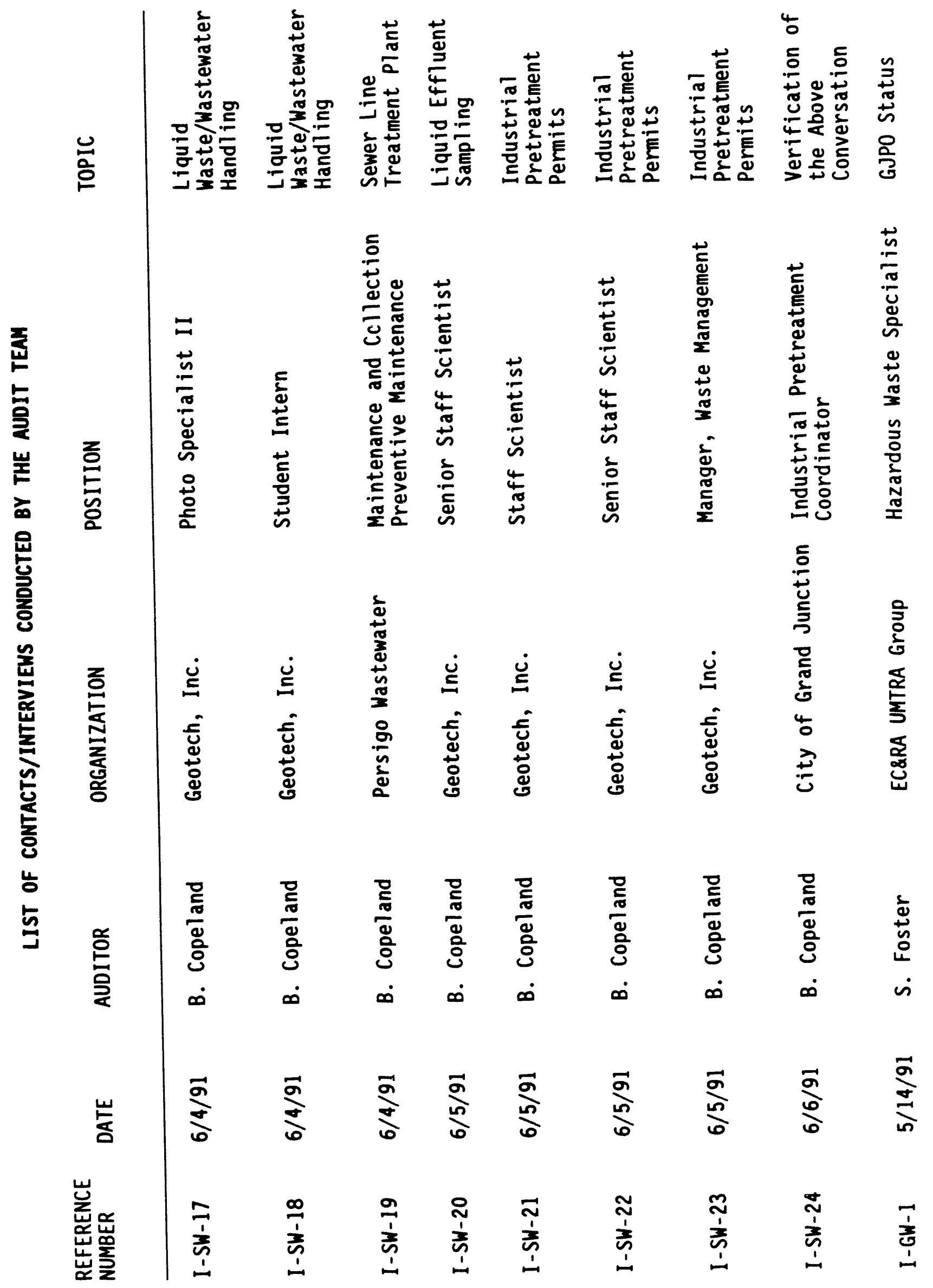




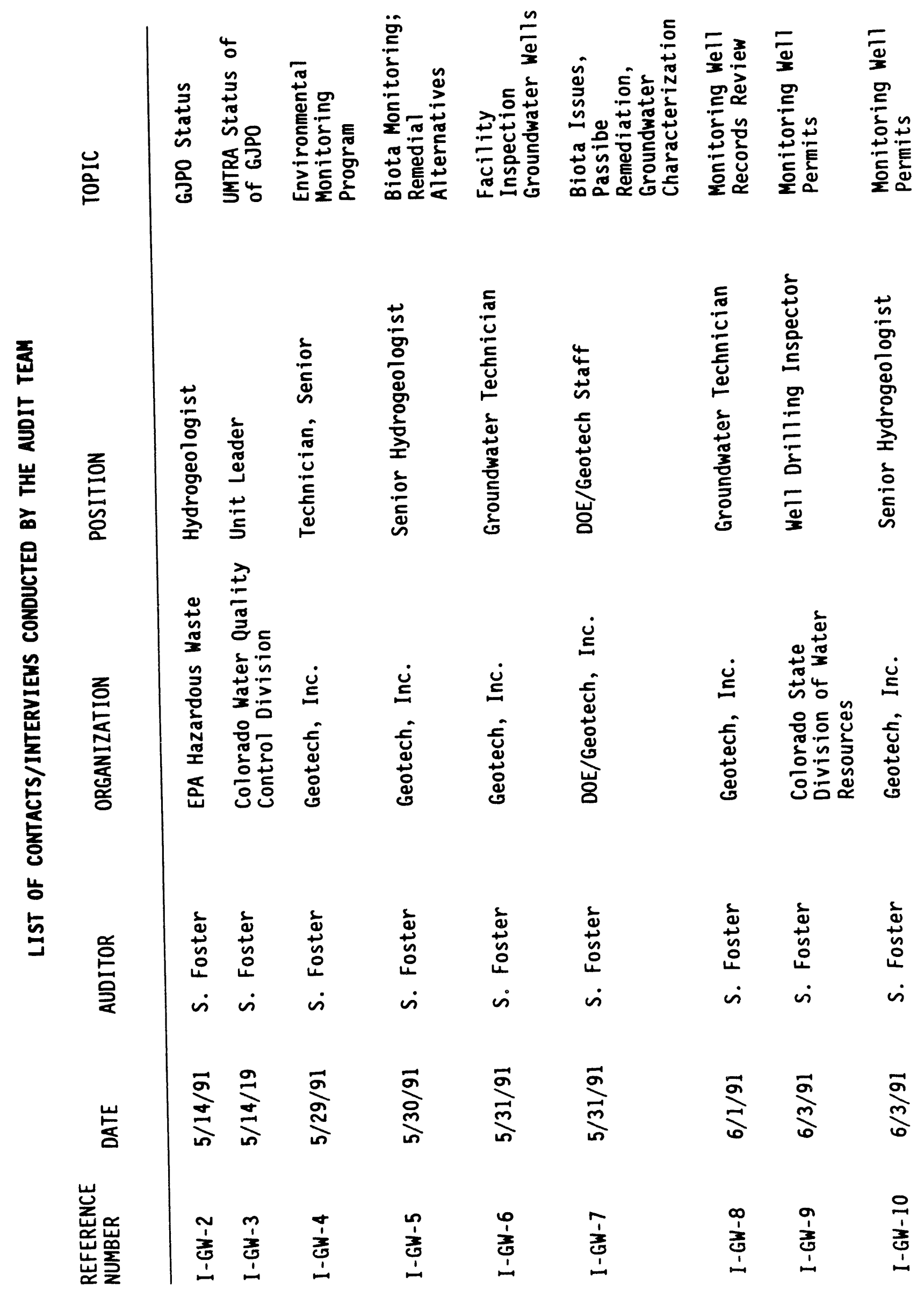




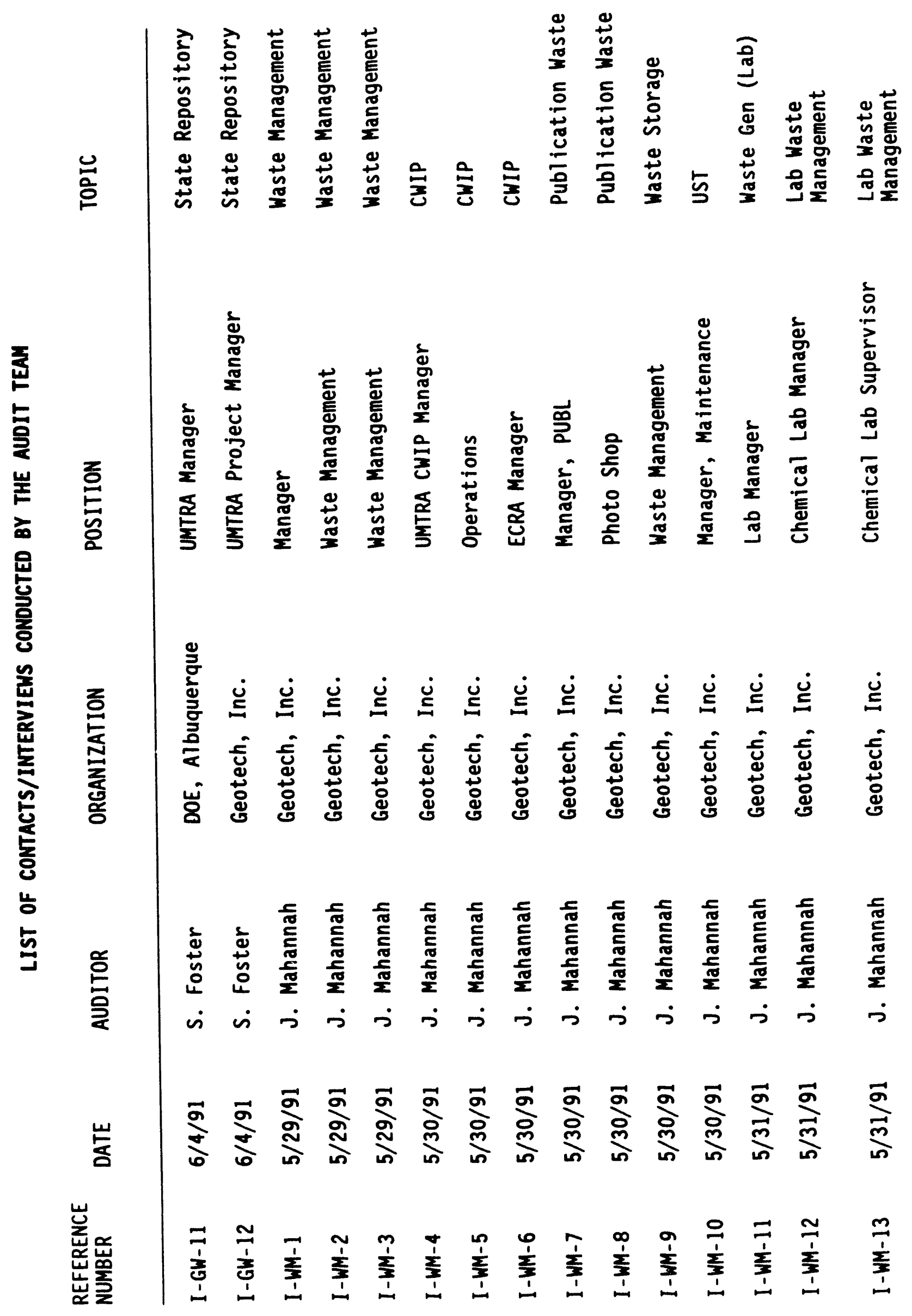




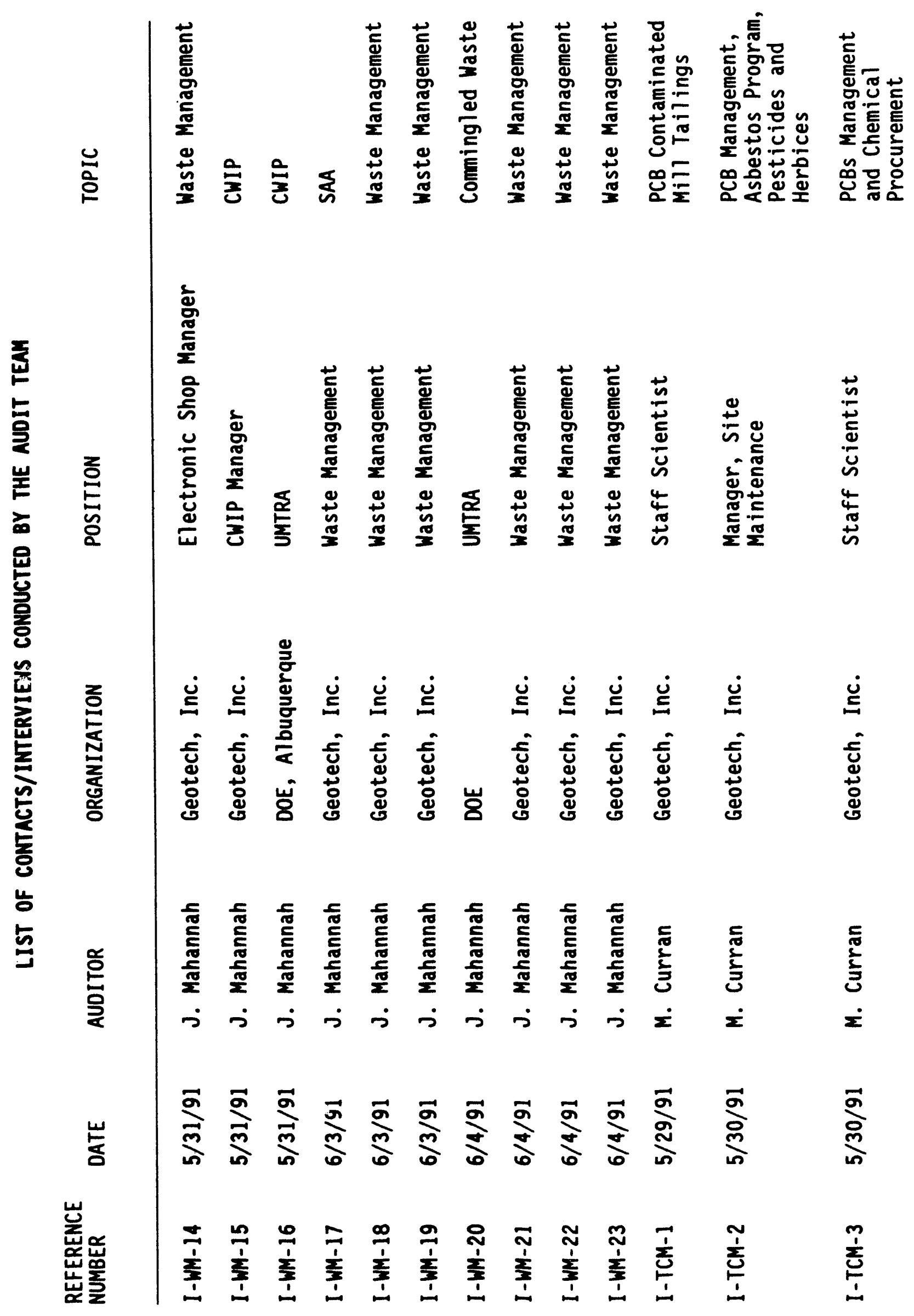




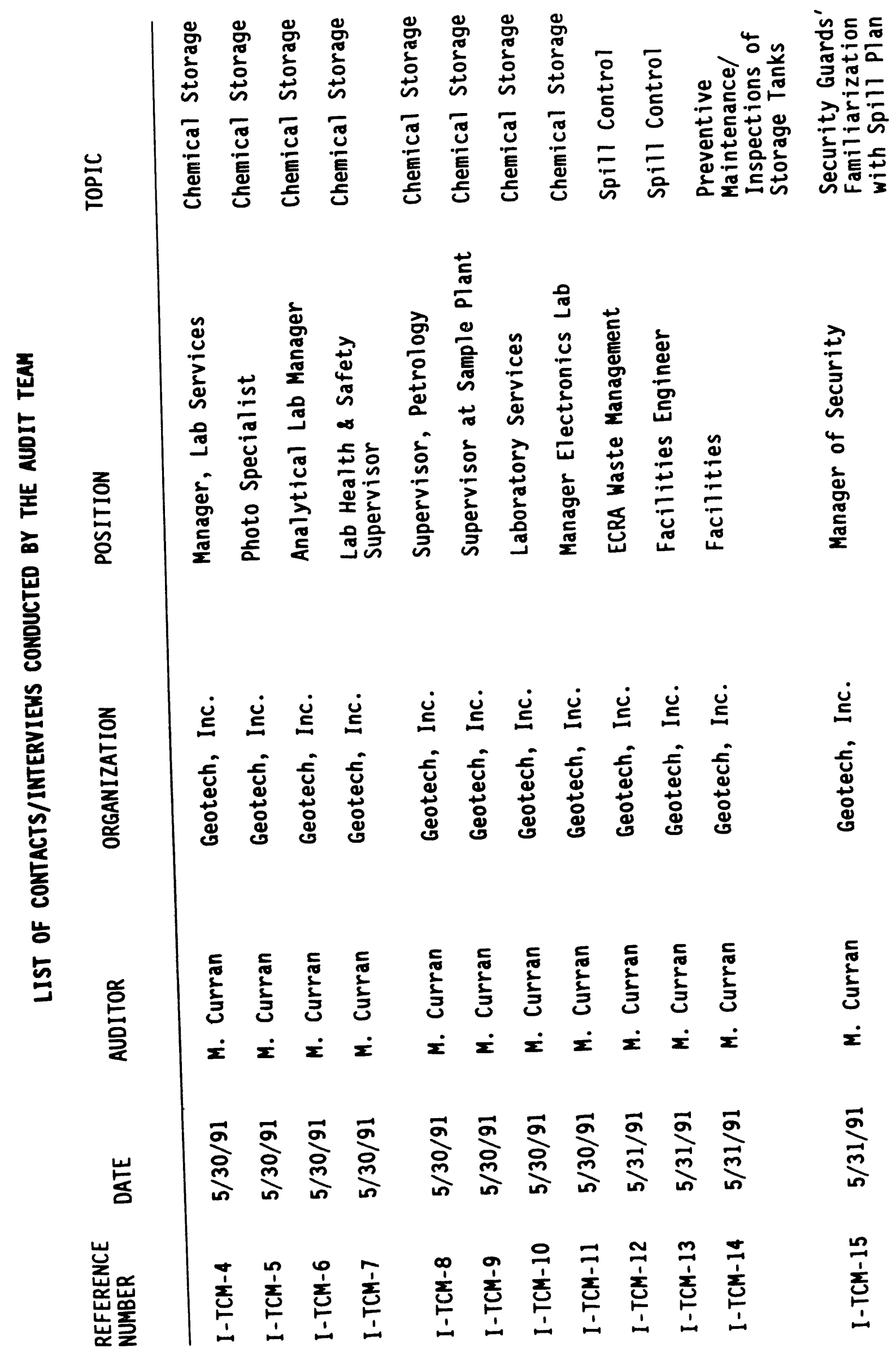




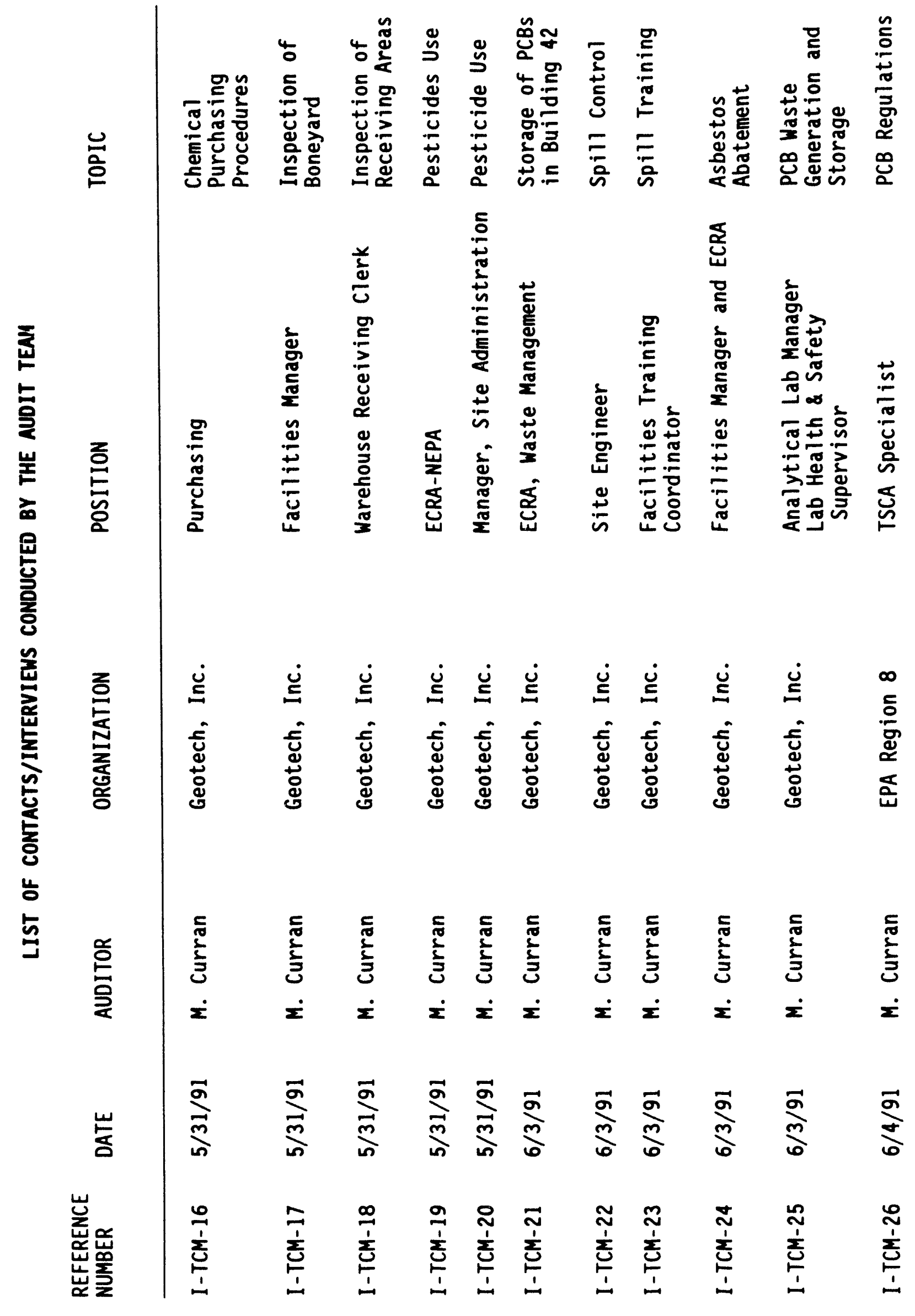




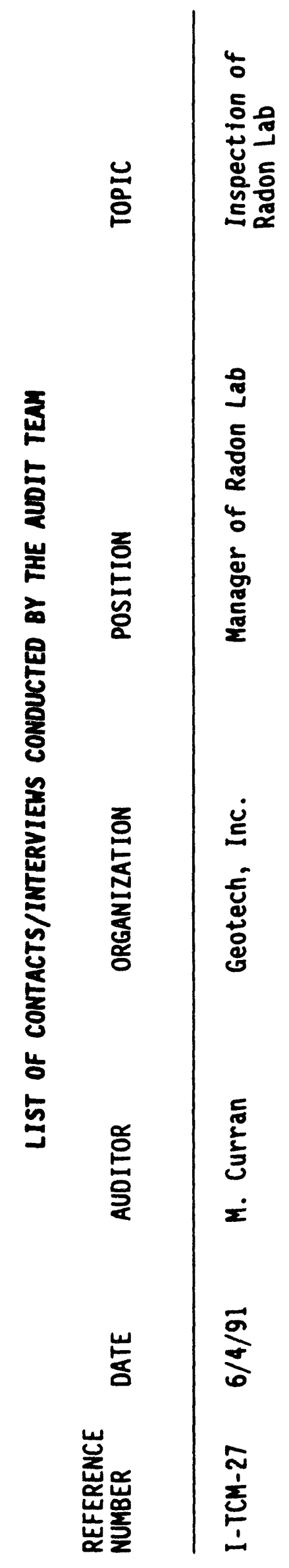




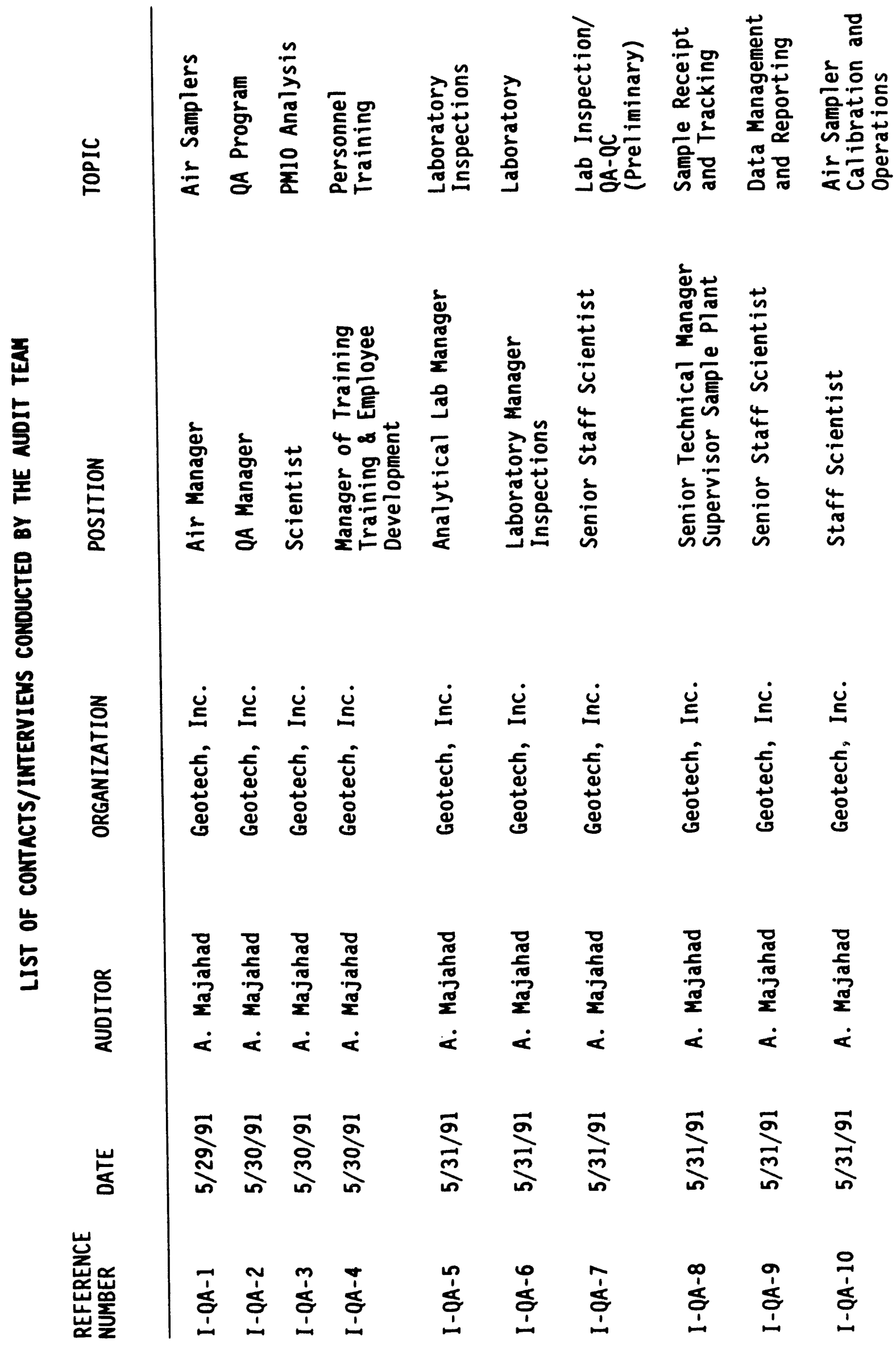




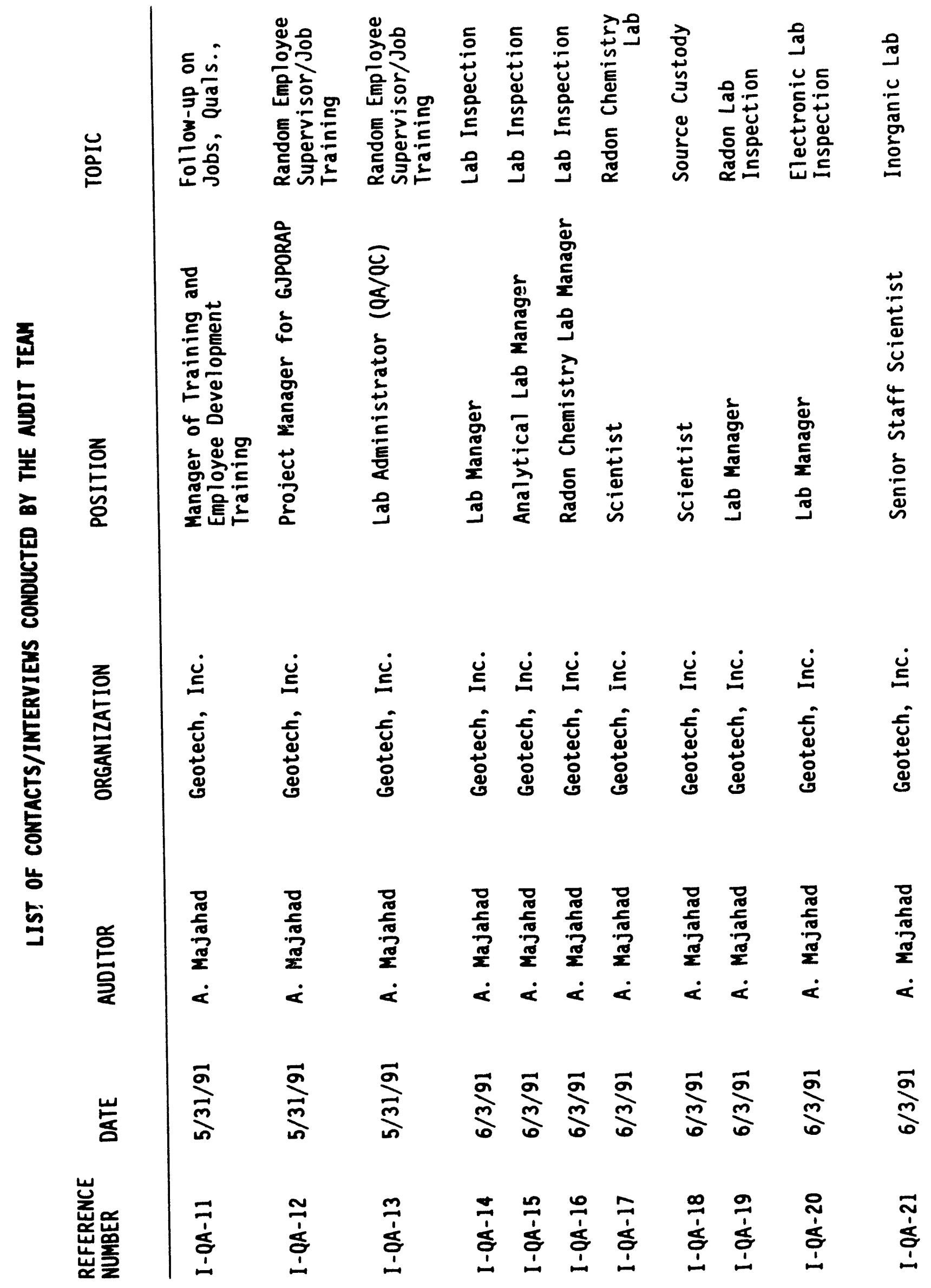




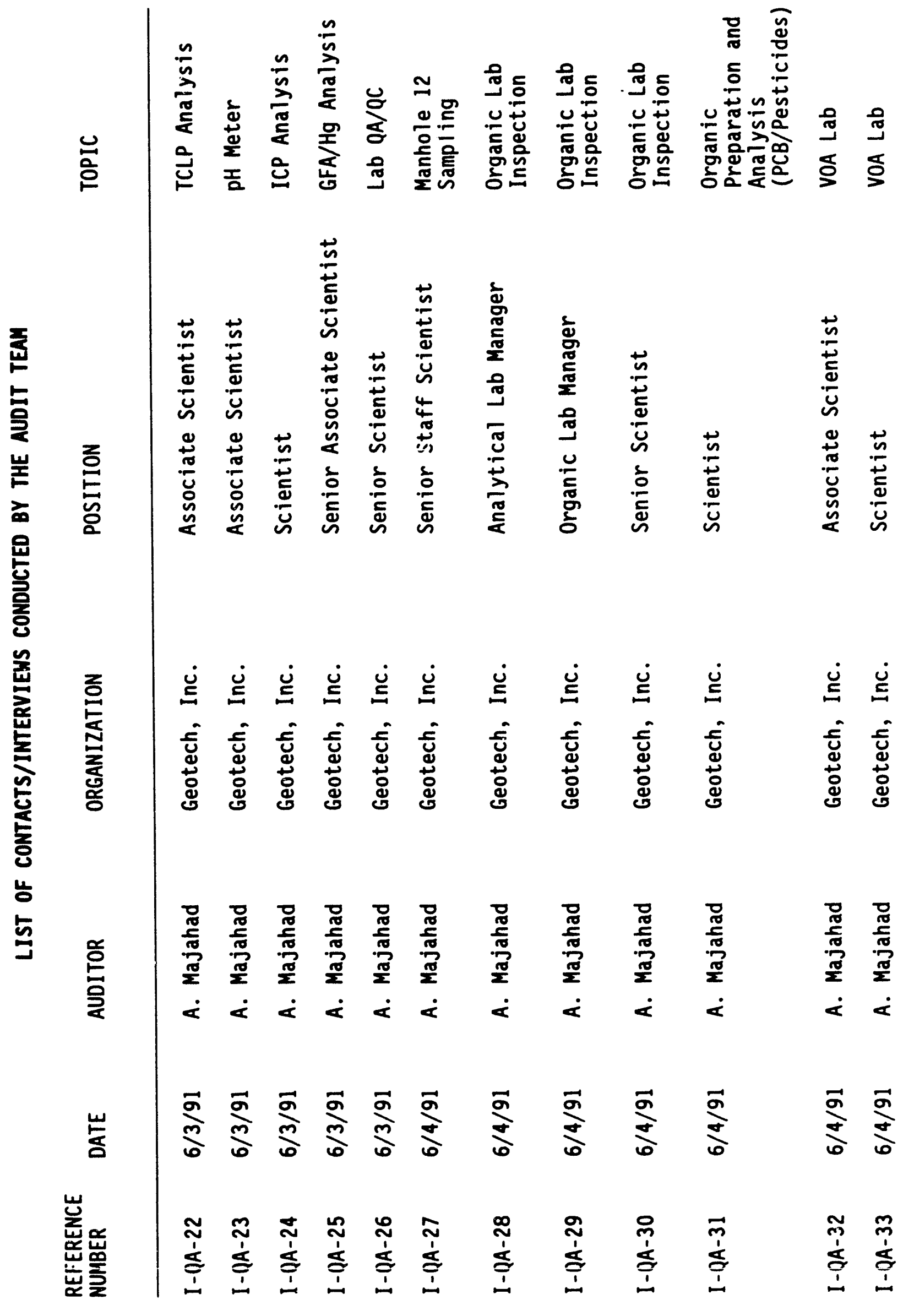




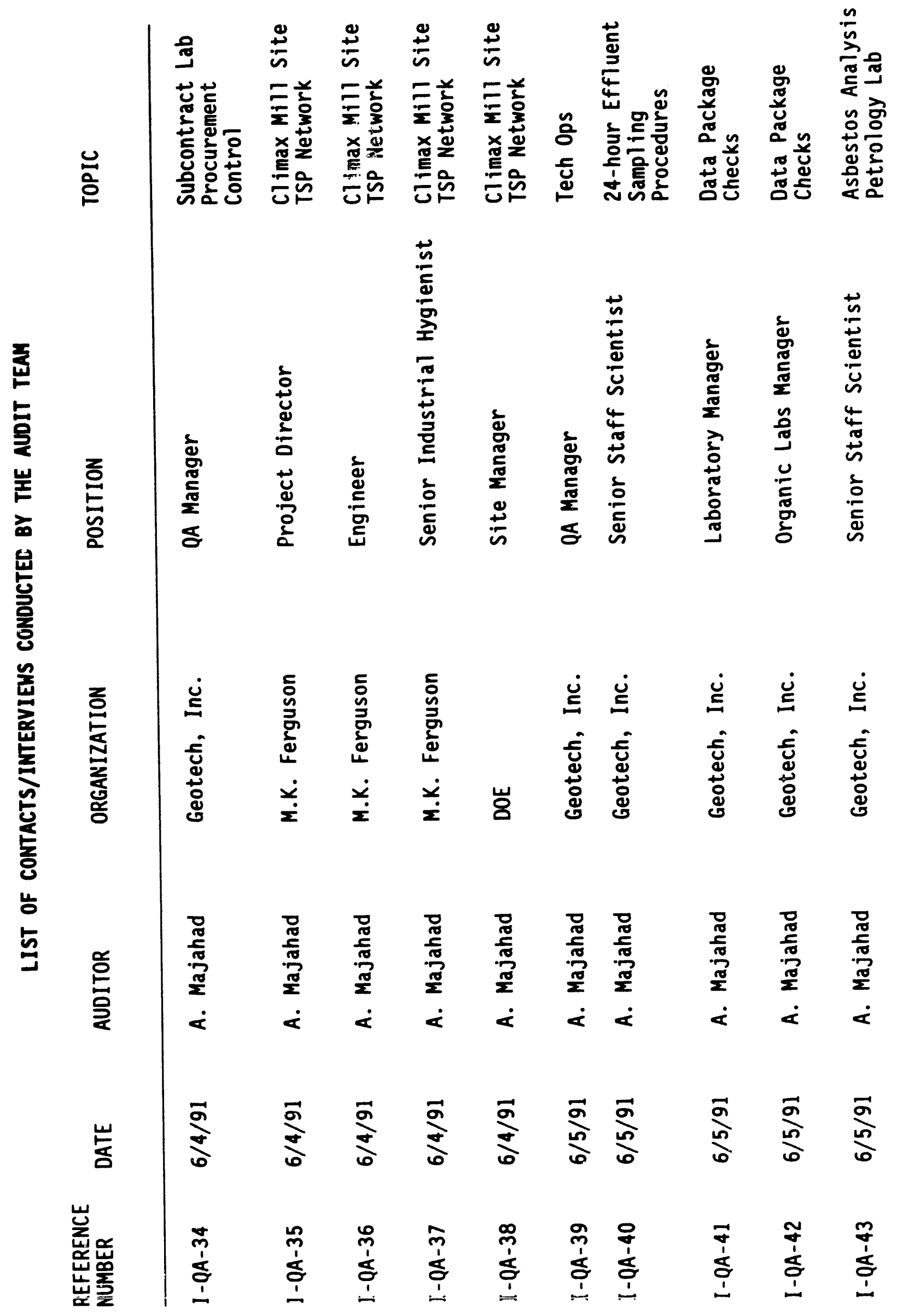




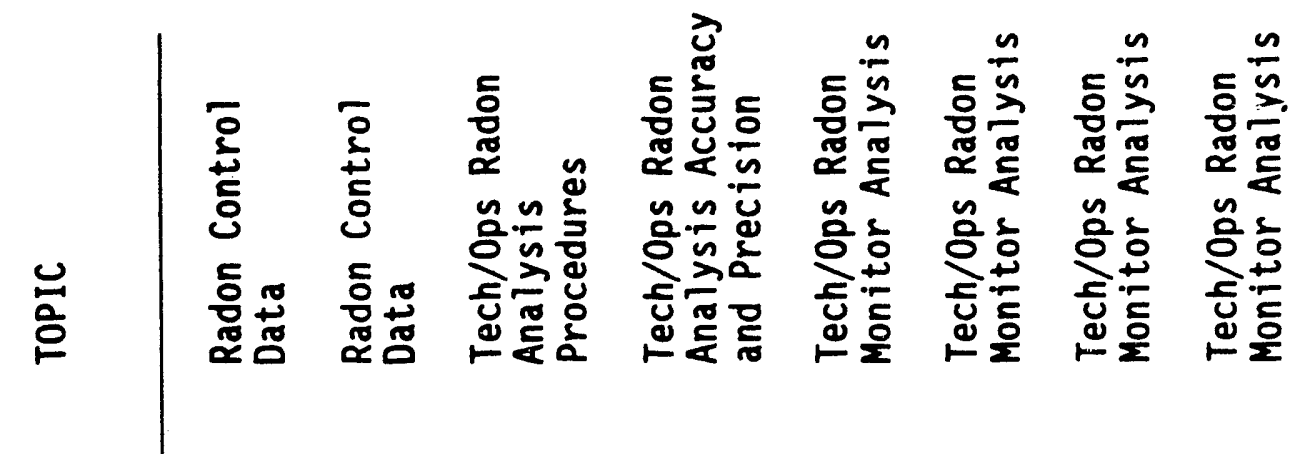

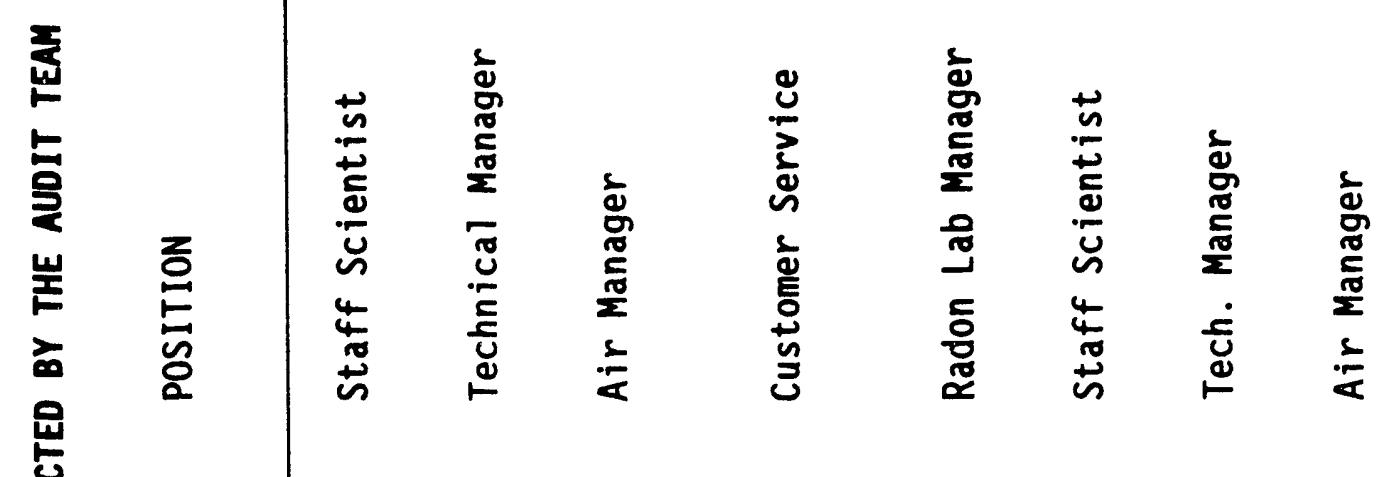

$$
\begin{aligned}
& \text { 粍 }
\end{aligned}
$$

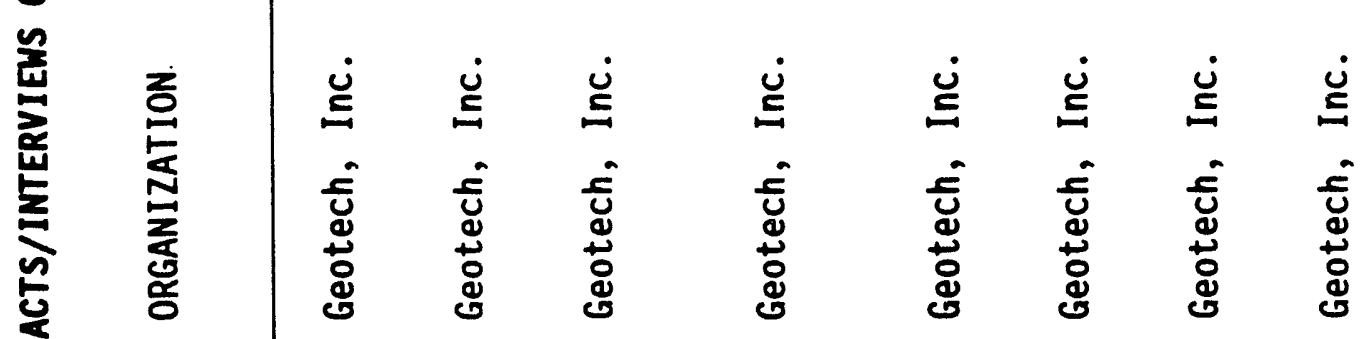

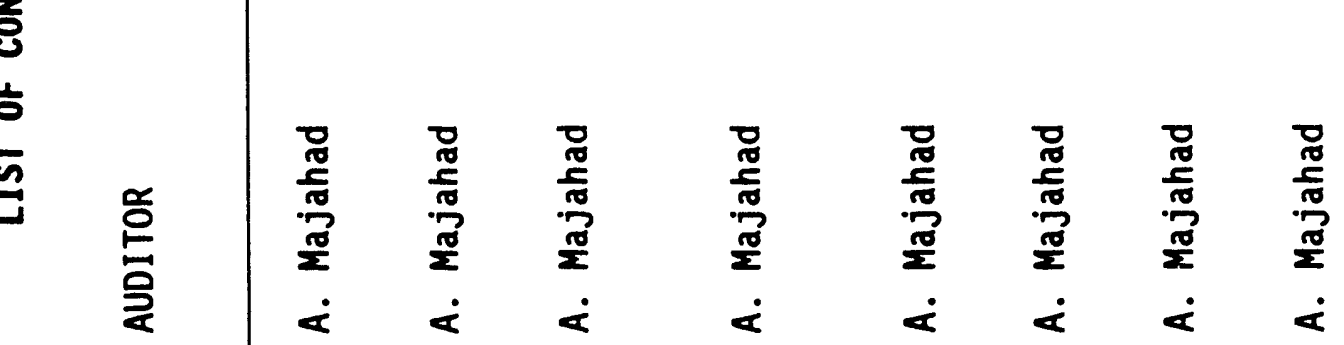

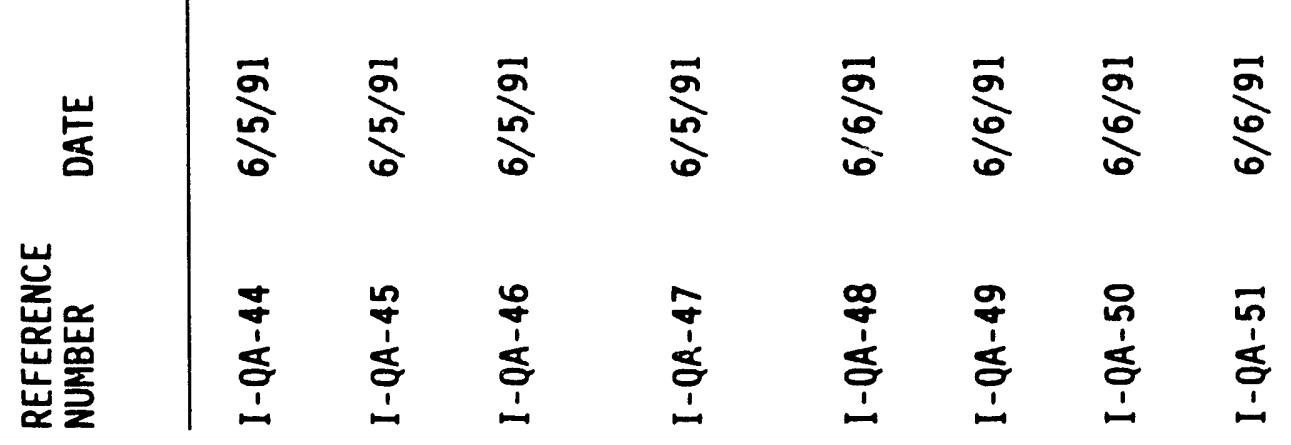




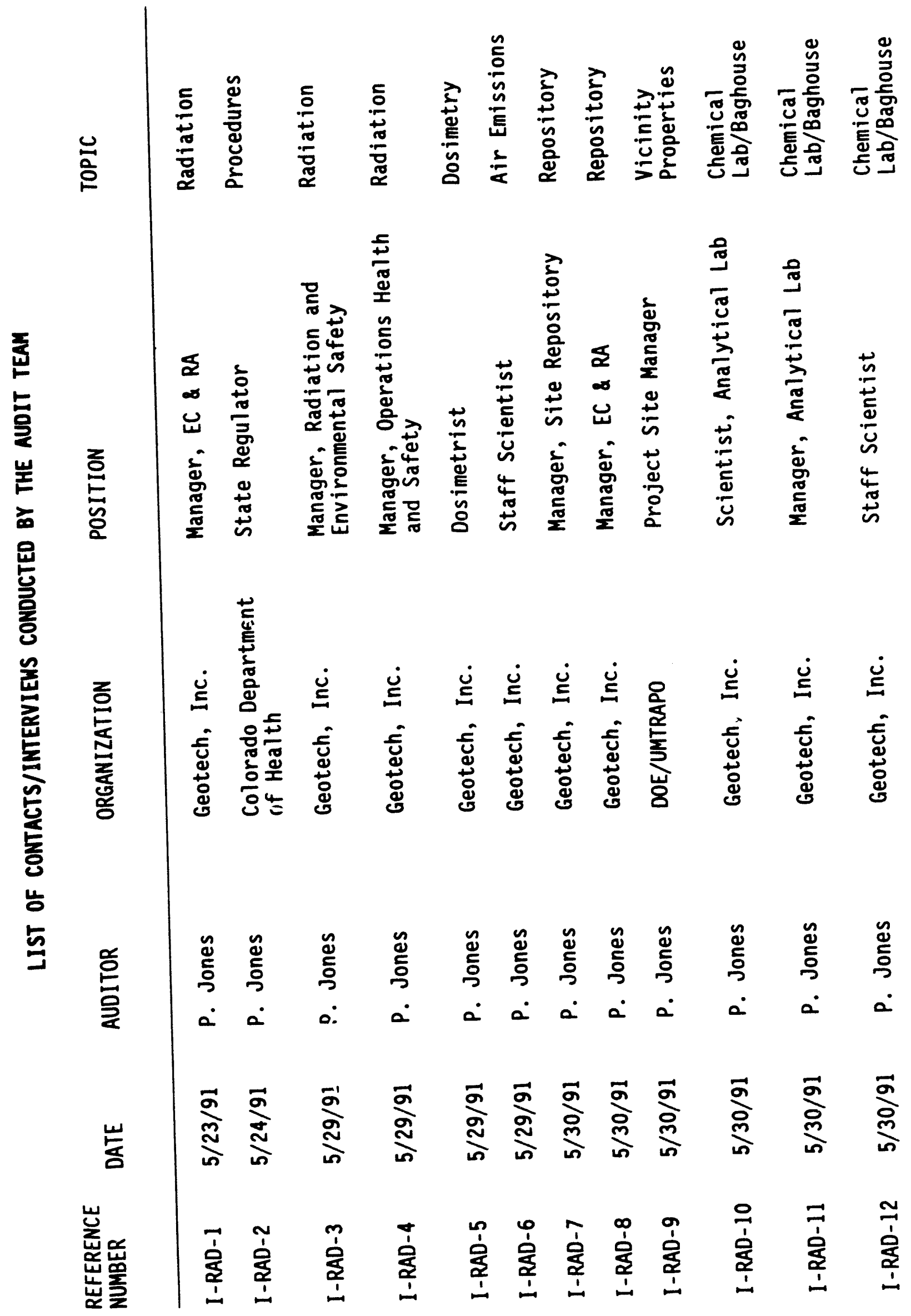




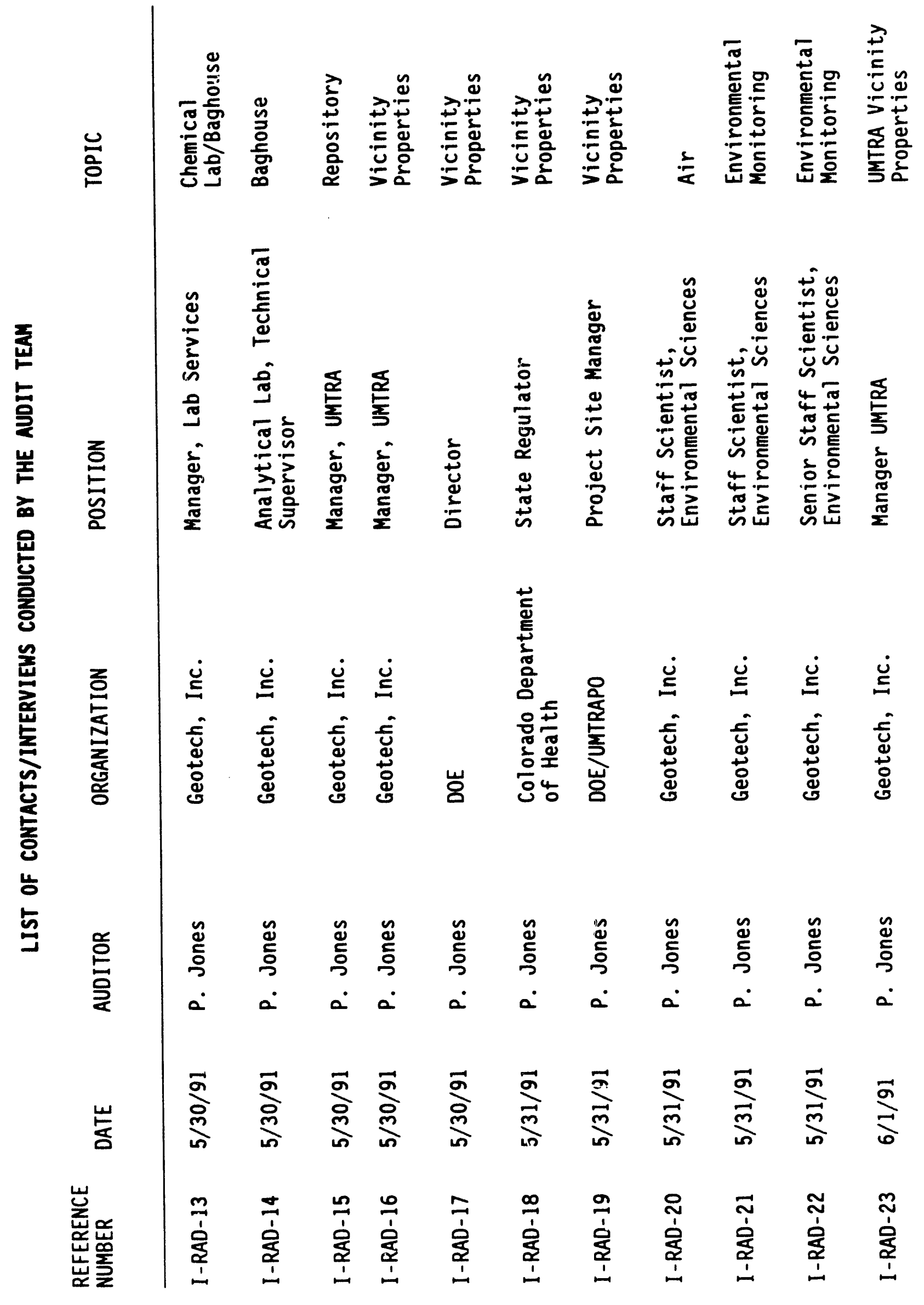




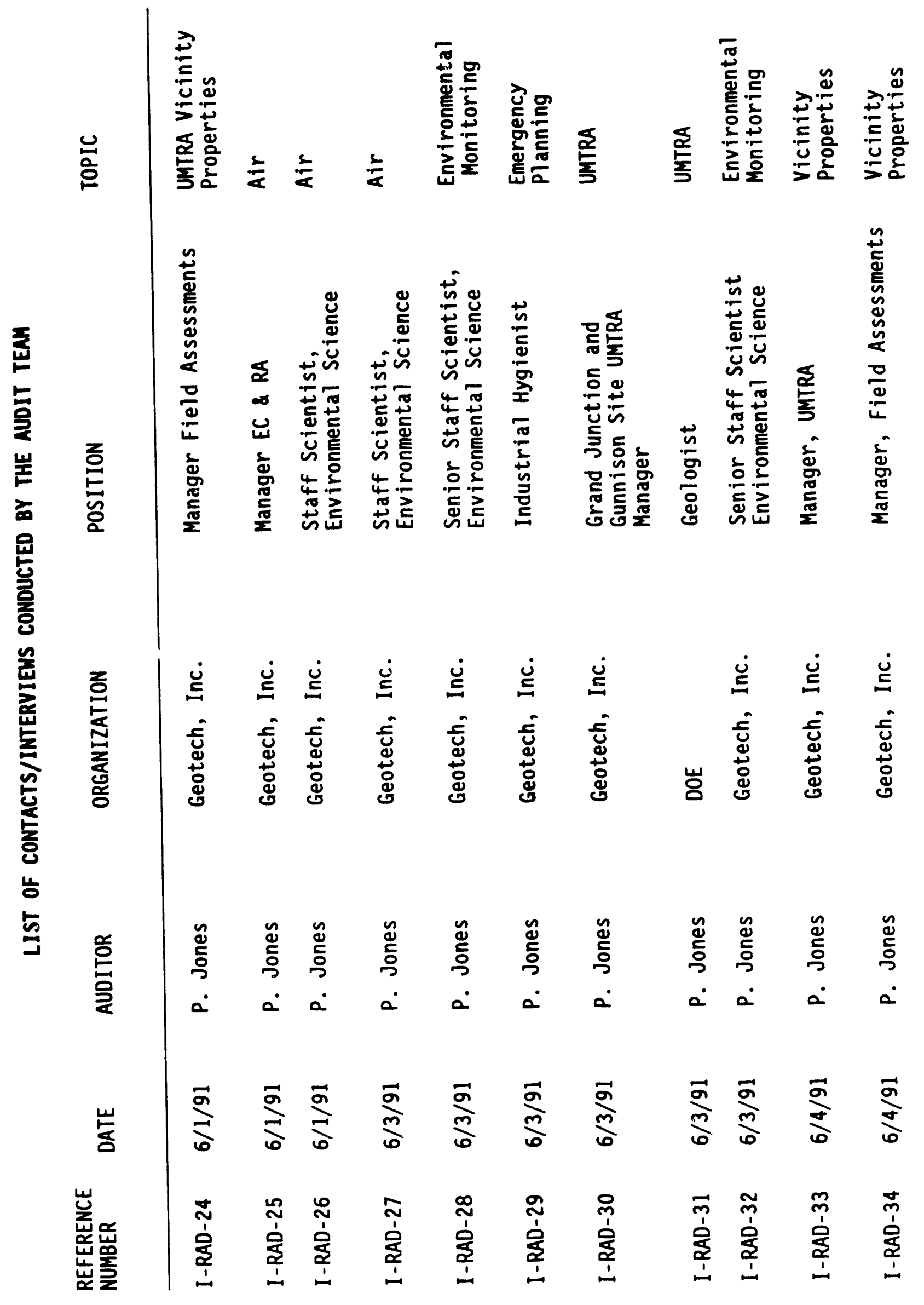




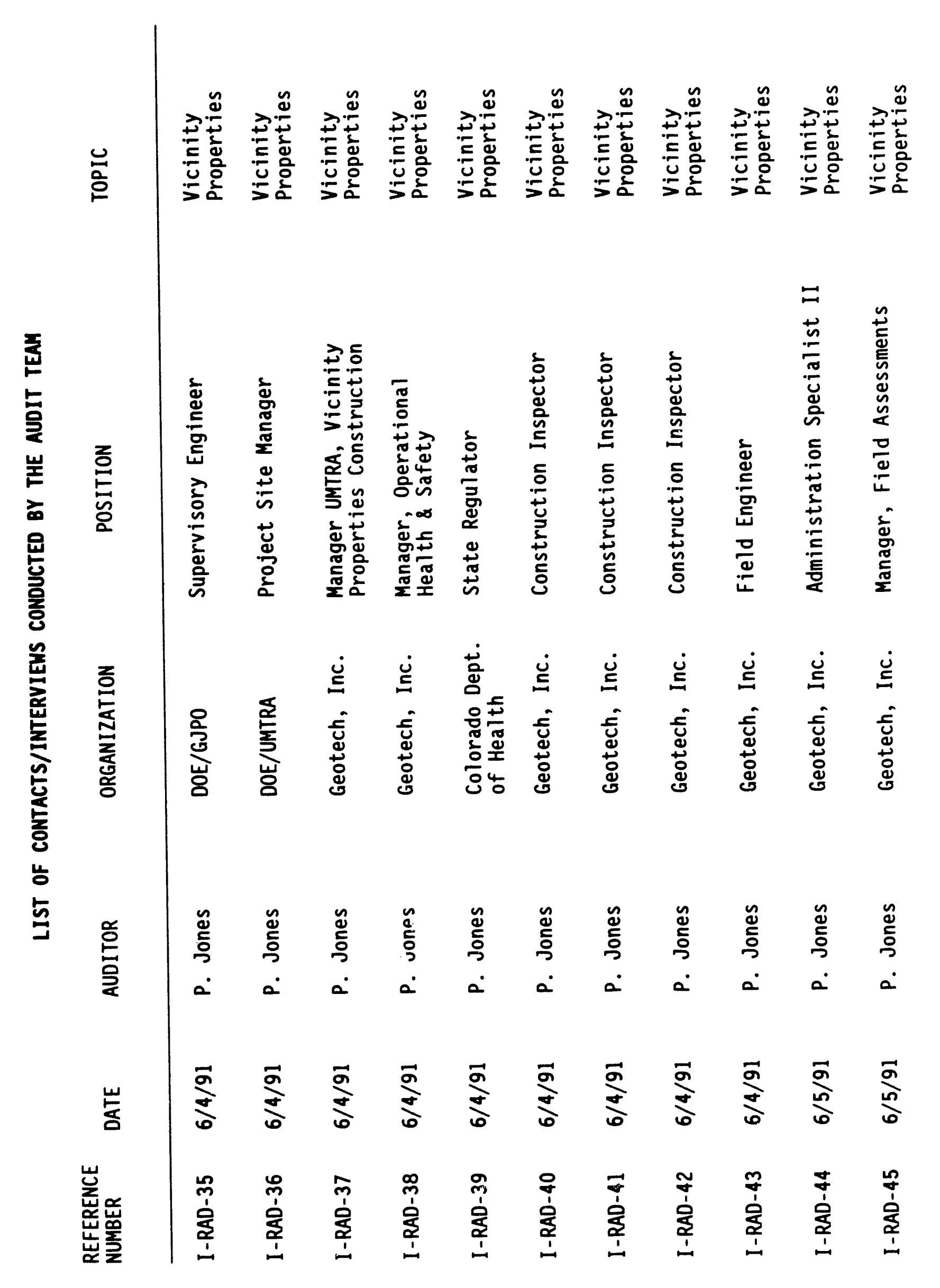




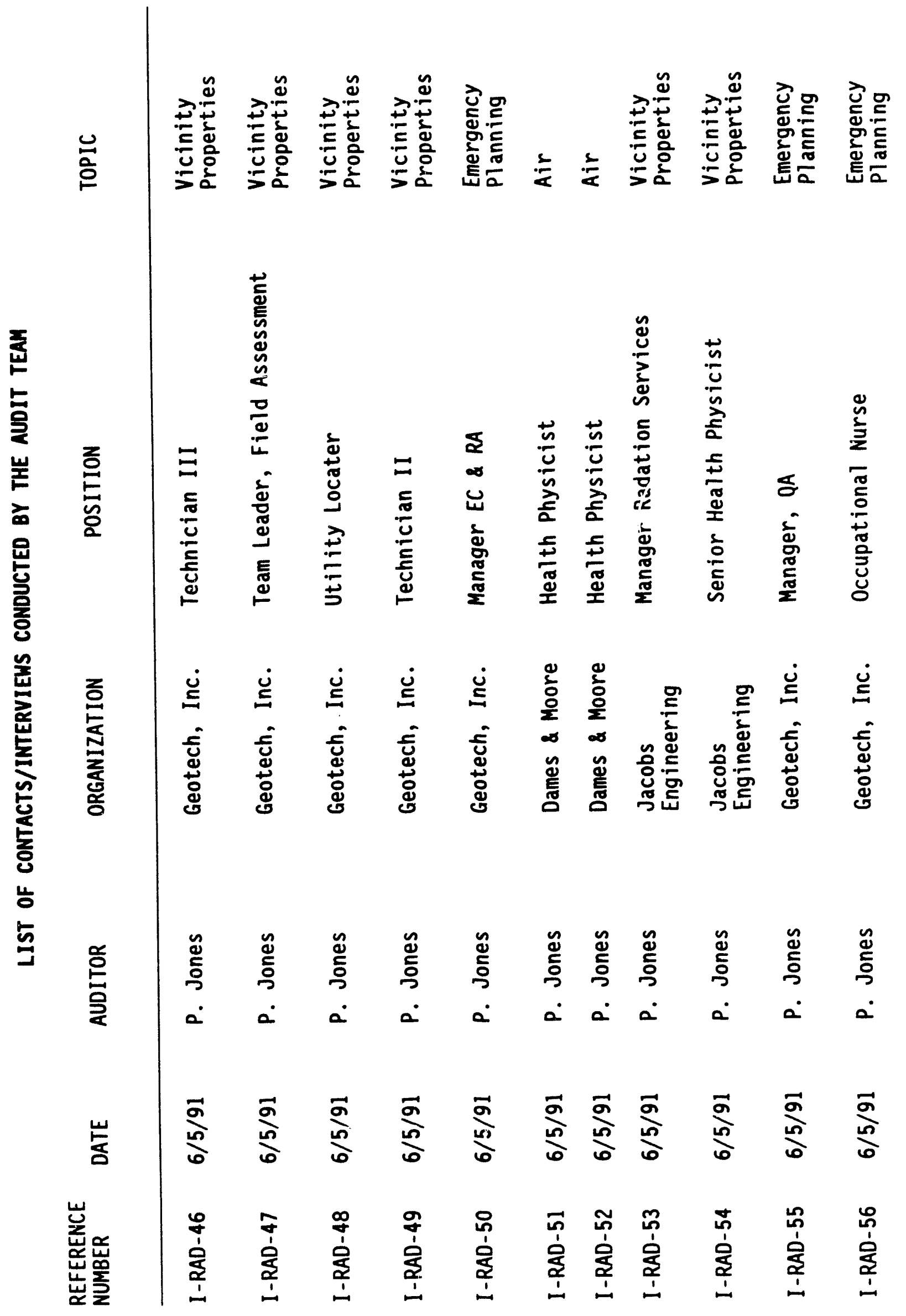




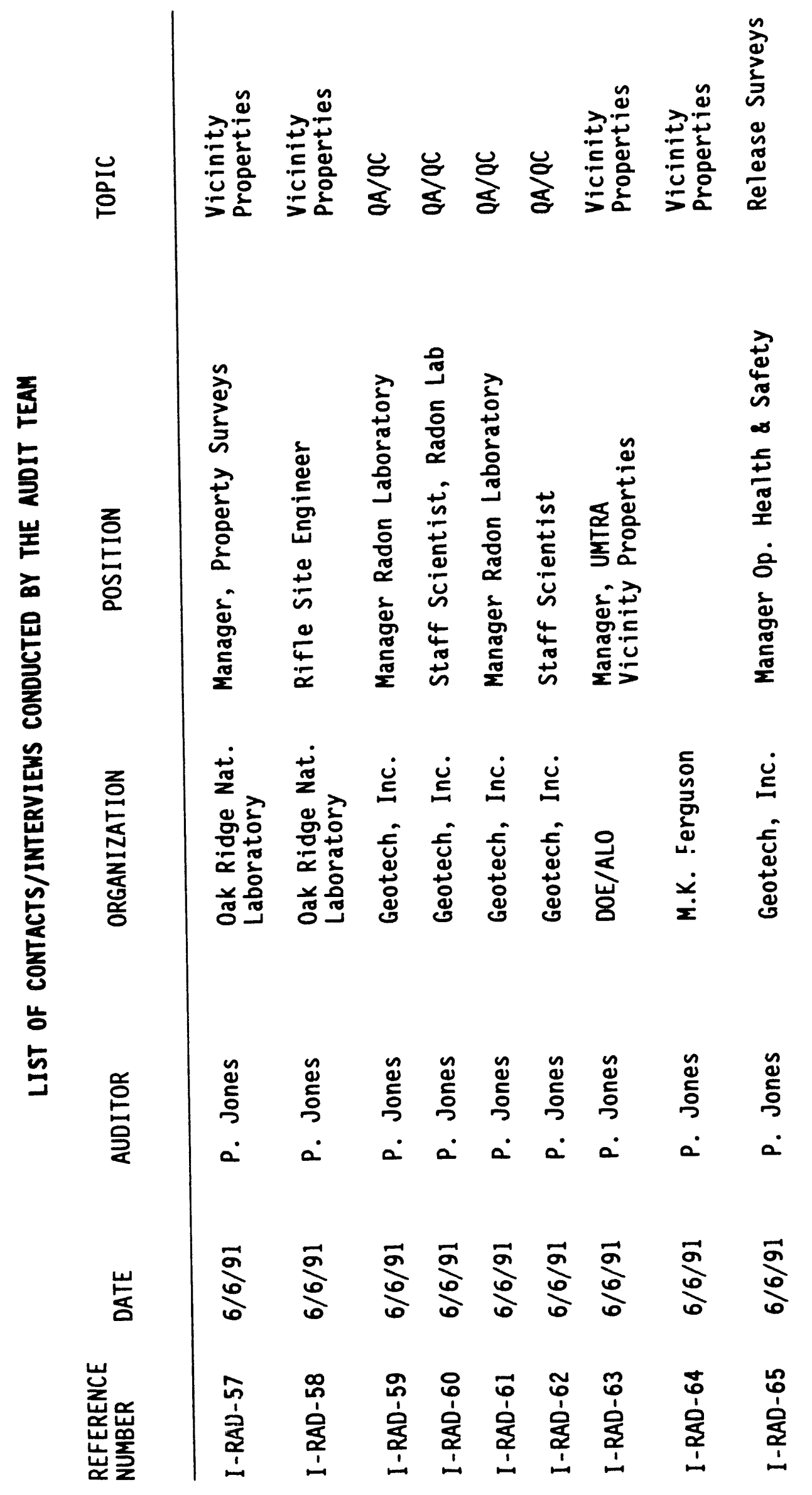




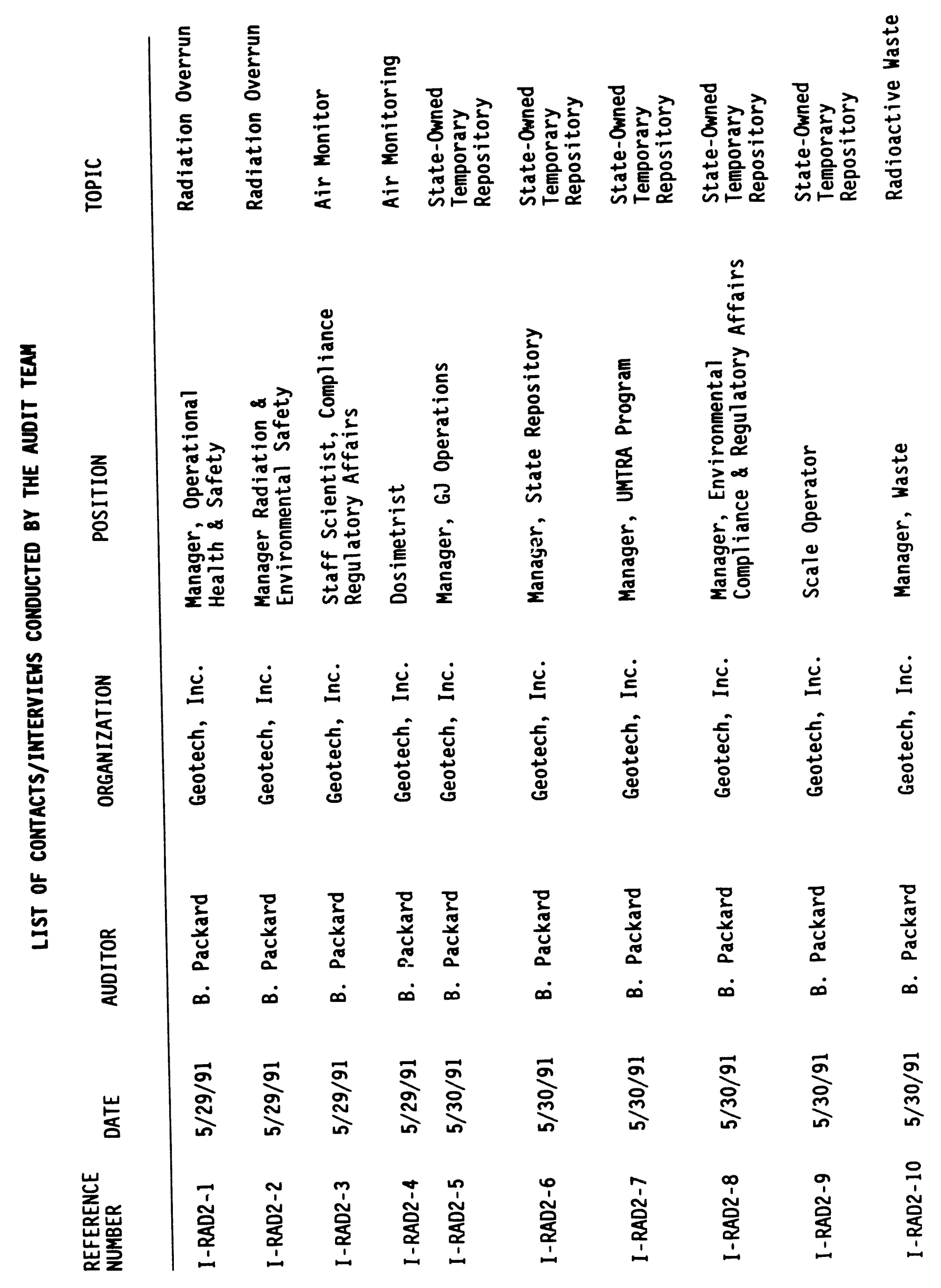




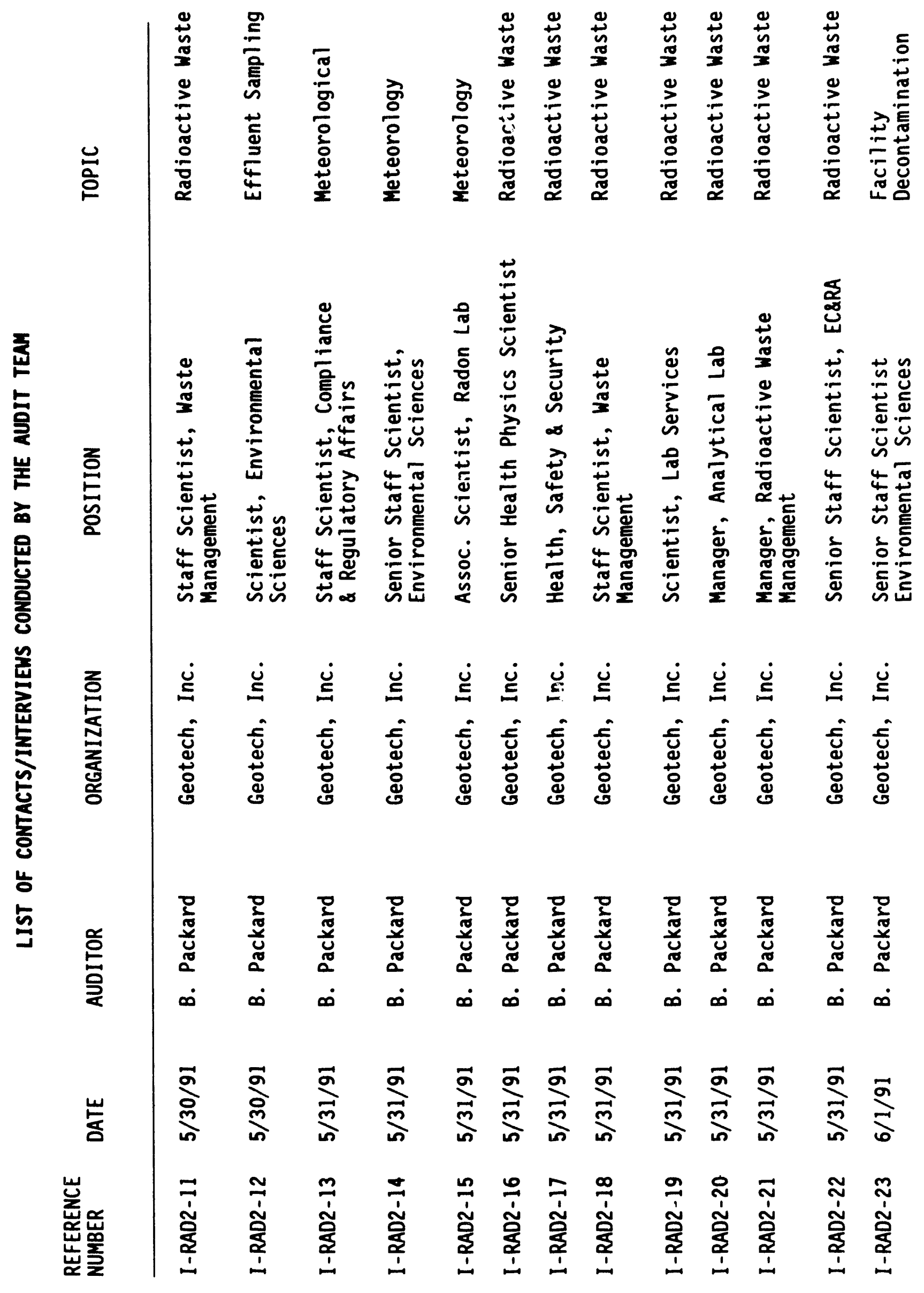




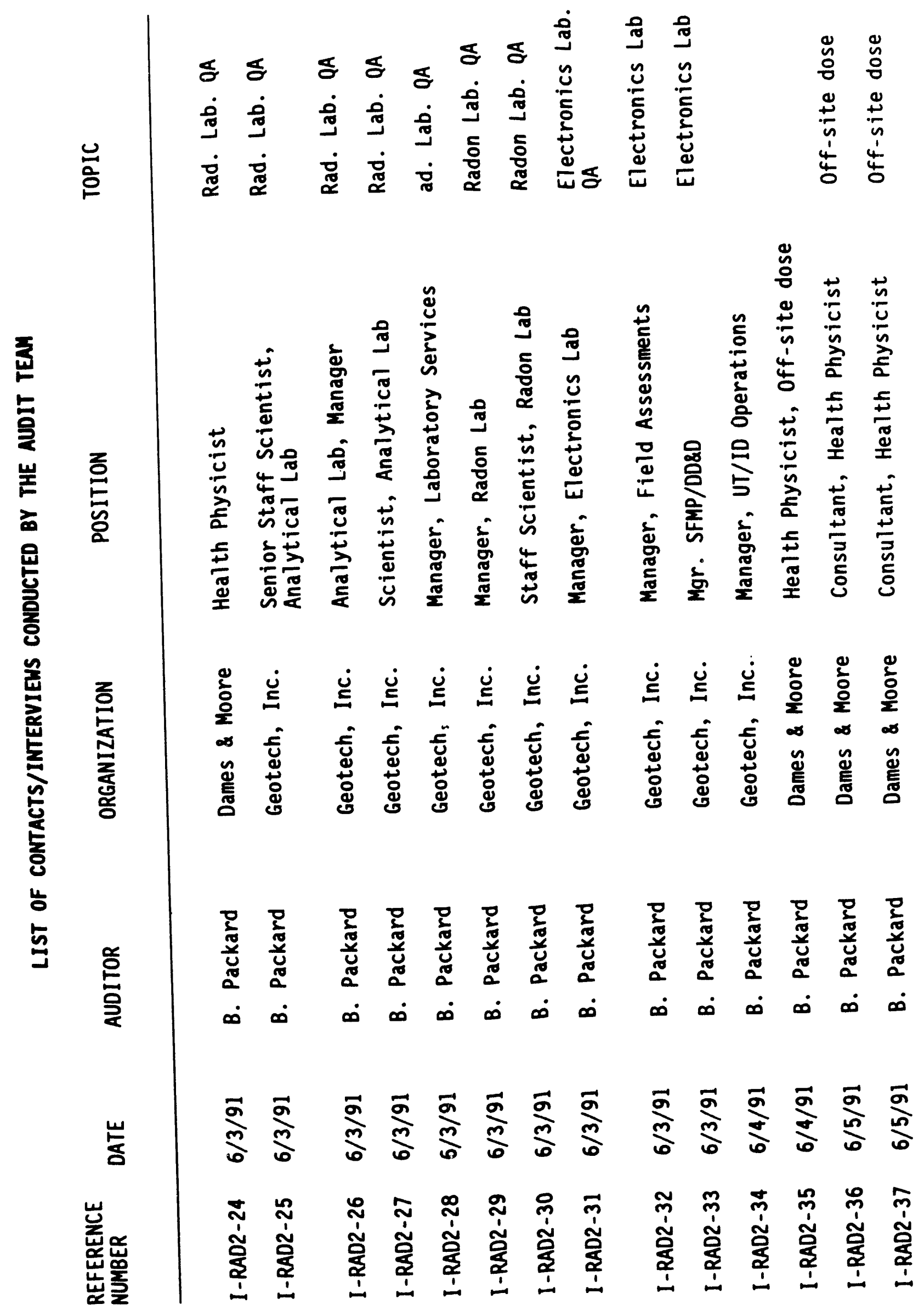




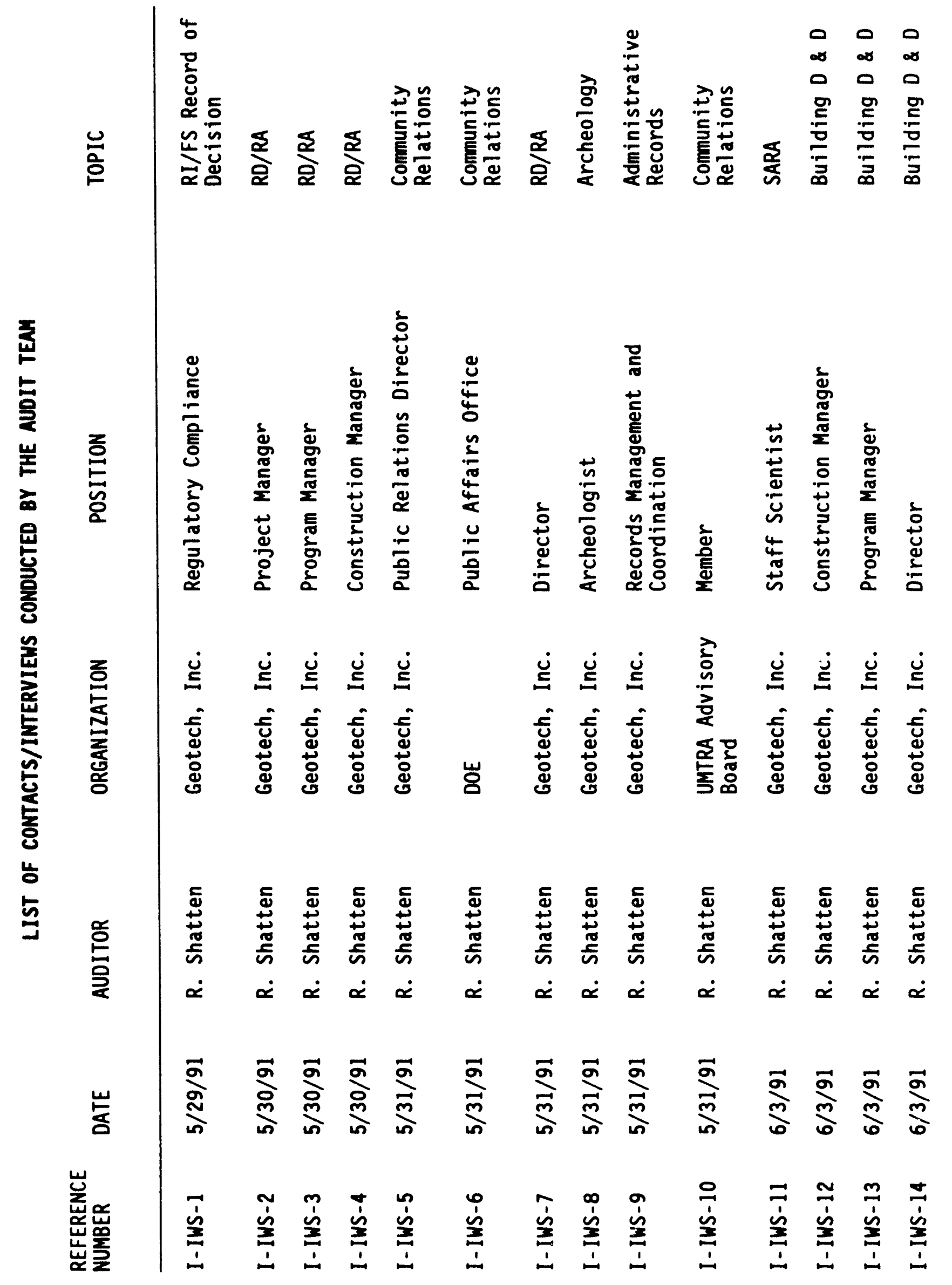




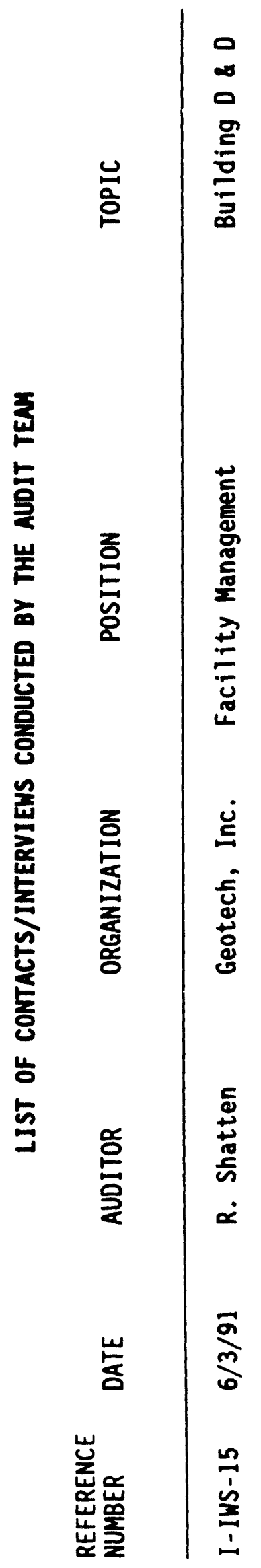




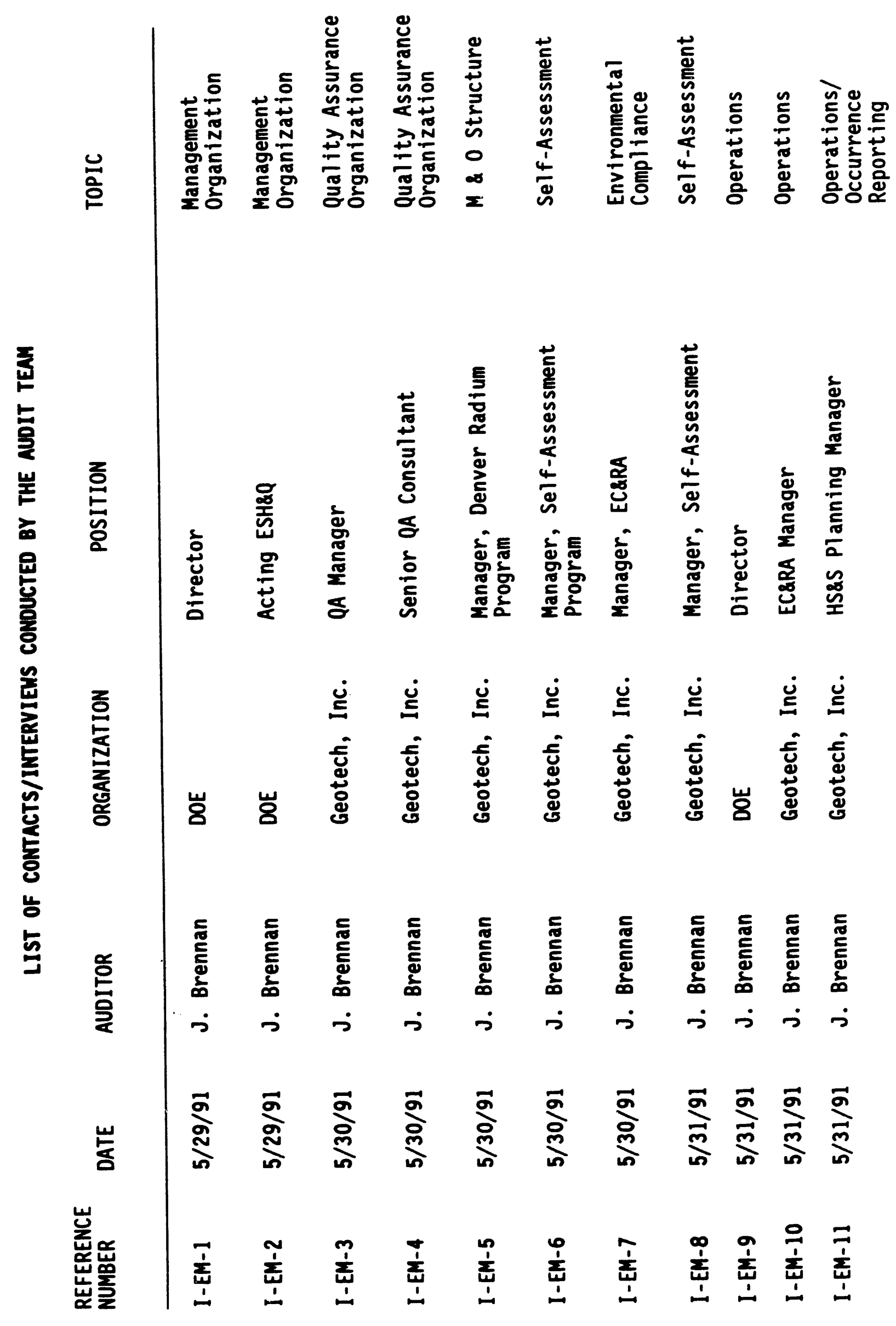




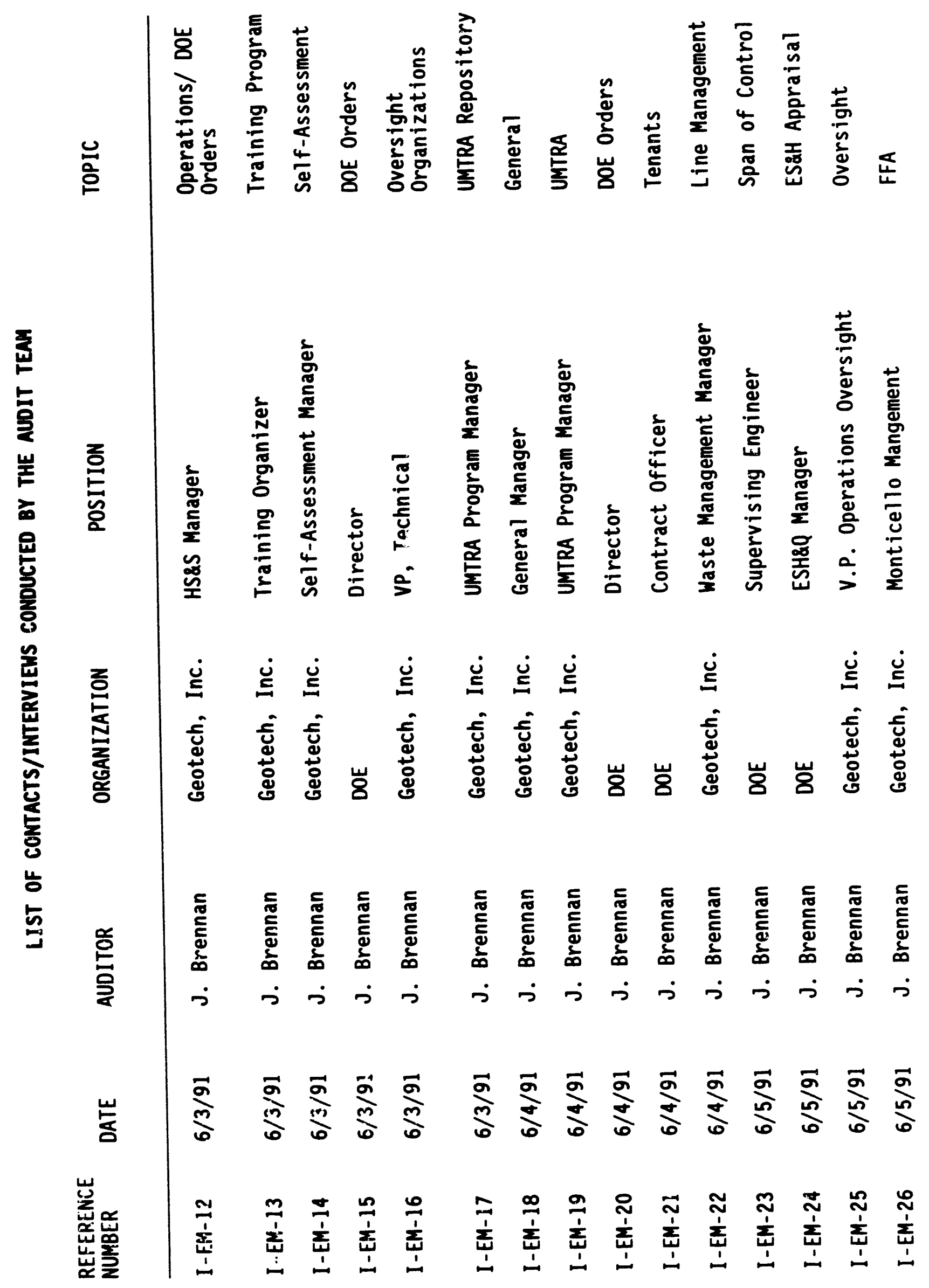


APPENDIX G

PROBABLE CAUSAL FACTORS 
This page was intentionally left blank. 
POLICY

Evaluate if ineffective, outdated, or nonexistent policies contributed to the finding.

\section{POLICY IMPLEMENTATION}

Ascertain if written policies reflecting Federal, state, and local laws and regulations, codes, and standarts were appropriately disseminated, implemented, and updated. If not, evaluate if this is a contributing factor to the finding.

\section{APPRAISALS, AUDITS AND REVIEWS}

Determine if ineffective or inefficient appraisals, audits, and reviews, and/or inadequate followup were contributing factors to the finding.

RISK

Evaluate if the site personnel responsible for a situation contributing to a finding have assessed and were aware of the relative degree of risk involved in the action.

\section{PROCEDURES}

Identify if written procedures that have been prepared to effectively implement site policy, DOE Orders, and Federal, state, and local laws and regulations were a contributing factor to the finding. Determine if unfamiliarity with or unavailability of those procedures contributed to the finding.

\section{PERSONNEL}

Identify if the educational and work experience backgrounds for personnel holding responsible positions contributed to the finding. Determine if the level of personnel knowledge about the technical and safety aspects of their jobs contributed to the finding. 


\section{RESOURCES}

Ascertain if the number of personnel assigned to a job was a contributing factor in the finding. Evaluate if inadequacies in facilities and equipment were a contributing factor to the finding.

\section{TRAINING}

Identify if adequate personnel training on implementing site policy, DOE Orders, and applicable Federal, state, and local laws and regulations was a contributing factor to the finding.

\section{CHANGE}

Evaluate if changes in site mission, function, operation and established requirements, which rendered existing policies or procedures inadequate or inappropriate, were contributing factors to the finding. Evaluate if the timeliness and effectiveness of changes to site and DOE policy, and the implementing procedures, were a contributing factor to the finding.

\section{QUALITY ASSURANCE/CONTROL}

Identify if inadequacies in the quality assurance/control program were causal factors in the identified finding.

\section{DESIGN}

Evaluate if inadequate design of a system was a contributing factor to the finding.

\section{HUMAN FACTORS}

Ascertain if human factors, such as fatigue or deliberate circumvention of a safety system, were contributing factors to the finding. 


\section{BARRIERS AND CONTROLS}

Determine if inadequacies in established barriers and controls, either administrative and physical, including operational readiness, routine inspections and preventive maintenance, and/or a lack of these controls, contributed to the finding.

\section{SUPERVISION}

Identify if ineffective supervisory controls for implementing policies, procedures, standards, laws, etc. were contributing factors to the finding. 
This page was intentionally left blank. 
APPENDIX H

LIST OF ACRONYMS 
This page was intentionally left blank. 


\section{ACRONYMS}

\begin{tabular}{|c|c|}
\hline $\begin{array}{l}\text { ACM } \\
\text { AEC } \\
\text { AL } \\
\text { ALARA } \\
\text { ANL } \\
\text { APCD } \\
\text { ARARS } \\
\text { ASER } \\
\text { AST }\end{array}$ & $\begin{array}{l}\text { Asbestos Containing Material } \\
\text { Atomic Energy Commission } \\
\text { Albuquerque Operations Office } \\
\text { As Low As Reasonably Achievable } \\
\text { Argonne National Laboratory } \\
\text { Air Pollution Control Division } \\
\text { Applicable or Relevant and Appropriate Pr:quirements } \\
\text { Annual Site Environmental Report } \\
\text { Aboveground Storage Tank }\end{array}$ \\
\hline $\begin{array}{l}\text { BMP } \\
\text { BMPF } \\
\text { BOD }\end{array}$ & $\begin{array}{l}\text { Best Management Practice } \\
\text { Best Management Practice Finding } \\
\text { Biological Oxygen Demand }\end{array}$ \\
\hline $\begin{array}{l}\text { CAA } \\
\text { CCR } \\
\text { CDH } \\
\text { CEQ } \\
\text { CERCLA } \\
\text { CESQG } \\
\text { CF } \\
\text { CLP } \\
\text { CM\&O } \\
\text { CO } \\
\text { COD } \\
\text { COE } \\
\text { CRP } \\
\text { CRS } \\
\text { CWA } \\
\text { CWQCA } \\
\text { CY }\end{array}$ & $\begin{array}{l}\text { Clean Air Act } \\
\text { Colorado Code of Regulations } \\
\text { Colorado Department of Health } \\
\text { Council oil Environmental Quality } \\
\text { Comprehensive Environmental Response, Compensation, and } \\
\text { Liability Act } \\
\text { Conditionally Exempt Small Quantity Generator } \\
\text { Compliance Finding } \\
\text { Contract Laboratory Program } \\
\text { Construction Management and Operations } \\
\text { Certificate to Operate } \\
\text { Chemical Oxygen Demand } \\
\text { U.S. Army Corps. of Engineers } \\
\text { Community Relations Plan } \\
\text { Colorado Regulations and Statutes } \\
\text { Clean Water Act } \\
\text { Colorado Water Quality Control Act } \\
\text { Calendar Year }\end{array}$ \\
\hline $\begin{array}{l}\text { DOA } \\
\text { DCG } \\
\text { DMR } \\
\text { DNT } \\
\text { DOD } \\
\text { DOE } \\
\text { DOE-HQ } \\
\text { DOE-OR } \\
\text { DOI } \\
\text { DPP }\end{array}$ & $\begin{array}{l}\text { Department of the Army } \\
\text { Derived Concentration Guide } \\
\text { Discharge Monitoring Report } \\
\text { Dinitrotoluene } \\
\text { Department of Defense } \\
\text { Department of Energy } \\
\text { Department of Energy, Headquarters } \\
\text { Department of Energy, Oak Ridge Operations Office } \\
\text { Department of the Interior } \\
\text { Decommissioning Project Plan }\end{array}$ \\
\hline $\begin{array}{l}E A \\
\text { EC } \\
\text { EERARA }\end{array}$ & $\begin{array}{l}\text { Environmental Assessment } \\
\text { Environmental Compliance } \\
\text { Environmental Compliance and Regulatory Affairs } \\
\text { Engineering Evaluation/Cost Analysis }\end{array}$ \\
\hline
\end{tabular}




\begin{tabular}{|c|c|}
\hline $\begin{array}{l}\text { EIS } \\
\text { EM } \\
\text { EMC } \\
\text { EMP } \\
\text { EMPP } \\
\text { EPA } \\
\text { EPCRA }\end{array}$ & $\begin{array}{l}\text { Office of the Assisiant Secretary for Environment, Safety an } \\
\text { Health } \\
\text { Environmental Impact Statement } \\
\text { Environmental Management } \\
\text { Environmental Monitoring and Compliance } \\
\text { Environmental Monitoring PIan } \\
\text { Environmental Monitoring Program Plan } \\
\text { Environmental Protection Agency } \\
\text { Emergency Planning and Community Right-to-Know Act } \\
\text { (Also known as SARA Title III) } \\
\text { Environmental Protection Implementation Plan } \\
\text { Environmental Proteciion Program Implementation Plan } \\
\text { Emergency Plans and Procedures } \\
\text { Emergency Preparedness and Response Plan } \\
\text { Environmental Restoration } \\
\text { Environment, Safety and Health }\end{array}$ \\
\hline $\begin{array}{l}\text { FFA } \\
\text { FIFRA } \\
\text { FS } \\
\text { FY }\end{array}$ & $\begin{array}{l}\text { Federal Facilities Agreement } \\
\text { Federal Insecticide, Fungicide, and Rodenticide Act } \\
\text { Feasibility Study } \\
\text { Fiscal Year }\end{array}$ \\
\hline $\begin{array}{l}\text { GFE } \\
\text { GIFO } \\
\text { GJPO } \\
\text { G.IPORAP } \\
\text { GPPMP } \\
\text { GW }\end{array}$ & $\begin{array}{l}\text { Government Furnished Equipment } \\
\text { Grand Junction Fire Department } \\
\text { Grand Junction Projects Office } \\
\text { Grand Junction Projects Office Remedial Action Program } \\
\text { Groundwater Protection Program Management Plan } \\
\text { Groundwater }\end{array}$ \\
\hline HEPA & High-Efficiency Particulate Air \\
\hline $\begin{array}{l}\text { IV } \\
\text { ID } \\
\text { IFB } \\
\text { IHR } \\
\text { IRA } \\
\text { IWS }\end{array}$ & $\begin{array}{l}\text { Isokinetic Variation } \\
\text { Idaho Operations Office } \\
\text { Invitation for Bid } \\
\text { Industrial Hygiene Resources, Ltd. } \\
\text { Interim Response Action } \\
\text { Inactive Waste Sites }\end{array}$ \\
\hline $\begin{array}{l}\text { LDR } \\
\text { LIMS } \\
\text { LLLW }\end{array}$ & $\begin{array}{l}\text { Land Disposal Restricted } \\
\text { Laboratory Information Management System } \\
\text { Low-Level Liquid Waste }\end{array}$ \\
\hline $\begin{array}{l}\text { MCL } \\
\text { MKF } \\
\text { MOU } \\
\text { MREM } \\
\text { MSA } \\
\text { MSDS }\end{array}$ & $\begin{array}{l}\text { Maximum Contaminant Level } \\
\text { M.K. Ferguson } \\
\text { Memorandum of Understanding } \\
\text { Millirem } \\
\text { Material Staging Area } \\
\text { Material Safety Data Sheet }\end{array}$ \\
\hline NCP & $\begin{array}{l}\text { National } 0 \text { il and Hazardous Substances Pollution Contingency } \\
\text { Plan (Also known as National Contingency Plan) } \\
\text { National Environmental Pol icy Act }\end{array}$ \\
\hline
\end{tabular}




\begin{tabular}{|c|c|}
\hline $\begin{array}{l}\text { NESHAP } \\
\text { NIST } \\
\text { NP } \\
\text { NPDES } \\
\text { NPL } \\
\text { NURE }\end{array}$ & $\begin{array}{l}\text { National Emission Standards for Hazardous Air Pollutants } \\
\text { National Institute of Standards and Testing } \\
\text { Noteworthy Practice } \\
\text { National Pollutant Discharge Elimination System } \\
\text { Hational Priorities List } \\
\text { National Uranium Resource Evaluation }\end{array}$ \\
\hline $\begin{array}{l}\text { ORNL } \\
\text { OSWER }\end{array}$ & $\begin{array}{l}\text { Oak Ridge National Laboratories } \\
\text { Office of Solid Haste Emergency Response }\end{array}$ \\
\hline $\begin{array}{l}\text { PAG } \\
\text { PCB } \\
\text { PIP } \\
\text { PM } \\
\text { PMC } \\
\text { PPAP } \\
\text { PPB } \\
\text { PPY } \\
\text { PRP } \\
\text { PSO }\end{array}$ & $\begin{array}{l}\text { Protective Action Guidelines } \\
\text { Polychlorinated Biphenyls } \\
\text { Productivity Improvement Program } \\
\text { Paticulate Matter ( } 10 \text { um dia.) } \\
\text { Project Management Contractor } \\
\text { Pollution Prevention Awareness Plan } \\
\text { Parts Per Billion } \\
\text { Parts Per Million } \\
\text { Potentially Responsible Party } \\
\text { Program Senior Official }\end{array}$ \\
\hline $\begin{array}{l}\text { QA } \\
\text { QAPjP } \\
\text { QAPP } \\
\text { QC }\end{array}$ & $\begin{array}{l}\text { Qual ity Assurance } \\
\text { Qual ity Assurance Project Plan } \\
\text { Quality Assurance Program PIan QC Quality Control } \\
\text { Qual ity Control }\end{array}$ \\
\hline $\begin{array}{l}\text { RAD } \\
\text { R\&D } \\
\text { RC } \\
\text { RCRA } \\
\text { RD/RA } \\
\text { RP } \\
\text { RI } \\
\text { RI/FS } \\
\text { ROD } \\
\text { RQ }\end{array}$ & $\begin{array}{l}\text { Radiation } \\
\text { Research and Development } \\
\text { Regulatory Compliance } \\
\text { Resource Conservation and Recovery Act } \\
\text { Remedial Design/Remedial Action } \\
\text { Request for Proposal } \\
\text { Remedial Investigation } \\
\text { Remedial Investigation/Feasibility Study } \\
\text { Record of Decision } \\
\text { Reportable Quantity }\end{array}$ \\
\hline $\begin{array}{l}\text { SAA } \\
\text { SAP } \\
\text { SAR } \\
\text { SARA } \\
\text { SDWA } \\
\text { SEN } \\
\text { SFMP } \\
\text { SI } \\
\text { SOP } \\
\text { SPAT } \\
\text { SPCC } \\
\text { SQG } \\
\text { SSB } \\
\text { SH } \\
\text { SWMU }\end{array}$ & $\begin{array}{l}\text { Satellite Accumulation Area } \\
\text { Self Assessment Plan } \\
\text { Safety Analysis Report } \\
\text { Superfund Amendments and Reauthorization Act } \\
\text { Safe Drinking Water Act } \\
\text { Secretary of Energy Notice } \\
\text { Surplus Facility Management Program } \\
\text { Special Issue } \\
\text { Standard Operating Procedure } \\
\text { Supply, Property and Transportation } \\
\text { Spill Prevention, Control, and Countermeasures } \\
\text { Small Quantity Generator } \\
\text { Soils, Sediment and Biota } \\
\text { Surface Water } \\
\text { Solid Waste Management Unit }\end{array}$ \\
\hline
\end{tabular}


SWATS Site-Wide Audit Tracking System

TBP

TCE

TCLP

TCM

TMC

TOX

TRU

TS

TSA

TSCA

TSDF

Tributyl Phosphate

Trichloroethane

Toxic Characteristic Leaching Procedure

Toxic and Chemical Materials

Technical Measurements Center

Total Organic Halogenated Compounds

Transuranic

Toxic Substances

Temporary Storage Area

Toxic Substances Control Act

Treatment, Storage, and Disposal Facility

UMTRA

UMTRCA

UST

Uranium Mill Tailings Remedial Action

Uranium Mill Tailings Radiation Control Act

Underground Storage Tank

VIPMIM

VOC

Vicinity Properties Management Implementation Manual

WITS

WM

WMP

WM/PPAP

WWTP

Volatile Organic Compound

Waste Inventory and Tracking System

Waste Management

Waste Management Plan

Haste Management/Pollution Prevention Awareness Plan

Waste Water Treatment P1 ant 

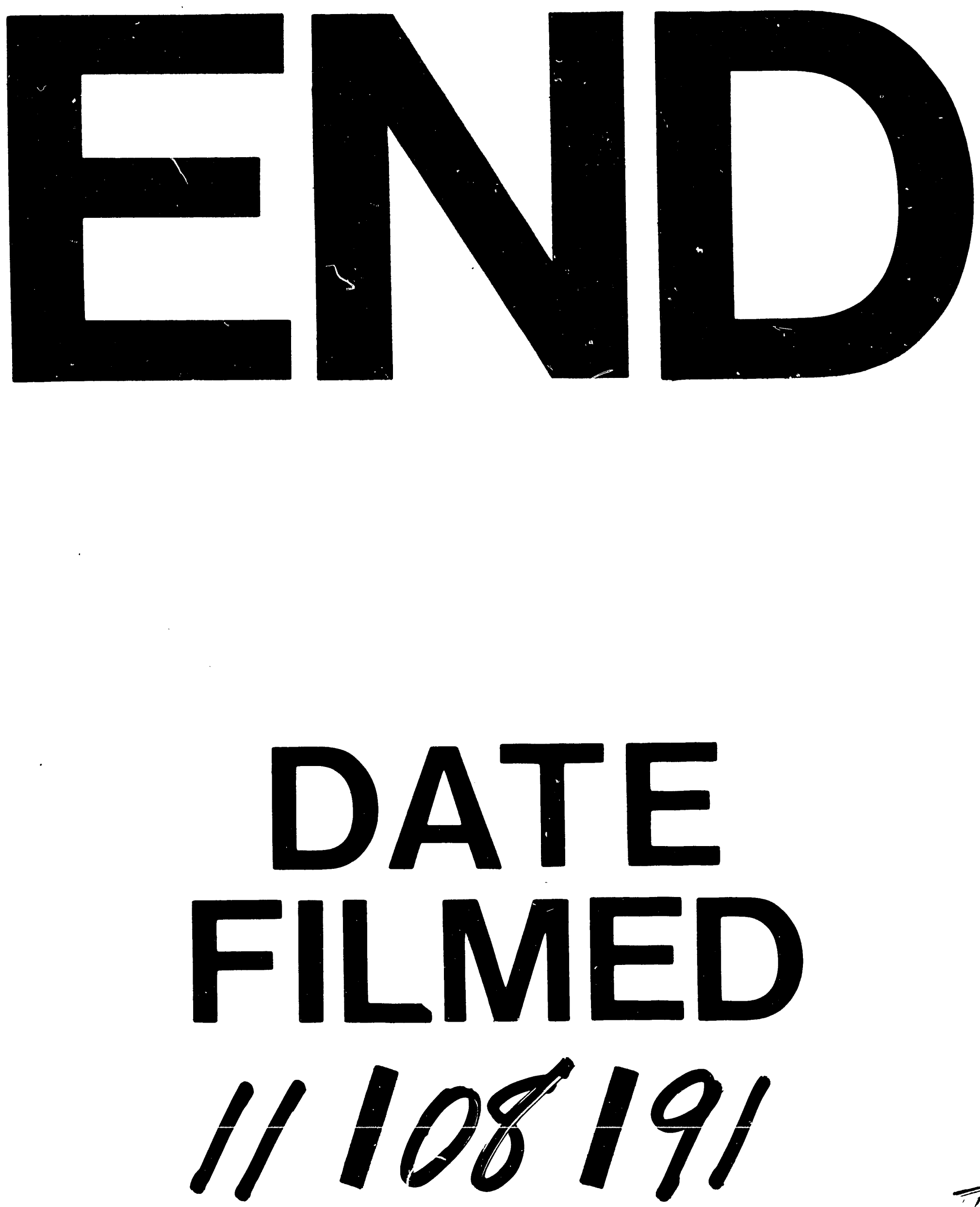
